Edited by

Marieke de Goede, Esmé Bosma and Polly Pallister-Wilkins

\title{
Secrecy and Methods in Security Research
} A Guide to Qualitative Fieldwork

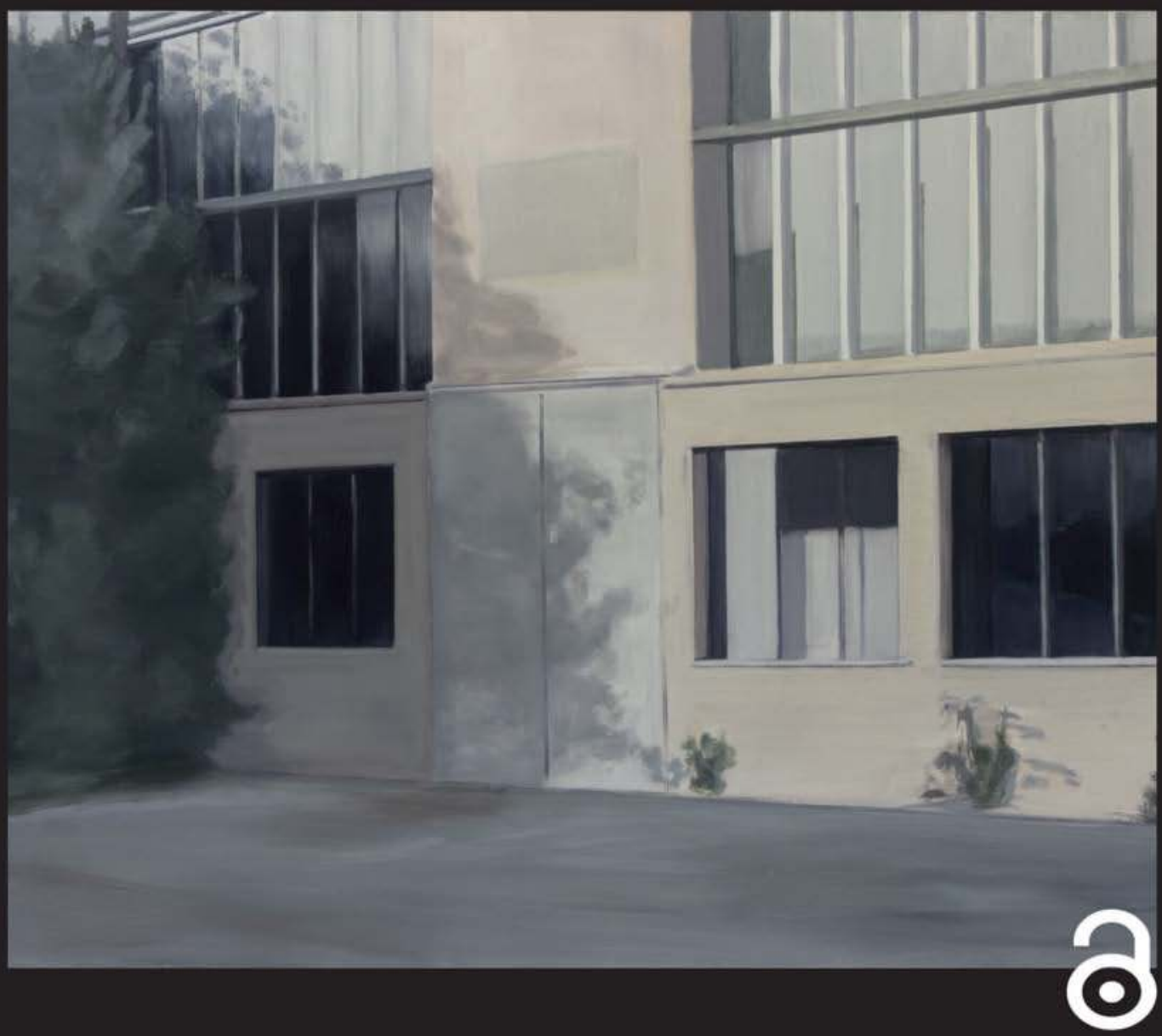




\section{SECRECY AND METHODS IN SECURITY RESEARCH}

This book analyses the challenges of secrecy in security research, and develops a set of methods to navigate, encircle and work with secrecy.

How can researchers navigate secrecy in their fieldwork, when they encounter confidential material, closed-off quarters or bureaucratic rebuffs? This is a particular challenge for researchers in the security field, which is by nature secretive and difficult to access. This book creatively assesses and analyses the ways in which secrecies operate in security research. The collection sets out new understandings of secrecy, and shows how secrecy itself can be made productive to research analysis. It offers students, $\mathrm{PhD}$ researchers and senior scholars a rich toolkit of methods and best-practice examples for ethically appropriate ways of navigating secrecy. It pays attention to the balance between confidentiality, and academic freedom and integrity. The chapters draw on the rich qualitative fieldwork experiences of the contributors, who did research at a diversity of sites, for example at a former atomic weapons research facility, inside deportation units, in conflict zones, in everyday security landscapes, in virtual spaces and at borders, bureaucracies and banks.

The book will be of interest to students of research methods, critical security studies and International Relations in general.

Marieke de Goede is Professor of Political Science at the University of Amsterdam. She is author of Speculative Security: the Politics of Pursuing Terrorist Monies and Associate Editor of Security Dialogue. She currently holds a Consolidator Grant of the European Research Council (ERC) called FOLLOW: Following the Money from Transaction to Trial.

Esmé Bosma is a Doctoral Candidate at the Department of Political Science of the University of Amsterdam and a member of project FOLLOW, funded by the European Research Council. For her research project she has conducted field research inside and around banks in Europe to analyse counter-terrorism financing practices by financial institutions. She has taught qualitative research methods to political science students and holds a master's degree in Political Science from the University of Amsterdam.

Polly Pallister-Wilkins is an Assistant Professor in the Department of Political Science, University of Amsterdam. Her work has been published in Security Dialogue, Political Geography and International Political Sociology amongst others. She is a principal investigator in the European Union Horizon 2020 project 'ADMIGOV: Advancing Alternative Migration Governance' looking at issues of humanitarian protection in wider systems of migration governance. 
$\Longrightarrow$ Taylor \& Francis

Taylor \& Francis Group

http://taylorandfrancis.com 


\section{SECRECY AND \\ METHODS IN \\ SECURITY RESEARCH}

A Guide to Qualitative Fieldwork

Edited by Marieke de Goede, Esmé Bosma and Polly Pallister-Wilkins 
First published 2020

by Routledge

2 Park Square, Milton Park, Abingdon, Oxon OX14 4RN

and by Routledge

52 Vanderbilt Avenue, New York, NY 10017

Routledge is an imprint of the Taylor E Francis Group, an informa business

(C) 2020 selection and editorial matter, Marieke de Goede, Esmé Bosma, Polly Pallister-Wilkins; individual chapters, the contributors

The right of Marieke de Goede, Esmé Bosma, Polly Pallister-Wilkins to be identified as the authors of the editorial material, and of the authors for their individual chapters, has been asserted in accordance with sections 77 and 78 of the Copyright, Designs and Patents Act 1988.

With the exception of Introduction, no part of this book may be reprinted or reproduced or utilised in any form or by any electronic, mechanical, or other means, now known or hereafter invented, including photocopying and recording, or in any information storage or retrieval system, without permission in writing from the publishers.

Introduction of this book is available for free in PDF format as Open Access from the individual product page at www.routledge.com. It has been made available under a Creative Commons Attribution-Non Commercial-No Derivatives 4.0 license.

Trademark notice: Product or corporate names may be trademarks or registered trademarks, and are used only for identification and explanation without intent to infringe.

British Library Cataloguing-in-Publication Data

A catalogue record for this book is available from the British Library

Library of Congress Cataloging-in-Publication Data

Names: Pallister-Wilkins, Polly, editor. | Goede, Marieke de, 1971- editor. | Bosma, Esmé, editors.

Title: Secrecy and methods in security research : a guide to qualitative fieldwork / edited by Marieke de Goede, Esmé Bosma, Polly Pallister-Wilkins.

Description: Abingdon, Oxon ; New York, NY : Routledge, 2019.

Identifiers: LCCN 2019014050 (print) | LCCN 2019981127 (ebook) | ISBN 9780367027230 (hardback) | ISBN 9780367027247 (paperback) | ISBN 9780429398186 (ebook)

Subjects: LCSH: Official secrets-Research-Methodology. | Confidential communications-Research-Methodology. | Security systemsResearch-Methodology. | Secrecy.

Classification: LCC JF1525.S4 .S49 2019 (print) | LCC JF1525.S4 (ebook) | DDC 001.4/33-dc23

LC record available at https://lccn.loc.gov/2019014050

LC ebook record available at https://lccn.loc.gov/2019981127

ISBN: 978-0-367-02723-0 (hbk)

ISBN: 978-0-367-02724-7 (pbk)

ISBN: 978-0-429-39818-6 (ebk)

Typeset in Bembo

by Apex CoVantage, LLC 


\section{CONTENTS}

List of figures

viii

List of boxes

List of contributors

Introduction: navigating secrecy in security research

Esmé Bosma, Marieke de Goede and Polly Pallister-Wilkins

Interlude: rigorous research in critical security studies

Can E. Mutlu

\section{PART 1}

Secrecy complexities

1 The problem of access: site visits, selective disclosure, and freedom of information in qualitative security research

Oliver Belcher and Lauren Martin

2 The state is the secret: for a relational approach to the study of border and mobility control in Europe 
vi Contents

3 Postsecrecy and place: secrecy research amidst the ruins of an atomic weapons research facility

William Walters and Alex Luscombe

Section II: Access, confidentiality and trust 79

4 Navigating difficult terrain $\quad 80$ Alexandra Schwell

5 Accessing lifeworlds: getting people to say the unsayable Jonathan Luke Austin

6 Research dilemmas in dangerous places Fairlie Chappuis and Jana Krause

\section{PART 2}

Mapping secrecy

Section III: Reflexive methodologies

7 Writing secrecy

Brian Rappert

8 Gender, ethics and critique in researching security and secrecy Marijn Hoijtink

9 (In)visible security politics: reflections on photography and everyday security landscapes

Jonna Nyman

\section{Section IV: Ethnographies of technologies}

10 The black box and its dis/contents: complications in algorithmic devices research

Till Straube

11 Multi-sited ethnography of digital security technologies Esmé Bosma

12 Researching the emergent technologies of state control: the court-martial of Chelsea Manning 
PART 3

Research secrets

Section V: Critique and advocacy

13 Searching for the smoking gun? Methodology and modes of critique in the arms trade

Anna Stavrianakis

14 Critical engagement when studying those you oppose

Erella Grassiani

15 Secrecy vignettes

Marieke de Goede

Section VI: Research ethics in practice

16 Research ethics at work: account-abilities in fieldwork on security

Anthony Amicelle, Marie Badrudin and Samuel Tanner

17 Material guides in ethically challenging fields: following deportation files

Lieke Wissink

Index

306 


\section{FIGURES}

0.1 Gate by Rob Ward 3

0.2 Gate by Rob Ward 4

1.1 FOIA request by Lauren Martin to Immigration and

3.1 Laboratories 4 and 5 ("The Pagodas"), Orford Ness 68

3.2 A tour group approaches Laboratory 2, Orford Ness 70

9.1 Security guard at Houhai Lake, Beijing 163

9.2 Anti-terror patrol in Kashgar, Xinjiang 164

12.1 Screenshot of attempt to access the US Army's FOIA website 219

12.2 Screenshot of attempt to access US Army's FOIA website 219

12.3 Screenshot of attempt to access US Army's FOIA website 220

12.4 Screenshot of file downloading from the US Army's FOIA website 221

12.5 Email from Columbia University's SIPA 223

13.1 Iterative, mutually reinforcing methods 236 


\section{BOXES}

0.1 When is a secret secret? 11

0.2 Over-research and 'hot' field sites 17

0.3 Balancing consent, confidentiality and academic integrity in practice

1.1 Tips on Freedom of Information Act and Open Records requests in research 41

2.1 Performativity, immanence and following actors 54

$\begin{array}{ll}2.2 & \text { Methodological tips } \\ 3.1 & 58\end{array}$

3.1 Postsecrecy 66

$\begin{array}{ll}3.2 & \text { Questions of validity } \\ 4.13\end{array}$

4.1 First contact - situating and being situated 84

$\begin{array}{lll}4.2 & \text { Obstacles and pitfalls for qualitative research in security agencies } & 87\end{array}$

4.3 Security anxieties - posing a threat 88

4.4 Practical tips for ethnographers entering difficult terrain 93

$\begin{array}{ll}5.1 \text { Positionality and accessing lifeworlds } & 100\end{array}$

5.2 Accessing the lifeworld of torturers 101

$\begin{array}{ll}5.3 \text { Basic elements of an ethnographic interview } & 107\end{array}$

6.1 Practical measures for personal safety 116

6.2 Questions to ask yourself when engaging local expertise 121

7.1 Shortened rendition of a snippet 135

$\begin{array}{lll}\text { 8.1 Security trade exhibitions as research sites } & 146\end{array}$

8.2 Feminist writings on field research have ... 148

9.1 Questions to reflect on when using photographic methods 166

9.2 Questions to consider when thinking about using participatory photography 169

10.1 Variations on the black box 181

$\begin{array}{ll}11.1 \text { Counter-terrorism financing by banks } & 195\end{array}$ 
$\mathbf{x}$ Boxes

11.2 An ethnography of which technology?

11.3 Questions to consider when following technology from design to use

11.4 Questions to consider when thinking about observing human-computer interaction

12.1 Theorising the state

12.2 From the Pentagon Papers to WikiLeaks: leaked data in an Internet age

12.3 Researcher in practice: on feeling like a conspiracy theorist

13.1 Controversy over arms sales in the Yemen war

13.2 Useful data sources

13.3 Interviewing and participant observation (PO)

13.4 Using Freedom of Information laws

14.1 Non-ethnographic anthropological research

16.1 Fieldwork

16.2 Direct benefits for the institution

17.1 Is it ethically justified to continue research if

17.2 Ethical boundaries that presume a singular actor 


\section{CONTRIBUTORS}

Anthony Amicelle is an associate professor in criminology at the University of Montreal. His research examines practices of policing, surveillance and intelligence at the interface of finance and security, with a particular focus on 'new' technologies of control. His recent publications include 'Suspicion-in-the-making: Surveillance and denunciation in financial policing' (British Journal of Criminology, 2018 - with Vanessa Iafolla) and 'Policing through misunderstanding: Insights from the configuration of financial policing' (Crime, Law and Social Change, 2018).

Jonathan Luke Austin is lead researcher at the Violence Prevention (VIPRE) Initiative of the Graduate Institute of International and Development Studies, Geneva. His work has been published and/or is forthcoming by European Journal of International Relations, International Political Sociology, Security Dialogue, Review of International Studies, Cambridge University Press, and elsewhere.

Marie Badrudin is a doctoral candidate in criminology at the University of Montreal. Her ethnographical dissertation focuses on the regulation of financial markets as well as law enforcement regarding insider trading and market manipulation. She is a recipient of the Social Sciences and Humanities Research Council doctoral scholarship for her research examining practices of surveillance and policing in relation to financial crime.

Oliver Belcher is an assistant professor of human geography at Durham University. His research on the American wars in Afghanistan, Iraq, and Vietnam has been published in the Annals for the Association of American Geographers, Political Geography, Antipode, Area, and elsewhere. He is currently writing a book on Counterrevolutionary Logistics: Computation, Techno-Politics, Vietnam, which examines the US military's adoption of computer systems during the Vietnam War. This British 
Academy-funded project shows how mid-century data-intensive computer technologies and metrics were turned into a violent tool of imperialism against Vietnamese peasants.

Esmé Bosma is a doctoral candidate at the Department of Political Science of the University of Amsterdam and a member of project FOLLOW, funded by the European Research Council (ERC). For her research project she has conducted field research inside and around banks in Europe to analyse counter-terrorism financing practices by financial institutions. Her research lies at the intersection between (critical) security studies and science and technology studies. Her research interests are the interrelations of security, finance and technology. She has taught qualitative research methods to political science students and holds a master's degree in Political Science from the University of Amsterdam.

Fairlie Chappuis is a peacebuilding specialist and an Associated Researcher at swisspeace and the University of Basel. She holds a doctorate from the Otto Suhr Institute of Political Science, Freie Universität Berlin, and graduate degrees from the University of Auckland and the Graduate Institute of International Affairs, Geneva. Previously, Fairlie worked at the Geneva Centre for Security Sector Governance (DCAF), and the Collaborative Research Center (SFB) 700: Governance in Areas of Limited Statehood. She was also a Visiting Fellow at the Kofi Annan Institute for Conflict Transformation at the University of Liberia and at the Stimson Center in Washington DC.

Huub Dijstelbloem is Professor of Philosophy of Science and Politics at the University of Amsterdam (UvA) and Senior Research Fellow at the Netherlands Scientific Council for Government Policy (WRR) in The Hague. He works on the intersection of philosophy of science and technology, political theory, and science and technology studies. His research concerns democracy and technology and the politics of border control and migration policies. He is one of the initiators of Science in Transition, a movement that aims to reflect on the organization of quality assessment and social impact of science and research.

Philip Garnett is a lecturer in the York Cross-disciplinary Centre for Systems Analysis and School of Management, University of York. He is interested in the application of complex systems theory in organizations, and how organizational culture, memory, and knowledge can be theorized as an emergent property of the system itself.

Marieke de Goede is Professor of Political Science at the University of Amsterdam. Her research focuses on counter-terrorism and security practices in Europe, with a specific attention to the way in which financial data become used for security decisions. De Goede is author of Speculative Security: The Politics of Pursuing Terrorist Monies (2012), and co-editor of the special issue on 'The Politics of the List,' in 
Environment and Planning D: Society and Space. De Goede is Associate Editor of Security Dialogue. She currently holds a Consolidator Grant of the European Research Council (ERC) called FOLLOW: Following the Money from Transaction to Trial (www.projectfollow.org).

Erella Grassiani works as an anthropologist at the University of Amsterdam. She does research on the Israeli security industry as part of a wider project on privatization and globalization of security. Her work traces the flows of (Israeli) security worldwide and looks at the way cultural ideas, technologies, and consultants move around globally. In the past she has done extensive research on the Israeli military and has published a book on the topic: Soldiering under Occupation: Processes of Numbing among Israeli soldiers in the Al-Aqsa Intifada (2013).

Marijn Hoijtink is an assistant professor in International Relations at VU Amsterdam. Her research interests include emerging security technologies and their relation to the politics of risk, militarism and weapons research, and the global circulation of security and military technologies. She has recently received a four-year Veni grant from The Netherlands Organisation for Scientific Research (NWO) to study the politics of engineering lethal autonomous weapons systems.

Sarah M. Hughes is an ESRC postdoctoral fellow within Durham University's Geography Department. She is interested in questions of resistance, knowledge production and what constitutes 'the political'. Her current research explores conceptualizations of resistance within the UK asylum system.

Jana Krause is an assistant professor in the Department of Political Science at the University of Amsterdam. She holds a PhD from the Graduate Institute in Geneva and was Visiting Fellow at King's College London and Yale University. Her research focuses on civilian agency and civilian protection in communal conflicts and civil wars; local peacebuilding and social resilience; and gender and peacebuilding. She has conducted field research in Indonesia and Nigeria, and more recently in South Sudan and Myanmar. Her book, Resilient Communities: Non-Violence and Civilian Agency in Communal War, was published in 2018.

Alex Luscombe is a PhD student at the University of Toronto's Centre for Criminology \& Sociolegal Studies and a Junior Fellow at Massey College. His research interests include high and low policing, corruption, secrecy, and freedom of information law. His research has been published in a number of scholarly journals including Social Forces, British Journal of Criminology, Sociology, Canadian Journal of Criminology \& Criminal Justice, International Political Sociology, and Policing \& Society.

Lauren Martin is an assistant professor of human geography at Durham University. Her research focuses on the spatial practices and economies of migration control, 
especially family detention and the commercialisation of detention and asylum accommodation. She has published on migrant precarity, immigration detention, borders, security and carceral geographies in international journals such as Political Geography, Territory Politics Governance, Geopolitics, and Progress in Human Geography.

Can E. Mutlu is an assistant professor of global politics at Acadia University, in Wolfville, NS, Canada. His research intersects critical security studies, border security, and science and technology studies. He is the co-editor of Research Methods in Critical Security Studies: An Introduction (2013) and Architectures of Security: Design, Control, Space (2019).

Jonna Nyman is a Leverhulme Fellow and Lecturer in International Politics at the University of Sheffield, UK. Her research broadly centres on the politics and ethics of security, with particular interests in energy security, climate politics, and China. She is currently undertaking a major three-year research project funded by a Leverhulme Trust Early Career Fellowship, titled 'Securing China: Understanding security politics beyond the West'. Previously, she has published a monograph titled The Energy Security Paradox: Rethinking Energy (In)security in the United States and China (2018), and a co-edited collection Ethical Security Studies: A New Research Agenda (2016).

Polly Pallister-Wilkins is an assistant professor in the Department of Political Science, University of Amsterdam. She works at the intersection of critical security studies and political geography researching the interrelations of mobility, border control and humanitarianism. Her work has been published in Security Dialogue, Political Geography and International Political Sociology amongst others. She is a principal investigator in the European Union Horizon 2020 project 'ADMIGOV: Advancing Alternative Migration Governance' looking at issues of humanitarian protection in wider systems of migration governance.

Annalisa Pelizza is Professor of Technology Studies of Communication at the University of Bologna, and Visiting Professor at the Science, Technology and Policy Studies department of the University of Twente. She leads the "Processing Citizenship" (http://processingcitizenship.eu) research group. The group investigates transnational data infrastructures for migration management as activities of European governance transformation. Her research lies at the intersection of science and technology studies, communication science and political theory, with a focus on governance by data infrastructures and how they shape institutions inherited from Modernity. In the past she worked with governmental agencies and engineering companies, developing large-scale IT infrastructures.

Brian Rappert is Professor of Science, Technology and Public Affairs at the University of Exeter. His long-term interest has been the examination of the strategic management of information; particularly in the relation to armed conflict. His 
books include Controlling the Weapons of War: Politics, Persuasion, and the Prohibition of Inhumanity; Biotechnology, Security and the Search for Limits; and Education and Ethics in the Life Science. More recently he has been interested in the social, ethical, and political issues associated with researching and writing about secrets, as in his books Experimental Secrets (2009), How to Look Good in a War (2012) and Dis-eases of Secrecy (2017).

Alexandra Schwell is an anthropologist and professor of intercultural communication at Ludwig Maximilian University, Munich. Her research interests include border studies, anthropology of the political, Europeanization, and ethnographic methods. She was work package leader in the FREE project ("Football Research in an Enlarged Europe", FP7) and subproject leader in the project "Doing World Heritage" (BMWFW).

Anna Stavrianakis is senior lecturer in International Relations at the University of Sussex, UK, where she researches and teaches on UK arms export policy, the international arms trade, multilateral arms transfer control, and militarism. She is the author of Taking Aim at the Arms Trade: NGOs, Global Civil Society and the World Military Order and the co-editor (with Jan Selby) of Militarism and International Relations: Political Economy, Security, Theory. She is also an Associate Editor at Security Dialogue, where she co-edited (with Maria Stern) the special issue on "Militarism and Security: Dialogue, Possibilities, Limits".

Till Straube is a research associate at the Department of Human Geography at Goethe University Frankfurt. His research interests centre around critical data science, digital infrastructures and security technologies with a focus on STS- and ANT-inspired methods. Before attaining his master's degree in Human Geography, Till worked in the technology sector as a software engineer and project manager. He shares his expertise by designing theoretically informed, hands-on learning experiences that introduce students to Geography's quantitative methods in meaningful ways. His teaching underlines the importance of data literacy and critical approaches to digital technologies.

Samuel Tanner is an associate professor at the School of Criminology, University of Montreal. He is also affiliated to the International Center for Comparative Criminology (CICC) and is a member of the executive committee of the Canadian Network for Research on Terrorism, Security and Society (TSAS). His work focuses on the impacts of technology on security as well as the use of digital media platforms in collective action.

William Walters is Professor of Political Sociology at Carleton University, Canada. His main research interests are secrecy and security, borders and migration, and mobility and politics. He is completing a book called The Production of Secrecy and co-editing Viapolitics: Borders, Migration, and the Power of Locomotion. 
Previous publications include Governmentality: Critical Encounters (2012). He is the currently the principal investigator on The Air Deportation Project, a multi-country inquiry into the aerial geographies of forced removal and expulsion in and from Europe which is funded by Canada's Social Sciences and Humanities Research Council (2017-2022).

Lieke Wissink is a $\mathrm{PhD}$ researcher in anthropology at the University of Amsterdam. Her PhD research focuses on bureaucratic practices and their materialities in contemporary deportation policies. Her contribution to this volume was partly developed in 2018 during her visiting fellowship at the New School for Social Research that was generously supported by the Jo Kolk study fund. 


\section{ACKNOWLEDGEMENTS}

Many thanks to all contributors to the "Secrecy and Methods in Security Research" Workshop at the Teylers Museum in Haarlem in October 2017, including Rivke Jaffe, Marlies Glasius, Mark Salter and Liat Shetret. Thanks also to all contributors to the "Secrecy and Methodology in Security Research: Challenges and Strategies" at the Annual European International Studies Conference (EISA) in Prague in September 2018, and all participants at the "Secrecy and (In)Security workshop" at the University of Bristol in November 2018, for offering inspiration and helpful comments to the themes of this volume, especially Claudia Aradau, Andrew Dwyer, Anna Leander, Debbie Lisle, Xymena Kurowska, Matthias Leese, Simon Rushton, Elke Schwarz, Benjamin Tallis, Owen Thomas, Elspeth van Veeren and William Walters. Marie Irmer provided valuable research assistance in compiling the book's index.

The project benefited from discussions with colleagues of the Transnational Configurations, Conflict and Governance Research group at the University of Amsterdam.

We would like to acknowledge the support of Rob Ward, for allowing us to use his artwork Gate to illustrate the themes of this book and for kindly providing images and encouragement. Many thanks to Adzer van der Molen for allowing the use of his painting 'Factory' as cover image.

Special thanks to the FOLLOW team and friends: Tasniem Anwar, Rocco Bellanova, Malcolm Campbell-Verduyn, Beste İşleyen, Pieter Lagerwaard, Bruno Magelhães, Natalie Welfens, Mara Wesseling and Carola Westermeier, for their support of this project and their very helpful comments on an earlier version of the book's introduction.

This research is supported by European Research Council project: FOLLOW: Following the Money from Transaction to Trial (ERC-2015-CoG 682317). 
$\Longrightarrow$ Taylor \& Francis

Taylor \& Francis Group

http://taylorandfrancis.com 


\title{
INTRODUCTION
}

\section{Navigating secrecy in security research}

\author{
Esmé Bosma, Marieke de Goede \\ and Polly Pallister-Wilkins
}

\section{Introduction: approaching a gate}

How can researchers challenge, navigate and engage secrecy in their fieldwork, when they encounter confidential material, closed-off quarters or bureaucratic rebuffs? This is a particular challenge for researchers in the security field, which is by nature secretive and particularly difficult to access. In security research, classification and obfuscation are the rule. Operational information of security professionals is secret; private security institutions carefully shield their practices and protocols; the workings of security algorithms are most often proprietary and difficult to understand, even for those who work with them. Warzones are difficult and dangerous to access; military operations are by nature classified or subject to aggressive 'information management' (Campbell 2003). Moreover, gaining trust is a specific challenge for researchers critical of the operations of security practitioners.

Secrecy pertains to all domains of social life, but has particular pertinence in relation to security policies, practices and protocols. The challenge of secrecy is crucial to all phases of security research. When drafting a proposal or research design, researchers have to anticipate strategies of access, ethics and (data) security. Approval by supervisors, ethical boards, research councils and potential funders depends upon considerations of access and feasibility of the study. While in the field, researchers are continuously confronted with ethical and practical dilemmas around confidential and sensitive issues. Even after leaving the field when writing, issues will arise: what to leave out, what to disclose, how to anonymise and how to store information that is secretive, sensitive and confidential (Glasius et al. 2018: 111-115)?

This book addresses these questions (and many more), and offers the reader practical tips, guidance and best- and worst-case examples from experienced security researchers. We discuss the themes of this book through the sculpture Gate by Rob Ward, a sculptor and painter with a noteworthy interest in a "poetry of reflection" (Wood 2009: 4). ${ }^{1}$ When looking at Gate (Figures 0.1 and 0.2), we see 
two gates at right angles made out of stainless steel, creating a reflecting effect. At first glance, it seems as if one can see through the gate and enter what lies behind: people, buildings, the field. Yet from another vantage point it seems that the gates are actually closed. As the Cass Sculpture foundation describes Gate:

This work ... has a reflective surface that dematerialises its form and incorporates the viewer and landscape into its composition. This disorienting effect alters one's perceptual experience of the work whilst providing a dynamic vision of the viewer's surroundings. Gate's composition initially seems to deny its meaning, yet Gate provides access to one's surrounding environment by encouraging an activated consciousness of that environment.

(Cass Sculpture Foundation n.d.)

Ward's Gate draws attention to at least three aspects of secrecy that shape critical security research: gaining access, barriers of secrecy, and the position of the researcher.

First, a gate typically grants or permits someone access. Individuals who facilitate research access are commonly called 'gatekeepers'. Before researchers set out to gather data however, it is often difficult to identify where the gate is, who function as gatekeepers and what they will find once access is gained. The presence and characteristics of the gate may be camouflaged by its surrounding context. The security field is constituted by numerous states, (non-)governmental organisations, companies and individuals who are configured transnationally (see Dijstelbloem and Pelizza, Chapter 2). In this dispersed and ambiguous context, it is often not immediately clear who could function as gatekeepers. Fieldsites are sometimes formally classified, and often obfuscated, such as asylum detention centres (see Belcher and Martin, Chapter 1) or security fairs (see Hoijtink, Chapter 8). Gaining access is relational; it is co-created between researcher and researched: a continuous and dynamic process that goes on even after leaving the field (Riese 2018). This complex, uncertain and obfuscated research terrain is one of the main themes of this volume.

But even when "passage through the mysterious gates remains impossible" (Wellman 2009: 220), like in Gate, we ask what does become possible if we take barriers of secrecy as objects of study? This is the second way in which the Gate sculpture speaks to the themes of this book: barriers of secrecy are not mere obstacles to overcome but are productive of research strategies and findings. Documenting and analysing where secrecies are, how they function and who is involved, can be revealing in itself. Like Ward's mirrored gate, our focus is not only on what is behind the gate, but also the way in which barriers of secrecy function as reflective surfaces ${ }^{2}$ that create an activated consciousness of our constantly changing surrounding environment as well as our own presence and role in it (Wellman 2009: 216). Observing and mapping the gate itself, including our own reflections, becomes a productive and revealing exercise.

We do not consider closed doors, partial visibilities and obfuscation necessarily to constitute failed research. Instead of considering what has been lost or what stays 


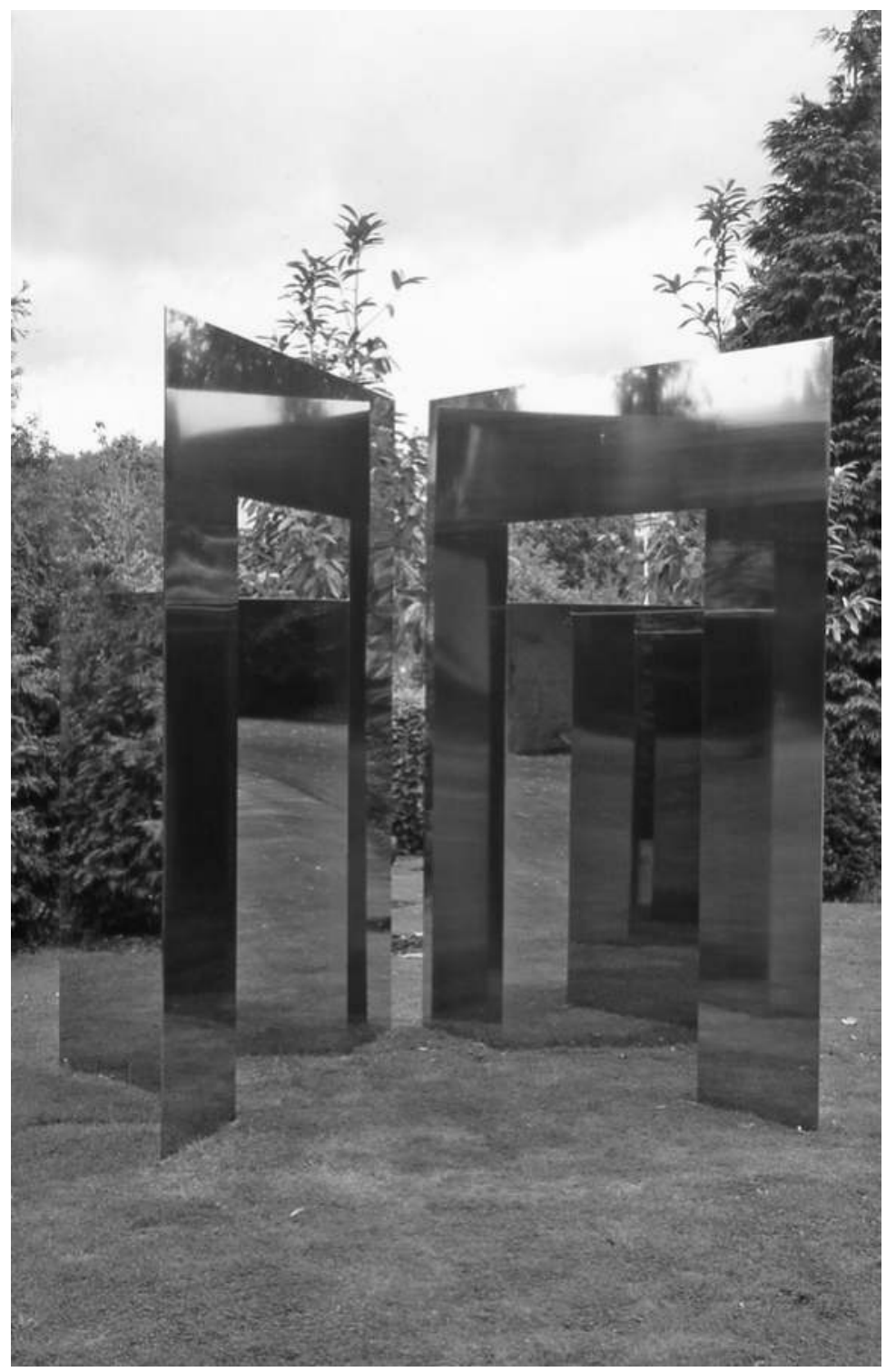

FIGURE 0.1 Gate by Rob Ward. Reprinted with permission of the artist.

out of the picture, we ask, what does mapping the contours of secrecy and obfuscation add to our analysis? By acknowledging that secrecy mediates our knowledge production and our perhaps ever partial visibilities, our aim is to present a fuller contextual picture of the reality of (research) practice. In their chapter about a formerly secret atomic weapons research facility, for example, William Walters and Alex Luscombe's aim is not necessarily to reveal the secret: "our task is not to 


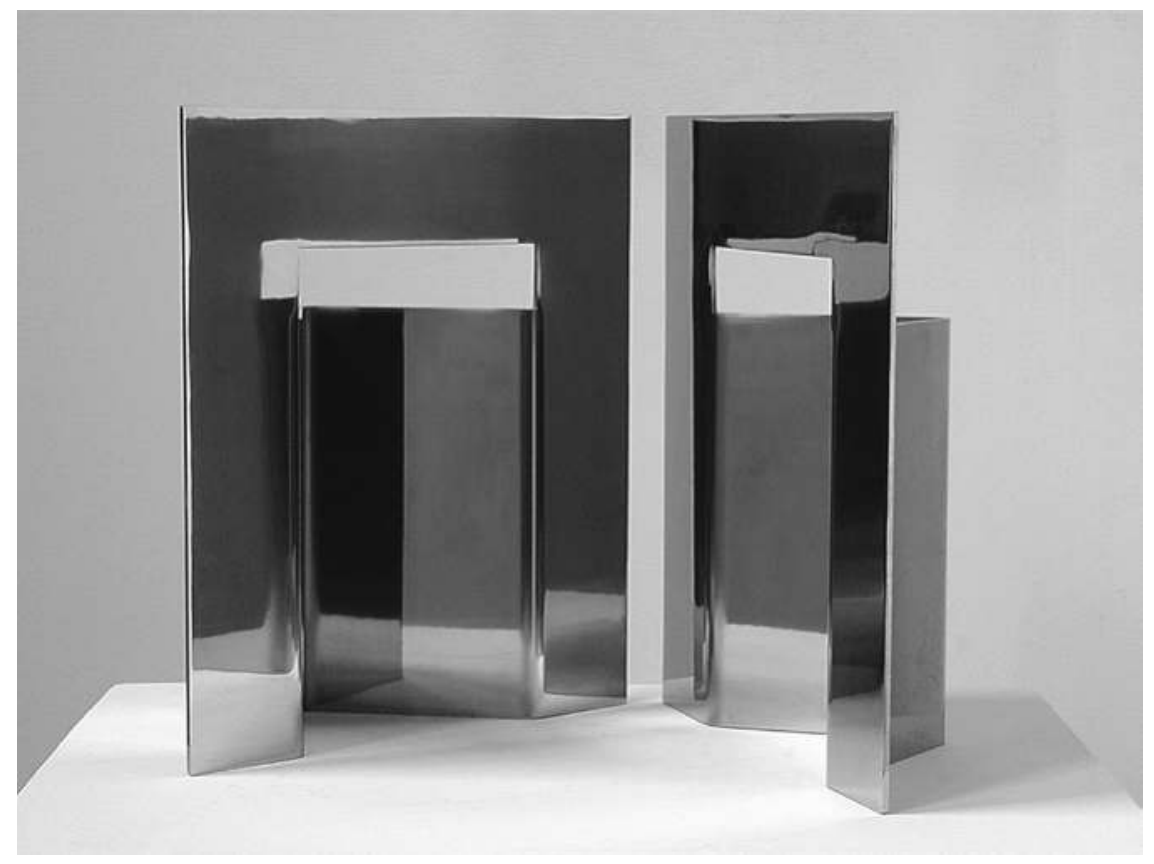

FIGURE 0.2 Gate by Rob Ward. Reprinted with permission of the artist.

uncover a singular, hidden, truth so much as to document and interpret the ways in which actors are reanimating the secret in the present" (see Walters and Luscombe, Chapter 3: 73). They show what unconventional respondents, such as ufologists and veterans, can add to our analysis of secrecy and security in practice.

Third, Gate draws attention to the position of the researcher.

The observer is the real focus. If the observer changes his vantage point, if he walks around the sculpture, the perspective structure of the reflection changes as well. Sooner or later, he will see himself in the sculpture's surface and see himself as the instigator of that interplay of colors and light at the sculptures' surface that transcends the lifelessness of the material.

(Wellman 2009: 220)

In provoking the relation of the viewer to the Gate,Ward depicts a situation similar to the one researchers experience in an often dispersed and ambiguous security field. He draws attention to positionality and to how our own vantage points may change in dialogue with a dynamic field. How do (critical) security researchers position themselves as part of the field and what kind of ethical dilemmas do they face? The security field is in constant flux, and like the representation of Gate: "it is circular, not linear, exploring reflective ideas in different contexts" (Email Rob Ward, 2018). In this volume, we develop ways to encircle, observe, document and analyse what secrecy does in practice. 
This book introduction is structured as follows. In the next section 'Security and secrecy' we reflect on the challenge of secrecy in qualitative security research. Then, after formulating the 'Book objectives', we briefly elaborate on the title of the book in a 'Note on methods'. The last section outlines the book structure by discussing three avenues for navigating secrecy in security research that broadly map onto the three parts of the book: 'Secrecy complexities', 'Mapping secrecy' and 'Research secrets'.

\section{Security and secrecy}

Today, long-term, fieldwork-based, qualitative, ethnographic work is increasingly undertaken in the realm of (critical) security research. This is partly driven by new understandings of how and where securing and securitisation takes place. We see a reinvigorated attention to securing as a mundane, dispersed practice that involves citizens and mid-level professionals. Novel conceptualisations of securitisation as an iterative and dispersed practice (instead of a public, high-profile, singular speech act) require research design and methodological approaches that seek long-term immersion in the field (Bigo 2002; Hansen 2006; Huysmans 2006). These approaches seek to trace iterative frameworks over longer time horizons and across institutional boundaries (e.g. Bonelli and Ragazzi 2014). They entail a pragmatic and practicecentred perspective, which "involves focusing on how security works in practice and what it 'does' in different empirical contexts ... and to understand when it is 'good' in a particular time and place" (Nyman 2016: 132). As Mark Salter has put it, security researchers need to immerse themselves into daily expert practice, "learning the daily language, plotting the struggles . . . understanding the deep well of common sense beliefs" (2013: 105). In addition, studies at the intersection between (critical) security studies and Science-and-Technology Studies (STS), redeploy reflexive, ethnographic methods, including participant observation, to new ends (Bourne et al. 2015; Jacobsen 2015; Suchman et al. 2017).

Doing qualitative and ethnographic fieldwork in the security domain, however, encounters very specific challenges of secrecy and confidentiality that largely remain under-theorised. More generally, in International Relations the long Realist tradition of studying security policies like nuclear deterrence reveals little about how challenges of secrecy and access were navigated (for example, but not exclusively, Gaddis 1982). However, the security field is conditioned and partitioned through classification, restriction, obfuscation and confidentiality. In the case of STS approaches, Walters has reflected on the differences between studying security and studying laboratory life: "How do we 'follow the actors' when they operate under cover of national security? How do we study political controversies when public disclosure is the exception and secrecy the norm?" (2014:105). Security and policing researchers face what Randy Lippert, Kevin Walby and Blair Wilkinson (2015) have called "spins, stalls, or shutdowns", whereby officials delay and avoid research encounters, or create obstacles and obfuscations.

Furthermore, it is well known that secrecy holds a certain allure or seduction. It is often the researcher's expectation that there is a core of valuable truth at the 
heart of the invisible or the forbidden. As Graham Jones has put it, it is tempting to equate "secrecy - and the difficulty of access - with the depth and authenticity of knowledge" (2014: 61). Remote locations, shielded laboratories, concealed documents, are easily inscribed with a particular value. However, we must be mindful of what Jacques Derrida called the "secrecy effect". As Derrida (1994: 245) notes, there is a certain "value" to the secret, which he called a "capital of the secret", that forms a basis for its authority. In this sense, secrecy's value entails something like a "magical reification" of the professional in possession of the secret.

We now have a vibrant literature, sometimes called Secrecy Studies (Birchall 2016a; Maret 2016), which problematises the 'secrecy effect' and which shows that secrecy is more than a barrier to be overcome (for example: Balmer 2012; Birchall 2011, 2016b; Bok 1983; Horn 2011; Kearns 2016; Rittberger and Goetz 2018; Thomas 2015; Rappert 2009, 2010, also this volume; Walters and Luscombe 2016). However, this literature (with some exceptions) says little about the specific methodological implications of encountering classification and confidentiality. On the other hand, we have a vibrant and growing literature on methods in International Relations, (critical) security studies and adjacent fields (Salter and Mutlu 2013; Aradau et al. 2015a; Montgomerie 2017; Klotz and Prakash 2008). Yet, in this literature, explicit reflection on navigating and negotiating secrecy is limited. One exception is Seantel Anais' (2013: 196) discussion of her careful assembly of a "living" archive of documents concerning the use of non-lethal weaponry in US cities, through a variety of strategies, including Freedom-of-Information requests.

Anthropology also offers important methodological starting points and a longer tradition of reflecting on questions of access, (in)visibility and ethical complicity in fieldsites (for example, Bourgois 2003; Hammersley and Atkinson 2007; ScheperHughes 2004; Van Maanen 1981). While security researchers can certainly draw on the methodologies of anthropological fieldwork, most researchers in security studies do not strictly undertake ethnographies, nor are they necessarily trained to do so (Vrasti 2008).And even when they do, they need to reflect on the ways in which ethnographic literatures and lessons can be appropriated to security research (González 2012). As for example Erella Grassiani (Chapter 14) and Lieke Wissink (Chapter 17) show in this volume, the deployment of ethnographic methods in the highly secretive and sensitive security field entails its own specific set of methodological challenges and ethical dilemmas. Ethical dilemmas of security research are different than those in - for example - the observation of health practices (Cloatre 2013) or social movements (Riles 2001). Questions of confidentiality, anonymisation and secrecy play out in different ways in relation to qualitative immersion into security communities. As Fairlie Chappuis and Jana Krause show in this volume, the safety of researchers and their subjects requires special consideration, and has specific ethical implications.

\section{Book objectives}

This book offers scholars in Critical Security Studies, International Relations, International Political Sociology, Human Geography, Critical Military Studies, Border 
Studies, and adjacent fields, their own set of tools and approaches to the question of researching secret domains. The aim of this book is to offer not just a conceptual reflection on the dynamics of secrecy, but also practical, hands-on methodological guidance for qualitative fieldwork in the security domain. Often, the hard work of gaining access, developing fieldwork strategies, navigating secrecy and adapting research design in light of classification are kept implicit. The starting point of this collection is that the challenges of secrecy need to be explicitly addressed in research design. Secrecies and confidentialities are not simply obstacles to overcome or barriers to break through: they can themselves become objects of study and analysis. As Clare Birchall put it: in addition to "recognizing the consequences of how certain secrets are managed by organizations, communities, technologies, and states" we should also "work with secrecy - seek inspiration from it as a methodological tool and techno-political tactic" (2016b: 153, emphasis in original). Secrecies pose substantial challenges to research ethics and integrity: what if secrecy prevents meaningful research access to fieldsites or interviewees? Perhaps even worse: what if the researcher becomes initiated into secrets that $\mathrm{s} /$ he cannot share, or that put her in a compromised ethical position?

The book offers a rich set of analyses of the challenges of secrecy in security research, and sets out practical ways to navigate, encircle and work with secrecy. Specifically, the book has two objectives. First, to creatively conceptualise, assess, discuss and analyse the challenges of secrecy in security research. The book conceptualises and unpacks the question of how secrecy operates, and how it relates to confidentiality and invisibility. How can secrecy be conceptualised and incorporated into a rigorous research design, that is attentive to the particular dynamics of (in)visibility in this sensitive research domain? The book sets out new ways of conceptualising secrecy in relation to fieldwork, by understanding secrecy as more than a barrier to be overcome. It shows how secrecy itself can be made productive to the analysis: mapping secrecies and sensitivities in the field can itself be revealing; navigating obfuscation is co-productive of research design and data. What do security practitioners themselves find to be most sensitive and why? The collected chapters develop tools and methods for navigating, mapping and working with secrecy as part of research objectives.

Second, to offer reflexive methodological tools and best-practice examples for students and researchers on ethically appropriate ways of navigating secrecy in security research. The book focuses explicitly on questions of access, trust and anonymity in qualitative security research, and suggests ways in which researchers can deal with these issues. As Johnna Montgomerie (2017: 13) puts it, we need to render explicit the "deliberative moments" of our research design and practices: the "choices, trade-offs and judgements" we make in research design and in research practice, especially when encountering challenges of confidentiality. Accordingly, the chapters here offer concrete guidance to students and researchers who are about to embark on secrecy-sensitive fieldwork. How, in practice, can the researcher approach security professionals and gain access for longer-term (or short-term) fieldwork? How can we build a research design that reflects on the 
challenges of access and secrecy, and that does not merely regard the 'arrival story' as an irrelevant or amusing prelude to the real research (see Schwell, Chapter 4). How to immerse ourselves into communities of practice, learning from security practitioners without judgement, but without losing critical distance? The volume includes examples of best- and worst-practice experiences from researchers with a track record in qualitative security research. It provides students, $\mathrm{PhD}$ researchers and senior scholars with hands-on tips for working with secrecy, that balance professional demands for confidentiality with academic freedom and integrity.

\section{Note on methods}

Before we go on to clarify the book structure and sections, a brief note on the 'methods' that are part of the book's title. This book is part of an emerging tradition of increased attentiveness to methods and methodology in (critical) security studies and adjacent fields (Aradau et al. 2015a; Salter and Mutlu 2013). A distinction is commonly made between methods on the one hand - referring to all the tools, techniques and methods of analysis that are used to carry out research (i.e. interviews, participant observations, discourse analysis) - and methodology on the other:"the presuppositions about the 'reality status' (ontology) of the subject of study and about its 'knowability' (epistemology) that are enacted through research procedures of various sorts" (Haverland and Yanow 2012: 401). Contributions in this volume offer both methodological reflections, for example on relational ontology (see Dijstelbloem and Pelizza, Chapter 2), and methods such as "observing human-computer interaction" (see Bosma, Chapter 11). Considering the wide variety of contributions, our aim here is not to provide an umbrella methodological framework or approach to method(ology). Instead, we encouraged contributors to reflect on and make explicit their own methodological considerations and creative methods to navigate secrecy; whether they were developed and deployed as a "bridge between theory and method" or through "improvisation and bricolage" (Aradau et al. 2015b: 7).

As Claudia Aradau, Jef Huysmans, Andrew Neal and Nadine Voelkner (2015b: 4) have pointed out, the development of tools and methods in relation to critical approaches should resist the function of "hygiene" and "gate-keeping" that methodology sometimes exercises. The risk is that 'clean' and 'clear' research design erases the reflexive, iterative and associative capacities of critical research. At the same time, we find that it is important to develop methodological strategies and narratives that explain how research was done in practice (to funders, to colleagues, to journal editors and conference audiences). Here, we take our cue from Annemarie Mol's suggestions for "attending to method". Mol seeks to move beyond a binary approach to methods that either seeks to establish laws for research validity, or that questions the very possibility of such an aim. Instead, she proposes that we orient ourselves to methods as "interferences", and invites us to ask: "what is a good way of doing research, of going about the assembling and handling of material?” (Mol 2002: 157). The 'good' in this equation, for Mol (2002: 158), is not defined through "living up" to reality, but through "living with" reality. It involves recording and reflecting on, and coming to grips with, "what we are doing" when we go into the field. One way 
of thinking about the 'good' in this context is the aim to achieve rigour, understood by Can E. Mutlu to mean "thoroughness and carefulness" in researcher design. For Mutlu, this entails explicitly "laying out steps taken in research, avenues pursued and avenues exhausted” (Mutlu, this volume, also Salter and Mutlu 2013).

The methodological stakes for the research fields mentioned above, then, is to develop their own methodological practices that do justice to their reflexive and heterodox nature, while being capable of helping researchers develop meaningful fieldwork strategies (while also satisfying grant-awarding committees!). The challenge is to enable methodological toolkits attuned to the open-endedness and the "happening" of social worlds (Lury and Wakeford 2012: 2). The goal is to develop thoughtful and plausible narratives of how research is done, and a reflexive vocabulary for navigating secrecy in particular. Accordingly, the chapters that follow provide countless examples, discussions and vignettes of what researchers did when they sought to "observe, make notes, count, recount, cut, paste, color, measure, slice [and] categorize" when researching confidential and secretive security practices (Mol 2002: 158).

\section{Secrecy and methods: book structure}

The book distinguishes three avenues for navigating secrecy in security research, broadly mapping onto the three parts of the book. The first part of the book is focused on reconceptualising secrecy as a complex practice and mode of power. This helps rethink traditional notions of 'access' and 'gatekeeping', through an attentiveness to the multiplicities of secrecy, confidentiality and obfuscation. The second part of the book discusses reflexive research approaches that seek to map secrecy itself through creative methods and encircling. Contributors enquire into the dynamics of secrecy and how to make these productive in their analysis. This part of the book also reflects on the secrecy challenges of technologies and offers approaches to studying expert, obfuscated practices like digital technology. The third and final part of the book sets out ways to develop balanced research strategies that combine confidentiality with academic freedom. Key here is to reflect on the ethical implications of studying secret practices, and the challenging dynamic between proximity and critical distance.

In practice, researchers will most likely use all of these strategies to some extent, and they are certainly not mutually exclusive. Also, some themes including confidentiality and research ethics are at work throughout all of these themes. Nevertheless, distinguishing these approaches helps clarify what is at stake in different ways of thinking about secrecy, and how we may carve out concrete methodological approaches and choices in this complex terrain.

\section{Part 1: Secrecy complexities}

The first part of this book - entitled 'Secrecy complexities' - offers a set of perspectives that moves beyond secrecy as something to be uncovered, in order to unpack secrecy as a complex dynamic of power. The sculpture Gate shown at the beginning of this introduction illustrates the complexity of secrecy. Secrecy and visibility are 
not a simple binary (information is either secret or public), but entail complex trajectories and contestations. The sculpture Gate plays with these in/visibilities: with its confusing lay-out and reflecting surface, the viewer does not necessarily know which side s/he is on. How does one approach the Gate and how does that affect what becomes visible? Where is the threshold or passing point for entry? In this sense, Gate plays with and resists the seduction of secrecy and the promises of its uncovering. Accordingly, the contributions to Part 1 probe the value of the secret itself. Studying secrecy is not strictly about uncovering the kernel of the hidden, but is about analysing the play of power and authority that secrecies enable and produce (as exemplified in Box 0.1). Moreover, it is important, as researchers, to resist the 'magical reification' of the secret or the holder of secrets.

Building on recent work in (critical) security studies and International Relations (Van Veeren 2018; Walters 2014; Walters and D'Aoust 2015; Walters and Luscombe 2016), the chapters in Part 1 develop an understanding of secrecy as relational. In this approach, what becomes important to understand about the secret is less its hiding per se, and more the way in which it structures social relations, regulates communication, and distributes political power. The "choreography" of social positions revolving around the secret says something about the distribution of power, according to Eva Horn (2011: 109-110). As Brian Balmer (2012: 116) shows, moreover, secrecy is not a mere obstacle, but functions as an "active tool" that allows the "exercise of spatial-epistemic power". For example, even if documents and information are not strictly secret, they can be subject to limited circulation and regulated visibility, sometimes even aggressive information management by state or private actors. The analysis of such spatial-epistemic power and secrecy's "enactment, meanings and effects" (Balmer 2012: 2), is at least as important as the enquiry into secret materials itself.

A common response to secrecies is to understand the hidden as intentionally concealed, and "at least in principle, knowable" (Van Veeren 2018: 197). Subsequently, research may seek to reveal secretive practices, information or sites. Sam Raphael, Crofton Black, Ruth Blakeley and Steve Kostas (2016) for instance, triangulate logistical data (flight records) with other sources to uncover secret prisons and torture practices by the CIA. Torin Monahan and Jill Fisher, by comparison, set out nine strategies for gaining access to secretive organisations, ranging from the relatively familiar avenues of building trust and demonstrating legitimacy, to methods with 'surprise' effect, like cold calling and "making barely announced visits" (2015: 722). Together, these nine strategies offer a very helpful guide to the security researcher, but they remain quite firmly focused on the secret as something that needs to be uncovered or revealed. In her ethnographic research into organ-trafficking, Nancy Scheper-Hughes (2004: 37) explicitly attempts to "pierce the secrecy surrounding organ transplantation and to 'make public'... practices regarding the harvesting, selling and distribution of human organs and tissues". Some researchers even make the case for covert research (Calvey 2008), for example by entering a field under false pretences, or by using one's social position or job as fieldwork without asking consent (Holdaway 1982). While recognising the many concerns over covert research, for example, Scheper-Hughes (2004: 45) did so anyway: "how else, except in disguise, 
could I learn of the hidden suffering of an invisible, silenced and institutionalized population..?". Although important findings may arise from covert research, in this collection we do not encourage students to undertake undercover research. Not only because of ethical and safety considerations, but also because we consider the secret not purely as something to be uncovered or overcome.

\section{BOX 0.1 WHEN IS A SECRET SECRET?}

In 2006, the New York Times revealed the existence of a secret datamining programme that used financial transactions data for counter-terrorism. This programme - the Terrorism Financing Tracking Programme (TFTP) - had been put in place immediately after the $9 / 11$ attacks and uses wire transfer data from the Belgian-based SWIFT company to map suspect financial networks at the US Treasury. The NYT revelation was strongly condemned by US authorities, which blamed the newspaper for jeopardising national security.

However important that NYT publication was, the existence of the Terrorism Financing Tracking Programme wasn't really secret to begin with, and the revelation did not really reveal. To some extent, as we document elsewhere, the programme was not really secret because its existence had been known to an ever-wider circle of insiders, including the European Central Bank and other professionals. In a different perspective, the NYT article did not really reveal, because even if it brought the existence of the programme to public attention, it raised more questions than it answered, especially concerning the data-analytics at work in the programme, and the type of interventions to which it could concretely lead. It would take another five years before concrete case examples were made public, and even then they were cryptic and lacking in detail.

The point here is not to belittle the importance of the NYT publication (which did, in fact, lead to an important transatlantic discussion concerning this data-led security programme and its implications for privacy). Rather, the point is to problematise what Claire Birchall (drawing on Jodi Dean) calls the 'drama' of concealment and revelation, which is how we often think about security secrecy. Instead of a moment of revelation, we have suggested that it is more useful to think of the NYT publication as one moment in a longer contested knowledge practice (de Goede and Wesseling 2017). Secrecy and (de)classification can be more ad hoc and controversy-driven than the formal classification rules would lead to suggest (also Balmer 2012). Contested knowledge practices are political and material. Secrecy/publicity dynamics play an important role in regulating knowledge, structuring the field of legitimate speakers, and influencing the direction and themes for public debate. In the case of the TFTP, the contestation over its openness or secrecy has to some extent displaced substantive discussion concerning its legitimacy and effectiveness. 
However, if secrecy is complex, non-binary, ad hoc, and related to obfuscation and evasion (as much as formal classification), new methodological approaches are necessary. Such approaches are laid out in the contributions to Section I on 'Secrecy, silence and obfuscation'. First, as Oliver Belcher and Lauren Martin show, deliberate strategies of what Peter Galison (2004) called "removing knowledge" are not always the main challenge to researchers. More important than formal classification, in many cases, are situations where information is restricted, sensitive or limited (also Curtin 2014). Chapter 1 shows how secrecies can operate through bureaucratic obfuscation, silences and delays in replying to research requests (also Belcher and Martin 2013). In this sense, secrecy itself offers insights into the (dis)functioning of the state. Belcher and Martin show how they grappled with the methodological challenges of secrecy in their research on detention centres and military practices. They offer lucid, practical advice on how to work with the grey area of off-therecord conversations and how to undertake Freedom of Information requests.

For Huub Dijstelbloem and Annalisa Pelizza in Chapter 2, the 'real secret' is the "nature of the state", and they analyse how research is co-constitutive of how the state appears in view. Dijstelbloem and Pelizza offer the notions of performativity and immanence to conceptualise the in/visibility of state practices. If research starts from the premise that "the study of states, borders and infrastructures starts in the middle of things without having a view from above", Dijstelbloem and Pelizza offer concrete examples and tools to develop what they call an "oligoptic" analysis of state practices in relation to migration control.

In Chapter 3, William Walters and Alex Luscombe introduce the notion of "postsecrecy" to conceptualise places or practices that are no longer strictly secret, but the appearance of which is still regulated through partial in/visibilities, rumours, "fuzziness and ambiguity". Their study of former UK weapons testing site Orford Ness offers a compelling account of a place haunted by secrecy, which profoundly problematises the secrecy/transparency binary. It also offers a rich methodological toolkit of researching postsecrecy, including joining guided tours, immersion in archives, and drawing upon the unexpected (and often dismissed) knowledge of ufologists.

Section II, called 'Access, confidentiality and trust', offers creative and selfreflexive ways of gaining access and working with confidentiality. As Didier Fassin's ethnography of urban, street-level policing in Paris also shows, fieldwork access is not so much a clear moment, but is precariously negotiated through ongoing "critical dialogue" (2013: 19). How can we include the moments where 'access' is denied or difficult, and let them be illustrative for the way in which security is constituted? As Alexandra Schwell discusses in Chapter 4, the 'arrival story' is a classic trope in ethnographic literatures. Too often, however, the arrival story remains an anecdotal prelude to the 'real' research analysis; gaining access is reduced to an initial barrier to be overcome before the research process can commence. Far less often do we reflect on the ways in which our modes and practices of access reflect back on our research questions and findings themselves.

By comparison, in Chapter 5 Jonathan Luke Austin reflects on the challenging process of accessing the 'lifeworlds' of perpetrators of torture, and the complex 
responsibilities and ethics it involves. Austin discusses how he redeployed the ethnographic method of 'deep hanging out' in his research to create proximity to possible interviewees. He suggests creative ways of engendering conversation on sensitive topics such as torture, including the use of re-enactment, because 'showing' might sometimes be easier for interviewees than 'telling', and it allows the researcher the "opportunity to observe the facial expressions, verbal communications, emotional states". Proximity with perpetrators of extreme violence moreover raises poignant questions concerning ethics and the researchers' positioning, that Austin discusses.

In Chapter 6, Fairlie Chappuis and Jana Krause give a frank account of their fieldwork experiences in dangerous conflict and post-conflict settings. They draw on their research and fieldwork experiences in Burundi, Liberia, Indonesia, Nigeria, Myanmar, and South Sudan to show how local contexts can shape the research process in unexpected ways. The resources and bureaucratic capacities of local institutions as well as the presence of other actors such as "human rights investigators and activists, journalists, and spies" present opportunities as well as ethical challenges. Importantly, their chapter highlights the importance of the safety of researcher and respondents, by discussing many practical considerations and tips.

\section{Part 2: Mapping secrecy}

In the second part of the book, called 'Mapping secrecy', we explore how we can make the barriers of secrecy and the contours of obfuscation, productive in our analysis. The sculpture Gate generates a dynamic vision of the barrier to entry as well as its surroundings. Every time the observer changes position, Gate becomes different. From one angle it is closed, yet from another angle entry seems possible and permitted. Sometimes, one can glimpse (a snippet) of what lies behind the gate, although its context may remain unclear. By making Gate out of a reflective surface it was the sculptor's intention to create an activated consciousness of the viewer's environment. As such, Gate does not symbolise that which is beyond vision, but emphasises what we do see.

Contributions to 'Mapping secrecy' draw from and contribute to a growing body of literature on secrecy that encourages us to "experimen[t] with and explor[e] the productive possibilities of secrecy, fog, obfuscation" (Birchall 2016b: 161). It can be revealing in itself to map and analyse secrecy, obfuscation and the blurry boundaries of the visible and invisible. In such an approach, mapping the dynamics of openness and closure becomes part of the research: how are secrecy controversies productive of the ways in which security phenomena become known (e.g. De Goede and Wesseling 2017)? Which practices, protocols and information are security professionals willing to share, and which do they close off, and why? Where are lines of visibility and access (deliberately or unwittingly) drawn? Previous research has shown that the issues that professionals find sensitive are not always the most interesting issues from a research point of view. The barriers of secrecy that governmental institutions put up can, moreover, be instructive in themselves (Anais 2013: 197; Bryman 2012: 151). 
In addition, secrecy may arise less from a deliberate hiding or classification, and more from the need for specialised knowledge or expertise to decipher practices or discourses (Van Veeren 2018). Sometimes, the secret is kept in public. Michael Taussig (1999: 5) coined the term 'public secret' to denote "that which is generally known, but cannot be articulated". Often practices are not necessarily secret, but are not readily analysable for other reasons; they could be too overwhelming in volume, too distant, foreign, or too complicated to understand in the often limited time available for the research project. Accordingly, contributions to Part 2 of the book engage with the challenge of understanding the role and inner workings of complex security technologies. All kinds of security practices, from border security, to drone warfare, to "securing with algorithms", are technology-led in ways that are opaque to researches and practitioners alike (e.g. Amoore and Raley 2017; Bourne et al. 2015). In what ways do technologies require specialised knowledge to design, implement, use, and understand them and what does this mean for our knowledge production about security decision-making and practices?

Contributions in Section III, called 'Reflexive methodologies', make dynamic encounters with secrecy a primary object of analysis. Rather than strictly seeking access, these contributions start thinking about ways of encircling secret sites and obfuscated practices. The perspective on secrecy as a dynamic practice and a mode of power - as developed in this introduction and Part 1 of the book - directs us to creative methodological approaches that do not so much seek to break through, but that advocate a particular encircling. Encircling entails a lateral, multipronged, creative, iterative approaching of secret sites, confidential materials and classified practices. It is less focused on uncovering the kernel of the secret, than it is on analysing the mundane lifeworlds of security practices and practitioners that are powerfully structured through codes and rites of secrecy. The chapters show in different ways how an enhanced understanding of the ways in which secrecy mediates both research and the topic under investigation, can be revealing in unexpected ways. How can researchers move beyond the binary of visibility and invisibility and navigate and analyse these blurry boundaries? How can we describe and analyse objects and terrains that are not directly visible for multiple reasons?

Researchers might experience different affective states in relation to secrecy "ranging from guilty excitement of penetration to intense paranoia about the consequences of approaching or disclosing secrets" (Jones 2014: 61). Although these experiences may have a profound effect on research and researchers, they are often not explicitly addressed. A reflexive attitude generates awareness for the ways in which secrets shape our own knowledge production, and how our methods may affect our respondents. Aradau and colleagues (2015b: 3) have urged us to "expand the question of reflexivity to include an analysis of the effects that methods as practices have". Rightfully, they emphasise that methods are practices. We do methods. They are embodied. They may "enact" identities (ibid.). And, "methods circulate through other social spaces" than the academic field. Importantly, in this expanded notion of reflexivity, they ask: "how does the practice of the method constitute us as researchers, when we think about methods, learn methods, discuss methods, and 
most importantly, use methods?” (Aradau et al. 2015b: 6). For security researchers then, secrecy is not simply a hurdle to overcome in the first phase of the 'research design', but asks for a continual reflexive attitude before, during and after fieldwork.

Contributions to this section explore what secrecy adds to our conception of security practices. In Chapter 7, Brian Rappert explores how "what is not in our analysis" can become a productive aspect of our research, by outlining experimental forms of writing that may help us to "skillfully write with and not just about secrecy". Drawing from his own research into disarmament and arms control communities, he offers strategies to "exemplify the interplay of disclosure and concealment". Contributors also draw attention to the way in which barriers of secrecy may act as reflective surfaces that mirror one's own role in the field. In Chapter 8, Marijn Hoijtink draws on feminist literature to offer a reflective discussion of "genderrelated opportunities and pitfalls associated with research on security and secrecy". Using generous examples from her research on security technology and corporate actors in European security, she shows how our positionality may provide or deny access to the field, but that we also bring our own background and assumptions to the field. She advocates for "a commitment to openness in research encounters" in security contexts.

In probing what security is and where we might see security, in Chapter 9 Jonna Nyman "challenges the ongoing link between security and secrecy". Drawing on her ethnographic fieldwork on the everyday security landscapes of Chinese security politics, she provides methodological guidance and practical tips for researchers who want to use visual ethnographic methods. She combined auto-photography and photo-elicitation to explore how security is "lived" by ordinary Chinese citizens; what security means to them; what they deem relevant; and how it intersects with their daily life. By showing how our own knowledge production is mediated through secrecy and obfuscation - including our own 'secret' assumptions and inclinations - we do not mean to say that is impossible to conduct objective research. Rather, by explicating these elements, we aim to produce a more realistic research account.

In Section IV, called 'Ethnographies of technologies', contributors explore strategies to map the dynamics of secrecy inherent to complex digital security technologies. Contributions in this section offer researchers methodological guidance and practical tips on how to understand and account for the increasing role of technologies in effecting judgements and decisions in the security realm. Such technologies are sometimes classified (as in proprietary algorithms), but they can also be obfuscated in multiple ways. The sheer technical knowledge required to understand their functioning renders them particularly secretive. Digital technologies often entail what Elspeth Van Veeren has called “invisibility as inexpertise" (2018: 197). Researching such invisibilities may require developing technical knowledge and expertise, and sometimes also relies on "identifying the traces of things" (Van Veeren 2018: 198). How can we account for the role of complex security technologies without 'drowning' in technical details? Given that technologies assemble many different ideas and objects, how do we decide which part of the technology to 
describe or leave out? How do we describe the complex technical characteristics of security technologies and relate them to their wider socio-political context? How could we complement ethnographic approaches with novel methods to observe technology? And, how do we write about technologies to a non-specialised audience in a way that is analytical and not purely descriptive?

In Chapter 10, Till Straube shows how the social sciences and popular media have often mobilised the notion of the black box to call attention to the opacity of digital technologies and algorithms. Through a hypothetical analysis of the racial bias exhibited by face-detecting algorithms, he illustrates and explores practical and conceptual challenges of 'opening the black box of algorithmic devices'. Highlighting a "set of real-life roadblocks that algorithm studies are prone to", he offers researchers in social sciences at all levels of expertise, specialised methods to study digital devices. His analysis shows that it is crucial to direct our attention to include the socio-technical characteristics of digital devices, as politics are inscribed into security technologies (Akrich and Latour 1992). Studying digital security technologies may help to map "the less immediately visible violences that see war spilling over into the spaces of everyday life" (Amoore and De Goede 2014: 513). In Chapter 11, Esmé Bosma draws on her research into counter-terrorism financing practices by banks to offer a multi-sited ethnographic approach to study digital security technologies. Based on her experiences of analysing the financial transaction monitoring systems used to filter and monitor unusual financial activity and suspicious transactions, she offers two methodological starting points centred around "sites of experimentation": to follow technology from design to use and to observe human-computer interaction.

Whereas Straube and Bosma mainly focus on digital security technologies, Sarah Hughes and Philip Garnett in Chapter 12 develop a broader understanding of 'technology' as a mode of governing that includes "multiple technologies by which state actors work to influence a narrative surrounding an event or process". They show how researching technologies is not only a matter of technical expertise. In their analysis of the court-martial of Chelsea Manning, they offer multiple ethnographic methods to critically analyse "emergent technologies of state control". In addition, they consider the ethical, practical and technological challenges of working with leaked material. Contributions in Part 2, then, offer ways to make secrecy productive to our analysis before, during and after our data collection.

\section{Part 3: Research secrets}

Part 3 of the book, called 'Research secrets', reflects back on the role of the researcher and the things in our own research practice that - while perhaps not strictly secret - often remain unsaid or at the very least under-articulated. Returning to consider the sculpture Gate, the researcher is confronted with the possibility of a prescribed and conditional access, but also with an image of themselves. In encountering Gate, the researcher is asked to consider their own position and where they stand in relation to the field and in relation to what can and cannot 
be seen. Where the researcher stands in relation to Gate determines not only how the researcher encounters it, but also what is reflected back, making visible the researcher's own role, processes, and position. Gate makes it possible to see ourselves as active and present agents and raises further questions about our roles as critical security researchers. These questions include our impact on the field; if and how we engage in advocacy and critique; and ethical concerns around confidentiality and academic integrity.

Thinking about 'research secrets' generates attentiveness to the things we do not often make explicit in our research processes when working with, around, and through secrecy. These processes include how we negotiate issues of ethics and academic integrity, and the choices we make when engaging in advocacy or crafting critique. These make up a central part of our research practice, and yet they remain mostly hidden or silenced in our writing that focuses on research results. As one of us shows in Chapter 15 (de Goede) on 'secrecy vignettes', these are the stories of our research experiences we may 'close the gate on', that we often do not tell, and the secrets we construct about and around our own research.This connects to recent literatures that address these silences, or moments of unease, and their effects on the research process from fieldwork to writing that take seriously the ethical and emotional challenges of engaging challenging security fields (Eriksson Baaz et al. 2018).

One paradoxical consequence of the way that secrecy plays out in security research, is that some fieldsites may become overexposed, as others remain inaccessible. The Gate offers the possibility for access, but this can result in greater numbers of researchers visiting the Gate. How other researchers behave at the Gate can alter the environment: maybe these other researchers (unintentionally) damage the Gate or the environment around it. Issues of accessibility, including location, security, infrastructures capable of supporting a community of researchers including hotels, restaurants and communication networks, and the presence of sympathetic gatekeepers, all lead to certain places and people becoming a focus of research. The number of other researchers present alters the Gate's accessibility, as more and more people become reflected, altering what can and cannot be seen. As Tom Clark (2008) has argued in relation to such sites of 'over-research', as certain places and communities become the subject of more and more research, we not only limit the topics of research, but participants and researchers themselves become increasingly sceptical of research's potential to offer critique and to advocate for meaningful social change (Box 0.2).

\section{BOX 0.2 OVER-RESEARCH AND 'HOT' FIELD SITES}

To give an example, following the civil war in Syria and the subsequent 'refugee crisis', Za'atari refugee camp in Jordan became a locus for research. In discussing the infrastructures of over-research Elisa Pascucci has shown how due 
to its location in "one of the most politically stable and accessible (to Western visitors) countries in the Middle East, Jordan, Za'atari has also become one of the main hubs for academic researchers looking for 'data'" (2017: 249). An "unmanageable number of research projects" focused on Za'atari and Syrian refugees led to reports of 'research fatigue' amongst humanitarian organisations acting as informal research gatekeepers but officially charged with assisting and managing the Syrian refugee community. This research fatigue, in turn, led to the subsequent creation of a coordination structure designed to screen research projects "on the basis of operational needs and in the best interest of the refugee population" (Ahmadzadeh et al., quoted in Pascucci, 2017: 249).

Here we see the dynamic relations of secrecy and access in structuring methodological choices and ultimately knowledge production itself. Issues of secrecy and access lead, in certain instances, to particular places and populations becoming over-researched, which can then lead to the (re)production of secrecy through the imposition of restricted access and demands for particular types of knowledge production by various gatekeepers. Importantly in discussing the issues of over-research, Pascucci stresses the constitutive role of research infrastructures. In her case the research infrastructure is constituted by the presence of humanitarian actors who play an important role in facilitating access to the field, even when they are not the subjects of the research. Their presence in many instances also makes research in the field practically possible, from the presence of suitable transport networks and accommodation, something Pascucci calls "safe transnational mobility channels".

Amongst other scholars reflecting on 'hot' research sites, Katerina Rozakou has reflected on her engagement with Moria the EU's migrant processing 'Hotspot' on the Greek island of Lesvos (2017). In reflecting on the impacts of over-research and our complicit role in the production of such she considers how she is seen by the Hotspot manager as "just 'another' researcher, similar to the detested journalists who crave for an easily digested account and a simplified image" (Rozakou, 2017). Being seen as 'just another researcher' craving an 'easily digested account' or a 'simplified image' calls into question the (un)productive nature or the potential (un)productive nature of our work in the eyes of the people we curate our research with. Issues of accessibility, including location, security, infrastructures capable of supporting a community of researchers including hotels, restaurants, and communication networks and the presence of sympathetic gatekeepers, all lead to certain places and people becoming a focus of research.

In Section V, 'Critique and advocacy', contributions engage with differing notions of when, how or if to speak out, and how to engage in critique amid the dynamics of secrecy. Much security research is marked by its ambition to raise critical questions about practices of securing, and to challenge the ways in which 
societal issues become securitised. In security studies there have long been debates and divisions over whether security is positive or negative, what 'ethical security studies' entails, and about what it means to study security from a 'critical' perspective (Austin et al. 2019; Aradau et al. 2015a; Nyman and Burke 2016; Salter and Mutlu 2013). A "pragmatic practice-centered approach" recognises that "there is no one 'truth' and so no 'correct' approach to critique or ethics" in 'critical' or 'Critical' security research (Nyman 2016: 138-139). Secrecy is a factor in our ability to act as critical observers of the world(s) we encounter, working to structure what can and cannot be said, or how we frame our interventions. Working with secrecy raises questions for advocacy as well as questions about the balance between observation and engagement including going beyond important questions about introducing classified knowledge into the public domain, or when - if ever - to act as a whistleblower.

When dealing with 'secret' or sensitive data, researchers have to consider a range of factors that relate to their subject position relative to their research subject(s) and their own agency or role in being a vehicle for disclosure. Researchers have to continuously navigate and reassess the methods and ethics of disclosure. We have to decide what we reveal and how in accordance with our particular relationship to both the person and/or organisation who has shared information with us, or the particular subject matter. Scholars researching security have differential subject positions vis-à-vis their research subjects. In some instances, we may be 'studying up' and thus reliant on powerful others for research access; in other instances the relationship may be a more equal one between professionals who share professional interests if not professions; while at other times researchers may find themselves in positions of authority, both in terms of their academic expertise but also in terms of the knowledge they possess about other people's lives. Here ethical processes of disclosure or counsel help to shape what we choose to say and how we choose to say it. Telling peoples' stories crafts the researcher into a powerful subject especially when those stories involve processes of revelation and curation. Additionally, researchers have to think carefully about using information that may have negative consequences on people's lives.

Section $\mathrm{V}$ offers practical, reflective accounts of how and why researchers have chosen to make specific decisions regarding advocacy and critique. Researchers reflect on their own positions in their particular research field and show how political affiliations, worldviews, and power relations influence how, when and if they choose to practice advocacy and critique. Researchers may feel the need to both speak-out on particular issues, as experts with particular knowledge, while maintaining access to particular security domains for themselves and others. However, as Anna Stavrianakis also shows in Chapter 13, the role of critic is not always a comfortable one, or a role researchers give themselves. It is also how we are viewed by our interlocutors. While it is important to acknowledge that identities are multifaceted and "exist in constant flux" (Dingli 2015: 729), the role of expertise in academia and beyond may be gendered and/or racialised (see Hoijtink, Chapter 8 ). We have been trained to engage in critique and the more experienced 
amongst us have the CV and publications to show that our peers have judged us worthy of playing such a role. This also makes us useful for articulating ideas, pushing boundaries, and making arguments that our research subjects working in the field of security (broadly defined) cannot engage in, for reasons of secrecy yes, but also institutional politics, and professional discretion. This, however, leads to further questions of where our analysis and scholarly independence ends, and the wishes of our interlocutors to engage in their own form of advocacy or critique begins. As such, the balance between publicly engaged academia that informs advocacy efforts and offers critique, and the need for integrity around transparency and confidentiality is highly context and researcher specific.

Stavrianakis makes clear in Chapter 13 that researching the UK arms trade politicised her. She sets out the multi-method approach with which she studies the UK arms trade. Noting that learning about the secretive world of arms trading made her 'angry' about the way it was justified, she was then confronted with questions concerning whether and how to engage politically. Stavrianakis reluctantly became invested in the UK 'impact agenda' by speaking out as a public expert on these issues, and her chapter discusses the "challenges of moving between scholarship and activism". Issues of critique and efforts at advocacy can also drive us to research those we oppose, as Erella Grassiani shows in Chapter 14. Grassiani explores ways of navigating this relationship in a way that enables her to engage in both advocacy and critique, while being mindful of her ethical commitment to do no harm to her research subjects. She uses the anthropological idea of the 'trickster' to unsettle the focus on empathy with research subjects common in ethnography. Using the approach of the trickster helps Grassiani highlight the ambivalence of researching those to whom you have an ethical obligation to do no harm but with whom you might politically and ethically disagree. In contrast to studying those we oppose, close research relationships with research respondents can lead to friendships that, while facilitating and smoothing our access to the field, can make our role as critical security scholars more difficult. In Chapter 15, Marieke de Goede also engages the themes of critique and entanglement, albeit from a very different angle. Chapter 15 explores the use and usefulness of auto-ethnographic 'vignettes' to give secrecy a place in academic writing. It explores the ways in which vignettes can broaden the register of academic voice, to reflect on fieldwork dilemmas and discomforts, and on the complex entanglements between researcher and researched that participant-observation produces.

\section{BOX 0.3 BALANCING CONSENT, CONFIDENTIALITY AND ACADEMIC INTEGRITY IN PRACTICE}

In discussing the problems researchers face in balancing issues of consent, confidentiality and academic integrity we draw on our own recent experiences in finalising a grant agreement with the European Union for a multi-country, 
multi-sited, multi-researcher, multi-language and multi-method project. In this instance, secrecy became visible and a clear methodological and ethical challenge (as opposed to an issue of concern written into the initial grant proposal) when in finalising the ethics section for approval from the European Commission we were expected to balance the need to gain consent from all those involved in the research with the need for confidentiality, the safety of our data and research respondents and the academic integrity demands of open access to our data. This was and remains a Gordian knot.

First, there was no way we could promise to gain the active consent, in the shape of a signed form, from every single person encountered in the process of research that will involve participant observation in places, such as the Hotspots on the Greek islands or informal migrant settlements in Ethiopia, with not only hundreds of people present, but additionally people with multiple different languages and some illiteracy. Second, the need for confidentiality and the safety of our research respondents is actively in tension with the need for active consent and open access research results required under academic integrity guidelines. The European Union requires our research data to be stored on a repository and to be available to other researchers. Meanwhile, our research project involves vulnerable groups of people, refugees, victims of torture, political dissidents, and (potentially unknown to us) unaccompanied minors; to ask for and record their consent has the potential to risk their safety in an environment of heightened tensions and physical violence between different groups.

Furthermore, allowing potentially anyone access to this data brings further potential harm to our research subjects. In addition, the call for a radical academic transparency that underpins the sharing of research data highlights an inability of funding councils to consider the nature of many ethnographic-style data collection methods. When issues of reporting on possible human rights abuses and criminality [when most of our vulnerable research respondents have been technically criminalised as irregular migrants] are thrown into the mix the exercise becomes even more fraught with contradictions.

Here the idea of a signed consent form alongside the archiving of data in an open access repository appears as a material embodiment and performance of our academic integrity. They provide the research team with a way of demonstrating our commitment to an ethical system supposedly committed to doing no harm and an academic system committed to transparency and accountability in knowledge production. However, are these ex ante systems capable of producing such ethical research or upholding academic integrity on their own?

Section VI, 'Research ethics in practice', addresses ethical considerations that can create conflicting demands for researchers. Encountering and navigating secrecy 
in research inevitably raises important questions of ethics and research integrity. The need for active consent can challenge our responsibility to do no harm. Ethical review increasingly takes place ex-ante requiring all ethical issues to have been anticipated and prepared for in advance. Ethical reviews can sometimes function more as university risk management exercises, rather than reflexive processes of ethics in practice (e.g. Robinson 2011). Meanwhile, an increasing requirement for transparency and open access data repositories required under well-meaning academic integrity efforts creates further complications (see Box 0.3).

Contributions to Section VI reflect explicitly on the ethical questions accompanying qualitative security research. Researchers have to balance integrity, that is the ability to show the strength of your research foundation, with considerations around anonymity and confidentiality that are not only driven by research ethics but sometimes legal concerns. For instance, one of the contributors to this edited volume has had to negotiate how much detail they can reveal about their fieldsite and research respondents in concert with their academic institution that is fearful of possible legal repercussions.

As is made clear throughout this volume, security research is an active, embodied and engaged process that often asks difficult personal and ethical questions of researchers as they attempt to access field sites. Researchers find themselves encountering, uncovering and working with highly sensitive data such as policing strategies (see Amicelle, Badrudin and Tanner, Chapter 16) or asylum requests (see Wissink, Chapter 17). What types of decisions do researchers make regarding the selection and access to field sites in their research? How do they choose to access the site (or not) or use such data (or not)? How do they maintain confidentiality of fieldnotes (see Nyman, this volume), and balance the need to account for the validity of their data with other aspects of academic integrity related to confidentiality? And importantly, how do researchers account for the validity and rigour of their data when such data and its sources are confidential or of a sensitive nature?

If we appear to have more questions that definitive answers, this is because research is an active process as many of the contributions in Section VI and the volume as a whole make clear. For example, there is a difference between 'planned ethics' written in to research design and grant proposals and 'ethics in practice'. But as Anthony Amicelle, Marie Badrudin and Samuel Tanner as well as Lieke Wissink stress (in Chapters 16 and 17), we should consider not only ethics in practice but also ethics as practice. Ethics or ethical practice is not something that can be simply written into a form or approved by an ethics committee although these encounters often offer useful ways to start 'thinking' ethics. All stages of the research process require continuous (ethical) reflection that asks us to think across a range of temporalities, drawing on both past and present experiences but also asking us to imagine future possibilities.

Finally, Section VI asks what happens to issues of consent and confidentiality when what is being studied as an important actor in the security field with the capacity to affect change is not a human agent capable of consent, active or 
otherwise? As contributions to this volume make clear (see, for example, Bosma, Chapter 11 and Straube, Chapter 10), scholars of security increasingly research the non-human agents of security such as algorithms, databases, and infrastructures that do very real work in the world alongside and in conjunction with their designers, coders, and users (e.g. Amoore and Raley 2017; Pallister-Wilkins 2018; Read et al. 2016). What ethical responsibilities do researchers have in relation to these security actors in their work? Work on security infrastructures such as border technologies - surveillance systems, walls, checkpoints, gates - for example, are focused on non-human actors, yet humans still interact with and use these infrastructures in relational ways meaning that work detailing particular aspects of these infrastructures can have very real human impacts. It is not possible in these instances to gain the consent of the people who are affected by and encounter these (border) technologies, e.g. the irregular migrants made visible to search and rescue regimes by surveillance systems at sea even if research into these systems has the capacity to alter the security field (Dijstelbloem et al. 2017). In Chapter 17, Wissink discusses following deportation files as a significant actor containing important information about migrants. In Wissink's research the file is a taxonomic system materially and digitally representing individuals neither of whom - the file, or the individual categorised and codified in the file - can consent to being studied. In such circumstances what are our ethical responsibilities when we are not researching people directly but indirectly through the devices of security?

In 'Research secrets' researchers offer personal reflections on their own decisionmaking processes relating to the handling of confidential and sensitive research information. They show how decisions are highly context specific and related to particular aspects and issues within the security domain such as the relative power of research subjects. As the contributions show, it matters what type of data is being made visible or invisible, who and what the subjects of this data are as well as the intended audience.

\section{Concluding}

The sections that follow discuss three avenues for navigating secrecy in security research. The first part reconceptualises secrecy as a complex practice and mode of power and helps think through the methodological implications of this shift. The second part of the book sets out the objective to map the contours of secrecy itself through creative and reflexive methods of encircling. The third and final part of the book sets out ways to develop balanced research strategies that combine researching secret domains with academic integrity and practices of critique. It helps rethink research ethics in practice. Ranging from creatively conceptualising secrecy, postsecrecy, (in)visibility, to thinking about strategies of access and researcher safety, to reflecting on the challenges of entanglement and critique, the authors have generously shared their experiences and best- and worst-case examples. Together, they showcase the multiple, reflexive and productive ways in which secrecy can be navigated in security research. 


\section{Suggestions for further reading}

- $\quad$ Marieke de Goede and Mara Wesseling (2017) "European Secrecy and Post9/11 Security Practice”, Journal of European Integration, 39(3): 253-226.

- Marlies Glasius, Meta de Lange, Jos Bartman, Emanuela Dalmasso, Adele Del Sordi, Aofei Lv, Marcus Michaelsen and Kris Ruijgrok (2018) Research, Ethics and Risk in the Authoritarian Field. Cham: Palgrave Macmillan.

- Hugh Gusterson (1998) Nuclear Rites, A Weapons Laboratory at the End of the Cold War. Berkeley: University of California Press.

- Graham M. Jones (2014) "Secrecy", Annual Review of Anthropology, 43: 53-69.

- Mark B. Salter and Can E. Mutlu (eds) (2013) Research Methods in Critical Security Studies. New York: Routledge.

- William Walters and Alex Luscombe (2016) "Hannah Arendt and the Art of Secrecy; Or, the Fog of Cobra Mist”, International Political Sociology, 11(1): 5-20.

\section{Notes}

1 The artwork is currently on display at the Cass Sculpture Foundation in Goodwood, UK (http://www.sculpture.org.uk/artwork/gate-1). Prof. Rob Ward was born in 1949 in Nottingham. He studied at the University of Newcastle-upon-Tyne, The University of Reading,(1973-1975), Rome Academia di Belle Arti and Athens Polytechnion. He is a Fellow of the Royal Society of Arts and a Fellow of the Royal Society of British Sculptors. For more information about Rob Ward's oeuvre see http://www.robwardsculpture. co.uk/ and Rob Ward (ed.) (2009) Reflections. Isle of Wight: MakingSpace Publishers.

2 The use of a reflective surface is a conscious and consistent continuation of topics in Rob Ward's work, inspired by artists like Constantin Brancusi and the art-history dimension of the mirror image in the Renaissance. By making the structure of a series of sculptures entirely reflected, the sculpture is "present both in real form and (together with its surroundings) as an image, as an intangible representation" (Wellman 2009: 216).

\section{References}

Akrich, Madeleine and Bruno Latour (1992) "A Summary of a Convenient Vocabulary for the Semiotics of Human and Nonhuman Assemblies", pp. 259-263 in Wiebe E. Bijker and John Law (eds) Shaping Technology/Building Society: Studies in Sociotechnical Change. Cambridge, MA: MIT Press.

Amoore, Louise and Marieke de Goede (2014) “What Counts as Violence?”, pp. 496-518 in Jenny Edkins and Maja Zehfuss (eds) Global Politics: A New Introduction, second edition. London Routledge.

Amoore, Louise, and Rita Raley (2017) "Securing with Algorithms: Knowledge, Decision, Sovereignty", Security Dialogue, 48(1): 3-10.

Anaï, Seantel (2013) "Objects of Security/Objects of Research. Analyzing Non-lethal Weapons", pp. 195-198 in Mark B. Salter and Can E. Mutlu (eds) Research Methods in Critical Security Studies. New York: Routledge.

Aradau, Claudia, Jef Huysmans, Andrew Neal and Nadine Voelkner (eds) (2015a) Critical Security Methods. New Frameworks for Analysis. Oxon: Routledge.

Aradau, Claudia, Jef Huysmans, Andrew Neal and Nadine Voelkner (2015b) "Introducing Critical Security Methods", pp. 1-22 in Aradau et al. (eds) Critical Security Methods. New Frameworks for Analysis. Oxon: Routledge. 
Austin, Jonathan, Luke, Rocco Bellanova and Mareile Kaufmann (2019) "Doing and Mediating Critique: An Invitation to Practice Companionship", Security Dialogue, 50(1): 3-19.

Balmer, Brian (2012) Secrecy and Science: A Historical Sociology of Biological and Chemical Warfare. London: Routledge.

Belcher, Oliver and Lauren Martin (2013) "Ethnographies of Closed Doors", Area, 45(4): 403-410.

Bigo, Didier (2002) "Security and Immigration: Toward a Critique of the Governmentality of Unease", Alternatives, 27(1, supplement): 63-92.

Birchall, Clare (2011) "Introduction to 'Secrecy and Transparency': The Politics of Opacity and Openness", Theory, Culture \& Society, 28(7-8): 7-25.

Birchall, Clare (2016a) "Six Answers to the Question 'What is Secrecy Studies?”, Secrecy and Society, 1(1): 2 .

Birchall, Clare (2016b) “Managing Secrecy”, International Journal of Communication, 10(0): 12.

Bok, Sissela (1983) Secrets: On the Ethics of Concealment and Revelation, first edition. New York: Pantheon Books.

Bonelli, Laurent and Francesco Ragazzi (2014) "Low-tech Security: Files, Notes, and Memos as Technologies of Anticipation", Security Dialogue, 45(5): 476-493.

Bourgois, Philippe (2003) In Search of Respect: Selling Crack in El Barrio. Cambridge, UK: Cambridge University Press.

Bourne, Mike, Heather Johnson and Debbie Lisle (2015) "Laboratizing the Border:The Production, Translation and Anticipation of Security Technologies", Security Dialogue, 46(4): 307-325.

Bryman,Alan (2012) Social Research Methods (fourth edition). Oxford and New York: Oxford University Press.

Campbell, David (2003) "Cultural Governance and Pictorial Resistance: Reflections on the Imaging of War”, Review of International Studies 29: 57-73.

Calvey, David (2008) “The Art and Politics of Covert Research: Doing 'Situated Ethics' in the Field”, Sociology, 42(5): 905-918.

Cass Sculpture Foundation (n.d.) Description of Rob Ward's sculpture Gate, available at http://www.sculpture.org.uk/artwork/gate-1. (accessed 4 February 2019).

Clark, Tom (2008) “'We're Over Researched Here!' Exploring Accounts of Research Fatigue within Qualitative Research Engagements”, Sociology, 42(5): 953-970.

Cloatre, Emilie (2013) Pills for the Poorest:An Exploration of TRIPS and Access to Medication in Sub-Saharan Africa. New York, NY: Palgrave Macmillan.

Curtin, Deirdre (2014) “Overseeing Secrets in the EU: A Democratic Perspective", Journal of Common Market Studies, 52(3), 684-700.

De Goede, Marieke and Mara Wesseling (2017) "Secrecy and Security in Transatlantic Terrorism Finance Tracking”, Journal of European Integration, 39(3): 253-269.

Derrida, Jacques (1994) “To Do Justice to Freud”, Critical Inquiry, 20(2): 227-266.

Dijstelbloem, Huub, Rogier van Reekum and Willem Schinkel (2017) "Surveillance at Sea: The transactional Politics of Border Control in the Aegean", Security Dialogue 48(3): 224-240.

Dingli, Sophia (2015) "We Need to Talk about Silence: Re-examining Silence in International Relations Theory”, European Journal of International Relations, 21(4): 721-742.

Eriksson Baaz, Maria, Harriet Gray, Maria Stern (2018) "What Can We/Do We Want to Know? Reflections from Researching SGBV in Military Settings", Social Politics: International Studies in Gender, State \& Society, 25(4): 521-544.

Fassin, Didier (2013) Enforcing Order: An Ethnography of Urban Policing. London: Polity.

Gaddis, John Lewis (1982) Strategies of Containment. Oxford: Oxford University Press.

Galison, Peter (2004) "Removing Knowledge”, Critical Inquiry, 31(1): 229-243. 
Glasius, Marlies, Meta de Lange, Jos Bartman, Emanuela Dalmasso, Adele Del Sordi, Aofei Lv, Marcus Michaelsen and Kris Ruijgrok (2018) Research, Ethics and Risk in the Authoritarian Field. Cham: Palgrave Macmillan.

Gusterson, Hugh (1998) Nuclear Rites, A Weapons Laboratory at the End of the Cold War. Berkeley: University of California Press.

Hammersley, Martyn and Paul Atkinson (2007) Ethnography: Principles in Practice, third edition. London and New York: Routledge.

Haverland, Markus and Dvora Yanow (2012) "A Hitchhiker's Guide to the Public Administration Research Universe: Surviving Conversations on Methodologies and Methods", Public Administration Review, 72(3): 401-408.

Hansen, Lene (2006) Security as Practice. Abingdon: Routledge.

Holdaway, Simon (1982) “'An Inside Job': A Case Study of Covert Research on the Police”, pp. 59-79 in Martin Bulmer (ed.) Social Research Ethics: An Examination of the Merits of Covert Participant Observation, London: Palgrave Macmillan.

Horn, Eva (2011) “Logics of Political Secrecy”, Theory, Culture and Society 28(7-8): 103-122. Huysmans, Jef (2006) The Politics of Insecurity. London: Routledge.

Jacobsen, Katja Lindskov (2015) "Experimentation in Humanitarian Locations: UNHCR and Biometric Registration of Afghan Refugees", Security Dialogue, 46(2): 144-164.

Jones, Graham M. (2014) “Secrecy," Annual Review of Anthropology 43: 53-69.

Kearns, Oliver (2016) "State Secrecy, Public Assent, and representational Practices of U.S. Covert Action”, Critical Studies on Security, 4(3): 276-290.

Klotz, Audie and Deepa Prakash (eds) (2008) Qualitative Methods in International Relations. Basingstoke: Palgrave.

Lippert, Randy K., Kevin Walby and Blair Wilkinson (2015) "Spins, Stalls, and Shutdowns: Pitfalls of Qualitative Policing and Security Research", Forum Qualitative Sozialforschung, 17(1) Art. 10.

Lury, Celia, and Nina Wakeford (eds) (2012) Inventive Methods: The Happening of the Social. Routledge, Oxon and New York: Routledge.

Maret, Susan (2016) “The Charm of Secrecy: Secrecy and Society as Secrecy Studies”, Secrecy and Society, 1(1): 1.

Mol, Annemarie (2002) The Body Multiple: Ontology in Medical Practice. Durham, NC: Duke University Press.

Monahan, Torin and Jill A. Fisher (2015) "Strategies for Obtaining Access to Secretive or Guarded Organizations”, Journal of Contemporary Ethnography, 44(6): 709-736.

Montgomerie, Johnna (2017) Critical Methods in Political and Cultural Economy. London: Routledge.

Nyman, Jonna (2016) "Pragmatism, Practice and the Value of Security", pp. 131-144 in Jonna Nyman and Anthony Burke (eds) Ethical Security Studies. London and New York: Routledge.

Nyman, Jonna and Anthony Burke (eds) (2016) Ethical Security Studies. London and New York: Routledge.

Pallister-Wilkins, Polly (2018) "Médecins Avec Frontières and the Making of a Humanitarian Borderscape", Environment and Planning D: Society and Space, 36(1): 114-138.

Pascucci, Elisa (2017) “The Humanitarian Infrastructure and the Question of Over-research: Reflections on Fieldwork in the Refugee Crises in the Middle East and North Africa", Area, 49(2): 249-255.

Raphael, Sam, Crofton Black, Ruth Blakeley and Steve Kostas (2016) "Tracking Rendition Aircraft as a Way to Understand CIA Secret Detention and Torture in Europe", The International Journal of Human Rights, 20(1): 78-103.

Rappert, Brian (2009) Experimental Secrets: International Security, Codes, and the Future of Research. New York: University Press of America. 
Rappert, Brian (2010) "Revealing and concealing secrets in research: the potential for the absent”, Qualitative Research 10(5): 571-588.

Read, Rósín, Bertrand Taithe and Roger Mac Ginty (2016) "Data Hubris? Humanitarian Information Systems and the Mirage of Technology", Third World Quarterly, 37(8): 1314-1331.

Riese, Juliane (2018) “What Is 'Access' in the Context of Qualitative Research?”, Qualitative Research, 1-16.

Riles, Annelise (2001) The Network Inside Out. Ann Arbor: University of Michigan Press.

Rittberger, Berthold and Klaus H. Goetz (2018) "Secrecy in Europe", West European Politics, 41(4): 825-845.

Robinson, Fiona (2011) Ethics of Care: A Feminist Approach to Human Security. Philadelphia, PA:Temple University Press.

Rozakou, Katerina (2017) "Access to a Hot Field: A Self-Reflexive Account of Research in the Moria Camp, Lesvos”, blog 9 November 2017, Border Criminologies, available at https://www.law.ox.ac.uk/research-subject-groups/centre-criminology/centrebordercriminologies/blog/2017/11/access-hot-field (accessed 25 February 2019).

Salter, Mark. B. (2013) "Expertise in the Aviation Security Field", pp. 105-108 in Mark. B. Salter and Can E. Mutlu (eds) Research Methods in Critical Security Studies. New York: Routledge.

Salter, Mark B. and Can E. Mutlu (eds) (2013) Research Methods in Critical Security Studies. New York: Routledge

Scheper-Hughes, Nancy (2004) "Parts Unknown: Undercover Ethnography of the Organstrafficking Underworld", Ethnography, 5(1): 29-73.

Suchman, Lucy, Karolina Follis, and Jutta Weber (2017) “Tracking and Targeting: Sociotechnologies of (In) security”, Science, Technology, \& Human Values, 42(6): 983-1002.

Taussig, Michael T. (1999) Defacement: Public Secrecy and the Labor of the Negative. Stanford: Stanford University Press

Thomas, Owen D. (2015) “The Iraq Inquiries: Publicity, Secrecy and Liberal War”, pp. 128149, in Alan Cromartie (ed.) Liberal Wars: Anglo-American Strategy, Ideology and Practice, Abingdon, Oxon: Routledge.

Van Maanen, John (1981) “The Informant Game: Selected Aspects of Ethnographic Research in Police Organizations", Journal of Contemporary Ethnography, 9(4): 469-494.

Van Veeren, Elspeth (2018) "Invisibility", pp. 196-200 in Roland Bleiker (ed.) Visual Global Politics. London: Routledge.

Vrasti, Wanda (2008) “The Strange Case of Ethnography and International Relations”, Millennium, 37(2), 279-301.

Walters, William (2014) “Drone Strikes, Dingpolitik and Beyond”, Security Dialogue, 45 (2): 101-118.

Walters, William and Anne-Marie D’Aoust (2015) "Bringing Publics into Critical Security Studies: Notes for a Research Strategy", Millennium, 44(1): 45-68.

Walters, William and Alex Luscombe (2016) "Hannah Arendt and the Art of Secrecy; Or, the Fog of Cobra Mist”, International Political Sociology, 11(1): 5-20.

Wood, Jon (2009) "Preface", pp. 4-7 in Rob Ward (ed.) Reflections, Isle of Wight: MakingSpace Publishers.

Wellman, Marc (2009) “Reflections”, pp. 216-221, translated by Christopher Mühlenberg in Rob Ward (ed.) Reflections, Isle of Wight: MakingSpace Publishers. 


\title{
INTERLUDE
}

\section{Rigorous research in critical security studies}

\author{
Can E. Mutlu
}

Rigour over validity and reproducibility! This was a key provocation behind the co-edited volume on Research Methods in Critical Security Studies (Salter and Mutlu 2013). In that volume, Mark Salter and I pushed our contributors to think openly and clearly about how they do what they do when researching. We asked them to think about: sufficiency, coherency, and criticality, especially in relation to clarity, fit, and reflexivity. Our provocation was not grounded in an attempt to create a litmus tests to measure validity for different kinds of research under the critical security studies umbrella. We don't care for that. I certainly don't believe that validity or reproducibility, as those terms are operationalized in the traditionally positivist core of security studies, should be our aspirations for methodological discussions in critical security studies.

Critical security studies have different epistemological and ontological points of departure and aspirations moving forward. To make legitimate knowledge claims we don't need to translate our findings into the language of traditional social science frameworks of analysis. Mutual comprehension does not require submission to external norms. Instead, we define criticality through reflexivity and inclusivity. In that definition, quantifiability, reproducibility, or validity do not play an important role.

Instead, the principles of rigour, transparency, and reflexivity can function as driving forces behind methodologically sound research projects in critical security studies. As discussed in this volume, secrecy is often central to security practices that we study. Transparency and secrecy may seem like contradictory concepts. However, by transparency, I am not referring to being transparent about the facts and matters of the empirical that we engage with. Full transparency in relation to secrecy is unattainable. Instead, as researchers we should render explicit choices that inform our research process as much as possible. If secrecy informs our choices as a researcher, we must be transparent about 
where/when secrecy impacts our choices in our works. I have written about this elsewhere (Mutlu 2015), where I suggested that

scholars should not erase their own footprints from their publications. The relationship between methodological transparency - that is, clear discussion of the preferences that impacted the research design process and the ways in which empirical information was collected and analysed through different research methods - and pedagogy - that is, reflexive engagement with the theory, practice, and praxis of research - is a significant one that should be central to discussions of research methods.

(Mutlu 2015, 932)

Taking that argument a step further by focusing more on rigour, moving beyond just transparency, here I argue that critical security studies researchers must be honest to themselves and to their audiences about their thoroughness and carefulness in designing their research. We cannot simply "improvise" our research, or make decisions on the go. This does not mean that every aspect of our research needs to be mapped out and designed ex ante; instead, it is an invitation to continuously reflect on the process of research and the methods we use to collect and analyse our engagement with the empirical. Rigorous research requires transparency in the form of laying out steps taken in research, avenues pursued and avenues exhausted. In essence, rigour in the sense of the word as I use it here requires an a priori reflection over a thoroughly planned and well-articulated research design. In that reflection, we must acknowledge limitations of our own research, as defined by a negotiation between limits and aspirations of our research design.

As a field of inquiry, critical security studies is prone to external criticisms focusing on lack of standards for validity, or reproducibility by methodically conservative and dogmatic approaches. But critical security studies need not worry about such external criticisms. The field should aspire to develop internally comprehensible and legible benchmarks for rigour. It must aspire to continuously self-evaluate and be evaluated based on our internal criteria of rigour, as measured through our transparent and reflexive discussions. By focusing on discussions of rigour, critical security studies can offset or challenge criticisms around validity of methods. Our research employs rigorous methods that engage with the empirical in robust and reflexive ways. Critical security studies presents an opening to include diverse voices, perspectives, and experiences to be heard on reflecting on what counts as security. Reducing that debate to one over validity or reproducibility does not do justice to the core potential of the field.

\section{References}

Mutlu, Can E. (2015) "How (Not) to Disappear Completely: Pedagogical Potential of Research Methods in International Relations", Millennium: Journal of International Studies, 43(3) 931-941.

Salter, Mark B. and Can E. Mutlu (eds) (2013) Research Methods in Critical Security Studies:An Introduction. New York: Routledge. 
$\Longrightarrow$ Taylor \& Francis

Taylor \& Francis Group

http://taylorandfrancis.com 
PART 1

Secrecy complexities 
Section I: Secrecy, silence and obfuscation 


\section{THE PROBLEM OF ACCESS}

\section{Site visits, selective disclosure, and freedom of information in qualitative security research}

\section{Oliver Belcher and Lauren Martin}

- Research objective: This chapter will aid researchers working with participants who are reluctant to speak "on the record." This chapter will help researchers working with freedom of information act requests, as well as contexts where private contractors hold important information related to their projects.

- Research puzzle: This chapter explores how qualitative research can evoke the secrecy, security, and politics it seeks security research seeks to explore. We rethink what access and denial can mean for researchers. We argue that deferrals, indecision, and off-the-record comments provide insight into participants' understanding of security discourse itself.

\section{Introduction}

Access, confidentiality, and classified information can be tremendous challenges for research on security. Confidentiality and classified information have long had an aura attached to them, as they are often represented in newspapers, popular media, and film as the means par excellence by which state and military actors deny the public access to information. Access by researchers into state, military, and nongovernmental institutions usually requires sensitivity, a performance suggesting that some activities or scenes must remain behind closed doors to all but the most qualified individuals, even in nominally democratic societies. However, as we explore in this chapter, holding up appearances of secrecy and confidentiality does not always indicate sensitivity, but can instead indicate moments of inaction by state actors, a lack of clear policies, busyness on the part of officials, or even a desire by officials not to reveal internal institutional tensions or disagreements.

In critical scholarship, it has become almost cliché to describe state power and institutions as messy, incoherent, and grounded in everyday practices (Mitchell 
1991; Mountz 2004; Painter 2006; Jeffrey 2013). However, issues of access and confidentiality are rarely considered as instruments that have a specific function in relation to a messy state. Our own work has also shown us that access and the selective disclosure of information are more than annoyances. Rather, they offer insights to understanding the production of security, state power, and knowledge. Requesting information, interviews, and documents reproduce the mechanisms of disclosure. In this sense, we regard security research to be a critical "inscription" device (Aradau and Huysmans 2014), particularly for the selective constructions of "the record." Therefore, one has to pay close attention to pending applications, deferred access to research sites, "off the record" conversations, and classified secret documents. Across our different projects, our experience shows much more of an "ad-hoc-racy" than a bureaucratic logic, and that the "state effect" (Mitchell 1991) arises as much from indecisions as it does from coherent policy.

Drawing on our respective research on U.S. military facilities and U.S. immigration enforcement practices (Belcher and Martin 2013), we argue that confidentiality, classified documents, and "off the record" conversations are crucial for understanding the everyday and embodied workings of security and state power. The chapter includes anecdotes and lessons drawn from our experiences with selective disclosure and access, as well as Freedom of Information and open records requests. Like other chapters in this volume, we offer some practical tips for doing research on securitization and militarization. We emphasize to researchers, especially young scholars, the importance of repeated attempts and persistence.

\section{Insights into the messy state: site visits, access, and confused authority}

In our research, we rely primarily on three sources: site visits, interviews, and archival research. The next three sections will consider questions of access in relation to these three sources. Our research on U.S. immigration detention and military trainings and operations has brought us into contact with American state, border and military officials for access, and increasingly with for-profit contractors as numerous functions of the U.S. state have been privatized. As we discuss below, our dealings with private contractors have been tricky, as the authority to grant or deny access to information, institutions, and field sites is often unclear - and undecided - between state and non-state actors. Moreover, contractors' operations and procedures can be considered proprietary information and therefore beyond the reach of freedom of information laws, which can pose serious obstacles for the researcher.

Our methodological approaches with immigration enforcement and military officials have primarily involved semi-structured interviews (Belcher and Martin 2013), non-participant observation (cf. Belcher 2014), and archival research. Along with careful planning and the tried-and-true method of cold-calling/emailing, we have found these methods to be the best in terms of rich informational content for our research. Aradau and Huysmans (2014: 604) have shown how methods in qualitative security research work as "inscription devices": "As devices, methods 
enact social and political worlds in multiple ways." This is important not only for qualifying and situating the knowledge we produce, but to understand research as a process through which securitization, depoliticization, and marketization are expressed. Paradoxically, this can mean that the process of not getting access, the paperwork of denial, deferral, pending applications, and so on, can also constitute moments in which "security" can be produced and understood. Thus, our research practices ask how people, institutions, and objects (such as bureaucratic paper files) draw together in particular ways; or, to put it differently, the way we seek access often organizes those modes of access.

For example, in her research at the T. Don Hutto Family Detention Facility in Taylor, Texas, Lauren interviewed detention visitation coordinators and worked to establish rapport with personnel (Martin 2014). Lauren's fieldwork provided interesting insights into the everyday functioning of a major immigration detention facility. The ambiguous authority of private prison and detention contractors like CoreCivic and GEO Group created regular difficulties for researchers and visitors. Telephones worked intermittently, making it difficult for visitors to plan visits, and for detainees to communicate with family and legal representatives. The privatized staff were often ill-trained in the rights and limitations of detainees' visitors and legal representatives. Attorneys negotiated continually changing visitation requirements. Sometimes the facility management required identification and clearance ahead of time, sometimes not. Dress codes were open to interpretation, so that women, for example, could be denied access for wearing a sleeveless blouse (commonly worn during hot Texas summers). In the absence of federal detention visitation policies, contractors and sub-federal agencies were unclear whether they were authorized to make visitation policies.

This led in many cases to private contractors running detention facilities to defer to Immigration and Customs Enforcement (ICE) who handled detainee rights, who in turn would defer to a different private contracting entity tasked with handling operational matters at and between facilities. The rapid expansion of detention as a cornerstone of immigration enforcement in the mid-2000s meant that there was, for a considerable period of time, no clear policy on who makes visitation policy. At another family detention facility in Berks County, Pennsylvania, Lauren was similarly bounced around between county and federal officials, while both parties argued that they did not have the authority to grant research access. Speaking with families, researchers and attorneys, it became clear that this confusion was endemic to the broader "chaotic geographies" non-citizens and citizens alike struggled to navigate (Hiemstra 2013).

This speaks to the often-confused authority at work in contemporary visits to nominally state institutions. In the case of immigration detention centers, what interests us is not so much the frustration experienced towards private and government officials that made access unpredictable (although that frustration was certainly real!). Rather, the unpredictability and confused authority provide the researcher a partial window into the mechanics of the late-modern state. Instead of a seamless bureaucracy that is effectively oppressive because it is fine-tuned administrative machine, we are instead exposed to partially privatized state apparatus that functions 
in fits and starts, with deferred accountability and phantom authority in legal grey zones. Sometimes the problem is simply funding and staff capacity (see also Carte 2017). Based on our field experiences, the summer 2018 catastrophe of the Trump Administration's taking migrant children from their families and "losing" them in the immigration system was hardly surprising. In fact, the tragedy, ongoing as we write this, tells us a lot about how unsystematic the U.S. immigration system really is.

In stark contrast, Oliver has had a largely smooth experience gaining access in his fieldwork conducted at U.S. military facilities. This is not to say that all military facilities are easily accessible. Rather, the protocol for entry tends to be more streamlined and uniform. While a range of components of the U.S. military have been systematically privatized - from security services and repairing vehicles to dining facilities and logistical supply chains - it remains the norm that the U.S. military command runs the facilities where they operate, with private contractors following the chain of command. For example, during his non-participant observations ${ }^{1}$ of trainings for counterinsurgency warfare at Muscatatuck Urban Training Center (MUTC) and Camp Atterbury in central Indiana, U.S. military officers determined access to the bases, while the McKellar Corporation managed the training scenarios in which U.S. military personnel participated (see Belcher 2014).

The timing of Oliver's fieldwork (2010-2011) was interesting, because it took place at a moment when the U.S. military was actively engaging with the academic community to bolster its "cultural awareness" initiative in Iraq and Afghanistan (Gregory 2008). Like Lauren's experiences in immigration detention facilities, the grey-zone of authority was also apparent within these two military bases. For example, while Oliver was technically a guest of the U.S. military, McKellar Corporation personnel were unclear about the extent to which he could take part in the trainings, which were kind-of-but-not-quite proprietary information. After Oliver received approval to observe all the trainings, the extent to which he could interact with personnel remained unclear. On the one hand, Oliver had full access to the U.S. military personnel participating in the trainings, even while the trainings were in action. On the other hand, interactions with Afghan and Iraqi refugees also participating in the trainings were technically employees of the McKellar Corporation, and were therefore reticent to speak. Yet, on the days, all the participants were fully engaged with one another, thus making technical boundaries of access and restriction fluid. What our different experiences show is two different federal departments (Homeland Security and Defense, respectively) devolve research access very differently. The difference here shows not only a messy state in a broad sense, but ways in which localized relationships between federal, local and non-state actors become more discernible through the access process itself.

\section{Interviews: selective disclosure and off-the-record conversations}

In his 2015 Political Geography Plenary Lecture at the American Association of Geographers Conference in Chicago, Dr Mat Coleman argued that despite the 
seemingly spectacular violence of police violence in the U.S., it has been difficult for him (and others) to research police violence in practice, not to mention document and record in ethnographic field notes, interviews, and secondary data. In the published version, Coleman (2016) identified a range of issues that resonate with our interview experiences. In his experience of researching immigration policing in North Carolina and Georgia, Coleman describes studying the police as uneventful, cruddy, diffuse. Coleman tells the story from his research on local immigration policing, and the controversial policy of local police collaborating with federal immigration officials. The immigrant advocacy literature is rife with stories of parents going to work and never coming home. Coleman began to focus on traffic stops as a site (or so he thought) of strategically locating undocumented migrants (Coleman and Stuesse 2016). As migrant communities are often described as "under siege," Coleman assumed that this atmosphere of fear and siege would be evident in the urban landscape. However, he never found anything observable in the traditional sense. Driving around a relatively small area for weeks, the traffic stops never became visible; that is, they did not have a durable presence. Yet, the traffic stops were very much active and alive in the fear and distrust experienced by undocumented migrants in the area which they interviewed. Borrowing from Elizabeth Povinelli (2011), Coleman (2016: 77) calls this "invisible police work" affective, yet effective - "uneventful police rule."

To understand police practice, as an object of inquiry, Coleman details his own problems of access and struggles to get useful information. He describes over 50 interviews with police chiefs, high-ranking officials, and county prosecutors as "controlled public relations exercises on the where and how of policing which are highly selective on details" (Coleman 2016: 78). Only on one on-the-record conversation did a police chief provide

a rousing critique of racial profiling and defense of community policing; problematize using drivers license violations to check drivers for legal status; made clear a distinction between civil immigration violations and criminal law enforcement ... In the larger context of my other interviews that summer ... the interview with [Doraville Police Chief, John] King was a breath of fresh air due to the fact that I was able to talk frankly about policing and race.

(Coleman 2016: 78)

In our experience, interview participants are often highly trained and educated professionals - like police chiefs and county prosecutors - who possess the uncanny ability to consistently craft responses to interview questions that say little more than "talking points" that is, until you turn off the voice recorder (Kuus 2013). Many of our research participants were highly aware of research as "the record," which has the power to shape policies, experiences, and understanding when brought to the public. This was especially true in Lauren's research, where immigrant detention is a highly charged and highly politicized topic, 
making interviews a potential site of exposure to public scrutiny, particularly in nominally liberal societies like the United States that remains answerable to a voting public.

Frequently, we have encountered the refrain, "this is off the record, but you might be interested in ..." These conversations are usually the most revealing, detailed, relevant ... and unpublishable. Coleman (2016) reports a 90-minute conversation with a police chief who discussed extensively the problematic ways in which local police have been militarized - off the record. Lauren's research included many community organizing meetings with attorneys representing detained women and families. These attorneys frequently stated, "This is off the record," at which point those in attendance visibly placed their pencil on the table or folded it onto their notebook. The attorney would relate stories of women's abuse by private detention guards, the deterioration of detainees' mental health over time, or growing evidence being collected for a lawsuit. Because access - even legal access - can be denied without explanation, attorneys were particularly concerned that their comments not make it into the newspapers or online. But for a qualitative researcher, these moments pose important ethical questions. What is the status of information that we know, but cannot record? How do we include these moments in our research without violating the trust involved in our presence there? What is our own relationship to, and role in producing, the "record"?

While not precisely secrets, un-recordable facts and stories are an essential part of our research. On the one hand, this information is hidden in some way, unable to be made fully public. Yet, on the other hand, someone has shared it with us, which can give the un-recordable information an aura of authenticity and truth. What's more, we have been trusted with this information ("you might be interested in ..."); we have been given a gift and are now bound by some kind of obligation, an obligation to exercise judgment on how the gifted information does and does not circulate. In this regard, every case is unique. For our part, we always weigh the ethical demands of our research projects and the different communities of responsibility in which we work. For example, in his limited conversations with the Iraqi and Afghani refugees participating in counterinsurgency trainings, who were pressured to remain quiet on their experiences in the trainings, Oliver did not hesitate to disclose how a training scenario gone wrong revealed underlying tensions and anger between the refugees and military personnel (e.g., Belcher 2014: 1019-1021), or the context in which they were now living:

Their stories, especially among the men, were common: They had served as translators or helpers for U.S. soldiers in Afghanistan and Iraq and had been some of the lucky few to have been granted visas, in exchange for their battlefield assistance, to live and work in the United States. All of them have suffered, leaving their immediate families behind in hopes of getting a foothold halfway across the world in the United States. They now live in cities, usually alone, across the country: Detroit, Milwaukee, Nashville, Chicago, and Washington, D.C. Most looked forward to coming here to Indiana, if anything, for 
the conversation. Whenever I would ask if they would like to return to their homes, a melancholy would hang heavily between us. The answer was almost always the same: It is too dangerous for former translators and helpers of the U.S. military to return. Instead, here in Muscatatuck, they spend their days drinking tea and sleeping in the concrete shacks, waiting for the next group of soldiers to arrive and, when prompted, to resume their roles and places as introductory warning signs for U.S. soldiers to learn and interpret before they enter the abyss. Such is the tragedy, the vortex of late-modern war.

(Belcher 2014: 1026)

Off-the-record information or interview material that cannot be recorded still has immense value for the researcher. Unrecordable data function like an absentpresence in our work. The researcher understands its presence in the acts of collating and organizing data, as well as its spectral presence in the act of writing. The researcher, of course, is restrained in what can be conveyed through writing, and allowed to make the reader only dimly aware of unrecordable data as a sort of chiaroscuro pictorial effect in the text itself. Nevertheless, unrecordable data not only have the power to clarify our understanding of messy state power but can actively (re)frame our research focus and interests. Practically speaking, this kind of information goes into our general background knowledge, coming back up (carefully) in conversation with other insiders, or pointing us towards peoples and places - such as the archive - that we might otherwise have missed or might seem tangential. Unrecordable data offer us vocabulary for later interview questions or steers us towards particular people, events, or relationships. Secrecy can organize our research practice, as well.

\section{Archival research and Freedom of Information Act (FOIA) requests}

A substantial portion of our research time has been spent in various archives. For Lauren, this has involved tracking down zoning plans and facility blueprints for detention centers in Pennsylvania and Texas (Martin 2012a). Oliver spent a significant portion of his graduate and postdoctoral career in the U.S. National Archives (College Park, Maryland) and Lyndon B. Johnson Presidential Library (Austin, Texas) uncovering the early use of computers in U.S. military and Central Intelligence Agency operations in the Vietnam War, from the Hamlet Evaluation System to the "Phoenix" assassination program (Belcher 2016). Both projects have involved making extensive Freedom of Information Act (FOIA) requests for information that has either been deemed confidential by the state, or, as can often be the case, information that has not yet been generated by a governmental entity.

An example of the latter is a current project conducted by Oliver and a group of researchers from Lancaster University (Belcher et al., 2019) to determine the hidden carbon costs of the so-called "War on Terror" from Fiscal Year 1999-2016. The focus of Oliver and the Lancaster group has been on fuel purchases made by 
four branches of the U.S. military (Army, Navy, Air Force, Marines) through the Defense Logistics Agency (DLA). The DLA is the one-stop shop for all fuel-purchases within the U.S. military, both domestically and internationally, and they are required by law to maintain records of every purchase made by military personnel. Over 2017-2018, our research group made several FOIA requests to gain access to these records (successfully), which has given us a very clear picture of emissions based on fuel types purchased and consumed by the U.S. military over a roughly 17-year period. Importantly, the reason for the multiple FOIA requests is that the DLA had no single database where all the purchase receipts were located. Thus, they had to generate the information for us based on our FOIA requests - another instance when seeking access organizes modes of access.

In qualitative security research, the archive often becomes an important site when interviews either need to be contextualized or have achieved a dead-end. Oliver's research in particular has often had to resort to archival research in order to understand the historical context in which American counterinsurgency doctrine took shape, particularly in the Vietnam War (Belcher 2012; Belcher 2016). In his research, there have been many instances where Oliver has needed to submit FOIA requests. In the United States, FOIA requests are an official process circumscribed by a legal framework at the federal, state, and county levels. Public institutions are required by law to address every FOIA request (see Box 1.1 below). However, that neither means institutions are required to grant access to documents or information requested by researchers, nor that they always respond in a timely manner (in our experience). In one particular instance, Oliver submitted multiple FOIA requests to the U.S. Department of Army and the Army Corps of Engineers for blueprints and/or information related to the reconstruction of Taroke Kalacha, a village in Arghandab Province, Afghanistan, that had been razed by the U.S. military in October 2010 (see Belcher 2018). However, he never received a response. As a practical matter, we both tend to request documents early and often. Methodologically, requesting information can be one way of interrogating the politics of information around a particular issue.

For example, Lauren has had to make several FOIA requests for information that rests in the grey zone between public and proprietary, which reveals some of the ways in which the participation of commercial actors can affect data collection. Commercial actors operate under specific legal frameworks that protect their intellectual property and operations processes. Private companies, such as those running detention facilities, can be obstacles to accessing places, people, documents, and practices in security-related contexts. Legal frameworks vary greatly by country and jurisdiction. In the United States where the bulk of our research has taken place, outsourced services and trainings are considered proprietary information and therefore exempt from federal FOIA requests. Yet, contracts and procurement agreements (often with payments redacted) are releasable, while in the United Kingdom, by contrast, contracts and procurement agreements need not be releasable (see also Stavrianakis, this volume). 


\section{BOX 1.1 TIPS ON FREEDOM OF INFORMATION ACT AND OPEN RECORDS REQUESTS IN RESEARCH}

The Freedom of Information Act is federal legislation governing the public release of government documents, and U.S. states also have various forms of "sunshine laws" outlining procedures, timelines, and costs for information requests to state, county, and municipal agencies. Depending on your research topic, the federal government may not hold the documents you need. States and federal agencies have different rules for the kinds of documents you can request - and different capacities for responding to requests. Before you submit your requests, think about the following:

Tip 1. Find out who has the document or information. Many securityrelated issues will involve more than one agency, and each agency will have a different records request process. Some are more open, organized, or funded than others. Similarly, civil rights and legal advocacy organizations may have your documents - or be willing to support your request if you face challenges.

Tip 2. Do you need to file a request? Sometimes, an email and phone call can get you what you need and faster than the official process.

Tip 3. Start local. Local (state, county, municipal) agencies field far fewer requests, respond more quickly, and are easier to contact by email and phone. Local governments work with the public continually, while federal agencies may leave this to public relations offices.

Tip 4. Check current procedures. The internet has made requests far easier and many requests can be made online - but not all. Each agency will have slightly different procedures and some will ignore or reject your request on procedural grounds.

Tip 5: Request early, request often. State and federal requests will return different information and on different timelines. If you can't get what you need by email or phone, file requests with any agencies involved.

Tip 6: Be specific. Requests for "all documents related to matter $x$ " are difficult to process because the boundaries are unclear. Requests for "facility inspection reports, emails between county commissioners and contractors, complaints reports filed with local law enforcement between 2007 and 2011" give clearer guidelines and are more likely to receive timely responses.

Tip 7: Be prepared to contest security exemptions. Most open records and FOIA procedures allow exemptions for security-related and proprietary information. As we discussed above, these increasingly overlap as governments outsource security functions. Some agencies will 
respond to a request with a security exemption rather than sort through which documents can and cannot be released. Be prepared to make a case for the public interest in this information or its (perhaps small) role in your final dissertation. Be prepared to qualify your request, to rephrase it, or to exclude certain kinds of information. Legal advocacy organizations (see 'Further reading') can be helpful and are sometimes interested in pursuing cases that align with their campaigns.

Deidre Conlon and Nancy Hiemstra's work (2017) on detention center work programs revealed much about the politics of access and privatization, including a complex chain of subcontracting and multiple points of price gouging and labour exploitation. Governments at county and state-level release information on work programs, but private firms do not. Therefore, it is possible that documents end up "on file" with county governments through their oversight procedures, even if a private firm denies access to this information. Similarly, as the work program contract-holder in many cases, county governments often manage contracting arrangements for federal immigration agencies, which means they can hold documents at a county level that may not be available through a federal FOIA request. In some cases, it is possible to trace how local and county governments participate in immigration detention practices by following the trail of legal geographies of information, oversight, and documentation. What is far more difficult to understand, however, is what power these documents hold, what actions they provoke, who reads them, or how they circulate.

Take, for example, a family detention center compliance report (Figure 1.1). What is it? The report compiles findings from a visit by six members of the Nakamoto Group, a company hired by the U.S. Department of Homeland Security, ICE, and other agencies to provide "compliance support"; i.e., to help managers comply with federal and state regulations. The report includes a series of calculations and judgments measuring detention conditions against ideal benchmarks, derived from Family Residential Standards (US ICE 2009). It communicates progress on certain indicators to facility staff and to federal agencies who contract them. Technically, noncompliance can become grounds for ending a contract between, in this case, the facility in Berks County and the federal government. The document itself is for guidance purposes only, so there are no direct legal consequences for failing to meet Family Residential Standards. The document represents a contracting relationship between the Nakamoto Group and federal agencies. It is one device linking these institutions together, and it is also part of a longer process of harmonizing detention standards and practices through the circulation of expertise, trainings, and protocols. It is a device that includes practices of abstraction, measurement, and judgment with the aim of building consensus around a set of acceptable detention practices. 


\section{Berks Family Residential Center}

\section{Bi - Annual Compliance Review Report}

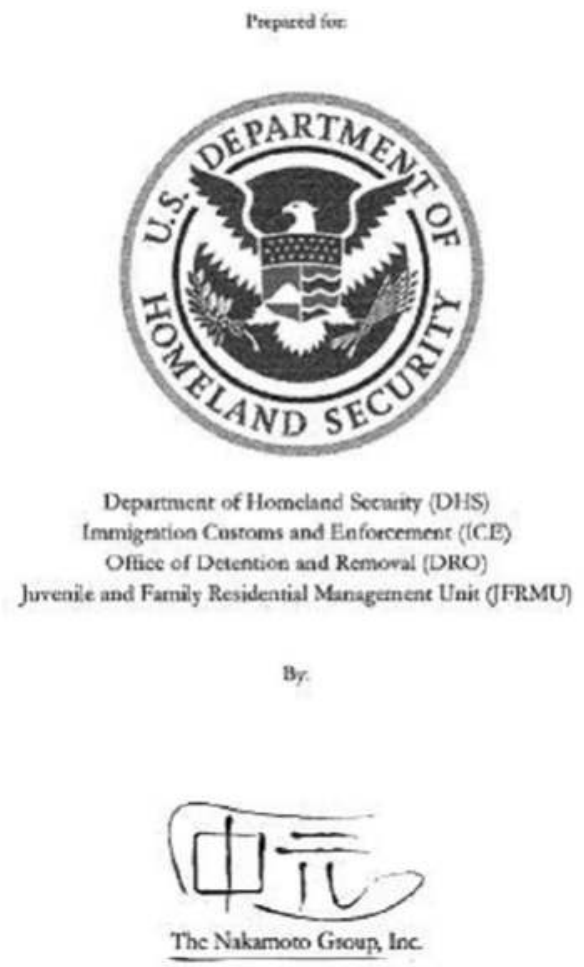

FIGURE 1.1 FOIA request by Lauren Martin to Immigration and Customs Enforcement, on file with author.

These kind of documents can be more difficult to get from privately-owned facilities. For this reason, private corrections companies have been facing litigation for nondisclosure for some time. U.S. courts have rendered different decisions on matters of disclosure, which depend significantly on how judges prioritize intellectual property and proprietary information against the public's right to know. Here, 
privatization works to make state-authorized activities obscure. For this reason, some have argued that such legal aporias have been crucial in the development of the "immigration-industrial complex" (Doty and Wheatley 2013; Golash-Boza 2009). While the political implications of privatization of state functions have been much discussed in terms of shrinking access to due process, rights violations, transparency, and accountability of government, far less attention has been given to the ways in which privatization links these practices up with different forms of valuation, measurement, and circuits of exchange. These socio-technical practices not only do political work, but they also produce public-private boundaries that directly affect research.

It is important to note that one need not always make a formal FOIA request for information. FOIA requests can often generate bureaucratic labor for agencies that can slow down one's research if a student or researcher relies upon the request too heavily. Many government offices in the U.S. can be understaffed or under-enthusiastic to take requests from the public (even if they are bound by law to do so). There have been many times that we have simply cold-called an agency, by phone or email, and asked for a specific document, and successfully received it within days (see Martin 2012a). We often ask our interviewees for leads on documents that we may not know about, or for documents that we know to exist but have not been able to obtain. Lauren's research included lawsuits and litigation (Martin 2012b), and conversations with public interest lawyers yielded key documents in her research. In the spirit of reciprocity, she shared FOIA documents she had obtained with the lawyers in return. In the U.S., transparency activism is wellorganized, so legal clinics and think tanks can be important contacts for finding information (see Box 1.1 and 'Further reading').

\section{Conclusion: the power in muddling through}

In this chapter, we have shared experiences of gaining access to fieldsites, mitigating problems that occur in confidential interview settings and in the archive, and submitting FOIA requests to fill holes in our research. We want to underscore that we gained access to our research sites in different ways, and largely on a try-andtry-again basis. Getting access to the securitized migration and military facilities can feel like winning the lottery. And one learns very quickly that gaining access, as in all qualitative research, can come with all sorts of expectations, hiccups, and trialand-error situations, which we've tried to share above.

We would like to offer two concluding points. First, the various ways in which researchers can be granted or denied access to research sites, documents, and information can be an opening to understanding how contemporary state practices work. Quite often, state functions are described in popular media and everyday discourse as "the system"; e.g., "the entire system is corrupt." However, what we have tried to emphasize is that the state in the abstract and in practice are two very different phenomena, with the latter tending to be very messy. In our experience, access and confidentiality are important instruments within the messy state that 
reveal as much as they conceal. Therefore, the researcher must very often commit to muddling through the process of accessing interviews and information. Repeated requests often land on different desks, and responses can be helpful and timely, or unpredictable and fruitless. Both of us have been granted access to facilities where we know other colleagues' requests were denied, and vice versa. Responses, exchanges, deferrals, and silences are moments when we occupy positions that construct a unique terrain of information and dis/closure. Muddling through is a common condition among both researchers, officials, and state/non-state employees. It is both a pragmatic and strategic opportunity, as well as a field of analysis in itself. More than a methodological qualification about the limitations of research design or partiality of evidence presented, negotiating dis/closure is the production of knowledge in action. While one always has to be mindful of their research project's time constraints, especially in postgraduate research, months of unanswered requests can yield a rich few weeks of access.

Second, it is important to always remain persistent in one's requests for access, either to visit a fieldsite, gain access to an institution, or to request information through official channels (e.g., FOIAs). Repeated requests reveal not just banal bureaucratic practices but serve as important political encounters with institutions holding sensitive, classified, and proprietary information. Moreover, it is good practice to get in contact with people who are also trying to gain access to the same or similar information through different official channels. Making repeated requests for information is a common strategy for government transparency activists. By comparing different disclosures of the same document, one can sometimes piece together different words or sections that may have been redacted; or learn novel ways of gaining information. Working with journalists and lawyers can be particularly helpful in spreading the financial burden in situations where information requests come at a financial cost.

\section{Further reading}

- Oliver Belcher and Lauren Martin (2013) "Ethnographies of Closed Doors: Conceptualizing Openness and Closure in US Immigration and Military Institutions", Area, 45(4): 403-410.

- Mat Coleman (2016) "State Power in Blue", Political Geography 51: 76-86.

- Deirdre Conlon and Nancy Hiemstra (2017) "Beyond Privatization: Bureaucratization and the Spatialities of Immigration Detention Expansion", Territory, Politics, Governance, 5(3): 252-268.

- Reporters Committee for Freedom of the Press "Open Government Guide" details open access regulations in all 50 US states. They also publish a useful "Federal Open Government Guide." https://www.rcfp.org/browselegal-resources/guides

- The American Civil Liberties Union works on FOIA and open records cases specifically related to secrecy: https://www.aclu.org/issues/national-security/ secrecy 
- The Center for Constitutional Rights has won a number of FOIA lawsuits related to security and secrecy: https://ccrjustice.org/

\section{Note}

1 By "non-participant observation," we mean that Oliver did not actively participate in any military trainings. However, his relationship to the trainings as an observer was fraught and complicated by the fact that his presence, as an academic, lent some legitimacy to the trainings from the perspective of U.S. military personnel at MUTC. Oliver has discussed the methodological complications of "non-participant observation" in Belcher (2014).

\section{References}

Aradau, Claudia and Jef Huysmans (2014) "Introducing Critical Security Methods", pp. 1-23 in Claudia Aradau, Jef Huysmans, Andrew Neal, and Nadine Voelkner (eds) Critical Security Methods: New Frameworks for Analysis, London: Routledge.

Belcher, Oliver (2012) "The Best-Laid Schemes: Postcolonialism, Military Social Science, and the Making of US Counterinsurgency Doctrine, 1947-2009”, Antipode, 44(1): 258-263.

Belcher, Oliver (2014) "Staging the Orient: Counterinsurgency Training Sites and the U.S. Military Imagination”, Annals of the Association of American Geographers, 104(5): 1012-1029.

Belcher, Oliver (2016) "Data Anxieties: Objectivity and Difference in Early Vietnam War Computing", pp. 127-142 in Louisa Amoore and Volha Piotukh (eds) Algorithmic Life: Calculative Devices in a Digital Age, London: Routledge.

Belcher, Oliver (2018) "Anatomy of a Village Razing: Counterinsurgency, Violence, and Securing the Intimate in Afghanistan”, Political Geography, 62: 94-105.

Belcher, Oliver and Bigger, Patrick, Neimark, Ben, Kennelly, Cara (2019) "Hidden carbon costs of the "everywhere war": Logistics, geopolitical ecology, and the carbon boot-print of the US military”, Transactions of the Institute of British Geographers, DOI: 10.1111/tran.12319.

Belcher, Oliver and Lauren Martin (2013) "Ethnographies of Closed Doors: Conceptualizing Openness and Closure in US Immigration and Military Institutions", Area, 45(4): 403-410.

Carte, Lindsey (2017) "Mexican Bureaucrats and the Everyday Restriction of Transnational Migration in a Context of Scarcity", Territory, Politics, Governance, 5(3): 304-317.

Coleman, Mat (2016) "State Power in Blue", Political Geography, 51: 76-86.

Coleman, Mat and Angela Stuesse (2016) "The Disappearing State and the Quasi-Event of Immigration Control”, Antipode, 48(3): 524-543.

Conlon, Deirdre and Nancy Hiemstra (2017) "Beyond Privatization: Bureaucratization and the Spatialities of Immigration Detention Expansion", Territory, Politics, Governance, 5(3): 252-268.

Doty, Roxanne and Elizabeth Wheatley (2013) "Private Detention and the Immigration Industrial Complex", International Political Sociology, 7(4): 426-443.

Gregory, Derek (2008) "Rush to the Intimate: Counterinsurgency and the Cultural Turn", Radical Philosophy, 150: 8-15.

Golash-Boza, Tanya (2009) "The Immigration Industrial Complex: Why We Enforce Immigration Policies Doomed to Fail", Sociology Compass, 3(2): 295-309.

Hiemstra, Nancy (2013) “'You Don't Even Know Where You Are': Chaotic Geographies of US Migrant Detention and Deportation”, pp. 57-75 in Dominique Moran, Nick Gill, Deidre Conlon (eds) Carceral Space: Mobility and Agency in Imprisonment and Migration Detention, Farnham: Ashgate. 
Jeffrey, Alex (2013) The Improvised State: Sovereignty, Performance and Agency in Dayton Bosnia, London: Wiley-Blackwell.

Kuus, Merje (2013) "Foreign Policy and Ethnography:A Sceptical Intervention", Geopolitics, 18(1): 115-131.

Martin, Lauren (2012a) "Governing Through the Family: Struggles over US Noncitizen Family Detention Policy", Environment and Planning A 44(4): 866-888.

Martin, Lauren (2012b) “The Geopolitics of Vulnerability: Children's Legal Subjectivity, Immigrant Family Detention and US Immigration Law and Enforcement Policy”, Gender, Place and Culture, 18(4): 477-498.

Martin, Lauren (2014) "Getting Out and Getting In: Legal geographies of US Immigration Detention”, pp. 149-188 in Dominique Moran, Nick Gill, Deidre Conlon (eds) Carceral Space: Mobility and Agency in Imprisonment and Migration Detention, Surrey: Ashgate.

Mountz, Alison. (2004) "Embodying the State: Canada"s Response to Human Smuggling,", Political Geography, 23(3): 323-345.

Mitchell, Timothy (1991) "The Limits of the State: Beyond Statist Approaches and Their Critics", American Political Science Review, 85(1): 77-96.

Painter, Joe (2006) "Prosaic Geographies of Stateness”, Political Geography, 25(7): 752-774.

Povinelli, Elizabeth (2011) Economies of Abandonment: Social Belonging and Endurance in Late Liberalism, Durham, Duke University Press.

US Immigration and Customs Enforcement (ICE) (2009) Family Residential Standards. Available at: https://www.ice.gov/factsheets/facilities-residential-stds. Accessed 30 September, 2018. 


\title{
2
}

\section{THE STATE IS THE SECRET}

\section{For a relational approach to the study of border and mobility control in Europe ${ }^{1}$}

\author{
Huub Dijstelbloem and Annalisa Pelizza
}

- Research objective: This chapter will help researchers who want to experiment with a relational, performative, immanent approach to research in technopolitical security contexts.

- Research puzzle: The puzzle the chapter addresses in relation to secrecy and methods concerns the gap between accountability requirements posed on democratic states, on one hand, and technopolitical decisions often taken apart from public scrutiny, on the other hand, in contexts in which the state engages in transnational multi-actor and multi-level relationships.

\section{Introduction: states and secrecy in technopolitical contexts}

Secrecy is deeply intertwined with state actions, surveillance technologies and international politics when it comes to border control, migration policies and the management of international mobility. Border and mobility control belong to the central tasks states are concerned with. In order to be held accountable, states have to provide the public - consisting of citizens as well as travellers and migrants from other countries - with relevant information concerning their actual policies, including their technical means of implementation. However, the details of mobility partnerships between the EU and third countries are often not publicly shared, the role of private industries in promoting surveillance technologies is misty, the consequences of all kinds of border control technologies and surveillance policies are far from clear, when they are not hidden in the dark, and the exact number of the migrants who lose their lives on their way to Europe is covered in clouds. Policies requiring public consent often arise in the midst of so-called "crises" that necessitate "extraordinary measures", as EU-president Donald Tusk stated in his address to the European Parliament on the European Council of 15 October 2015 
on the migration and refugee crisis. ${ }^{2}$ This enables extraordinary decision-making procedures such as the EU-Turkey Statement of 18 March 2016.

How is the relationship between states and secrecy to be understood in this multi-actor and multi-level technopolitical context and how can this relationship be studied? In this chapter, we suggest the relationship between states and secrecy is constituted by co-production (Jasanoff 2004), a simultaneous development of institutes, objects, actions and techniques. The resulting configurations of states and secrecies deploy all kinds of politics and policies via a diversity of methods, tools, instruments and techniques, based on ways of knowing, ways of representing, ways of observing and ways of intervening. We will explore this co-production of states and secrecy by engaging with two related examples, namely the EU's so-called "Hotspot approach" and the European Surveillance program Eurosur.

According to the European Commission,

A "Hotspot" is characterized by specific and disproportionate migratory pressure, consisting of mixed migratory flows, which are largely linked to the smuggling of migrants, and where the Member State concerned might request support and assistance to better cope with the migratory pressure. ${ }^{3}$

The Hotspot approach is closely related to the Eurosur program: the European Commission memo of 29 November 2013 announcing Eurosur's launch also mentioned the option of installing "Hotspots". The European Commission in a memo describes Eurosur as follows:

The establishment of a European Border Surveillance System ("EUROSUR") is necessary in order to strengthen the exchange of information and the operational cooperation between national authorities of Member States as well as with the European Agency for the Management of Operational Cooperation at the External Borders of the Member States of the European Union. ${ }^{4}$

The Hotspot approach and the Eurosur program are exemplary cases of the intermingling of multi-level and multi-actor policies with technopolitics. Our analysis of the cases aims to show how the techno-policies in the context of European border control, mobility and migration should not be conceived as programs that are enrolled by political agents, policymakers and professionals as a clear means to a clear end. Instead, we argue that the variegated nature of these policies and politics can be analysed by applying a specific set of methods - underpinned by the concepts of performativity, immanence and following the actors. Such a set of methods can even display the plurality of relations these programs need to establish with local actors, citizens, social organizations and migrants; and the kinds of materialities, spaces, instruments and things they need to produce By doing so, the chapter will develop a relational perspective on the connection between states and secrecy. 


\section{Objectives}

This chapter aims to provide methodological and conceptual tools to researchers interested in unpacking the relationship between states and secrecy in the context of border control, migration policies and international mobility.

Methodologically, we suggest that the study of the various secrecies involved in these domains of international state politics can benefit from a particular approach that takes into account the situated and performative character of secrecy. Therefore, the chapter will set out some principles that - we suggest - should inform the study of secrecy in the context of migration policies, mobility management and border control, surveillance technologies and international politics. Namely, these principles refer to a (1) performative stance, (2) the notion of immanence and (3) a set of methods to follow actors.

Conceptually, the chapter claims that secrecy can be understood as a relational notion. With this, we mean that states and their constituencies do not exist in a vacuum, but in relation to each other. Secrecy in the context of border and mobility management constitutes a variety of political relationships, modes of knowing and ways of seeing, not only between the state and its traditional constituencies (i.e., individual citizens, organizations, businesses), but also between states and trans-national polities and actors (including migrants, travellers, European agencies, NGOs and researchers), as well as among the aforementioned actors in non-state relationships.

The "real secret" - we will argue - does not concern the specific actions, justifications, intentions or interventions by states but the nature of the state itself. What kind of political entities are emerging in the development of Europe's migration, mobility and border policies, which transcend the state? The methodology we outline is likely to unveil the contours of very mobile and infrastructural entities partially overlapping with what is formally known as "the state".

In short, the objectives are:

- To develop a relational, performative and immanent methodology and conceptual approach so as to study the relationship between secrecy and the state in the context of border control, surveillance practices and migration.

- To emphasize that in order to study secrecy, the "matter of concern" (Latour 2005) at stake, i.e. "the state", has to be unpacked and opened up.

\section{A situated methodology for secrecy in migration, mobility and border policies}

The chapter is grounded on Science and Technology Studies (STS) and International Political Theory, and relates to many neighbouring sub-disciplines such as Border Studies, Migration Studies, Mobility Studies, Surveillance Studies and (Critical) Security Studies. We mainly engage with examples that relate to the monitoring of migrants and the translation of their identities into legible knowledge. The focus will be on situations, practices and policies in Europe, but the insights of this chapter are likely to be applicable elsewhere. 
Before presenting two excerpts of case studies of the Hotspot approach and Eurosur, we will address three principles that we suggest can inform the study of secrecy in the context of migration policies, mobility management and border control, surveillance technologies and international politics, namely (1) the performative stance, (2) the notion of immanence and (3) a set of methods to follow actors.

\section{Performativity}

The particular angle we would like to elaborate on in this chapter proposes performativity of state and supra-state institutions as a key methodological principle to address the study of secrecy in the context of migration policies, mobility management and border control. Originally developed in the philosophy of language as a theory of speech acts by Austin (1955/1962), the notion of performativity has been elaborated in a more material way by various scholars (e.g. MacKenzie 2006; Callon 2007). It refers to discourses and practices that not only describe, explain or justify situations, but enact them, bring them into existence while representing them.

Following the late Foucault (2007), some authors have pointed out that states and their political bodies are performed, instead of assuming they exist as monolithic units (Passoth and Rowland 2010). Historical studies of state formation have developed accounts of how technopolitical practices brought nation states into existence. For example, the practice of counting populations has enabled the distinction between citizens and aliens. The drawing of maps has allowed the conceptualization of the state as a territorial entity (Carroll 2006; Mitchell 2002) and in some cases the creation of a central administration (Mukerji 2011). More recently, studies have argued that technopolitical practices can even de facto perform alternative orders of the state (Pelizza and Hoppe 2018). These studies show that states do not exist in abstract terms, but become visible when they are "performed": when frontiers are built, diplomacies invoked, soldiers sent abroad, territories measured and bounded by procedures, infrastructures deployed and human bodies labelled as citizens or aliens. Embracing the theory of performativity, such studies emphasize the materially embedded and knowledge-related activities of state formation.

Which kind of state is thus performed through current datafied bordering, migration and mobility management practices? Broeders and Dijstelbloem (2015) argue that the datafication of border regimes enacts the state as a mediator whose goal is to transform data into reliable facts. Pelizza (2019) suggests broadening the state perspective by addressing how the informational governance of borders, migration and mobility enacts multi-level and multi-actor polities, of which contemporary Europe is the most notable example. With bordering, migration and mobility management practices, we should not assume that the state is performed as a whole. Some branches of the state (e.g. the Ministry of Interior) are more and more involved in security activities in strict coordination with non-state actors (e.g. European agencies, humanitarian actors, IT companies supplying software solutions). On the contrary, other state bodies witness their role shrinking (e.g. Ministry of Health, Ministry of Welfare). 
In this fluid landscape, we might even ask whether the state is not performed when negotiations about the meaning of secrecy are conducted. As we will see with the first example below, different institutional actors can have different understandings of what should count as a secret. This insight brings about the role of the researcher, who is not a mere observer, but enters the security context with a "position", and can contribute to unpack what should be regarded as secret.

\section{Immanence}

Surveillance has become a key concept in border, migration and mobility studies to describe the variegated nature of borders and their control. Although the notion of surveillance captures the non-site-bounded nature of control, one disadvantage is that it might overstate the consistency and coherence of monitoring. Instead of creating an all-seeing eye or a seamless web, the coupling of different technologies has led to a combination of powerful systems with many gaps in between, what Latour (2005: 181) has called "oligopticon".

The notion of the oligopticon exemplifies an immanent perspective, i.e. a perspective that, contrary to a transcendent point of view, acknowledges that there is no independent position from the outside available to oversee the whole. In that sense, an immanent perspective is in line with the situational methodology as sketched above. According to Latour, oligoptica are exactly the opposite of panoptica. Panoptica are "all-seeing" systems such as penitentiary houses. They were famously theorized by Foucault as architectures of control, exemplary for forms of surveillance that discipline people and create particular kinds of subjects. Oligoptica, according to Latour the opposite of panoptica, "see much too little to feed the megalomania of the inspector or the paranoia of the inspected, but what they see, they see it well". Latour considers parliaments, courtrooms and offices as examples of oligoptica. "From oligoptica", writes Latour (2005: 181),

sturdy but extremely narrow views of the (connected) whole are made possible, as long as connections hold. Nothing it seems can threaten the absolutist gaze of panoptica, and this is why they are loved so much by those sociologists who dream to occupy the center of Bentham's prison; the tiniest bug can blind oligoptica.

Oligoptica "provide the way to localize the global" (de Vries 2016: 97). Like "centers of calculation" in science, coordination centres in the field of border surveillance "provide forms, standards, metrologies that allow connecting activities and sites by formatting translations and 'acting at a distance', to bring about effects far beyond the normal reach of humans" (de Vries 2016: 96).

This oligoptic picture strongly resembles what Donna Haraway (1988: 581) has famously called "situated knowledges". The notion of situated knowledge recognises the impossibilities of the "god trick of seeing everything from nowhere". Instead, the study of states, borders and infrastructures starts in the middle of things 
without having a view from above. This is in agreement with what Latour stated in the opening lines of Paris: Invisible City (Latour 2006) i.e. that

no single control panel or synoptic board brings all these flows together in a single place at any one time. .. . No bird's eye view could, at a single glance, capture the multiplicity of these places.... The total view is also, literally, the view from nowhere.

(Latour 2006: 32)

In the technopolitical landscape of border and mobility control in Europe, reality is fragmented, a complete picture of it is impossible, let alone an appeal to a position from which that overview can be obtained. What remains is a variety of visions and viewpoints, perspectives that do not take their meaning from their foundation, but from their interplay of forces.

As a consequence, methods in security research need to take immanence into account. First, as we suggest in what follows, researchers should not consider themselves on a different position than those they observe. "Following the actors" and "positionality" are tools developed in ethnography and science and technology studies to provide researchers - also in security contexts - with reflexive tools. Second, if a complete overview is not possible, then the source of actions should enter the research equation, and always be contextualized.

But then how is it possible that actors arrive at pictures of their environment? And how is it possible for the analyst, the writer, the scholar, to describe these actors and their interactions? In the following we will show some specific methodological tools that have been developed to acknowledge the notion of immanence and its consequences in the study of actors.

\section{Following actors and things}

One of the most applied and discussed methodologies in Science and Technology Studies and in related fields is the so-called actor-network theory approach (ANT), originally known as the "sociology of translation". This approach, developed in the 1980s at the École des Mines in Paris by scholars like Madeleine Akrich, Michel Callon, Antoine Hennion and Bruno Latour, aims to set out a consistent way to pursue an immanent perspective. This approach has indeed opened up innovative ways to study performativity, namely the interactions and transactions that take place in the encounter between institutions, technologies and people, including researchers.

Actor-network theory is actually at the same time a theory and a method that aims to analyse how actors and organizations come into being - are performed, instead of postulating them ex ante. The key notion of "translation" refers to the work of making equivalent two things that are not the same (Latour 2005). Translation is at the same time a linguistic act (i.e. to translate across two languages) and a geometrical move (i.e. to create a chain of equivalences). In a chain of equivalences, the actor that emerges at each step of the chain of translation is said to "speak for" 
the previous actor. For example, a retina scanned image "speaks for" the human retina, it translates it into a different form of materiality. Following the chain of equivalences through which actors - both human and non-humans - are translated and so materially performed is what ANT calls "following the actors". What makes ANT and its "following actors and things" perspective particularly interesting from a methodological point of view is that it suggests operative questions and an epistemic attitude to analyse the object of our interest (i.e. migration, international mobility and the movements of states and technologies). We might ask who speaks for migrants, other actors and the state in the context of border control, migration policies and international mobility. Such an approach - which could be framed as following actors through their chains of translations - promises to open up new analytical perspectives in the field, as we are going to show in what follows.

Furthermore, "following the actors" suggests a precise epistemic attitude by the researcher, who is aware of never being a mere observer. As followers, researchers too have a role in bringing situations into existence (Latour 2005). Researchers have a "positionality", given by their social characteristics (e.g. gender, class, race, nationality), but also by the specific ways they use to enter the security domain, as we will see in the first case below.

\section{BOX 2.1 PERFORMATIVITY, IMMANENCE AND FOLLOWING ACTORS}

In short, the three principles we have set out inspire us to study:

1 How states and broader polities emerge - are "performed" - in various practices and situations. For example, physical border building is a way to perform the state as a territorial entity.

2 How the study of security contexts can benefit from a method oriented to analyse oligoptica and situated knowledges. For example, researchers can focus on a specific set of technologies used in a given context by specific actors, instead of trying to grasp the whole infrastructure.

3 How "following the actors" can suggest operative questions and an epistemic attitude to analyse migration, international mobility and the movements of states and technologies. For example, the police officer at the border "speaks for" the state.

And to acknowledge that when studying these issues:

- There is no all-knowing perspective or view from above from which these studies can be conducted.

- Researchers themselves are involved in making things happen, in performing their objects of study. 


\section{Secrecy in action: border control in Europe}

In the following, we will present two examples of contemporary technopolitical border control in Europe. While controlling the external borders of the European Union was a common task from the outset, the legal order that developed in the legislation and policies of border surveillance did not provide a blueprint for installing border infrastructures. Rather the opposite, the legal order of the EU and the states participating in the control of the external border developed from the inside out, from the very construction of these border infrastructures. In this sense, border infrastructures have been performative of new legal orders. The introduction of the so called "Hotspot approach" and the Eurosur program are exemplary points in case. They provide empirical discussion of the methodological principles up to now introduced related to the issue of secrecy and the state. Underpinning both discussions is an understanding of secrecy as a relational notion that constitutes a variety of political relationships and modes of knowing, not only between the state and its traditional constituencies (i.e., individual citizens, organizations, businesses), but also between states and trans-national polities and actors.

\section{Case 1. The European Hotspot approach: defining the secret}

The Hotspot approach to third-countries citizens' registration and identification has been established by the European Commission in 2015 with the goal to "swiftly identify, register and fingerprint incoming migrants" (EU Commission 2015a). Hotspots are meant to provide coordinated on-the-ground operational support by European agencies - namely European Asylum Support Office (EASO), Frontex and Europol - to frontline Member States in dealing with the immediate challenge of large-scale arrivals of migrants (EU Commission 2015b; EU Council 2015). As a consequence, the Hotspot approach implements highly codified processes, in which Standard Operative Procedures (SOPs) are established to deal with almost every aspect of migrant population management.

What characterizes this approach is its rather loose policy framework. Technologically mediated activities of identification, screening, sorting, debriefing, fingerprinting, accommodation and relocation undertaken by EU agencies in collaboration with national staff perform a de facto multi-level and multi-actor governance of European borders. Multi-level, because both national and trans-national actors collaborate in registration and identification activities tasked with translating unknown identities into European-legible ones (Pelizza 2019). Multi-actor, as humanitarian non-state actors are increasingly involved in population management activities that used to be conducted by states (Painter et al. 2017; Pallister-Wilkins 2015). All in all, the form of the state that emerges from Hotspot arrangements is very different from accounts in political theory manuals.

In such a heterogeneous yet securitized Hotspot landscape, where vulnerable people are identified and their movements restricted, researchers are rarely admitted. When they are, they have to adhere to strict confidentiality, privacy, spatial and 
security constraints, so that their view cannot be but partial, situated, oligoptical (see also Wissink, this volume). Furthermore, they have to be aware of their positionality. Here, in order to be precise it is necessary to bring a situated example, like the case of one of the authors of this chapter, who negotiated access to Hotspots in the context of a major European-Commission-funded research project.

As a white, European, middle-class female scholar, the researcher expected she did not constitute a major threat to authorities granting access to Hotspots. However, being a researcher, she might be seen representing other knowledge actors, i.e. she might be seen as speaking for categories like journalists, human-rights activists or lawyers. Furthermore, acting as leader of a European-Commission-funded project might even position her towards state authorities in the uncomfortable position of a European controller. For the researcher, addressing these deadlocks entailed by her position required unpacking what should be regarded as secret, and what not.

As a matter of fact, during negotiation the researcher and the research assistants had to preliminarily share with authorities what they were planning to observe at Hotspots, and the type of questions they wished to ask officers. On their side, authorities agreed on some questions and observations, and asked to redefine others, thus creating oligopticon conditions. In particular, both researchers and authorities agreed that migrants' personal data were to be regarded as secret, while registration and identification procedures were not to be considered as such, as long as the researchers did not record migrants' answers, but only officers' questions. In other words, researchers and authorities negotiated over what was (not) to be known, over what should count as "secret". In this negotiation, secrecy was a situated, contingent relationship between the researchers and the authorities.

Furthermore, it should be noted that different institutional actors can have a different understanding of what should count as a secret. Neither the state nor the European Union are monolithic bodies, and what is regarded as secret by some agencies might not be so for others. For example, database ontologies - i.e. the categorizations and categorical values through which migrants are classified - were not initially shared in written form by the police who developed the information systems used at Hotspots. They were, however, orally discussed by registration officers who encounter daily challenges in finding the best categorical values for highly heterogeneous personal data. In this case, it was not documents but registration officers who "spoke for" ontologies. In other words, "following the actors" methods brought about by researchers enabled elements of the state to see themselves in relation to other parts of the state (e.g. police developers realizing missing values for registration officers). In this regard, we can say that the state itself is performed as a secret, not only for migrants and researchers, but also for diverse parts of the state (see also Belcher and Martin, this volume).

\section{Case 2. Eurosur: establishing connections between ways of seeing and ways of knowing}

From the start, Eurosur could be conceived as merely a "systems of systems", or, more in line with our angle, a "network of networks" rather than as a panoptical 
all-encompassing surveillance program. Its main goals of establishing interoperability between all kinds of variegated local, technical, professional and policy systems as to arrive at situational awareness of international mobility, migrant movements and critical border situations have resulted in a patchwork of instruments, organizations and interventions.

We studied this variegated landscape by conducting (1) a genealogy of the historical technopolitical background of the emergence of Eurosur; (2) a network analysis of the ways coordination of knowing and seeing takes place between local, regional and transnational actors and organizations; and (3) ethnographic research at specific locations at which various streams of information, knowledge, images, representations, and know-how tend to come together, such as patrol boats, coordination centres and local offices of border guards (Dijstelbloem, Van Reekum and Schinkel 2017; Van Reekum 2018).

Eurosur's goal of achieving situational awareness is a means to bridge the gap between vision and action so as to enable critical border interventions in real time. Its history can be traced back to previous surveillance programs in Spain and North Africa, while US and Israeli security systems and border surveillance technologies have influenced EU policies. Another factor is the growing role of the transnational security industry, with private companies promoting the integration of various systems to gather, interpret, use and transport data and information for multiple applications.

Eurosur not only adds an extra layer of instruments and data traffic but "Europeanizes" surveillance by extending the chains of associations between patrol boats, regional authorities, headquarters and Frontex officials. In doing so, Eurosur also emphasizes Europe's infrastructural layout. Instead of being a coherent and allencompassing program, Eurosur connects and selects, mediates representations, things and people, relates observations and interventions of different sorts to each other whilst excluding other, just like many other cooperation and integration processes in Europe.

We studied the development of Eurosur, its local applications and impact and the way connections are - or refrain from being - established. The goal was to follow the relation between observations from border guards at sea to regional coordination centres to the headquarters of Frontex in Warsaw and vice versa. To do so, we aimed to unpack the technopolitical networks of Eurosur at the Greece Aegean islands of Chios and Lesbos in the period 2014-2016.

One of the insights of this research was that Eurosur not only aims to connect different places, actors, technologies and bits of information but also very different territories (land, sea, air) and variegated ways of seeing and knowing that tend to be situated and relational (e.g. Haraway 1988). A technopolitical project such as Eurosur not only relates all kinds of existing policies, actors and instruments (or fail to do so) but also performs novel political relationships, between people, territories, and ways of knowing and seeing.

In order to reveal these relationships, as part of our research to gain insight into these entanglements, a series of interviews with various Greek authorities, coast guards, representatives of Greek and international NGOs, grassroots organizations 
and local volunteers were conducted on the Aegean Islands of Chios and Lesbos. One interview that turned out to be striking in particular was with a Union representative of the Hellenic Coast Guard. As a kind of mediator between the Guards and the State, as well as between the Guards and the local community and their home villages, the interviewee vividly described the gap between the goals, ambitions and pretensions of Eurosur to arrive at "situational awareness" and the daily practices at land and at sea. Of importance to us was not only the interviewee's account, but also the way we, as researchers, arrived at the interviewee by following the chain of conversations of events and the different representations of the border control landscape people provided us with.

This, and many other interviews, emphasized how Eurosur exemplifies the aforementioned oligoptica that "provide the way to localize the global" (de Vries 2016: 97). As Follis (2017: 1016) argues,

transterritorial vision such as that produced by Eurosur likewise may offer the illusion of transparent surveillance at what one document describes as a "non negligible" distance (European Commission JRC 2015). And yet, the picture it delivers is always already compromised by the oligoptic characteristics of its own infrastructure and by the culturally and politically mediated preconceptions of its embedded actors.

The three notions of the situated methodology we outlined previously (i.e. (1) the performative stance, (2) the notion of immanence and (3) a set of methods to follow actors) proved to be helpful as they keep the researcher aware of the impossibility of arriving at a view from nowhere or reaching a full overview. This concerns the object (Eurosur) as well as subject (the researcher) of the study and is much in line with our previous discussion of positionality. One of the consequences is that the development, implementation, application and meaning of Eurosur is highly dependent of very specific events. Instead of being a well-connected system of systems, Eurosur often tends to have more in common with a border bricolage in which improvisations, provisional arrangements and ad hoc decisions are as important as the implementation and extension of European programs.

\section{BOX 2.2 METHODOLOGICAL TIPS}

- $\quad$ Transform your questions into research questions.

If after thorough analysis you do not succeed in separating your concepts because they seem too related, then study this relationship and turn it into a research question. For instance, in our studies we found secrecy is not just an 
object states are concerned with or a characteristic or quality of a state. There is an intimate relationship between states and secrecy in many cases. Continuing from that proposition proved to be very productive.

- Methodology is not mere methods.

The research we undertook for our various studies is empirically grounded in semi-structured interviews (individual as well as on group level), observations, and the analysis of various documents. Throughout the chapter, however, our methods were part of a methodological and conceptual endeavour that favoured the three guiding principles of (1) performative stance, (2) the notion of immanence and (3) the imperative to follow the actors. Methods have to be applied thoroughly, correctly and consistently, but the same applies to methodologies and conceptualizations.

\section{- $\quad$ Expect the unexpected}

Taking the imperatives of "performativity" and "following actors and things" seriously also means one has to be willing to arrive at unexpected locations and to end up with unannounced guests. Tracing chains of associations and following connection of peoples, institutions and technologies leads the researcher through a myriad of networks.

\section{Conclusion: the state is the secret}

The conclusion that can be drawn from our research, based on the situated methodology we presented, is that states and secrecy are co-constructed. Instead of considering the state as a well-defined entity and secrecy as a mere attribute, or, conversely, foregrounding the notion of secrecy as a clear concept and questioning the idea of the state, we suggest states and secrecies are co-produced. Instead of being each other's cause or consequences they emerge in mutual interaction. And instead of being welldefined objects from the start, they develop as entities and attributes, in different circumstances. Neither states nor secrecies have clear boundaries - they are mediated via each other. As a consequence, secrecy can be understood as a relational notion. It constitutes a variety of political relationships, modes of knowing and ways of seeing, not only between the state and its traditional constituencies, but also between states and trans-national polities and actors. Unpacking multi-actor and multi-level technopolitics of border control and migration and mobility management in Europe allows for a re-evaluation of the notion of the state as well as the notion of secrecy. The methodological and conceptual issues we have outlined suggest the contours of very mobile and infrastructural entities partially overlapping with what is formally known as "the state". In the Hotspot approach as well as in the Eurosur program, the 
state arises out of the intermingling of policies, agencies and technologies, and something is considered a secret always in a specific situation, and not in a vacuum. In this, who or what is "speaking for" the secret is relevant, as well.

The state in the context of border infrastructures is not just the next phase in the development and exercise of state power. States may increasingly apply infrastructural power to organize and penetrate society but the thesis here holds that states themselves are increasingly entangled in infrastructures. Border infrastructures are not just the result of human design or political will. The technopolitics of border infrastructures generates configurations in which states are neither the sole nor the final architects.

Although European surveillance programs have often been typified in term of panoptica and all-seeing apparatuses, our research (and that of many others) suggests technopolitical infrastructures in the context of border control and migration policy ought to be conceived as highly constructed and composed complex networks. Instead of depicting realities and existing critical border events, policy programs such as the Eurosur project and the Hotspot approach tend to multiply the nature and amount of political relationships. They perform the relationships between migrants, state officials, professionals and policymakers in various configurations at multiple locations.

Our three methodological angles of performativity, immanence and following actors and things proved to be helpful in detecting the various associations and transformations that take place in the interaction and transaction between people, institutions and technologies that constitute the novel political relationships and the conditions of secrecy.

\section{Suggestions for further reading}

- Louise Amoore (2006) "Biometric borders: Governing mobilities in the war on terror", Political Geography, 25: 336-351.

- Dennis Broeders (2007) “The new digital borders of Europe. EU databases and the surveillance of irregular migrants", International Sociology, 22(1): 71-92.

- Huub Dijstelbloem and Dennis Broeders (2015) "Border surveillance, mobility management and the shaping of non-publics in Europe", European Journal of Social Theory, 18(1): 21-38.

- Eva Horn (2012) "Logics of political secrecy", Theory, Culture E Society, 28(78): 103-122.

- Annalisa Pelizza (2016) "Developing the vectorial glance: Infrastructural inversion for the new agenda on governmental information systems”, Science, Technology and Human Values, 41(2): 298-321. DOI: 10.1177/0162243915597478

\section{Notes}

1 This chapter draws on research conducted by Annalisa Pelizza in the context of the "Processing Citizenship. Digital registration of migrants as co-production of citizens, territory and Europe" project that has received funding from the European Research Council (ERC) 
under the European Union's Horizon 2020 research and innovation programme under grant agreement No. 714463 and on the research by Huub Dijstelbloem on surveillance and counter-surveillance in Europe (2014-2016) supported by a grant from the Open Society Foundations (OSF) no. OR2014-16667. Both authors wish to thank Ermioni Frezouli and Aristotle Tympas for their efficient and effective support in establishing "secrecy relationships". Both authors are grateful to the three editors of this book.

2 http://www.consilium.europa.eu/en/press/press-releases/2015/10/27/pec-speech-ep/

3 European Commission, Fact Sheet "The hotspot approach to managing exceptional migratory flows", 8 September 2015 at http://ec.europa.eu/dgs/home-affairs/what-wedo/ policies/european-agenda-migration/background-information/docs/2_hotspots_en.pdf

$4 \mathrm{http}: / /$ frontex.europa.eu/assets/Legal_basis/Eurosur_Regulation_2013.pdf (24 June 2017).

\section{References}

Austin, John L. (1955/1962) How to Do Things With Words?, Oxford: Clarendon Press.

Broeders, Dennis and Huub Dijstelbloem (2015) "The datafication of mobility and migration management: The mediating state and its consequences", pp. 242-260 in I. van der Ploeg and J. Pridmore (eds) Digitizing Identities: Doing Identity in a Networked World, New York and London: Routledge.

Callon, Michel (2007) "What does it mean to say that economics is performative?", pp. 310357 in D. MacKenzie, F. Muniesa and L. Siu (eds) Do Economists Make Markets? On the Performativity of Economics, Princeton, NJ: Princeton University Press.

Carroll, Patrick (2006) Science, Culture, and Modern State Formation, Berkeley, CA: University of California Press

DeVries, Gerard (2016) Bruno Latour, Cambridge, UK: Polity Press.

Dijstelbloem, Huub, Rogier van Reekum and Willem Schinkel (2017) "Surveillance at sea: The transactional politics of border control in the Aegean", Security Dialogue, 48(3): 224-40.

EU Commission (2015a) “The Hotspot approach to managing exceptional migratory flows", available at http://ec.europa.eu/dgs/home-affairs/what-we-do/policies/europeanagenda-migration/background-information/docs/2_hotspots_en.pdf (last visited: 27 December, 2018).

EU Commission (2015b) "Communication from the Commission to the European Parliament, the Council, the European Economic and Social Committee and the Committee of the Regions.A European Agenda on Migration", available at http://ec.europa.eu/dgs/homeaffairs/what-we-do/policies/european-agenda-migration/background-information/ docs/communication_on_the_european_agenda_on_migration_en.pdf

EU Council (2015) "Statement of the special meeting of the European Council, 23 April 2015”, available at http://www.consilium.europa.eu/en/press/press-releases/2015/04/23special-euco-statement/ (last visited: 27 December, 2018).

Follis, Karolina S. (2017) "Vision and transterritory: The borders of Europe", Science, Technology, and Human Values, 42(6): 1003-1030.

Foucault, Michel (2007) Security, Territory, Population. Lectures at the College de France 19771978, New York: Palgrave Macmillan.

Haraway, Donna (1988) "Situated knowledges: The science question in feminism and the privilege of partial perspective", Feminist Studies, 14(3): 575-599.

Jasanoff, Sheila (ed.) (2004) States of Knowledge:The Co-Production of Science and Social Order, London/New York: Routledge.

Latour, Bruno (2005) Reassembling the Social: An Introduction to Actor-Network-Theory, Oxford: Oxford University Press. 
Latour, Bruno (2006) Paris, Invisible City, available at http://www.bruno-latour.fr/node/343 (last visited: 27 December, 2018).

MacKenzie, Donald (2006) An Engine, Not a Camera. How Financial Models Shape Markets, Cambridge, MA: MIT Press.

Mitchell, Timothy (2002) Rule of Experts: Egypt, Techno-Politics, Modernity, Berkeley, CA: University of California Press.

Mukerji, Chandra (2011) "Jurisdiction, inscription, and state formation. Administrative modernism and knowledge regimes", Theory and Society, 40(3): 223-45. DOI:10.1007/ s11186-011-9141-9.

Painter, Joe, Evie Papada, Anna Papoutsi and Antonis Vradis (2017) "Hotspot politics or, when the EU state gets real”, Political Geography, 60: 259-260. DOI: 10.1016/j. polgeo.2017.02.012

Pallister-Wilkins, Polly (2015) "Humanitarian borderwork", pp. 85-102 in Cengiz Günay and Nina Witjes (eds) Border Politics. Defining Spaces of Governance and Forms of Transgressions, Chaom: Springer.

Passoth, Jan-Hendrik and Nicholas J. Rowland (2010) “Actor-Network State: Integrating actor-network theory and state theory", International Sociology, 25(6): 818-841. DOI:10.1177/0268580909351325.

Pelizza, Annalisa (2019) "Processing alterity, enacting Europe. Migrant registration as coproduction of individuals and polities", Science, Technology and Human Values, first published online on 6 February: 1-27. DOI: 10.1177/0162243919827927.

Pelizza, Annalisa and Rob Hoppe (2018) "Birth of a failure: Consequences of framing ICT projects for the centralization of inter-departmental relations", Administration and Society, 50(1): 101-130. DOI: 10.1177/0095399715598343

Van Reekum, Rogier (2018) "Patrols, records and pictures: Demonstrations of Europe in the midst of migration's crisis", Environment and Planning D: Society and Space, 0(0): 1-19 DOI: 10.1177/0263775818792269. 


\title{
POSTSECRECY AND PLACE
}

\section{Secrecy research amidst the ruins of an atomic weapons research facility ${ }^{1}$}

\author{
William Walters and Alex Luscombe
}

- Research objective: This chapter will help researchers explore places where secrecy persists despite acts of declassification and derestriction intended to make them more "open" and "transparent".

- Research Puzzle:The puzzle the chapter addresses in relation to secrecy and methods is how to examine these "postsecret" places by using a wide range of data sources, some of which may be considered unorthodox by traditional social scientific standards.

\section{Introduction}

The heat of the Cold War forged a world in which national security came to be staked upon complex and large-scale technoscientific systems, the most notable being atomic weaponry. One of the consequences of this development was to accord state secrecy a new geography (Paglen 2010). States on both sides of the bipolar conflict created areas, and even whole cities (e.g., Oak Ridge in the US or the "closed" cities of the USSR) dedicated to military and security functions that included weapons development, surveillance, intelligence, and communication activities. This new geography was not confined to the surface of the earth, nor its surveillance from the sky by planes and satellites. A new underworld also took shape with the expansion of bunkers, tunnels, silos, and control rooms. Most aspects of this new security infrastructure were deemed top secret. Physical access to these sites was tightly controlled. Knowledge about their very existence and location was strictly policed. And work within these settings was rigidly "compartmented", structured on a "need-to-know" basis.

Now, the secrecy of the Cold War was by no means reducible to this archipelago of secured places. After all, this was a time when the advent of atomic weapons 
research was transforming the very "ontology of secrets" (Galison 2010: 961), calling forth new bureaucratic procedures (e.g., restricted data) and new concepts (e.g., the idea that scientific knowledge could be "born secret"). Nevertheless, the construction and management of these covert, dedicated infrastructures was a huge undertaking that gave rise to a new kind of shadow world, a world that most citizens could access only through rumour, fiction, and the occasional leak (Melley 2012).

Some parts of this infrastructure, such as the Nevada National Security Site, remain in active use, being no less subject to official secrecy today than they were at the height of the Cold War. Inasmuch as it is a practical and material undertaking, state secrecy is, among other things, a matter of sunk costs and path dependence. Once you have made the investment to forge a particular geography of secrecy you may as well keep exploiting it, perhaps adapting it to new purposes. But many parts of this infrastructure have been decommissioned and mothballed, either because the systems themselves have been rendered obsolete by geopolitical and technological change, or relocated. Some of these structures have turned into ruins, others have been repurposed for non-militarized use. More than a few have been turned into official or semi-official places of memory, tourism, and even nature conservation (Bennett 2013; Forbes et al. 2009).

This chapter is an argument for researching state secrecy through a focus on these formerly secret sites. More generally, it presents the case for researching secrecy from the angle of place. The chapter is based on our experience of researching one such place: Orford Ness on the east coast of England. Throughout the Cold War, Orford Ness was the home of numerous, militarized and covert projects, most notably an atomic weapons component testing facility and an Anglo-American radar intelligence operation. Today, the remnants of these two major artefacts remain partially intact, and people can visit and tour them to learn about their eerie and mysterious histories.

Let us clarify what we understand by place as a methodological angle. After all, don't all secret activities have to take place somewhere? Isn't place always and necessarily a feature of what we research? Geographers often contrast space and place. To speak of place is to imply something more than physical location or setting; place can be thought in terms of "milieux that exercise a mediating role on physical, social and economic processes and thus affect how such processes operate" (Agnew 2011: 317). Whereas space can be abstract and nodal, a focus on place introduces elements of meaning, experience and mood into the analysis. We are interested not just with the location of secret activities but how particular places come to be strongly associated with the secret, what meanings attach to those places, and how those meanings are produced and reworked. Does that mean that our research is confined to fieldwork at the specific site of Orford Ness? Certainly not. We take the view that the meaning of a place is never neatly contained within the physical coordinates of that place. Certainly, we learnt about Orford Ness as place from visiting the site, but from research in many other locales as well, whether archives held in distant buildings, ${ }^{2}$ materials 
gathered online, or interviews with informants wherever they might be. Since the production of place is necessarily a distributed affair, so too must research be about that place.

This chapter will offer some guidelines regarding how one might go about conducting research on secret sites. But it also introduces a new concept: postsecrecy. We stress at the outset that not every formerly secret site would qualify as postsecret; we have fashioned this concept in part to make sense of our unique encounter with Orford Ness though we suggest it has a much wider potential field of application.

Throughout the chapter we aim to address the following questions:

1 What is a "postsecret" place, how does a researcher identify one, and how does it differ from a "secret" or "formerly secret" place? What can we learn about secrecy from a focus on the postsecret?

2 What methodological strategies and data sources are useful in order to research a postsecret place?

The chapter is organized as follows. First, we discuss the idea of postsecrecy. Second, we nuance this idea through a short mapping of Orford Ness. We discuss the various sites and methods from which we obtained data about the postsecrecy of Orford Ness. Some of these are more conventional (e.g., interviews) while others may be more unexpected (e.g., UFO researchers). We focus on three method assemblages: interviews, UFO research, and archives. In a final section we offer some lessons learned.

\section{Postsecrecy}

What is postsecrecy? To describe something as postsecret might seem just a fancy term for public, open, or declassified. Or, more grandiosely, it might be read as a reference to a new age, a time when social media coupled with a growing culture of transparency and whistleblowing are spelling the demise of organizational secrecy (Sifry 2011). But we mean something entirely different. We use the term to capture the fuzziness and ambiguity that often attaches to our experience of that which was once officially secret. Postsecrecy names a certain condition. It confronts us with the puzzle that sometimes things can be simultaneously secret and non-secret. The idea of postsecrecy builds on an important current in recent secrecy research that questions the standard and sometimes clichéd binaries by which secrecy has usually been understood, such as secrecy vs publicity, visibility vs invisibility, open vs closed (Taussig 1999; Bratich 2006; De Goede and Wesseling 2017; Hilgartner 2012). As we show, based on our research at Orford Ness, the distinction between secrecy and publicity is rarely so clear cut. We use the term postsecrecy to theorize situations where formal declassification, coupled with enhanced public interest and familiarity with a given place, practice or incident, does not serve to lessen its aura of secrecy (Wilson 2006). 


\section{BOX 3.1 POSTSECRECY}

Declassification and derestriction do not always spell the death of a secret. When these events attract new inquiries, generate new rumours, incite a widespread feeling that the truth is still being hidden, or when they attract the attention of actors who translate the original secret into new forms (for example, through art), we call this "postsecrecy". In postsecret places the secret is reincarnated.

Let us clarify this concept of postsecrecy by way of an analogy. Think about the postcolonial. In certain readings we find convincing, the postcolonial condition is not merely a time that comes after colonialism, if by that we mean a time or an experience that has freed itself entirely from the mark of the power relations, identities, and geographies associated with the colonial. Rather, it designates a heterogeneous, mixed time. Mezzadra and Rahola put it like this: "Postcolonial time is that in which colonial experience appears simultaneously, to be consigned to the past and, precisely due to the modalities with which its 'overcoming' comes about, to be installed at the centre of contemporary social experience" (2006; their italics). With this understanding of the postcolonial, emphasis is placed on the ways in which societies actively remember and forget or disavow the colonial. In fact, one could say practices of remembering and forgetting become dynamically interconnected.

To speak of postsecrecy is to insist that what comes "after" state secrecy is not necessarily a clean break, a transparent time disentangled from the suspicion, memory, intrigue, hierarchy, charm and fear that might once have attached to the secret. It is to insist that there is an after-effect, after-lives, and even situations in which the secret is brought back to life, but invariably with a different inflection, rationale, or context.

If our argument about postsecrecy is correct it means that when we study formerly secret places, archives, events, policies, and so on, we are entering a complex and variegated terrain. We should not expect to find that everything has become opened to us. At the same time, we should also not assume that what we are looking at lacks contemporaneity, that there is no secrecy there, only remnants of a historical past. After all, sceptics would say that in researching the remains (and sometimes ruins) of the infrastructure of the Cold War you might learn about secrecy during that time but not today; that if you want to understand secrecy today you should look at contemporary infrastructures, such as the NSA surveillance programmes associated with the Snowden controversy. Following our hypothesis of postsecrecy we insist that these infrastructures of the Cold War are a vital and changing part of our secret present, and not merely the remnants of a former time. 


\section{The postsecrecy of Orford Ness}

Orford Ness is a former weapons testing, military research, and surveillance establishment located in rural Suffolk on the east coast of Britain. For nearly 60 years cutting edge work on aerial gunnery and aerial photography, bomb ballistics, radar intelligence, high speed photography, and the environmental testing of several generations of atomic bombs were all carried out at Orford Ness (Davis 2006; Heazell 2010; Cocroft and Alexander 2009). ${ }^{3}$ This accretion and interaction of multiple sediments of military and security practice at one site over a long period makes Orford Ness a fascinating place, a "palimpsest" (Davis 2006: 47) of the management of twentieth-century insecurities. Orford Ness takes its name from its peculiar geographical location: a long $(16 \mathrm{~km})$, vegetated shingle spit joined to the mainland by a narrow neck of land. At the start of WWI this remote peninsula began to be colonized by the military who were to turn "the island" (as it is known locally) into what the Official Secrets act designated as a "prohibited place" (Heazell 2010: 23). After WWII Orford Ness went nuclear. When the UK's Atomic Weapons Research Establishment (AWRE) expanded rapidly in the 1950s it had Aldermaston as its main site, but Orford Ness soon became an important facility within its geography of violence. In the 1960s, Orford also became the home of the highly elusive radar intelligence operation known as Cobra Mist. Cobra Mist was an "over the horizon" radar station jointly operated by Britain and America's respective defence agencies. For many generations of military planners the remoteness and seclusion which the geography of Orford Ness offered was a distinctive and prized asset.

In 1993, a while after the military establishment had decommissioned and abandoned it, the site was purchased by Britain's largest conservation organization, the National Trust (NT) (Wainwright, 2009: 136). The NT took a keen interest in Orford Ness due to its unique environmental profile: it is heralded as the "largest vegetated shingle spit in Europe" featuring "rare and highly specialised flora" (Wainwright 2009: 134-135). The NT's second reason for acquiring the site was historical. The site housed a series of decaying concrete bunkers, observation towers, and huge laboratories (see Figure 3.1). If the medieval age was memorialized by castles (many of which the NT now manages) then certain NT planners foresaw that Orford Ness would do something comparable for the Cold War. It would give a conflict, which otherwise had left relatively few discernible traces in the British landscape, some visible markers and a form of public memory (Wainwright 2009). Nevertheless, the acquisition of the site was controversial. Some argued that the NT should confine its activity to its more traditional domain, namely the management of castles and historic estates. Still, the purchase proceeded.The NT now opens the ruins of Orford Ness to a visiting public for 90 days per year. Today it is credited as "the only former atomic weapons testing site that may be freely visited" (Cocroft and Alexander, 2009: 62). Moreover, the historical significance of the AWRE ruins is now reflected in their listing as "scheduled monuments" (Historic England 2014). Though the section of Orford Ness which housed Cobra Mist is privately owned, its remnants are still visible from a distance and feature as themes in the NT's periodic guided tours of the site. 


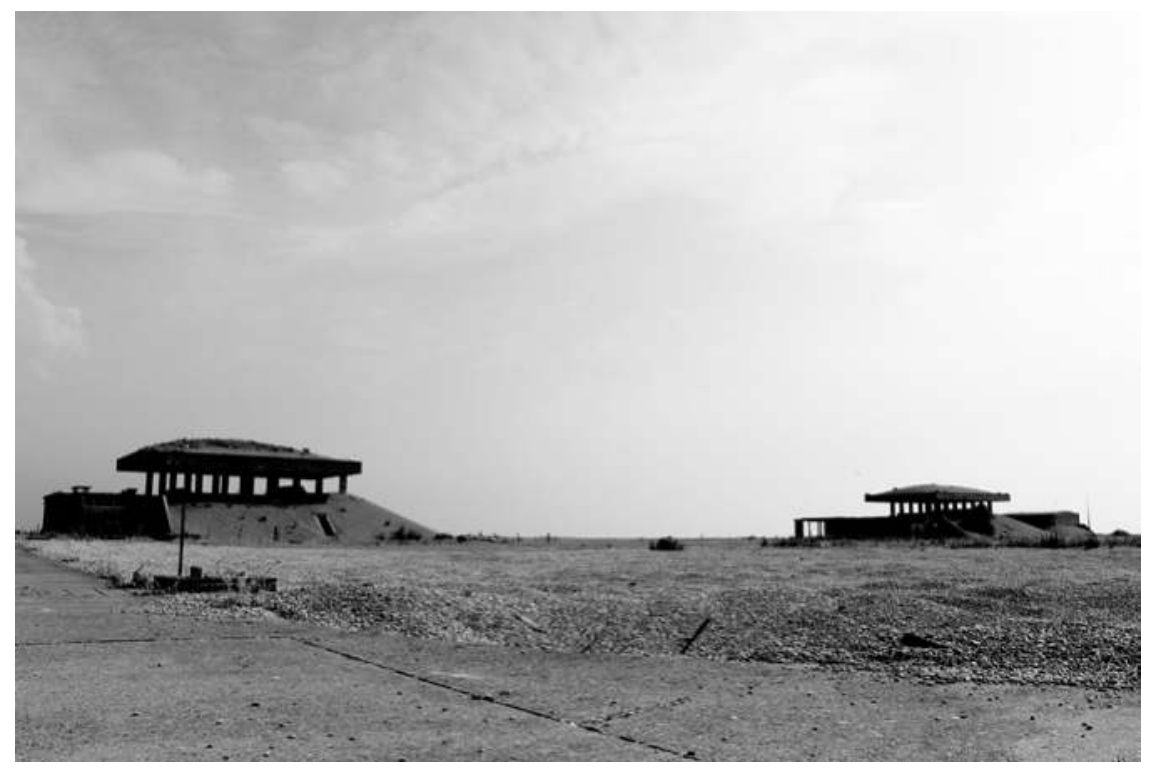

FIGURE 3.1 Laboratories 4 and 5 ("The Pagodas"), Orford Ness.

Source: William Walters.

Although "open to visitors", much about Orford Ness remains closed. Publicity and secrecy, fact and fiction, cohabit and resonate with each other in strange and unexpected ways on Orford Ness. When the NT acquired the property from the Ministry of Defence they were given relatively little information about its technoscientific past. Most of the official archive on AWRE, given the sensitivity of nuclear weaponry, remains classified. Other records have been lost or destroyed. A greater proportion of the official record on Cobra Mist has been disclosed and made available in Britain's National Archives, but some still remain classified. Knowledge about AWRE buildings, projects, and incidents has come not primarily through official sources but other modes of investigation and information. Perhaps the most important of these are the recollections of people who worked at Orford Ness during its active life. Their memories have been documented by NT officials as well as independent researchers and have provided a vital source of information about social, and, to some degree, technical aspects of Orford Ness. We discuss this production of memory, and its significance for postsecrecy, below.

But here we note that the materiality of this place is also an active element in the production of knowledge about its past. Archaeologists have conducted careful surveys of the site, seeking clues in the dimensions of buildings, or the remnants of mechanical structures, as to their exact uses in the past (Cocroft and Alexander 2009; Historic England 2014). In a sense archaeological practice has enacted and reinforced the impression that although Orford Ness is largely a product of twentieth century conflicts, state secrecy has made its ruins no less inscrutable than the ancient ruins with which 
archaeology is associated in the popular mind (Sebald 1998: 236-237). Secrecy, then, does not just control the flow of information. It can shape our experience of space and time, making some places and times very remote despite their material proximity.

Orford Ness is a quintessential postsecret site. Decades have passed since the closure of the military site, yet a plethora of actors continue to visit, debate and interpret it in ways that sustain a strong sense of enigma about the place. Journalists speculate as to what "really happened" at Orford Ness. Independent researchers examine fragments of its ruins seeking to establish just what secret purpose some of its structures once served. Bloggers recount the feelings of unease but also fascination which a visit to Orford Ness instilled in them. Artists explore it as a landscape and a soundscape, bringing added intensity to the feeling of mystery which now seem so much a part of its character. Ufologists weave it into narratives about unexplained incidents and reports of mysterious lights and sounds. Meanwhile, NT managers and guides take the view that a final "truth" about Orford Ness is unlikely to emerge, and that the rumours that shroud it are an essential feature of its identity. Not even the ground under the site is settled. Powerful ocean currents and winds continue to reshape the shingle spit and eat away at the coastline. The tallest structure on "the island" is a decommissioned lighthouse; coastal erosion makes its disappearance into the North Sea imminent.Very little at Orford Ness is fixed or certain.

\section{A note on method}

It would be nice to say we approached Orford Ness with a well-crafted method calibrated to a clear set of research questions and logically ordered research steps. But to claim that would be to engage in a kind of retrospective reconstruction, a photoshopping of what was far messier, ad hoc, and still unfolding (Law: 2004). At the outset we had not so much a single research question as a general fascination with the qualities of Orford Ness as a place, a ruin, an atmosphere, and an area that had for decades been highly restricted.You might say that what attracted us initially was the aura of secrecy itself: what the great Russian filmmaker, Andrei Tarkovskii, in his science fiction epic, Stalker (1979), called "the zone". Unlike investigative journalists we did not set out to unveil the "true nature" of a secret; as if Orford Ness were a box that needed to be unlocked and opened for all to see (see also Straube, this volume). Instead, we set out to explore what secrecy means, how it is practised, experienced, and felt, both in the past and in its present state of postsecrecy.

We had no privileged method so much as an attitude which corresponded with what the pioneering anthropologist of American nuclear secrecy, Hugh Gusterson (1997), called "polymorphous engagement". Research on official secrecy demands such a method: when researching a place like Orford Ness, one is not dealing with some singular and localized database so much as a series of fragmented and incomplete caches. These can be economically gathered and processed but finding them is opportunistic and usually lacks a clear roadmap. To begin, one uses what is close at hand and builds outwards sequentially based on whatever new tips and leads one can obtain about the next place to look. 


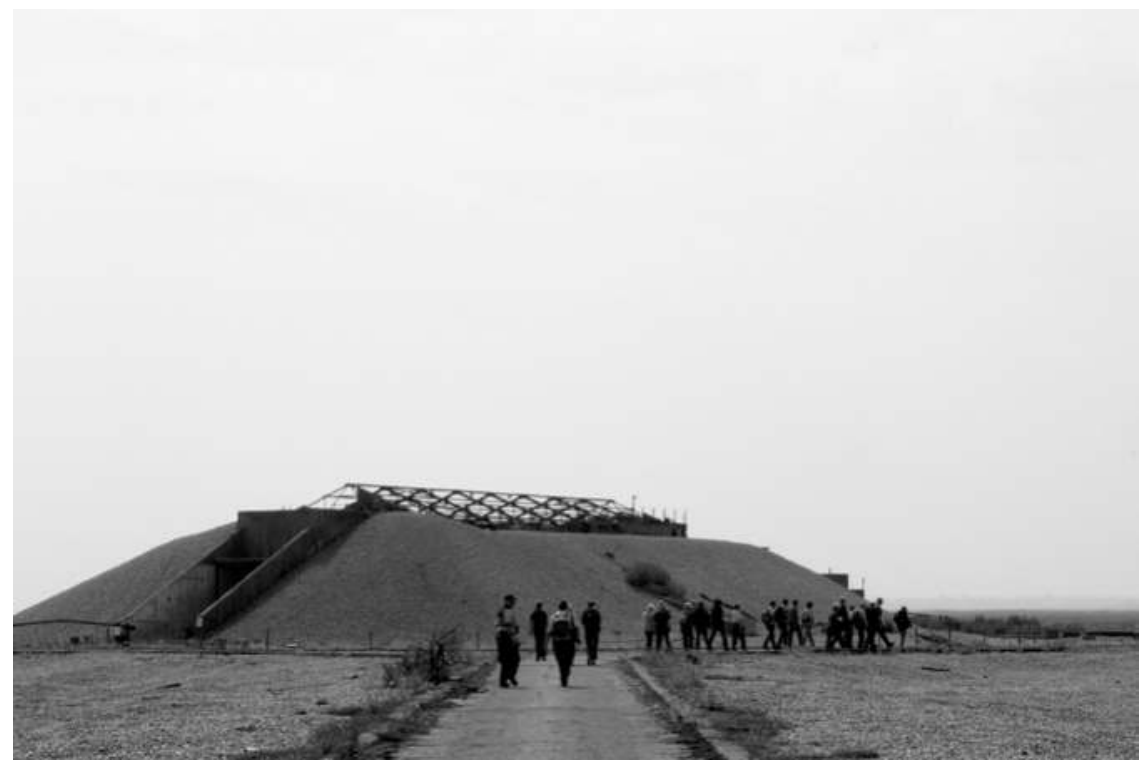

FIGURE 3.2 A tour group approaches Laboratory 2, Orford Ness.

Source: William Walters.

In our research on Orford Ness, we used a polymorphous assembly of methods and data sources and continue to learn about new ones to this day. This is often the thing about postsecret sites: parts become knowable to us, as through declassification of archival records, but rarely if ever all at once. We poured over declassified archives in London as well as regional offices like Ipswich and Bury St Edmunds - settings that felt a million miles away. We scoured newspapers for stories. We conducted site visits and participated in guided tours (see Figure 3.2). We conducted interviews with many actors including NT managers and planners who had been instrumental in the acquisition of the site, and who had fashioned a management philosophy for this place. And gradually we made contact with some veterans who had worked there at the height of the Cold War. In the following we recount our experience with some of these practices and how they relate to postsecrecy. We reflect on just three of the methods that formed our broader methodological assemblage: archival sources, UFO research (or ufology), and interviews with veterans.

\section{Archives}

When researching a decommissioned military site, the most obvious place to start is the archive. Depending on the age and sensitivity of the operation, an archive may hold hundreds or thousands of dense references of declassified records to sift through. It is important to recall however that these caches of declassified official texts are as partial and incomplete as any other data source. The information contained in these records can be incomplete and devoid of surrounding context, and 
it is usually impossible to determine how much of the entire written record one is actually viewing (Luscombe and Walby 2017). Archival records, depending on the nature of the information and the age of the document or programme, may also be stored by an archival facility but kept out of public reach. Of the nearly 9,100 references on the Atomic Weapons Research Establishment (AWRE) held by the National Archives in Kew (regarding AWRE's operations not just on Orford Ness but other locations in England as well, notably Aldermaston), over 50\% are labelled "closed or retained document". This means they are either being held by the National Archives but are closed to public access, or have been retained by the AWRE. And this only includes documents that have been catalogued in the National Archives online "Discovery" database (http://discovery.nationalarchives.gov.uk/). Countless others are likely unlisted in this database and an even greater number would have been lost or destroyed before archivists could even learn about them.

Still, the declassified records one obtains from archives can be telling. For example, archival work allowed us to follow in detail the way in which authorities and planners practice disinformation. The congenital failures of secrecy are such that bureaucrats often need to revise and revisit obfuscating strategies throughout an operation's term. A by-product of this need can be written communications and "post-mortems" that, when archived and declassified, can provide invaluable insight to the researcher. Although much of the more "revealing" records on AWRE's presence on Orford Ness are not (yet) part of the public record, a large portion of those pertaining to Cobra Mist have been opened. From these archival records on Cobra Mist, we discovered the practice of "cover-storying" (Walters and Luscombe 2016; Luscombe 2018). More generally, we learned about the ways that military bureaucrats managed the burden and uncertainty of secrecy in the midst of an active operation. Practices of cover-storying involved high ranking Cobra Mist officials (from the UK Ministry of Defence and US Department of Defense) regularly debating, on a "need-to-know" basis, the best actions to take to keep the public disinformed about the station's actual purpose. To Cobra Mist officials, the operation was a future "over-the-horizon radar" to provide military intelligence and early warning about future attacks from the Soviets. To everyone else, it was to be nothing more than a benign radar research station. In our analysis, we also found that Cobra Mist officials from the UK - less so their American counterparts - seemed to be involved in a process of self-deception, continually re-convincing themselves that outside publics were still buying their various cover-stories (about it being a benign radio research station) despite this being generally untrue. As a result of the reporting of major journalists like Chapman Pincher, it would seem that many outside publics had accepted quite early on in the operation's history that "research" was only part but not all of the story.

In our research on the postsecrecy of Orford Ness, we also sought records from more local archives in municipal facilities throughout Suffolk and the collection of the National Trust. Using records from the latter, we reconstructed part of the planning and acquisition process. NT records showed that planners had articulated a formal "philosophy" of the place that was to guide its management. Here we found that a mood of secrecy and a sense of mystery had been identified from the outset as a value, almost a property of the site, which the NT seeks to respect and preserve as an aspect 
of heritage. Hence, we can say that secrecy at Orford Ness is not merely a holdover from its military days but an experience that is actively and aesthetically crafted in the present. The NT does this through a variety of measures. Some are formal and quite procedural. For example, it limits the numbers of visitors on the site at any one time, not just for environmental or safety reasons, but so each visitor can contemplate this aura of mystery with a degree of solitude and isolation (Wainwright 2009:Davis 2006). It also fosters a sense of secrecy through indirect means. For example, the NT sometimes allows artists and "bunkerologists" (Bennett 2013) to work on the site. Many of these actors interpret it as a secret place whether through the imaginative production of new soundscapes, images, poems, or films (Wilson 2006; DeSilvey 2014).

But this attitude of fostering an experience of secrecy at Orford Ness also materializes on the scale of localized interactions and narratives. In the summer of 2014 we joined a group of visitors taking a guided tour of the site. The tour was led by Grant Lohoar, long-time senior manager of Orford Ness. At the end of the tour, with a hint of mischief, he told the group he had woven at least one falsehood into his narrative. We were surprised to learn that this would not be formally revealed to us. In an interview Lohoar explained his practice. His view was that in the course of managing Orford Ness, the NT had accumulated much new information about its past. Nevertheless, neither research nor management should aim to uncover the entire "truth" of what happened at Orford Ness. Such an aspiration was doomed to fail given the practical obstacles it faces. But it was also, he averred, at odds with the history and identity of the place. Secrecy was an integral part of Orford Ness, a defining characteristic. For nearly a century legends and rumours had swirled around the island - rumours that were sometimes the product of official disinformation campaigns, but often the way in which locals tried to make sense of this prohibited place. Taussig (1999) distinguishes between exposure and revelation: the former destroys the secret whereas the latter does justice to it. Lohoar, it seems to us, stands much closer to the latter.

While archives can be invaluable caches of information on postsecret places like Orford Ness, in our case revealing to us the practices of cover-storying and key aspects of the NT's approach to public education and tourism, they are necessarily partial and incomplete. To stop at the archive would be to miss much of the deeper complexity and surrounding intrigue that continues to characterize Orford Ness today.

\section{Ufologists}

A second, less conventional, cache of information we found useful in our research on Orford Ness was the websites of ufologists and other independent investigators. ${ }^{5}$ Although often written off as "wacky" or "conspiratorial", from a methodological perspective they dig things up, things that can prove useful to non-UFO related scholarly research. ${ }^{6}$ To the extent that many UFO researchers rely on the same methods (e.g., archives, FOI) and data sources (e.g., government records) as academics to build and support their theories, they can become unwitting and unexpected sources of secondary data. In our experience, we have also found these researchers 
to be quite transparent in the ways they share secondary data. Often, as if to be taken more seriously, these groups seek to strengthen their claims and arguments through a process of record disclosure. In relation to Orford Ness, an active group of ufologists were responsible for releasing key texts from the American Pentagon using Freedom of Information requests in the 1990s. ${ }^{7}$ They believed that one of Orford's operations was tied to the Rendlesham Forest incident in 1980, Britain's most famous alleged UFO sighting (Heazell 2010). These original documents were posted online and became quite useful for us in our own research endeavours. Had we simply written these groups off as "coocoo" and not worth engaging with, we never would have scoured their webpages and found these important records from American military officials tied to the earlier discussed operation known as Cobra Mist.

We also stress that UFO researchers are not only a potentially valuable source of secondary data, but as effective and significant actors in their own right. If a perspective of postsecrecy entails being attuned towards the way secrecy effects are generated in the present, and are not merely a legacy of the past, then ufologists and allied researchers need to be taken seriously, no matter how conspiratorial their arguments may seem. Following the lines, translations, and associations through which a secret government operation becomes postsecret means taking earnestly the claims of every actor, including those typically labelled "conspiracy theorists" - and note how the very term effects its own hierarchy around the activity of social inquiry. Claims about government cover-ups of UFOs and other visits from extra-terrestrial life are one of the ways that secrecy is reincarnated and brought to life again in the present: they generate stories, rumours, mystery, and when the public record is thin, they have more room to breathe. When publics do not receive a convincing account of a secretive military operation, as they rarely did regarding the many events and developments on Orford, it is often such speculative hypotheses which fill this void. The void created by government silence is filled by conspiracies, speculation, rumours. Thus, even on tours of Orford Ness conducted by reasonable NT tour guides, ufological theory is still part of the narrative. It stands as a kind of marker that even though such theories may be far-fetched, they can become durable features of the postsecrecy landscape.

\section{BOX 3.2 QUESTIONS OF VALIDITY}

For researchers who are looking to uncover truths about a secret place, programme or incident, the testimony of veterans and the findings of ufologists would present various problems of validity. How reliable are these sources, they would ask. A study in postsecrecy is not confronted with the same concerns. While we adhere to key norms of social inquiry (e.g., to accurately record and report our findings), our task is not to uncover a singular, hidden truth so much as to document and interpret the ways in which actors are reanimating the secret in the present. You do not have to believe in God(s) to be a good researcher of religious life! 


\section{Veterans, memory, and place}

The oral histories of veterans provided a third source of data for our research on the postsecrecy of Orford Ness. When the NT opened Orford Ness to the visiting public it set in motion - perhaps only inadvertently - a feedback process that would gradually generate new information about this place. What was this process? It had everything to do with veterans and their stories, as well as the power of place to elicit and collate memory. NT officials and volunteers recounted to us that amongst the small groups of people who would visit the site during the summer months when it was open to the public, there were frequently former employees: veterans of Orford Ness who were revisiting their place of work. Discussions between these visitors and NT staff (and note that some of the staff were themselves veterans) enabled the NT to tap into memories, and recollections of social and organizational life at this "prohibited place". The NT enhanced this process by contracting several researchers to recruit further veterans via the internet, message boards, and snowballing. Often, as a form of outreach and recognition, they would be invited to visit Orford Ness and receive a tour. These researchers made audio, and sometimes video, recordings with the veterans. These recollections were, of course, complicated by the inexorable processes of ageing. The NT would carefully cross-check and triangulate information it received with other sources. What emerged was not a coherent picture but a "patchy landscape" (De Goede and Wesseling 2017: 256). But the process was important: if official information about key aspects of Orford Ness's military history and secret past was relatively sparse it could now be supplemented and enriched by this new channel that was yielding details and insight about the social life of the place.

NT staff had mentioned the existence of these recordings as well as their plan to make them public via the internet. ${ }^{8}$ To date, this has not happened. For some time we found it difficult to locate them - a fact that probably had more to do with organizational dysfunction than any conspiracy of silence (see also Belcher and Martin, this volume)! An important breakthrough in our research came when we made contact with one of these researchers, David Warren. Now in his midseventies, Warren had worked at Orford Ness as a scientific assistant, including a spell with Britain's experimental middle-range ballistic missile, Blue Streak. Later he pursued a career in industrial engineering. Upon retirement he became a volunteer "ranger" at Orford Ness. Warren made available to us 44 audio recordings he made with other veterans between 2013 and 2017.

This oral archive is valuable for at least three reasons. ${ }^{9}$ First, it offers insight about the social life of secrecy. If official archives document the plans and strategies of officials, the veterans' accounts offer something else: how it felt to undergo an intimidating security clearance process that targeted not just your own history but your family as well; the disorienting experience of working on a need to know basis; and how people negotiated the boundaries of the knowable and the sayable. In short, it offers insight about ways in which people can be active agents who 
navigate secrecy in their everyday lives and not just its instruments. Second, this archive captures the diversity of experiences of secrecy. The interviews draw on some very different social backgrounds and functions including typists, draftsmen, builders, film analysts, pilots, and senior aeronautical engineers. They reveal that experiences of secrecy are modulated by gender, race, class, and profession - a fact that is typically obscured whenever secrecy is imagined in homogenized spatial terms such as veils or walls. Capturing this diversity is one of the principal merits of engaging secrecy from the angle of place.

Finally, this archive is significant because the precise conditions of its production help to further illuminate our notion of postsecrecy. NT officials mentioned to us that veterans display a range of emotions when asked about the nature of their work at Orford Ness. Many were happy to volunteer stories about the social life of the place, if not its technical details. Some took the view they were in their twilight years now: what did they have to fear from the official secrets act! But others were very cautious about what they communicated, a caution that suggested that despite the passing of decades and the decommissioning of Orford Ness, the subjective hold of secrecy remained powerful. This seems consistent with scholarship that stresses the modulation of secrecy by social relations of loyalty, duty, and belonging (Simmel 1906; Ellsberg 2010) - an affective grip that is not surrendered lightly. Indeed, we should note that the interview is not a neutral device in this context. In probing people about their experiences it can reanimate the secret. Thus we should observe that research methods are themselves entangled in postsecrecy: in their quest to learn more about a secret past they are capable of generating new secrecy effects in the present.

\section{Conclusion}

Through the concept of postsecrecy we have argued in this chapter for an approach to the study of secret places that is: (a) attentive to the past and present lines and translations through which formerly secret sites enter a "postsecret" rather than "transparent" state of existence; (b) polymorphous in its engagement with diverse actors and data sources; and (c) resistant to any simplified binary reasoning that treats a place's secrecy and publicity as either/or, zero-sum games. To illustrate our argument we have used Orford Ness, in our view a quintessential postsecret place. During the Cold War, Orford Ness was a key testing ground for Britain's Atomic Weapons Research Establishment and home of the elusive Anglo-American radar intelligence operation known as Cobra Mist. Today, most of Orford Ness is owned and managed by the National Trust, who treat it as both a heritage site and a place of nature conservation. Yet to call Orford Ness and its numerous decommissioned military programmes "formerly secret" would be both overly simple and inaccurate. So too would it be naïve to set out to settle once and for all Orford's many persisting mysteries. Rather it is only in acknowledging a site like Orford Ness's postsecret orientation that a researcher is able to begin to navigate and make sense of its layered complexities. 
To conclude, we draw out four major lessons that can help guide researchers who encounter their own postsecret places:

1 Not all formerly secret sites are "postsecret" in the sense we have described. A postsecret site is one that is characterized by an ongoing state of discord and controversy between diverse actors (debating secrets, revelations, myths, etc.) and whose contemporary state does not neatly fit on either side of a secrecy/ publicity binary.

2 To research postsecret sites, we must opportunistically follow different actors and leads as they become available and engage in which Gusterson calls "polymorphous engagement". This means taking all actors and data sources seriously, no matter how seemingly "alien" to one's disciplinary outlook. Different actors provide different data sources on postsecret sites, but they are also often themselves active claims makers in the ongoing debates surrounding a postsecret place's continued secrecy. We saw this with Rendlesham Forest ufologists.

3 Management and ownership matters. It shapes the degree of access we can obtain as outsiders and the kind of information we can obtain from interviews, records, and site visits, and the ethos with which a place is managed.

4 Research on postsecret sites calls forth a unique kind of researcher reflexivity. To the extent that postsecret sites are caught in a perpetual cycle of debate and unsettled truth, any papers, books, reports, etc. produced by that researcher are not authoritative texts, as if generating the Final Word on the site's real purposes, functions, etc.; they are rather part of the ongoing story.

\section{Suggestions for further reading}

- Hugh Gusterson (1998) Nuclear Rites: A Weapons Laboratory at the End of the Cold War, Berkeley, CA: University of California Press.

- Paddy Heazell (2010) Most Secret:The Hidden History of Orford Ness, Stroud, UK: History Press.

- Trevor Paglen (2010) Blank Spots on the Map: The Dark Geography of the Pentagon's Secret World, New York: New American Library.

\section{Notes}

1 We acknowledge the significant contribution Seantel Anaïs made in conducting fieldwork with us at Orford Ness during the summer of 2014. This fieldwork was funded by SSHRC (430-2013-0327). We thank officials and volunteers at the National Trust for answering our questions and facilitating our fieldwork at Orford Ness, especially Grant Lohoar (Coast and Countryside Manager), Angus Wainwright (Archaeologist), and David Warren (Volunteer Ranger and Researcher, Orford Ness). We are grateful to the editors of this book for their suggestion and comments. Sarah Wade-West excelled in editing the manuscript, for which we thank her.

2 An archive can provide data for the study of postsecret places and programmes, but note that under particular circumstances the archive can become a postsecret place in its own right. For example, see Verdery's (2014) wonderful ethnographic account of the archive 
where many of the Romanian secret police's surveillance files are now kept and made available to researchers.

3 The official line is that weapons tested at Orford Ness did not include any fissile material (Wainwright 2009: 137; but see Cocroft and Alexander 2009: 22). Environmental testing included vibration and temperature trials; it sought to simulate the conditions bombs would face in storage, transport and operational use (Cocroft and Alexander 2009: 21-22).

4 The concept of "prohibited place" makes an early appearance in the UK Official Secrets Act (1911) and, the US Espionage Act (1917). As Galison (2010: 942) explains, the concept allowed sites like the naval dockyard, canal, camp, communication centre, etc., to be designated as sensitive so that any attempt to photograph, sketch or snoop on them would become punishable under law. The prohibited place, we might say, effected a particular territorialisation of secrecy, and secretization of territory.

5 We refer to this network of actors as "ufologists" rather than "conspiracy theorists" since the latter term is hardly neutral and rarely used by the actors themselves. Whereas it is used by others, but usually in ways that dismiss and delegitimize. See Moore (2016) for a useful overview of debates about "conspiracy theory", including the work that this act of naming performs in de/legitimating different forms of power analysis.

6 A parallel can be drawn here with planespotters. Although sometimes regarded as eccentric, their passionate activity nevertheless generates an exhaustive log of flight activity which, under particular circumstances, can prove an invaluable archive for other researchers. For example, it was from planespotters that journalists and other researchers gleaned vital information about the CIA's programme of extraordinary renditions (The Guardian 2005).

7 Pentagon documents were released using FOIA in the 1990s by the Computer UFO Network (CUFON), digitally transcribed, and made readily available on their website. Part one of the four-part disclosure of Pentagon records on Cobra Mist can be found here: http://www.cufon.org/cufon/cobramst.htm

8 A small number are held in the British Library. At the time of writing they are not digitized and thus only accessible following a somewhat lengthy request process.

9 This paragraph draws on Walters (under review).

\section{References}

Agnew, John (2011) "Space and place", pp. 316-330 in John Agnew and David Livingstone (eds) Handbook of Geographical Knowledge, London: Sage.

Bennett, Luke (2013) "Concrete multivalence: Practising representation in bunkerology", Environment and Planning D: Society and Space, 31(3): 502-521.

Bratich, Jack (2006) "Public secrecy and immanent security: A strategic analysis", Cultural Studies, 20(4-5): 493-511.

Cocroft, Wayne and Magnus Alexander (2009) Atomic Weapons Research Establishment, Orford Ness, Suffolk, Swindon: English Heritage.

Davis, Sophia (2006) Military Landscapes: Scientific Ruins and Cold War Monuments at Orford Ness, MPhil Thesis, University of Cambridge.

De Goede, Marieke and Mara Wesseling (2017) "Secrecy and security in transatlantic terrorism finance tracking", Journal of European Integration, 39(3): 253-269.

DeSilvey, Caitlin (2014) "Palliative ruination: Art and entropy on Orford Ness", pp. 79-91 in Bjørnar Olsen and Dóra Pétursdóttir (eds) Ruin Memories: Materiality, Aesthetics and the Archaeology of the Recent Past, New York: Routledge.

Ellsberg, Daniel (2010) “Secrecy and national security whistleblowing”, Social Research, 77(3): 773-804.

Forbes, Neil, Robin Page and Guillermo Perez (2009) Europe's Deadly Century: Perspectives on 20th Century Conflict Heritage, Swindon: English Heritage. 
Galison, Peter (2010) "Secrecy in three acts", Social Research, 77: 941-974.

The Guardian (2005) "How planespotters turned into the scourge of the CIA", 10 December, https://www.theguardian.com/uk/2005/dec/10/usa.terrorism1.

Gusterson, Hugh (1997) "Studying up revisited", PoLAR: Political and Legal Anthropology Review, 20(1): 114-119.

Heazell, Paddy (2010) Most Secret: The Hidden History of Orford Ness, Stroud, UK: History Press.

Hilgartner, Stephen (2012) "Selective flows of knowledge in technoscientific interaction: Information control in genome research", British Journal for the History of Science, 45(2): 267-280.

Historic England (2014) Orford Ness: The Atomic Weapons Research Establishment Test Buildings and Associated Structures, list entry number: 1416933, https://historicengland.org.uk/ listing/the-list/list-entry/1416933

Law, John (2004) After Method: Mess in Social Science Research, New York, NY: Routledge.

Luscombe, Alex and Kevin Walby (2017) "Theorizing freedom of information: The live archive, obfuscation, and actor-network theory”, Government Information Quarterly, 34(3): 379-387.

Luscombe, Alex (2018) "Deception declassified:The social organisation of cover storying in a secret intelligence operation", Sociology, 52(2): 400-415.

Melley,Timothy (2012) The Covert Sphere: Secrecy, Fiction, and the National Security State, Ithica: Cornell University Press.

Mezzadra, Sandro and Federico Rahola (2006) "The postcolonial condition: A few notes on the quality of historical time in the global present", Postcolonial Text, 2(1). https://www. postcolonial.org/index.php/pct/article/view/393/819

Moore, Alfred (2016) "Conspiracy and conspiracy theories in democratic politics", Critical Review, 28(1): 1-23.

Paglen, Trevor (2010) Blank Spots on the Map:The Dark Geography of the Pentagon's Secret World, New York: New American Library.

Sebald, Winfried Georg (1998) The Rings of Saturn (trans. M. Hulse), New York: NDP.

Sifry, Micah (2011) "In the age of Wikileaks, the end of secrecy?", The Nation, 21 March.

Simmel, Georg (1906) “The sociology of secrecy and of secret societies”, American Journal of Sociology, 11(4): 441-498.

Taussig, Michael (1999) Defacement: Public Secrecy and the Labor of the Negative, Stanford, California: Stanford University Press

Verdery, Katherine (2014) Secrets and Truths: Ethnography in the Archive of Romania's Secret Police, Budapest: Central European University Press.

Wainwright, Agnus (2009) "Orford Ness - a landscape in conflict", pp. 134-142 in Neil Forbes, Robin Page and Guillermo Perez (eds) Europe's Deadly Century: Perspectives on 20th Century Conflict Heritage, Swindon: English Heritage.

Walters, William (under review) "Everyday secrecy: Oral history and the social life of a top secret research establishment during the Cold War".

Walters, William and Alex Luscombe (2016) "Hannah Arendt and the art of secrecy; or, the fog of Cobra Mist", International Political Sociology, 11(1): 5-20.

Wilson, Louise (2006) "Notes on a 'record of fear': On the threshold of the audible", Leonardo Music Journal, 16: 28-33. 
Section II: Access, confidentiality and trust 


\title{
4
}

\section{NAVIGATING DIFFICULT TERRAIN}

\author{
Alexandra Schwell
}

- Research objective: This chapter seeks to guide researchers who conduct qualitative research in state agencies or other institutions that are characterized by bureaucratic secrecies. It aims at guiding researchers in how to identify, "read", and interpret the challenges and pitfalls in bureaucratic field sites (conceptualized as "difficult terrain"), and how to make them actually meaningful and productive in the research process.

- Research puzzle: What can we learn from the various ways in which agencies try to control our research, and how they react to us as qualitative researchers? How can we make such obstacles fruitful for research?

\section{Introduction}

The state is the primary research subject for political scientists, but in recent decades social and cultural anthropologists have increasingly developed an interest in the state, in politics and policies as well as in state bureaucracies, as valuable fields of research. They seek to understand how the state exerts an impact on everyday lives, and how society, culture, and the state reciprocally relate to each other. This endeavour is largely informed by Laura Nader's (1972) demand for anthropologists to not only look "down" to the margins of society, but to "study up", i.e. to also investigate the power-holders, the elites, to get a more comprehensive picture of how inequalities and asymmetries within contemporary societies operate.

Ethnography, with its focus on everyday lived experience, is particularly well suited to gain insights into everyday practices and discourses within bureaucracies and state agencies and the assemblages that they are a part of. This chapter seeks to shed some light on the difficulties that ethnographers and other field researchers are likely to encounter in the study of bureaucratic state agencies. While many of these difficulties are certainly also familiar to researchers in other settings, state agencies 
constitute a specific cultural and social space due to their bureaucratic structure and their self-image as representatives of the state. But state agencies do not only consist of piles of paper; they are populated by human actors with agency. It is a necessary precondition for ethnographic researchers to get acquainted with state structures, such as organization charts, official documents, and legal acts. However, state structures alone are not sufficient to understand how state agencies actually operate, what everyday life within state agencies looks like, and which power dynamics inform them.

In this contribution, I introduce the metaphor of the "difficult terrain" to illustrate the specific obstacles, challenges, and pitfalls that the ethnographer is likely to encounter in bureaucratic fields. Particularly, the agencies' inherent secrecy poses a problem for field access. Often, ethnographic and other studies tend to omit these difficulties in their written accounts. Implicitly, assuming that actual fieldwork only starts after field access has been accomplished.

In this chapter, I argue that it is misleading to perceive field access as either-or, in or out. Field access is a gradual process, and in bureaucratic settings, field access does not happen once and for all, but includes continuously working one's way. Negotiations for field access already constitute potential points of friction between researcher and field; as such they are highly significant and meaningful. Hence, challenges and pitfalls that relate to the features of "difficult terrain" are not simply obstacles, but contribute to the research process, and shape the way the field interacts with the ethnographer. More importantly, they point towards power structures, hierarchies and asymmetries, and political culture, all of which structure the field and the research process, but are difficult for the researcher to trace.

In the following, I draw upon my own ethnographic experiences researching German-Polish border police cooperation (Schwell 2008) and the Europeanization of security in Austrian and Polish state agencies (see, inter alia, Schwell 2010, 2012, 2016). First, I show that field access is already an integral part of ethnographic research. Second, I develop the metaphor of the "difficult terrain", and I argue that entering bureaucratic fields entails specific challenges. Subsequently, I explain in detail how the specificities of bureaucratic fields, and their inherent secrecy in particular, exert an influence on ethnographic field research. Finally, I argue that the slow but continuous and indispensable process of trust-building in the field is potentially able to reconcile bureaucracy and human agency.

\section{Approaching the field}

On the first pages of one of the most widely read anthropological essays, "Deep Play: Notes on the Balinese Cockfight”, Clifford Geertz (1973a) describes how he and his wife faced severe initial difficulties in establishing rapport with the locals on Bali. They felt almost invisible, he writes. Nobody wanted to talk to them. Only when the police cracked down on an illegal cockfight, which Geertz and his wife had planned to attend, things changed. Both instantaneously decided to run from the police, just like the Balinese did, instead of staying and producing their 
American passports. From that moment on, Geertz was accepted. It turned out that the locals all the time had already observed him and his wife very closely, and that they knew all about them and their research plans. Geertz uses the story of his field entry as a prelude to his thick description of the "Cockfight". The opening scene is a truly entertaining read, and allows us to picture Geertz as a clumsy American with a sense for self-mockery. However, little do we learn about what it means for Geertz's research and his relation to his Balinese interlocutors.

The "Cockfight" has been subjected to considerable critique, also with regard to the arrival story. Critics have argued that Geertz's primary concern is to perform the transition from "outsider" to "participant", and finally, to confirm his subjective ethnographic authority as someone who has actually been "there", in the middle of events. In fact, as Crapanzano argues, his

conventional tale of entry serves a deictic function [... . It gives the illusion of specificity when there is no specific temporal or spatial vantage point. It attests to the ethnographer's having been there and gives him whatever authority arises from that presence.

(Crapanzano 1986: 75)

More importantly for the purpose of this contribution: in the "Cockfight" actual analysis and interpretation seem to begin when access to the field has been accomplished, in other words, when "ethnographic authority" has been established. After the raid, the field is wide open, and Geertz is in.

Obviously, ethnographic field research is never easy; more often than not ethnographers face difficulties when they try to approach a field. Although the "arrival story" has almost become a subgenre of ethnographic texts, few authors make their problematic field access fruitful for their analysis and interpretation through reflection. William Foote Whyte's study "Street Corner Society" (Whyte 1993) is such an example. In this classic of sociological research, Whyte lets the reader follow the author's, at times awkward, attempts to establish rapport with people in Cornerville, and share his reflections on attempts that terribly, or ridiculously, went wrong. With the help of his informant Doc, Whyte learns from his failures by improving his strategies. In addition, these difficulties also teach him about the laws, power structures, and cultural patterns, which inform his field, and about the way, he himself is situated and perceived by his interlocutors. Whyte's account shows how access to a multi-faceted field is a gradual process where one door might lead to another door, but each of the doors might as well be locked or pose its own difficulties.

\section{Ethnography in "difficult terrain"}

Initially, ethnography, and more precisely, participant observation, have been conceptualized by anthropologists such as Bronislaw Malinowski and Franz Boas as a method to gather knowledge about social and cultural groups in geographically remote, isolated and 'manageable' field sites. However, border guard cooperation, 
Europeanization or Schengen enlargement are not exclusive to one specific group of actors or to one particular field site. Such fields are multi-sited and characterized by a complexity of different sites and overlapping layers, of a multitude of actors and agencies. Research in political fields often includes state agencies and bureaucracies, which at first tend to appear like monolithic blocks where little individual agency seems to take place.

Bureaucratic fields are surrounded by an aura of secrecy, which also limits possibilities for research. In effect, the ethnographic gaze behind the curtains of state agencies bears specific challenges for both research and reflexivity; here, "classic" field research is often hardly possible or can only take place under aggravated circumstances. As Hugh Gusterson notes, the method of participant observation, itself an integral part of ethnography's typical equipment, cannot be easily transferred to complex late-modernity organizations:

participant-observation was designed to facilitate the understanding of small, face-to-face societies [...] where a stranger could easily be absorbed into the flow of daily life and no one was likely to tell the anthropologist that he or she was on private property and should leave.

(Gusterson 1997: 115)

Many fields have equal or stricter practices of secrecy, such as the ones researched by Humphreys (1975) on impersonal gay sex in public places and Scheper-Hughes (2004) on organ-trafficking. However, in state agencies and bureaucracy-shaped places difficult access is already structurally engrained. For such field sites, I suggest the notion of the "difficult terrain": this metaphor is able to capture not only the specificities of the field itself, but also the challenges for the ethnographer to navigate within the field. Entering "difficult terrain", in a figurative sense, includes a process of exploration and orientation, of familiarization in an expedition into the unknown, but it also includes the danger of tripping hazards and sometimes even of booby traps. Similarly, Rolf Lindner describes unfamiliar field sites as "unsecured terrain" from which the ethnographer reports back home as a kind of "special emissary" (Lindner 1981: 55).

In this contribution, "difficult terrain" shall refer to research fields where access is difficult or obstructed, and where the accessibility problem is not a result of the field's geographical remoteness, but of the cultural patterns, power dynamics, and structures that inform it. In difficult terrain, the ethnographer needs to be able to rely on landmarks and guideposts for orientation, e.g. people and places that become familiar, and whose judgment can be a reliable source of knowledge. To navigate difficult terrain may lead to unbridgeable gaps and unsurmountable walls, the ethnographer may even end up in dead-ends. Difficult terrain is not clearly marked territory, but confusing and hard to assess. Figuratively speaking, the official map only marginally matches the actual terrain on the ground; it only provides the ethnographer with a generalized overview. Without guides, signposts, and sherpas, the ethnographer may end up wandering about aimlessly without ever actually 
arriving anywhere. Similarly, Merje Kuus in her research in the European quarter in Brussels experienced the small paths in the "analytical terrain" she was navigating while trying to keep her interlocutors interested in her research: "The risk of being consigned to irrelevance by departing from this terrain is high" (Kuus 2013: 124). It is vital to formulate one's research topic in a way that keeps informants' motivation up; otherwise the ethnographer ends up in a dead-end, and will not only get no information, but worse, will also not be recommended to other interlocutors.

While there are numerous fields that are reluctant in accepting ethnographers, difficult terrain in this chapter focuses explicitly on bureaucratic and bureaucracylike fields. Following Max Weber, bureaucracies are characterized by specific features: (1) They are subjected to a narrow and rationally based judicial system and (2) they are hierarchically structured. (3) Bureaucrats have received specialized training and (4) operate on the basis of documents. Finally, (5) their work is determined by general and impersonal rules (Weber 1978: 956-958). This ideal-type image of bureaucracy is contrasted by everyday routines, habits, and organizational cultures, which shape bureaucratic work and interactions with the public (Herzfeld 1992; Hoag 2011).

Bureaucratic fields put up formalized barriers for access. The bureaucratic features create a power asymmetry between the ethnographer and the field. This power asymmetry is based on an unequal distribution of knowledge and the power to formulate a "truth". Finally, bureaucratic fields have different levels of secrecy that can be applied formally and informally. Classifications of secrecy function as objectivizing criteria and measures of gradual exclusion.

\section{BOX 4.1 FIRST CONTACT - SITUATING AND BEING SITUATED}

When I first planned the fieldwork on the cooperation of Polish and German border guards, I was quite optimistic. Being a German citizen, I thought, should automatically open doors to "my" border police. The Polish border police, I suspected, would be much more difficult to approach. I could not have been more wrong. The local Polish border police were very open and simply asked me to write an official letter to the headquarters in Warsaw and to submit a preliminary interview guideline; also, I had to promise not to participate in undercover police operations. The German border police, on the contrary, dug their heels in. Unfortunately, I could not be granted access, the headquarters informed me without further explanation.

Following the advice of a local superior officer, who was very interested in my research, I tried my luck again and submitted a letter of recommendation from the president of my university. Only shortly afterwards was I summoned to the headquarters. The high-ranking officer who now stood between me 
and my research immediately came to the point. The agency had rejected my request, because they did not want me to write about the border guards' political opinions. He made it very clear that he thought nothing of his EastGerman border guards all of whom he, as a West-German, considered rightwing radicals. Now I, and my PhD thesis, would bring this fact to light, and this had to be prevented. However, since I had submitted a letter from a dear friend, things have changed. Hence, the agency had decided to reconsider its decision. Good luck and enjoy your research!

The German border police had turned out to be an unexpected "difficult terrain", building up high fences that were difficult for me as an outsider to understand. To obtain access was a process that made me think about both formal and informal features of the field I wished to study. Features that were inherent to the field itself, but also related to other contextual factors. On the one hand, the border police are a bureaucracy, characterized by a multitude and simultaneity of actors, rules, and regulations, including "office secrets" and a distrust towards the unknowing public. On the other hand, one officer's personal situatedness as an "imported" West-German overseeing former GDR citizens, brought to my attention a power asymmetry and hierarchy, which would play an unexpected role in my later research.

Numerous scholars have dealt with the question how difficult terrain can become an object of anthropological research. Roberto González's (2012) thoughts on how to conduct "anthropologies of the covert" focus explicitly on secrecy and inaccessible field sites. He is interested in the Department of Defence's Human Terrain System (HTS), a support programme that employed anthropologists and other social scientists to improve soldiers' knowledge of local populations ("human terrain") in the "War on Terror". In his attempt to approach the field, he has to face the fact that physical access to the Pentagon and HTS training facilities is impossible. As a result, he bases his research on the analysis of both official and, where possible, classified documents, budget reports, leaked material, websites, as well as interviews with anonymous informants who participated in HTS. Thereby, he acquires knowledge about the field without being able to set foot in it. González's work follows in the footsteps of Hugh Gusterson, who compensates the lack of field access by researching the field's larger context. Since his field, the US nuclear bomb program, proves entirely inaccessible, Gusterson suggests the concept of polymorphous engagement:

Polymorphous engagement means interacting with informants across a number of dispersed sites, not just in local communities, and sometimes in virtual form; and it means collecting data eclectically from a disparate array of sources in many different ways. Polymorphous engagement preserves the 
pragmatic amateurism that has characterized anthropological research, but displaces it away from a fetishistic obsession with participant observation.

(Gusterson 1997: 116)

Not being allowed into the field itself, Gusterson takes part in the everyday life of the "people of the bomb" who work within the Program. Thereby, he succeeds in contextualizing the program together with other data from different sources (Gusterson 1996).

Other scholars pursue the strategy of insider ethnography where they themselves become part of their research field in an attempt to minimize problems of access, or they begin research from their position within the field which, in turn, produces its own ethical and methodological dilemmas (see, inter alia, Mosse 2006; Neumann 2007; Stepputat 2012).

In all of these cases, the ethnographers faced challenges and pitfalls that potentially can become, or actually turned out to be, serious barriers for research. All of the scholars mentioned above were confronted with difficult terrain. Some found ways to enter and inched their ways forward, others chose to circumvent it altogether and approach the field through its context. It is important to note that each way has its merits. We learn about a field's logic, structure, and cultural patterns when we take a closer look at how the difficult terrain attempts to make itself inaccessible.

\section{Secrecy and the difficult terrain}

The concept of the "office secret" is the specific invention of bureaucracy, and few things it defends so fanatically as this attitude which [...] cannot be justified with purely functional arguments.

(Weber 1978: 992)

Contrary to intelligence services or other secret institutions or societies, agencies such as ministries or the police are not entirely secretive and inaccessible. Public access is possible in designated areas and is part of the agency's duties. Also, in many countries a legal duty for transparency exists regarding administrative and political decisions and actions. However, the state agencies' internal area is closed off from the public sphere. Only the results of the agency's actions or official statements are publicly visible, or only specifically designated controlling institutions can gain insight. This curtain of carefully crafted official statements is an important part of state agencies' structurally inherent secrecy, which not only guards against the public or critical media, but also against other agencies. As such, it is a precondition for power, since "every domination established as a continuing one must in some decisive point be secret rule" (Weber 1978: 952 [italics in original]).

Varying degrees of secrecy exists not only between the public and the agency, but also between agencies, and even between different departments within the same agency. The knowledge linked to secrecy functions as a binding factor, creating 
a sense of identity for those who are knowledgeable, separating them from the unknowing others (in most cases, the public). Such degrees of secrecy do not only fulfil an important function for collective identity and esprit de corps, they also secure room for manoeuvre and make the agency appear more opaque to outsiders. Within certain boundaries, the agency is free to define the limits of secrecy and nondisclosure and to limit access to people, sites, and documents. While a certain degree of classification and secrecy is certainly necessary to keep bureaucracies functioning, police and security agencies in particular, can easily resort to "office secrets", "matters of national security", and a generalized secrecy as a universal weapon against unwanted intruders such as ethnographers (also Box 4.2).

\section{BOX 4.2 OBSTACLES AND PITFALLS FOR QUALITATIVE RESEARCH IN SECURITY AGENCIES}

State agencies tend to use "security as a rationale for what they do and thus as a means of avoiding scrutiny whenever deemed useful" (Lippert et al. 2016: Art. 10). The authors identify three categories of obstacles and pitfalls for qualitative policing and security research:

1 Security spins serve to change the meaning of the research and divert perceptive damage from the organization by reframing and deflecting statements, observations and practices of security agencies: "These spins are an effort to manage identified reputational risks" (Lippert et al. 2016: 9).

2 Security stalls are intended to slow down the research process: "Stalls occur while negotiating access for information from policing/security agencies" (Lippert et al. 2016: 10). Security stalls serve to limit the risk, which researchers pose for an organization's reputation, at least temporarily. Thereby, for instance, only piecemeal information is given, field access permit is delayed or the ethnographer is put off or referred to other actors.

3 Security shutdowns mean a breaking off of the research: "Shutdowns mean a complete lockdown of information release and are permanent" (Lippert et al. 2016: 11).

Security stalls are probably the most familiar kind of obstacles for research in state agencies and bureaucratic settings (also Belcher and Martin, this volume). Superior officers or ministry officials justify their hesitation or refusal with reference to the chain of command or other internal hierarchies, to impersonal rules or to superior levels. Often, contradictory information cannot be verified, and the line between fact and narrative strategy cannot be clearly drawn. Patterns of action and decisionmaking structures operate on the backstage to which ethnographers often have no access, to which they are unable to react, or that are altogether unknown. 
Moreover, actors in bureaucratic settings often internalize and reproduce their agency's public image, and thus seek to avoid any insight into their individual perspective because they are afraid that it could endanger them. Mosse advises against taking these actors' self-representation for their own views:

Relying on informant self-representation and allowing subjects to speak in their own words are not self-evident solutions for anthropologists of public policy whose informants are officials $[. .$.$] or any group with a strong organi-$ zational need to produce and protect authorized views.

(Mosse 2006: 937-938)

In such cases, bureaucratic actors use a pre-formulated narrative as a barrier against unwanted intruders. It is all the more important for the researcher to use her networks and obtain knowledge through her informants in order to look behind the curtain of this PR strategy. Such knowledge does not only help the researcher to triangulate information, but can also be practically used in conversations with gatekeepers as a proof of competency (but see Box 4.3).

\section{BOX 4.3 SECURITY ANXIETIES - POSING A THREAT}

There is a fine line between proving competency and posing a threat. When I had almost completed my research on German-Polish border police cooperation, and had already published some articles, I decided to send these articles to the regional Polish and German headquarters. Sharing and discussing results with informants during, or after, completion of a project is a way to involve informants into ethnographic research and to meet ethical requirements (AAA 2012). Not long after I was summoned to the German regional border guard headquarter to meet the head of the regional district, whom I had never met before. On his desk I could see my articles, marked with neon yellow text marker and covered with post-its. He seemed very puzzled. He told me that he had read my articles with great interest, but he had only one question: "Did you send them also to the Poles?" When I confirmed, he seemed desperate: "Oh, that is bad, that is really bad. But," he turned to me, hopefully, "you sent them the German texts, right? Not a Polish version?" I confirmed, and his mood slightly improved. I asked whether I had gotten something wrong in my written accounts, whether there were any mistakes or flaws from his point of view. No, he said, in fact it was exactly how I presented it in my texts. All of the problems and frictions I described existed and were indeed of much concern to the border guards. However, in the official image that Poland and Germany sought to present, these frictions were not allowed 
to exist. Yet here I was, writing it all down and publishing it. When I asked the head of the regional district about the implications, he replied: "I can't censor you. I can't censor you. Let's just hope the Poles don't read it." I do not know how my writings impacted the political level of German-Polish border police cooperation. What I learned was that, as Clifford Geertz (1973b: 19) famously noted, the ethnographer writes social discourse down, but he also inscribes it. This representation travels beyond the realms of academia and acquires new meanings and impact - which is not necessarily in the interest of the agencies under research.

\section{Formalized and informal status}

Access to state agencies is regulated, highly formalized, and relies on bureaucratic responsibilities and chains of command. Both the limitation of access, and the possibility of access more generally, are instructive with regard to the institution's image of self and other. Generally, the "right" citizenship can be helpful, but not necessarily. As Gazit and Maoz-Shai (2010) describe for the Israeli military, their "right" citizenship certainly is a precondition in conflict zones (also Grassiani, this volume). In peace times, however, bureaucratic self-defence and secrecy guard the agency from its own citizens (see Box 4.1).

Gatekeepers regulate access, and they exist in all ethnographic research projects. Gatekeepers can operate both formally and informally. Formal gatekeepers are actors with the responsibility and the power to grant access, and it is vital to identify them. Importantly, in bureaucratic settings gatekeepers have to obey the rules of their organizations, but are still able to act at their own discretion within certain boundaries (Lipsky 2010). For the researcher, not only formal but also informal rules of access decide. Beek and Göpfert (2011) describe the tedious way to identify officials who would be willing and able to grant access to their research fields in polices in West Africa. In their experience, a researcher needs door-openers, guideposts, pisteurs - i.e. bureaucratic trackers and knowledgeable insiders who know how to navigate the complex bureaucratic networks and structures (Beek and Göpfert 2011: 195) - and parrains, godparents who are able to establish trust to the high-ranking officials in charge with the power to decide over access (Beek and Göpfert 2011: 198).

As bureaucracies, state agencies have to categorize the researcher and ascribe a meaningful role. Such a categorization is needed, both for the negotiation of access, and for the research itself, since formalized environments have a hard time dealing with "wild" researchers without any official role. Rules and routines serve to reduce insecurities and complexities, and to smooth processes; hence requests for research need to be integrated in such routines. My status in the Austrian ministry of the interior was that of a "trainee" ("Volontärin"). My "guides" in the ministry had suggested applying for this category since it was a status that the ministry knew 
and which was tied to certain rights and duties: trainees agree to write a text of personal choice within a certain amount of time at a place of their choice. Upon completion of the traineeship I received a certificate. I was highly interested in the trainee position, not only because it provided me with a bureaucratic category, but because it came with several privileges, such as a desk, an internal phone number and, most importantly, an internal status. These paved my way for getting in contact with ministry officials. A desk and a phone number meant I could call someone and have this call appear as "internal" on the other's phone display, which signalled belonging and guaranteed trust in advance. The role as trainee secured me an official insider status. The role of an ethnographer, in contrast, embodies the status of the official outsider, like during my research in German and Polish border polices. In the ministry, I would always inform my interlocutors during our first face-toface contact that I was not a usual trainee, but a trainee/ethnographer. By this time, however, I was already in their office and had overcome important obstacles.

A researcher's status determines how she is talked to and what kind of trust she is shown. While superior officers often fear PR damages for their organizations, on the level of the rank and file there is often mistrust and fear to suffer personal disadvantages. Potential interlocutors in bureaucratic organizations may fear drawbacks caused by unforeseen events, and "intruders" such as ethnographers. Torin Monahan and Jill A. Fisher perceive this as an opportunity to make such fears fruitful for research: "Understanding the more complex and multifaceted ways in which potential informants might perceive the threats of participating in research is helpful for successfully negotiating access" (Monahan and Fisher 2015: 720).

At the German-Polish border, with its clear hierarchies between street cops and management cops (Reuss-Ianni and Ianni 2005), interaction with me oscillated between treating me as an ally against the superior officers and suspecting me of spying for the management level. The amount of trust within agencies, and between street and management level horizontally and vertically, differed considerably. German border guards often welcomed my research because they hoped for someone who would communicate problems to the superiors, which they themselves felt they lacked the power to do. Many Polish border guards, on the other hand, were initially reluctant to talk because they feared serious repercussions from their superiors. Early in my research, one Polish border guard asked me whether my $\mathrm{PhD}$ supervisor was a military or a civilian, i.e. whether I would report directly to the border guard superiors. After this interview, I made it clear with all my interlocutors that my background was purely civilian and that no superior officer would ever be able to trace the origin of my material. To anonymize my material in my written account, I used fake names, I camouflaged border posts and cities or avoided mentioning them altogether, and I even changed genders, where appropriate. The latter was of particular importance due to the very low number of women in the border police force and the resulting high visibility. I explicitly explained this procedure in my written account, not only with respect to transparency, but also because its necessity sheds a light on the pressure that is being exerted on officials in state agencies at almost all stages of the hierarchy, and the fears that result from it. Actors in 
the field face a multitude of insecurities, ranging from the researcher disturbing the functioning of the organization and work routines, to the actual threat of being fired.

Class, age, nationality, and gender situate the researcher within the field and shape expectations. The ethnographer should also be aware that members of the field might have previous experiences with researchers, which shape expectancies that the ethnographer may be unaware of. Again, this is not specific to research in state agencies, and contrary to other fields, ethnographers do not have to fear for their bodily integrity. Philippe Bourgois, researching crack dealers in East Harlem, reports how one of his informants explains to him the way he is perceived by the locals:

Felipe, people think you're a fed (federal agent) if anything. But that's good; it makes them stay away from you. Think about it: If you was selling shit on the street and you see a white guy coming by, you wouldn't really want to bother with him. But then again, some people also think, "he's white and he's in the neighborhood, so he must be crazy." If they didn't, they'd just come up to you and crack you in the face and take your wallet.

(Bourgois 2003: 33)

The position of women who seek to conduct research in culturally male dominated environments is particularly interesting (see also Hoijtink, this volume). In my experience, in such settings actors consider women to be less threatening and tend to take them less seriously. Within the same vein of thought, Rebecca Horn argues that in the eyes of many police officers the stereotypical " "traditional woman" tends to be seen as harmless and unthreatening, and slightly incompetent. Beliefs in women's 'harmlessness' may allow them access to areas which are barred to male researchers" (Horn 1997: 300). This, in turn, has great effects on women researching the police. In my experience, to be seen as less threatening potentially increases access. In male-dominated environments, it is much easier for women to ask their male interlocutors to explain their daily work or how certain procedures or devices function. To engage in this patriarchal "game", at least temporarily, allowed to ease the asymmetry of me as an academic vs. the police officers who mostly had a working class, non-academic background. I do not intend to suggest that women researching the police should submit themselves to traditional stereotypes, but to skilfully play with their subjectivities and expectations in the field.

Interestingly, initially women in the border police force were much more reluctant to become part of my research. I interpret their reluctance in terms of an anxiety on their part that an association with another woman might emphasize their categorization as "feminine" and simultaneously weaken their authority, thus endangering a professional status and symbolic capital they had very much worked for. The few women I worked with only opened up when they could be sure that I would not give their colleagues a reason to feminize them (again).

Generally, for my interlocutors at the German-Polish border, the categorization as "PhD student" was an unclear and hardly threatening position. This title was definitely better than being a "real" academic or, worse, a member of the press. The 
rank and file were interested, if at all, in the "why" of my research and how society would profit from it (and prospective researchers are advised to prepare themselves for a short and convincing reply). However, most would perceive my project and anthropology in general as an intellectual exercise with little or no relevance for the world outside academia. Hence, not only is the researcher allocated an official status within the bureaucracy, she needs to clearly communicate this status with her interlocutors and how she is situated with regard to the agency. Furthermore, she is also ascribed an informal status within the field, which situates her and her interlocutors reciprocally.

\section{The power of documents}

Bureaucracies operate on the basis of documents, they are paper-based. Beek and Göpfert distinguish between "ground work" and "paper work". The latter denotes how a request for research is dealt with in terms of documents and files, while the former means the way social contacts and informal networks are mobilized. Bureaucratic work, they argue, entails both modes of work, they are however differently valued depending on the situation (Beek and Göpfert 2011: 191).

During my fieldworks I carried my "official permit" with me like a pennant. It was supposed to assure my interlocutors that I was not "illegal", but also that they would not get into trouble by talking to me. In the Austrian ministry of the interior I learned that it is not only the confirmation and the standing instructions that exist by themselves and function as door-openers. Their relevance was reinforced by the "file" that was opened about me. I never came to see the file, which probably does not exist on paper but electronically. Yet over time, I learned to counter people who doubted my legitimacy within the ministry by referring them to the existence of the file. I do not know who actually checked whether my file existed and who wrote something in the file. It was only this collection of data and categorization within a bureaucratic system, this bureaucratic fetish, which made my existence as a person in the ministry become real (Hull 2012).

Since I was able to prove my rightful being in writing and was able to refer my informants to the "file" and a specific person or personified agency ("the headquarter", "the cabinet"), my interlocutors absolved themselves from the responsibility of deciding whether to talk to me or not. During my research stay at the Austrian ministry, there were clear rules about what I was allowed to see and what not. Within "my" department, a rule of thumb applied: I can do anything but participate in the weekly staff meeting. Thus, the formalities were being satisfied. However, I saw and heard many things that took place, or were said, in not explicitly forbidden or non-regulated spaces. Hence, this clear regulation had a quite paradoxical effect in practice: if something (my presence, a conversational topic) was not explicitly prohibited by the rules, then it was automatically permitted, as long as it did not leave any traces.

Traces were to be avoided. Such traces would e.g. be located in documents - like a note in a file or an email coming from an interlocutor. However, traces of my 
fieldwork could also affect the research situation itself. Interestingly, in the Austrian ministry, officials often guarded against all eventualities and double-checked my status. Lacking a strict chain of command, which would allow them to delegate responsibility, ministry officials took care not to make themselves internally vulnerable by talking to me. Not only did they ask about my formal status and my permit, but often they also asked whom I had already talked to before they decided to open up - or not. I learned that only carefully cultivated and far-reaching networks allow for a certain, yet temporal invulnerability. This research showed me that bureaucracies are inhabited by individuals - and individuals do not always act rationally and impersonally. The agency is characterized by a permanent ambivalence oscillating between conformity and subversion. The structures that operate as barriers against external researchers are part of a much larger and institutionalized reciprocal mistrust.

Finally, I want to point towards the importance of trust for fieldwork in bureaucratic settings. After several months in the Austrian ministry, having overcome the external border and slowly making my way inside the agency, the trust that I had accumulated, and which was granted to me as an ethnographer, proved to be even transferable to agencies in other countries. Bureaucratic secrecy and mistrust towards internal and external "opponents" coexist with the enormous importance of official and unofficial networks. Policing and security agencies foster internal, but also transnational, semi-informal networks to ensure flexibility and capacity to act (Schwell 2008). Since I had planned to continue my research in the Polish ministry of the interior, I asked the Austrian officials for contacts. This cross-border help did not explicitly follow the chain of command, but happened un-bureaucratically through personal contacts and networks. The trust that had been invested in the ethnographer, extends to other bureaucratic actors, as a kind of leap of faith, which in my case even crossed international borders.

\section{BOX 4.4 PRACTICAL TIPS FOR ETHNOGRAPHERS ENTERING DIFFICULT TERRAIN}

- $\quad$ First, contact middle- and low-ranking members of the organization you wish to study to gather knowledge about the field and its problematic, the relevant gatekeepers, formal and informal networks, and its dos and don'ts.

- Build your own network of valuable informants, which will be helpful to establish trust when establishing rapport throughout your research.

- With the help of your informants, identify gatekeepers, mostly senior and high-ranking officers, who are formally able to grant access and choose the appropriate way to apply for access. 
- Try to anticipate the agency's self-defence mechanisms with regard to secrecy and reduce insecurities by carefully considering how you and your research appear to the agency. Do not let yourself be considered as a threat to the agency.

- Acquire a formal status but be aware of the informal status ascribed to you.

- As a qualitative researcher, you do not only work with an agency, but with individuals within that agency. Think about how you and your interlocutors are socially and culturally situated, how this positioning frames your, and their views on the world, and how mutual perception and expectations frame your interaction.

- Write field notes after every interaction within the field. These will help you to discover hidden and less salient, but influential ways of how power operates in the field.

\section{Conclusion}

Field access in state agencies is a gradual process. It does not happen once and for all, but each new group, department, part of the agency, and actor requires the ethnographer to establish trust anew. In addition, the researcher constantly needs to expand her knowledge about networks, alliances, and enmities. Godparents, trackers, and door-openers are not only helpful but indispensable along the way. The ethnographer needs to look out for landmarks and guideposts for orientation, but she can also at any time in the research process be confronted with insurmountable barricades, dead ends, or find herself carefully navigating between landmines.

Navigating the "difficult terrain" of state agencies can be challenging, but it is these challenges and pitfalls that teach us about the field sites we are researching. Far from being simply nuisances and annoyances, the continuous search for access in bureaucratic and potentially secretive settings is already an integral part of fieldwork itself. In difficult terrain, sometimes unexpected doors open and pathways appear. State agencies are bureaucracies, and as such they are secretive, difficult to access and to navigate. Nevertheless, they are populated by human beings. Officials in state agencies are not rational(istic) and soulless recipients of orders, but subjects who engage with each other and the ethnographer under the specific conditions of their agency. Ethnography needs to reflect these conditions and make them fruitful for analysis.

\section{Suggestions for further reading}

- Josiah McC. Heyman (2004) “The Anthropology of Power-Wielding Bureaucracies", Human Organization, 63(4): 487-500.

- Michael Lipsky (2010) Street-Level Bureaucracy: Dilemmas of the Individual in Public Services, New York: Russell Sage Foundation. 
- Susan Wright (2011) "Studying Policy: Methods, Paradigms, Perspectives", pp. 27-31 in Chris Shore, Susan Wright and Davide Però (eds) Policy Worlds: Anthropology and the Analysis of Contemporary Power, New York; Oxford: Berghahn.

\section{References}

AAA (2012) "Principles of professional resposibility", AAA Ethics Forum, American Anthropological Association, http://ethics.americananthro.org/category/statement/, last accessed 09.01.2019.

Beek, Jan and Mirko Göpfert (2011) “'Ground work' und 'paper work': Feldzugang bei Polizeiorganisationen in Westafrika”, Zeitschrift für Ethnologie, 136(1): 189-213.

Bourgois, Philippe (2003) In Search of Respect: Selling Crack in El Barrio, Cambridge; New York: Cambridge University Press.

Crapanzano,Vincent (1986) "Hermes' dilemma:The masking of subversion in ethnographic description", pp. 51-76 in James Clifford and George E. Marcus (eds) Writing Culture. The Poetics and Politics of Ethnography, Berkeley; Los Angeles: University of California Press.

Gazit, Nir and Yael Maoz-Shai (2010) "Studying-up and studying-across: At-home research of governmental violence organizations”, Qualitative Sociology, 33(3): 275-295.

Geertz, Clifford (1973a) "Deep play. Notes on the Balinese cockfight", pp. 412-453 in Clifford Geertz (ed.) The Interpretation of Cultures, New York: Basic Books.

Geertz, Clifford (1973b) "Thick description: Toward an interpretive theory of culture", pp. 3-30 in Clifford Geertz (ed.) The Interpretation of Cultures, New York: Basic Books.

González, Roberto J. (2012) "Anthropology and the covert: Methodological notes on researching military and intelligence programmes", Anthropology Today, 28(2): 21-25.

Gusterson, Hugh (1996) Nuclear Rites: A Weapons Laboratory at the End of the Cold War, Berkeley; Los Angeles; London: University of California Press.

Gusterson, Hugh (1997) "Studying up revisited", PoLAR: Political and Legal Anthropology Review, 20(1): 114-119.

Herzfeld, Michael (1992) The Social Production of Indifference: Exploring the Symbolic Roots of Western Bureaucracy, Chicago; London: The University of Chicago Press.

Hoag, Colin (2011) "Assembling partial perspectives: Thoughts on the anthropology of bureaucracy", PoLAR: Political and Legal Anthropology Review, 34(1): 81-94.

Horn, Rebecca (1997) "Not 'one of the boys': Women researching the police”, Journal of Gender Studies, 6(3): 297-308.

Hull, Matthew S. (2012) "Documents and bureaucracy", Annual Review of Anthropology, 41: 251-267.

Humphreys, Laud (1975) Tearoom Trade: Impersonal Sex in Public Places, New York: Aldine.

Kuus, Merje (2013) "Foreign policy and ethnography: A sceptical intervention", Geopolitics, 18(1), 115-131.

Lippert, Randy K., Kevin Walby and Blair Wilkinson (2016) "Spins, stalls, and shutdowns: Pitfalls of qualitative policing and security research", Forum Qualitative Sozialforschung 17(1): Art. 10.

Lipsky, Michael (2010) Street-Level Bureaucracy: Dilemmas of the Individual in Public Services, New York: Russell Sage Foundation.

Lindner, Rolf (1981) "Die Angst des Forschers vor dem Feld. Überlegungen zur teilnehmenden Beobachtung als Interaktionsprozeß”, Zeitschrift für Volkskunde, 77: 51-66.

Monahan, Torin and Jill A. Fisher (2015) "Strategies for obtaining access to secretive or guarded organizations", Journal of Contemporary Ethnography, 44(6): 709-736. 
Mosse, David (2006) “Anti-social anthropology? Objectivity, objection, and the ethnography of public policy and professional communities", Journal of the Royal Anthropological Institute, 12(4): 935-956.

Nader, Laura (1972) "Up the anthropologist - perspectives gained from studying up", pp. 284-311 in Dell Hymes (ed.) Reinventing Anthropology, New York: Pantheon Books.

Neumann, Iver B. (2007) “"A speech that the entire ministry may stand for,' or: Why diplomats never produce anything new”, International Political Sociology, 1(2): 183-200.

Reuss-Ianni, Elizabeth and Francis A.J. Ianni (2005) "Street cops and management cops: The two cultures of policing", pp. 297-314 in Tim Newburn (ed.) Policing: Key Readings, Cullompton:Willan.

Scheper-Hughes, Nancy (2004) "Parts unknown. Undercover ethnography of the organstrafficking underworld", Ethnography, 5(1): 29-73.

Schwell, Alexandra (2008) Europa an der Oder: Die Konstruktion europäischer Sicherheit an der deutsch-polnischen Grenze, Bielefeld: transcript-Verlag.

Schwell, Alexandra (2010) “The Iron Curtain revisited: The 'Austrian Way' of policing the internal Schengen border”, European Security, 19(2):317-336.

Schwell, Alexandra (2012) "Austria's return to Mitteleuropa: A postcolonial perspective on security cooperation", Ethnologia Europaea, 42(1): 21-39.

Schwell, Alexandra (2016) "When (in)security travels: Europeanisation and migration in Poland", European Politics and Society, 17(2): 259-276.

Stepputat, Finn (2012) "Knowledge production in the security-development nexus: An ethnographic reflection", Security Dialogue, 43(5): 439-455.

Weber, Max (1978) Economy and Society: An Outline of Interpretive Sociology, Berkeley; Los Angeles; London: University of California Press.

Whyte, William Foote (1993) Street Corner Society: The Social Structure of an Italian Slum. Chicago; London: University of Chicago Press. 


\title{
ACCESSING LIFEWORLDS
}

\section{Getting people to say the unsayable}

\author{
Jonathan Luke Austin
}

- Research objective: This chapter aims to help researchers focused on gaining a lived, everyday, personal, and/or intimate understanding of the lives of those operating in secretive environments.

- Research puzzle: Gaining access to secretive environments is complicated in and of itself, but getting 'close' to those working in these areas and understanding the complexities of their personal worlds is often a doubly difficult task.

\section{Introduction}

We all have secrets. More than this, there are things we know that are secret even to ourselves. As Polanyi $(1983,4)$ put it, we always know more than we can tell: there are things we can't articulate to ourselves. Sometimes this is because these things are too mundane to ponder: crossing roads, queuing in lines, making dinner, or other such things. Other times, this is because these happenings are disturbing to any secure sense of self, consciously or not. Alternatively, it's because - quite simply - people are not allowed to tell us what they know. Accessing these secrets has long been, however, an important goal of social science. And for students of Critical Security Studies (CSS) this is especially true. The things we want those we speak with to describe are things they themselves are often unable to articulate beyond repeating the party line again and again (see Pouliot, 2008; Damasio, 2012).

In this chapter, I offer practical advice on how researchers can access these secrets, drawing on my own research speaking with perpetrators of torture. That research focused on understanding the 'lived' experience of harming human bodies: how a 'normal' person, just like you or me, came to be able to carry out these tasks and, more than that, justify and live with them. The chapter aims to help researchers, however, who are hoping to inquire into any secretive domain. Specifically, it is focused on scholars of CSS seeking to gain access to the 'lifeworld' of 
particular individuals or groups that are difficult to approach. The concept of the 'lifeworld' is a complex philosophical and sociological one (Schutz and Luckmann 1973). However, at the most basic level it refers quite simply to the everyday and 'lived' experience of individual human beings as they go about their days and, in particular, to how they experience this world without reflecting on it or analyzing it after-the-fact.

The challenges in accessing lifeworlds are multiple. The biggest difficulty is that every individual - including you and I - finds it very difficult to articulate even to ourselves the content of that world. While we can all construct an 'autobiographical' narrative of our lives (born here, went to school here, worked here, etc.), this narrative is very distant from the emotional, affective, and experiential content of our lives which rarely fits into a neat biography but is, instead, messy, non-coherent, non-rational, and non-reflexive (Damasio 2012). For researchers seeking 'micro' level insights into secretive domains, however, accessing these lifeworlds can be crucial. While it is always possible to approach particular places, phenomena, or people through alternative means (secondary documentation, structured interviewing, etc.), these approaches tend to miss a granular understanding of the improvisation, confusion, emotional valences, and other more 'subjective' qualities of life as it is experienced. For example, while it is possible to trace a prosaic, strategic, and/or institutional biography of the actions of George W. Bush that led him to invade Iraq, what more might we learn if we were able to uncover, say, his emotional and affective states at the time he made that fateful decision, or if we could ascertain the unconscious influence of popular-cultural processes of demonizing Iraq and the Middle East more broadly on his decision-making? It seems likely that learning more about the lifeworld of figures like Bush would reveal surprising new insights and that these insights would relate not only to the life of this one individual, but also to the broader societal structures (social, racial, gendered, religious, etc.) in which their experiences are inevitably embedded.

My goal here is to show how we can gain such insights by providing the reader with three concrete methods. These methods will be applicable to researchers drawing on several different theoretical approaches. Those employing practice theory (Adler and Pouliot, 2011), for instance, will find advice on how to help their subjects articulate the micro contents of everyday practices. By contrast, those drawing on Science and Technology Studies (STS) inspired approaches will be most concerned with how these methods allow researchers to appreciate the 'inter-twined' nature of the human and the non-human at different socio-technical levels (Bueger and Gadinger 2015). In addition, researchers interested in emotion or affect related tools will find advice on how they can move interviewees beyond a more rational and/or reflexive accounting of their actions towards an appreciation of these psychologically distinct processes (Fattah and Fierke 2009). Beyond these specifics, however, all these methods are designed to aid researchers who plan to conduct some form of fieldwork during their research, meaning - at a minimum - that they will seek personal contact with individuals who have personal or professional knowledge of the particular social domain that is their subject of interest. 
I begin now by discussing the importance of 'deep hanging out' and 'selfforgetfulness' in creating the time and space to do justice to the lifeworlds of respondents. This is followed by a discussion of the importance of employing a 'nonjudgemental' method in carrying out CSS research of this kind in order not only to build trust and rapport with those we are speaking to, but also to always appreciate the ethically fraught position of CSS researchers themselves. I conclude with a discussion of ethnographic interviewing, which is described as an interviewing methodology able to get us as close as is possible to the participant-observation of secretive domains. Throughout my discussion of these methods, I highlight both practical and political problems with their use, in order to forearm the researcher against possible criticisms, problems they will likely encounter, and ways around them.

\section{Deep-hanging out and self-forgetfulness}

One of the main difficulties in accessing the full breadth of the lifeworlds of those we come into contact with is simple: time constraints. Any research project has limits on its scope and decisions thus have to be made about what is feasible and what is not. More than this practical issue, however, it is noticeable that - for a while now - there has been a trend across qualitative methods in particular to "mobilize the standards of scientific method" that are more normally attributed to quantitative approaches (Aradau and Huysmans 2019). As Jef Huysmans and Claudia Aradau (ibid.) have described, this often results in qualitative researchers stressing the breadth of their work, specifying the (often large) numbers of interviews conducted and/or (typically extensive) time spent in the field.

Accessing lifeworlds requires, however, that this push for standards (of one sort or another) be rethought. While standards can be useful, they risk becoming a straitjacket preventing certain research endeavors, particularly where they militate against the possibility of engaging 'slower' or 'deeper' research strategies (c.f. Stengers, 2017). For example, accessing lifeworlds demands the researcher to dedicate considerable time to this task and, in particular, a willingness to employ the highly time-consuming research strategy known as 'deep hanging out' (Geertz, 1998). This refers to the process of immersing oneself in the world of an individual or set of individuals by, say, embracing meandering (and frequently non-research related) conversation, learning and mimicking the rituals of respondents, and participating in their everyday activities. This method is typically an anthropological one and not common to scholars working within the research standards of CSS. Indeed, as much of this volume demonstrates, methods like these require revision if they are to be integrated into CSS (c.f.Vrasti, 2008). This includes, for example, developing an understanding of how this intensely 'micro' level method can be 'scaled up' to produce a broader understanding of security (c.f. Marcus, 1995).

Deep hanging out is important, first, in order to build trust and rapport with those you are studying. As has long been debated in anthropology, establishing such rapport is always a "fluid, unique, and political" process beset by ethical difficulties (Sherif 2001, 446). In spite of this, gaining some sort of rapport through the direct 
participation in aspects of our informant's lives is crucially important in enabling our interlocutors to 'say more' than they would to a total stranger, as the final section of this chapter on interviewing will soon discuss in more detail. Beyond such trust-building, however, deep hanging out is important because it situates the story of one individual's life in context. Rather than only talking to an individual within a relatively artificial interview setting (though there is usually great value, in fact, in also carrying out such interviews), engaging in deep hanging out allows the researcher to connect their words to specific places, other people or groups, the tools they employ on a daily basis, the material infrastructures that structure their lives, and so on. In doing so, the 'world' of their 'lifeworld' becomes an integral and active part of the researcher's accounting of that person's life.

\section{BOX 5.1 POSITIONALITY AND ACCESSING LIFEWORLDS}

The methods of deep hanging out and self-forgetfulness are often highly contingent on your own positionality as a researcher. For example, my own hanging out in relatively 'rough' cafes in Beirut would be much more difficult for a woman to achieve given the gendered norms of these cafes (they are almost entirely male). Likewise, race often substantively limits a researcher's access, as does sexuality, social class, and beyond. In cases like these the researcher may find themselves frequently not being allowed to 'forget themselves'. Such dynamics can often be interesting for your research findings, however: exploring why you may have been treated differently (for better or worse) to a white, male researcher, for example, is in itself a component of the lifeworlds of those you are studying. Secrets are revealed differently to different people, put simply. Some researchers will have more power than others to carry out such research, power that - in fact - may even be coercive over those we are interacting with, especially vulnerable communities. It is therefore incumbent on researchers to reflect on these issues in full both before, during, and after their research project. For further discussions here see Grassiani (this volume) and Hoijtink (this volume).

Now, it will be obvious that deep hanging out is difficult to achieve for CSS researchers, especially those preoccupied with sensitive or secretive domains. This is a problem, however, wherever the method is used. For example, the gender or race of a particular researcher is likely to dramatically affect her capacity to 'hang out' with significant segments of society in, say, Saudi Arabia, military organizations, and beyond (see Box 5.1). More prosaically, language skills and social preferences will often dictate how feasible this approach is. Specifically, to many of the domains of interest to CSS, further problems emerge. In many cases, we simply cannot physically 
gain access to the sites that interest us: military installations, corporate meeting rooms, warzones, etc. Nonetheless, deep hanging out can be employed by CSS researchers, albeit with several modifications. Achieving this requires also engaging in what I term a type of self-forgetfulness. This refers to a temporary abandonment of social scientific inquiry, strictly defined. To simplify, the goal is to 'forget' whatever research plan you may have devised prior to your fieldwork and to accept the fluidity not only of your research findings but also whom precisely you will meet, and where you will end up meeting.

This act of self-forgetfulness is important because it loosens our understanding of who and/or what is a relevant subject of inquiry for our research. For example, in Box 5.2 I describe how some of my initial research encounters with perpetrators of torture began unpredictably via a haphazard encounter with a man in a café that I knew was regularly frequented by Syrian refugees. The possibility of this encounter only emerged because, beyond seeking to visit places I know Syrian refugees patronized, I did not A) seek out/focus on specific individuals to contact, B) consider it a 'waste' of research time to while away my hours in cafes, and C) stick rigidly to my initial research design in carrying out fieldwork activities. Deep hanging out in this context thus refers not to what occurs after we gain access to a particular social field but what must sometimes occur in order to gain a limited degree of access. And here, the process of gaining access thus often becomes intrinsic to research analysis itself.

\section{BOX 5.2 ACCESSING THE LIFEWORLD OF TORTURERS}

In 2015, I met a man named Ali in a little café in the Beiruti suburb of Daoura that attracts Syrian refugees who smoke nargilla (shisha) and drink sweet tea. I had been frequenting the café for some months. Another man I had come to know well there, bonding over a shared appreciation for apple-flavored nicotine, eventually introduced me to Ali. After a few weeks of intermittently getting to know each other, Ali began telling me stories of his time in the Syrian army. Nothing special at first. Eventually, however, he revealed he had served as a guard of an improvised detention center in Homs. And a little while after that he told me that he had not just been a guard but had also, and quite regularly participated in torture. Our conversations skirted around this subject for a few weeks before I finally asked if Ali would speak to me about it more fully. He accepted, and we came to meet (with others both in Beirut and my home institution aware of my whereabouts) often in his fifth-floor apartment building to discuss, step-by-step, how he tortured bodies during the Syrian civil war.

One day, I was asking Ali to lay out for me the practical contours of a torture technique known in the Middle East as the falaqa, which involves immobilizing 
a victim on the floor and raising their feet in the air before the soles of the feet are whipped. In many Middle Eastern countries, the use of this technique is especially unusual because a rifle - typically a Kalashnikov variant - is used to immobilize the feet. The rifle is used as a kind of 'stick' onto which the feet can be bound, before being held up on either side by two figures, whilst a third whips them. My interest was in discovering how the rifle had come to be used for this purpose. Ali's response to this question was simple:

It just works. It's there and you know how to use it. It's an easy tool.

As I pressed him to expand, Ali became frustrated. He got up suddenly and left the room. I was annoyed with myself at this and thought the interview was over. Perhaps I hadn't developed enough of a rapport? But before that thought was over, Ali had returned. He was holding an AK-47. This was surprising, to say the least. Sensing my apprehension, as my eyes snapped to the rifle, he laughed and said "Don't worry ya akhi [my brother]." Grinning, and with a cigarette in his mouth, he then pointed the rifle at me and conducted a brief mock execution. The firing pin pinged and he burst out laughing:

\section{Pow, Pow, Pow!}

I was confused. Soon, however, Ali was passing the rifle to me. The first thing you notice about a rifle, if you are not used to holding one, is how heavy it is. Promptly, my arms drooped under its weight and the barrel came to point at the floor. At this, a sense of embarrassment came over me: half a general wish not to look inept and half a kind of masculine desire to look like the kind of man I was talking to. Not to look too weak. Without thinking, I thus shifted my legs a little wider, and my shoulders upright, and tensed the tendons in my arms as I swung the rifle upwards, shifting the stock into the correct position against my shoulder, grabbing the pistol grip with my right hand, placing a finger swiftly around the trigger, and gripping the hand guard with my left hand. I surprised myself with this. There was surely much wrong with how I was holding it but I looked far more competent than I had a moment ago. And this had happened in a split second, automatically, and preconsciously. My arms, my muscles, and bones - my body - just moved into this position. Ali laughed again and, hardly impressed, remarked:

\section{Counter-strike, huh?}

His reference was to a popular 'First-Person Shooter' (FPS) video game that I had, indeed, played as a child. His implication was that I had learned to hold a rifle from popular cultural referents, rather than direct engagement in this 
practice. And he was certainly correct. From this brief collective enactment of the moment of torture, Ali later continued:

You see how good this tool is? It tells you what to do? Once you've played a game or seen it on TV or something . . . that's how it works. Even for you!

Here, Ali was forcing me, as researcher, to recognize how close our knowledge of violence was. He was forcing a self-declaration within me that blurred the boundaries between perpetrator and non-perpetrator, researcher and subject, and he did it quite deliberately. It seemed, in his particular case, that my use of ethnographic interviewing techniques was teaching me more about myself than about him.

Beyond gaining access, self-forgetfulness and deep hanging out are important for allowing greater 'texture' to enter into the researcher's understanding of the world. If a researcher was to, say, gain access to a specific list of individuals of relevance to their study (ex-intelligence agents, ex-torturers, border guards, etc.), and then to proceed solely to contact and interview these individuals, then much would be missed. Why? Because, most obviously, researchers who participate in deep hanging out, if only minimally, will slowly build-up a fuller picture of the interactional tendencies of individuals working in these social fields, the 'face-work' (i.e. attempts to present oneself in a particular way) intrinsic to these scenes (Adler-Nissen 2014), as well as much more. These 'textural' insights into an individual's lifeworld are not, moreover, incidental to questions of secrecy. By appreciating how near-enough any 'secretive' domain is also always partially 'open' to the everyday world, we undermine the idea of secrecy and/or secrets as operating within a 'closed' domain that is inaccessible (Walters forthcoming, also this volume). Instead, it becomes clear that the borders to these secretive worlds are porous. Of course, precisely which aspects of the 'texture' gained through the methods of self-forgetfulness and deep hanging out become relevant to the analytical phase of research (i.e. 'writing up' of our findings) will depend on the questions being posed as well as - to some degree - chance.

\section{Self-declaration and the suspension of judgement}

When researchers are seeking to access the specifically 'secret' world of any group then there is a stronger than usual temptation to be highly suspicious, judgmental, and paranoid in speaking to those we are interested in. For example, in their studies of Brazilian torturers, Huggins et al. $(2002,55)$ write that "even to merely secure accounts about a policeman's violence, and especially to go beyond them into his 
more deeply held secrets, the interviewers had to engage in espionage." For them, this research 'espionage' involved deliberately manipulating interview situations in order to 'depose' (using a legal metaphor) their respondents (by building and then, yes, breaking trust in different ways).

Research espionage of the kind described here is deeply controversial (see the introduction to this volume), given its many ethical and political dilemmas. Indeed, it is not something I would endorse. The approach was used by Huggins et al. mainly to ascertain what they saw as basic 'facts' (e.g. whom tortured whom, where individuals were tortured, etc.). For them, this was important because of the human-rights and activist-centric nature of their work, which engages a quite simple understanding of secrecy (e.g. individuals deliberately hiding 'facts') and almost seems to demand an extreme reliance on judgmental or paranoid types of social inquiry. Beyond the very serious ethical issues work of this kind raises, such a strategy is also ineffective in allowing researchers access to the depths of an individual's lifeworld because it focuses only on the surface events of their life, rather than their sensory, emotional, affective, cognitive, and other experiential forms of engagement with the world.

To access these deeper levels of meaning, a suspension of the researcher's judgmental faculties is required for at least two reasons. First, such a suspension of judgement is also important in gaining trust and/or developing rapport with interview subjects. It is difficult, however much one 'hangs out' with an individual, to gain their trust if one is continuously probing their truthfulness (c.f. Zournazi 2002). Second, this suspension of judgement is important analytically. The analysis of secret domains, in particular, still remains attached to what Stefano Guzzini (2013) describes as a 'benefit-fallacy' in which it is assumed that individuals who benefit from a particular social system (war, gender, etc.) are deliberately maintaining that status quo. As Guzzini (ibid.) writes, however, "to say that a system benefits certain people does not mean that they caused that benefit or that they control it." To some degree, this fallacy is a result of the critical attachment to what Rita Felski (2012) terms to the 'hermeneutics of suspicion' or which, more broadly, might be termed a form of conspiratorial reason (Latour 2004; Marasco 2016). When seeking to access the lifeworlds of individuals, it is important to move past such rhetorical assumptions, given that becoming preoccupied with our distant interpretation of what an individual's decisions, actions, etc. 'really mean' or 'intended' remains only our interpretation and not an account of the significance of these events for that person's lifeworld.

Suspending judgement allows researchers to move past suspicious attitudes and inquire, more broadly, into how agency and responsibility is often a "distributed" rather than "concentrated" quality: responsibility for what happens in the world can only very rarely be attributed to a single individual or small group of individuals who are deliberately controlling those outcomes (Latour 2014; Pickering 1993; Barad 2007). Much more commonly, world politics operates 'a-subjectively,' meaning without any singular point of control, through a complex web of networks or assemblages of individuals, groups, organizations, and material things. By suspending 
judgement, and accessing the complex positionality of an individual who is involved in but does not control these processes, the researcher thus gains a foothold into understanding how these a-subjective processes operate, as well as how they are experienced by those involved in them and so, finally, to present a more 'objective' (in Sandra Harding's (1992) sense) account of how security and secrecy is enacted in and on the world. Importantly, however, this suspension of judgement is only a suspension of our judgmental attitude towards individuals, rather than a suspension of normativity itself. It is perfectly possible to retain a caring and non-judgmental attitude towards those we speak with while still normatively rejecting and even attempting to combat the particular social system or events that they have been connected with.

In addition to this non-judgmental outlook, the researcher should also be careful not to separate themselves analytically from the phenomenon they are studying. Ethically and politically, it is crucial to recognize that however distant our own lives seem from intelligence agents, border guards or torturers, that they are often intimately and surprisingly intertwined. To help keep this in mind, a non-judgmental attitude can be accompanied with what I term a process of self-declaration. This process involves the transposition of ourselves into the position of our respondents. The goal here is to always connect their position back to our own: it is to see how their secrets are our secrets. It is to reflect on the fact that if we are studying, say, the secrets of torturers, that descriptions of their anger at meeting an enemy are also, often, uncannily similar our own feelings of anger (see Box 5.1). Or, if we are studying terrorists, it is to reflect on how their recounting of socio-political injustices as justifying political violence are sometimes also our own instinctive reactions to mass world political suffering.

Importantly, this process of self-declaration is different from the equally crucial process (see Box 5.1) in which the researcher acknowledges her own positionality and the power asymmetries, inequalities, etc. that this may produce. That process is more concerned with declaring differences between ourselves and our interlocutors (i.e. race, gender, class, power, etc.) whereas the process I am describing focuses instead on identifying and articulating similarities that we might otherwise not wish to acknowledge. For example, take Anna Leander's (2016) discussion of DAESH recruitment videos in which she diverts attention from the group's spectacular stagings of violence towards their prolific distribution of videos of hospitals, marketplaces, playgrounds and beyond. Rather than viewing these images as a manipulative form of propaganda, Leander argues these videos are crucial to understanding the lifeworld of violent militancy and, much more than this, suggest "that there might be commonalities" between researchers and their subjects even vis-à-vis "what is widely understood to be evil" (ibid., 364). Drawing out these "discomforting similarities" is always a crucial part of the process of self-declaration: they reveal how similar seemingly distant social fields can be and, more than this, in doing so always works to further chasten the intellectual temptation at outright condemnation or judgement.

Vis-à-vis CSS and studying secretive domains, this process of self-declaration is particularly key because it refuses to reify secrets as mystical, intrinsically important, 
and/or somehow socially unique. While it may often be considered vital to keep certain specific secrets hidden from public view, even these 'crucial' secrets (Davis 1973) can only be produced and/or kept through very mundane and everyday practices that are - always - eerily similar to distant social practices. Take, for example, the secret world of intelligence agencies. The methods used by intelligence agents to gather information, conduct interrogations, and beyond are - in fact markedly similar to many social scientific practices (Austin, Bellanova, and Kaufmann 2019). Indeed, Huggins et al.'s discussion of 'research espionage' is only the most obvious of such connections: the conspiratorial reason of much social science connects to the intelligence field, as do basic issues of confidentiality (see below). In fact, formal and informal connections between academia, the military, and the intelligence services are historically very deep.

The process of self-declaration is then about broadening our understanding of how secrecy is maintained by connecting the lifeworlds of its (professional) practitioners back to our own. In doing so, we break away from the view that secrets exist in a bounded, guarded, or separate world from our own and appreciate our own implication in their maintenance. In doing so, we also acknowledge our responsibility for social and political violences. And this is true even where these non-judgmental methods are being employed because, while "to be a friend is to stand in a relationship of trust ... to be a writer is to violate that trust for the sake of one's story" (Mills in Eakin 2004, 105). Every CSS account involves such an inevitable betrayal of trust, however much the author attempts to do justice to her interlocutors' words. As a result, declaring the place of our own violences, and their closeness to that of those we study, is an important ethical and political obligation for CSS researchers.

\section{Ethnographic interviewing and re-enactment}

The methods of self-forgetfulness and self-declaration described above are crucial, finally, to establishing a situation in which the researcher is able to elicit otherwise 'unspeakable' or uncommunicable stories from interlocutors in direct terms. There are many ways in which, once such an informal and non-judgmental research design has been established, to work towards drawing out relevant details from those we are speaking to. This includes the use of photo elicitation, film-making, oral history narratives, group-interviewing, and beyond (see Nyman, this volume). In this chapter I will outline perhaps the most broadly applicable method suitable for this purpose: ethnographic interviewing and re-enactment.

Frequently, an ethnographic inquiry into secretive worlds is near-impossible. For example, vis-à-vis my own research, Darius Rejali $(2007,434)$ notes that "it is not possible to do an ethnography of torturers 'on the job,", nor, indeed, would the majority of us want to, both for our own safety and sanity and, not least, the ethical implications of such research. Gaining ethnographic access to the worlds of intelligence agents, military practitioners, police forces, major corporations, and beyond, is often equally difficult. However, it is possible to access (as discussed earlier) figures 
from these worlds at an individual level and to gain the appropriate level of trust to begin engaging with them more fully.

With personal one-on-one access to these subjects, the 'next best' thing to carrying out ethnographic participant-observation involves what Spradley $(1979,9)$ calls ethnographic interviewing. Ethnographic interviews can be distinguished, first, from the common use of 'semi-structured' interviews because this method does not begin with a particular set of themes that must be covered during the interview, possess an 'interview guide,' or other formalities associated with semi-structured interviewing. Moreover, while ethnographic interviewing is close to 'open-ended' interviewing and incorporates many of its tools, the approach is distinct because it's one specific goal is to replicate - as far as is possible - a form of 'participantobservation' by asking questions that prompt respondents to effectively re-enact their every-day life in very practical, lived, corporeal, and experiential terms.

At its most basic level, an ethnographic interview can be compared with a "friendly conversation" (Spradley 1979, 55). As Spradley (ibid.) writes, ethnographic interviews proceed "as a series of friendly conversations into which the researcher slowly introduces new elements to assist informants." As in any friendly conversation, the goal is to learn more about the individual as a whole, rather than eliciting any particular fact per se. Box 5.3 is a simplified version of the methods Spradley suggests are core to this approach. Perhaps most central to the ethnographic interview is, however, asking 'descriptive' questions. These questions are essentially 'how' questions. They do not focus initially upon the 'whys' or the specific 'whats' of a person's life but, rather, how they have or are living on a daily basis.

\section{BOX 5.3 BASIC ELEMENTS OF AN ETHNOGRAPHIC INTERVIEW}

1 Greetings

2 Giving ethnographic explanations

Explain the purpose of your research/study and the procedures you will follow (ethical, practical, etc.).

3 Asking ethnographic questions

a Descriptive questions

b Grand-tour questions

Ask a broader question about your interlocutor's life and get them to 'guide' you through their answer: e.g. 'What do you do when you come to work every day?' Repeat the question if not enough detail is forthcoming and ask them to focus on the mundane aspects of their world. For example, if they talk about sending emails, ask them to expand on how they are sending mails to, who they are replying to, how this works, etc.

c Mini-tour questions 
On the basis of your 'grand-tour' question, 'drill-down' into one aspect of the person's life that they have described, and seek 'mini' (i.e. minute) details about it. Essentially, ask your interlocutor to teach you how to do what they do.

d Native-language questions

Throughout, be aware that your interlocutor will be 'translating' for you. Pick up on any slang or words that you do not understand, ask what they mean and begin using these in your own questions. In addition, always ask if there are special terms/terminologies used by your interlocutor and their social group.

4 Expressing interest

Typically, informants will find the questions you are asking uninteresting or boring, simply because these aspects of their lives are self-evident to them. Expressing interest in different ways throughout the interview is thus important.

5 Expressing cultural ignorance

Related to the above, expressing cultural ignorance of your informant's world makes clear your position as an outsider and disrupts the informant's frequent believe that their knowledge is self-evident.

There are many more aspects of the ethnographic interview, for a full description see Spradley $(1979,67,223)$.

For example, a 'grand-tour' question (in Spradley's terminology) involves beginning an interview by asking a person to recount their daily life at, say, work: beginning from the very moment they enter their workplace (the types of keys they use, for instance) through their banal activities (any paperwork, any preparation, etc.) through to the core of their activity (whatever it may be), until the moment they leave. These questions can then be supplemented by 'mini-tour' questions which drill further into the micro-details of particular events and/or, say, 'native-language' questions in which the interviewer attempts to - quite literally - learn the colloquial language of their respondent.

Take an example of this process in action: the documentary film Massaker (2004), which depicts interviews with perpetrators of the Sabra and Shatila massacre in Beirut, Lebanon. In the film, the interviewers ask the perpetrators to re-enact their actions for the camera. A moment like this allows for multiple observations:

- A detailed understanding of the physicality of a particular practice (knife-use);

- An 'in-the-moment' opportunity to observe the facial expressions, verbal communications, emotional states, and beyond of the practice being studied; 
- An 'after-the-moment' opportunity to assess the emotional and/or affective consequences of the re-enactment on the respondent, as well as - afterwards to drill down into details of the re-enactment through further questioning.

Indeed, literal re-enactments are often an important part of the ethnographicinterview process, emerging either at the request of the researcher or spontaneously (see Box 5.3). They are particularly visceral tools through which to break past the "verbalization of reflexive knowledge" and to allow access to the experiential content of a particular individual's lifeworld. This occurs because, very often, describing the practical, embodied, and/or non-discursive aspects of our lives is very difficult. As Pouliot $(2008,258)$ has written, "most of what people do . . . does not derive from conscious deliberation or thoughtful reflection . . . practices are the result of inarticulate, practical knowledge that makes what is to be done appear 'self-evident' or commonsensical.' In consequence, eliciting the practical content of a person's lifeworld often requires the presence of an external 'prompt' that changes the contours of a normal social interaction and allows individuals to analyze their own behavior more effectively. Within the ethnographic interview setting, this can occur through literal re-enactments or, alternatively, via step-by-step 'walkthroughs' of everyday life (grand or mini-tour questions), and other methods. Importantly, this process also allows respondents to engage with the researcher on their own terms: gifting a degree of power back to our interlocutors in ways that, again (see Box 5.3), are often equally uncomfortable for us as observers attempting to access their worlds.

\section{Conclusion}

Accessing lifeworlds is difficult. Researchers must thus learn to be creative in their use of methods. This includes questioning and indeed even rejecting any methodological prescription. No set of methods will work across every case. Sometimes, none will work. And whatever approach is chosen, unexpected issues will be encountered by researchers as they get closer to those they are studying: broader questions of anonymity, confidentiality, and ethics, for example, or problems of blocked access. These issues, as this entire volume attests, will be particularly acute for those CSS researchers concerned with the secretive aspects of world politics.

To conclude, however, with the material covered in this chapter, it should be noted that embracing these methods - deep hanging out, self-declaration, selfforgetfulness, and ethnographic interviewing - will often be most uncomfortable for the researcher themselves, not their respondents. The use of a non-judgmental frame of analysis, for example, will often unintentionally lead the researcher towards feeling sympathy for those with secrets, secrets which - for most CSS researchers are often things we wish did not exist (Austin 2019; Austin, Bellanova, and Kaufmann 2019). Navigating that discomfort will require tact and care (for both others and oneself) but it may also feed into the findings of your research. Accessing lifeworlds, indeed, ultimately teaches us as much about ourselves as those we are studying. 


\section{Suggested for further reading}

- Jonathan Luke Austin and Riccardo Bocco (2017) "Becoming a torturer: Towards a global ergonomics of care", International Review of the Red Cross, 98(903): 859-888.

- Jonathan Luke Austin (forthcoming) "Dangerous fieldwork”, In Mark B. Salter, Can E. Mutlu and Philippe M. Frowd (eds) Research Methods in Critical Security Studies, 2nd edition.

- Konstantin Belousov, Tom Horlick-Jones, Michael Bloor, Yakov Gilinskiy, Valentin Golbert, Yakov Kostikovsky, Michael Levi, and Dmitri Pentsov (2007) "Any port in a storm: Fieldwork difficulties in dangerous and crisis-ridden settings", Qualitative Research, 7(2): 155-175.

- Norman P. Peritore (1990) "Reflections on dangerous fieldwork," American Sociologist 21 (4).

\section{References}

Adler, Emanuel, and Vincent Pouliot (2011) "International practices", International Theory, $3(1): 1-36$.

Adler-Nissen, Rebecca (2014) "Stigma management in international relations: Transgressive identities, norms, and order in international society." International Organization, 68(1), 143-176.

Aradau, Claudia, and Jef Huysmans (2019) "Assembling credibility: Knowledge, method and critique in times of "post-truth"”, Security Dialogue, 50(1): 40-58.

Austin, Jonathan Luke. (2019) “A Parasitic Critique for IR", International Political Sociology, 13(2): 215-231.

Austin, Jonathan Luke, Rocco Bellanova, and Mareile Kaufmann (2019) "Doing and Mediating Critique", Security Dialogue, 50(1): 3-19.

Barad, Karen (2007) Meeting the Universe Halfway. Durham: Duke University Press.

Bueger, Christian, and Frank Gadinger (2015) “The play of international practice", International Studies Quarterly, 59(3): 449-460.

Damasio, Antonio R. (2012) Self Comes to Mind. New York:Vintage Books.

Davis, Murray S. (1973) Intimate Relations. New York:The Free Press.

Eakin, John P. (2004) The Ethics of Life Writing. Cornell: Cornell University Press.

Felski, Rita (2012) "Critique and the hermeneutics of suspicion", M/C Journal, 15(1).

Fattah, Khaled, and Karin M. Fierke (2009) "A clash of emotions: The politics of humiliation and political violence in the Middle East", European journal of international relations, 15(1): 67-93.

Geertz, Clifford (1998) "Deep hanging out”, The New York Review of Books, 45(16): 69-72.

Guzzini, Stefano (2013) "The ends of international relations theory: Stages of reflexivity and modes of theorizing", European Journal of International Relations, 19(3): 521-541.

Harding, Sandra (1992) "Rethinking standpoint epistemology", The Centennial Review, 36(3):437-470.

Huggins, Martha, Mika Haritos-Fatouros, and Phillip G. Zimbardo (2002) Violence Workers. Berkeley: University of California Press.

Latour, Bruno (2004) "Why has critique run out of steam?”, Critical Inquiry, 30(2): 225-248. Latour, Bruno (2014) "How better to register the agency of things", The Tanner Lecture on Human Values, Yale University, March 26. 
Leander, Anna (2015) "Ethnographic contributions to method development: "Strong objectivity in security studies", International Studies Perspectives, 17(4): 462-475.

Leander, Anna (2016) "Digital/commercial (in) visibility: The politics of DAESH recruitment videos”, European Journal of Social Theory, 20(3): 348-372.

Marasco, Robyn (2016) "Toward a critique of conspiratorial reason", Constellations, 23(2): 236-243.

Marcus, George E. (1995) "Ethnography in/of the world system: The emergence of multisited ethnography", Annual Review of Anthropology, 24(1): 95-117.

Pickering, Andrew (1993) "The mangle of practice", American Journal of Sociology, 99(3): 559-589.

Polanyi, Michael (1983) The Tacit Dimension. Gloucester, MA: Peter Smith.

Pouliot,Vincent (2008) “The logic of practicality", International Organization, 62(2): 257-288.

Rejali, Darius (2007) Torture and Democracy. Princeton: Princeton University Press.

Schutz, Alfred, and Thomas Luckmann (1973) The Structures of the Life-world. Evanston: Northwestern University Press.

Sherif, Bahira (2001) "The ambiguity of boundaries in the fieldwork experience: Establishing rapport and negotiating insider/outsider status", Qualitative Inquiry, 7(4): 436-447.

Spradley, James P. (1979) The Ethnographic Interview. New York: Holt, Rinehart \& Winston.

Stengers, Isabelle (2017) Another Science is Possible: A Manifesto for Slow Science. Cambridge, UK: Polity Press.

Walters, William. (forthcoming) The Production of Secrecy. London: Routledge.

Zournazi, Mary (2002) Hope: New Philosophies For Change. London: Routledge. 


\title{
RESEARCH DILEMMAS IN DANGEROUS PLACES
}

\author{
Fairlie Chappuis and Jana Krause
}

- Research objective: This chapter will help researchers who want to conduct security-related fieldwork in conflict and post-conflict settings. It helps researchers reflect on distinct dynamics of (post)-conflict and authoritarian settings, the researcher's safety and preparedness, and the responsibility to protect respondents' and collaborators' well-being.

- Research puzzle: The puzzle this chapter addresses concerns collecting often sensitive or confidential information in difficult and at times dangerous conflict environments while consistently judging safe access to and limitations of access and usage of such information.

\section{Introduction}

The 2016 kidnapping, torture and killing of Italian PhD student Giulio Regeni during fieldwork in Egypt and the 2018 arrest and life sentence for British PhD student Matthew Hedges in the United Arab Emirates (UAE) sent shockwaves through the academic community and encouraged further reflections on research risks and practice in the Middle East and North Africa (MENA) region. Matthew Hedges had dutifully obtained all required research permits yet was accused of spying for British intelligence and charged with espionage (and later pardoned). Regional authoritarian trends have impacted national and foreign researchers since the so-called Arab Spring of 2011 leading security apparatuses to "target academic communities on a new level" (Grimm 2018). These cases ${ }^{1}$ illustrate the difficulties of security-related research not only in the MENA region but in all places where state openness to research and democratic principles turns to repression, invasive surveillance, or autocracy.

This chapter addresses the challenges of researching security policies and practices in conflict-affected and undemocratic countries. Undemocratic, weak or 
authoritarian institutional structures, conservative cultures of security, and the dynamics of recent or ongoing conflict create complex methodological challenges for researchers whilst also posing security dilemmas for both the researcher and the people she works with. Conducting fieldwork that is both safe and successful in such contexts requires a learning process that this chapter aims to support.

We draw on our fieldwork experiences to offer practical reflections on handling research difficulties and ethical challenges. Between us we have worked extensively in Burundi, Liberia, Indonesia, Nigeria, Myanmar, and South Sudan, interviewing a broad sample of respondents ranging from local communities and civil society, to vigilante, gang and militia members, military and police, national security officials, and UN peacekeepers (Krause 2018; Jamar and Chappuis 2016).

This chapter approaches the challenges of safe and successful research in potentially dangerous secretive environments from three angles: first we sketch how the nuances of institutional setting shape security and secrecy in conflict-affected contexts and the implications for researchers; secondly, we examine how the identity of the researcher within such settings poses challenges both for safety and methodology; and finally, we turn the same question to the position of local or national research partners and respondents. We engage with the following questions:

1 How do varying degrees of institutional capacity across security institutions in conflict-affected contexts enable and constrain research?

2 How can the researcher successfully navigate the difficult methodological terrain of research access - in particular with regard to gender - while keeping herself and her respondents safe and treating them with the respect and dignity that they deserve?

3 What steps can a researcher take to ensure that her work is successful without endangering herself or her informants and respondents in volatile contexts?

\section{Security research in conflict-affected and authoritarian states}

In this section, we focus on varying state institutional capacity for security and potential implications for fieldwork. In democracies with a robust framework for rule of law and a political culture of public debate, researchers have recourse to institutional mechanisms that promote transparency, such as classification schedules and freedom of information laws. Researchers can make use of legal standards and respondents can evaluate researchers' requests for interviews based on a clear sense of the scope of what can be shared safely and legally. Moreover, respondents may share an appreciation of the value of critical research and respect for its place in a free and democratic society. Yet even in the world's freest democracies, such efforts are often met with resistance within the security sphere both at individual and institutional levels: secrecy, obfuscation, a sense of professional exclusion, or hostility to outside perspectives are all alive and well within security institutions that are largely subordinate to civilian and democratic control (see Belcher and Martin, this volume). The context of weak or authoritarian states amplifies the obstacles 
and dilemmas that researchers face, keeping in mind that the limitations governing research in such contexts can change dramatically over time and across contexts.

Surmounting the barriers of secrecy that surround security institutions starts with a contextual knowledge of how they function. Security institutions are the means of coercive force by which governments of every political variation create and enforce order. The benign or aggressive nature of elite politics towards the population (and by extension towards researchers) shapes security institutions and will have a defining effect on how the researcher's activities will be received, as will the bureaucratic capacity of security institutions themselves. For example, a state that emerges victorious from a military confrontation or which has succeeded in suppressing organized and armed resistance is likely to command a sophisticated military-intelligence-police complex with a high degree of institutionalized capacity for action. States such as Myanmar or Burundi have relatively well-functioning military and intelligence institutions with a reputation for human-rights abuses. Security institutions in such contexts are likely to be controlled by rigid hierarchies of command and control based on a strong culture of professionalization. They may command significant loyalty among the rank and file by offering a source of steady employment and social status, as well as by punishing insubordination harshly. Petty corruption may be rampant, especially where soldiers or security officers are expected to "pay themselves" through extortion of the population. The levels of violence used to maintain such a system may be extreme, including high rates of illegal and politically motivated detention, abuse, abductions, disappearances and torture.

One consequence of violent autocratic configurations is that policies of abuse, influence and repression are rarely a matter of accident or incompetence (as they may be in less institutionally developed contexts). Researchers should therefore remain attentive to the likelihood that whatever is observed or heard may be the result of an explicit decision at an official level. Systematic policies of repression may or may not be formally declared decisions or orders in such contexts, and they may or may not be public. Understanding which is the case is thus a central methodological aspect of understanding why security institutions use violence as they do, and therewith a key element in explaining the nature of the political situation.

Security institutions with less institutionalized capacity present different patterns and different problems for the researcher. In contrast to strongly institutionalized contexts, relative inaccessibility of security institutions may be less the result of an express effort at secrecy than of low resource levels and disorganization. Researchers should carefully distinguish such contexts because the characteristics of power and decision-making can be qualitatively different. For example, the security institutions may be barely operational due to a lack of resources and bureaucratic capacity for organization and management. At the same time, resource scarcity is generally accompanied by high rates of corruption at all levels and competition over "resource generating" security activities (e.g. access to natural resources, traffic policing or issuing of official permissions, the imposition of road blocks). Where resource extraction from the population is wide spread, the relationship between 
security institutions and the population is likely to be deeply negative, which can affect the views of potential respondents.

The incapacity typical of institutionally weak security forces is often visible in patterns of policy formation and implementation. For example, technical competence may be concentrated at the top of an institutional hierarchy, which struggles to implement its decisions because of capacity deficiencies at lower levels of management and implementation. In such situations, formal and informal hierarchies and networks for decision-making may not align or overlap much because there may be little ability to control formal security institutions or incentive to attempt to do so because of their ineffectiveness.

States with high-capacity security institutions tend to have well-developed surveillance capacity often based on dense local networks of informants and may take a dim view of outsiders asking sensitive questions. Sensitivity to foreign critique stems from the fact that bad publicity can harm government relationships with donors or undermine a particular political narrative the government may wish to promote (for example, in contexts where media and press freedoms are heavily restricted to hide human rights abuses). At the formal level, there are likely to be strict regulations with regard to research, often involving onerous processes of obtaining official permissions, special entry visas and local sponsors. For example, in Indonesia, a postauthoritarian democratic state, strict research visa rules were put in place several years after the democratic transition, with several ministries and the military approving or declining a foreigner's permit request. Researchers who do receive permission need to register with the local police station, which implies a certain level of surveillance. Researchers generally offer their respondents anonymity and protection of the information they are willing to share. Under conditions of state surveillance, it is also the researcher's responsibility to inform the interviewee of her registration because it may undermine assurances of anonymity or potentially expose them to state reprisals. In (post-) authoritarian conflict settings a climate of pervasive fear and paranoia may prevail, which affects everyday life and renders people suspicious and careful with sharing information. This may limit common fieldwork practices of ethnographic immersion and participant observation. A foreigner's long research stay or a continued presence in daily activities can invite attention that respondents may not wish for (see also Glasius et al. 2017). Researchers need to account for the effects of pervasive fear or paranoia on data collection and respondents' views.

The relative stability of the state and safety of a foreign researcher within larger cities (such as Yangon in Myanmar), where she is not affected by open armed conflict may result in a false sense of overall stability and security. In such a climate, assessing the safety of the researcher and her informants can be difficult. Respondents who have lived through long periods of authoritarian control, armed conflict, and state reprisals may have a deeply internalized fear of sudden and unpredictable harm by security agents or suspicion of their neighbours. Even if respondents are part of the security apparatus, their willingness to meet with a researcher and provide information may be limited and can change unexpectedly and rapidly over the course of the research process. Researchers need to remain attentive to these 
challenges and adapt their strategies accordingly: this could mean asking different questions or dropping certain aspects of the research altogether.

By contrast, in weak or failing states, such as post-war Liberia, surveillance capacity may be much lower but people fear direct physical abuse by security forces and armed crime. Entry-level visa and permit rules may equally apply to the researcher but with less menacing undertones. Furthermore, in post-conflict contexts where international peacekeepers effectively provide security, such as Liberia and South Sudan, tensions between state security actors and international peacekeepers are common and may affect how the researcher can navigate her field site. She may be seen as just another international staff member, which can facilitate her movement but also make her a target to those who oppose the presence of foreign peacekeepers. The following sections examine how the researcher can mitigate the effects of such institutional and context factors on her research and her own safety and well-being.

\section{Research access and safety concerns}

In this section we ask how researchers can protect themselves in the field and how these concerns can interact with research strategies. Ethical field research demands extensive preparedness, which is challenging given that most academic researchers do not benefit from the same level of institutional support and training as their journalist and humanitarian colleagues (Lake and Parkinson 2017). While International Review Boards and publications on fieldwork in conflict settings expect and offer vital discussion about keeping respondents safe, the researcher's wellbeing is often treated as secondary. However, the physical and emotional challenges of fieldwork should not be underestimated and require emotional maturity, time-consuming planning, and extensive self-care (Jamar and Chappuis 2016; Theidon 2014; Wood 2006). Researchers who work in intense conflict environments increasingly complete professional training courses (Hostile Environment Awareness Training, HEAT) to learn how to minimize personal risks in conflict settings. While foreign staff members may rely on their organizations to support them with the practicalities of arranging safety and emergency care, academic researchers generally need to establish their own care networks and gather safety advice. When researching in conflict zones, we found the points discussed in Box 6.1 useful.

\section{BOX 6.1 PRACTICAL MEASURES FOR PERSONAL SAFETY}

- $\quad$ Ask researchers and international staff who have worked in the area you plan to visit for extensive safety and practical advice. People working in such environments rely on information exchange to assess often rapidly changing conditions on the ground and tend to be generous with tips, tricks, and contacts. 
- Underdeveloped banking services often mean that researchers must travel with large amounts of cash to cover foreseeable expenses. It is important to have well-trusted drivers arranged for airport pickup and mobility throughout the research stay. Dividing cash into smaller bundles and storing it in a range of different hiding places, or asking the hotel manager to safekeep part of the money can minimize losses in case of theft.

- Research in active conflict zones should only be conducted with extensive insurance coverage. So-called war insurances require the researcher to check-in via text or email at least every 24 hours and report her condition and location for the unlikely case that a rescue operation needs to be arranged. The researcher should have a carefully planned emergency protocol that her supervisor or institutional colleagues understand well. Registration with the local embassy is generally expected so that consular support can be offered in case of emergency, although in conflict zones such support is often limited and the researcher needs extensive medical and evacuation insurance.

- To facilitate support in an emergency, and to generally guard against assault, it is important to inform trusted research partners, assistants, local friends, or trusted hotel managers about planned daily movements and the drivers and assistants one works with. It can be helpful to carry personal defence devices, such as a personal alarm, a loud whistle or pepper spray (ensure that national laws allow this, as well as the airline carrier you are travelling with). In hotel rooms, using a door-stop to wedge bedroom doors shut from the inside at night and having padlocks to secure windows/doors may be useful. Safe accommodation that comes with a recommendation is indispensable. If you have a choice, choose a room high enough from the ground to prevent direct access but low enough that you could feasibly escape in the event of a fire (first-third floors are typically best).

- $\quad$ Foreigners can be high-value targets for abduction. Special safety measures should be adopted in areas with kidnapping risk while high-risk areas should be avoided. Measures can include daily changes to route of travel and schedule and careful sharing of information about whereabouts to outsiders (abductions typically require advanced planning). Paying attention to your surroundings with regard to surveillance and people's movements is generally useful.

- Make sure your accommodation contains enough supplies to be selfsufficient for several days in case you cannot leave or major services breakdown: stockpile in advance water (for drinking and washing) and food, as well as other essentials such as medicine/first aid supplies, candles, generator fuel, cash (ATMs/power may fail in an emergency), a batterypowered radio, spare vehicle fuel. 
Safety concerns in conflict-affected or fragile contexts, as elsewhere, have distinct gender dimensions. Instances of sexualization and harassment, particularly for female researchers, are common in conflict zones as elsewhere (Hanson and Richards, 2017). Researchers should be careful not to mistake a veneer of officialdom or cultural proximity for a guarantee of safety. For example, one of us investigated the dynamics of security reform in Liberia using a snowballing strategy among United Nations police and peacekeeping personnel in Monrovia. An initial thirdparty introduction led to a series of interviews and eventually the researcher was invited to join a semi-official social event hosted by a contingent to the UN forces: a valuable opportunity to gain better access to the research site and proof of the usefulness of the sampling strategy. During conversations, the researcher met a military officer and accepted an offer of transport leaving the event, which took place in a UN compound at night somewhat outside of town. This offer had been made to a group of people but at the moment of leaving others decided not to join and the researcher found herself alone with the UN officer, who began to make inappropriate advances. Instead of taking the road back to town, he drove to a secluded building and invited the researcher to come inside on the pretext of fetching a personal item. Uncomfortable and worried, the researcher insisted on staying in the car and phoning a friend to say she was on the way into town. This call was contrived to take place within earshot of the UN officer so he would know that a third person was aware of her current whereabouts, who she was with, and the alarm would be raised should she fail to arrive.

Gender is also a determinant factor in strategies for access in the security field because security officials are overwhelmingly male and often older. The categories of young/woman/researcher/foreigner are all pretexts for exclusion from conservative security cultures whereas older/man/technical expert/professional "brotherhood" are categories that may win trust. A female researcher - especially a younger researcher - may first need to convince her respondent that she is knowledgeable and that an interview is no waste of time. Women or non-binary researchers are likely to have a harder time building credibility or trust, which means they may not get passed on to more important contacts as easily, with consequent implications for snowballing. In some instances, no level of professional competency will be sufficient to overcome prejudices inherent to the field of practice, in which case women and non-binary researchers will need to develop alternative methods for gaining access. Informal access can be valuable for new information, triangulation or alternative contacts but is typically reserved to a conservative sphere of male-based socializing. Women may not get the kind of "back-room" access male researchers may be able to make use of. Not only are women or non-binary people typically excluded from such sites of research but socializing may carry the extra risks of being misconstrued as sexual availability.

In one instance, one of us compared and contrasted her experience of conducting the same semi-structured interview schedule with the same sample of respondents in a comparable post-conflict context, with those of her male colleague 
working on the same project. Where she was often met with bemusement, scepticism and an air of patronizing indulgence in asking specialized questions about security arrangements, his questions were met with a sense of complicity. This difference was not a straightforward methodological advantage for the male researcher since he found that respondents would often assume he knew things that he did not know and asking for clarification risked jeopardizing the status of knowing-insider they had spontaneously labelled him with. The patronizing indulgence spent on the female researcher often allowed her to ask usefully detailed and particularly searching questions, which were interpreted as naive rather than intrusive and thus met with detailed explanations: her assumed ignorance became a means to overcome the barriers of secrecy because she was not perceived as a credible threat (see also Hoijtink, this volume).

However, academic researchers can arouse suspicion because they are only one kind of visitor to such places who may be asking difficult or sensitive questions concerning security institutions. Human rights investigators and activists, journalists, and spies are all likely to be seeking similar information about the inner-workings of the security state, and some may be explicitly posing as foreign academics. Moreover, it may be common in such contexts for these categories to overlap. For example, interviewing a wide range of national and international respondents about the details of security function and reform in Liberia entailed a stay of several months in the capital city for one of us. Monrovia is a small city with a tight-knit social scene and a relatively large number of internationals working in various NGOs, and bilateral or multilateral missions. This concentration of actors meant that the regular daily activities of eating out, shopping, relaxing, etc. quickly began to bring the researcher into social contact with other internationals working in the same context. New friendships inevitably form under such conditions and this proved to be not only an enriching personal experience but also an extremely useful source of new information and contacts.

Once these relationships had deepened into more candid friendships, the researcher began to field more searching questions about the nature of her work learning that "research" is a commonly used cover for espionage and that some had inferred from the nature of her research focus that she was in fact a spy, asking her directly if this was the case. It was methodologically useful to become aware of this new element in the context because it helped to explain the behaviour of some respondents who may have been operating under this assumption: for example, insisting to meet after-hours and off-premises, using external email accounts or contacting only by phone, breaking off meetings unexpectedly. In such situations it is important for the researcher to explain her project repeatedly to her interlocutors and to provide credentials, such as letters from her institutions, to guard and maintain trust among those she works with. Nevertheless, researchers should remain attentive to the fact that institutional credentials will not remove the inherent ambiguities of such a situation and this ambiguity only highlights the need to take seriously the safety of those with whom a researcher works, as the last section discusses. 


\section{The safety of respondents and ethical concerns}

In this section, we focus on protecting respondents and collaborators during field research (see also Glasius et al. 2017). Respondents and in-country research partners may generally deal with a heightened degree of risk and intimidation for participation in security-related research. The researcher needs to carefully assess how she can ensure the safety and well-being of such respondents (Cronin-Furman and Lake 2018; Wood 2006). She should reflect about her own assumptions concerning visibility and impact on the research environment, the nature of social interactions among interlocutors and communities.

A common but particularly dangerous assumption among (early) field researchers is the feeling that a researcher's presence or activities may go largely unnoticed. A foreign researcher usually has the luxury of leaving the situation or turning to a foreign embassy for assistance should her work attract the attention of authorities. This is not the case for local contacts who must face the consequences of the researcher's conduct. For this reason, researchers should fully understand that it is practically impossible for a foreigner to move unnoticed through a local community, including (perhaps even especially) in densely populated urban environments. What may look like the chaos of anonymous strangers to the outsider is often a tight-knit social system of people who know and depend on each other through intertwined livelihoods, family ties and community identities. Urban neighbourhood communities often have quite clear boundaries and social hierarchies and residents notice who does what and meets with whom. Researchers need to operate on the assumption that their contact with respondents is widely known at the community level, and therefore also to state authorities engaged in surveillance, or political groups active in a particular area (should they take an interest).

It is the responsibility of the researcher to consult local contacts and community members about the political situation and whether participating in research exposes respondents to any kind of risk. For example, conducting interviews in an outer neighbourhood of Bujumbura, Burundi appeared to the eyes of the researcher as an innocuous visit to a local community. However, this was also a community where state-sponsored youth militia were becoming increasingly active and violent to the extent that it was not considered safe for the researcher to stay in the area after-dark or to visit on days of political mobilization. Certain questions about the nature of insecurity in the area could have exposed the research respondents to critical attention from such groups. For this reason, information about their activities was principally gathered from people who had first-hand knowledge and experience of the situation but were not themselves based in the community and therefore not exposed to the same direct threat.

Developing a reliable understanding of the current political-security situation is essential to ensuring the integrity of the research process as well as protecting the safety of both the researcher and her respondents. Publication processes are typically too slow to provide current information on relevant political and security dynamics: they are also rarely fine-grained enough to cover local level dynamics. 
Local media, social media, blogs and online forums may provide more immediate information on local political and security conditions but need to be cross-checked against other sources for factual accuracy and political bias. It may also be possible to access security briefings or at least up-to-date assessments by foreign embassies, international NGOs, or multilateral missions but this is usually proprietary information that is hard to come by and best accessed informally through personal networks and handled with discretion. Inevitably, the single most important step in becoming aware of current local dynamics is engaging knowledgeable and reliable local contacts - whether on the basis of informal practical advice offered by contacts on the ground or on the basis of an experienced and knowledgeable local guide employed as a research assistant or "fixer".

The logistics of interview-based research require finding a location to meet potential informants that is convenient but also safe. Meeting with international or government officials will usually entail an invitation to an office building during business hours or a high-security embassy compound. Researchers in this situation will likely be asked for an official letter vouching for their affiliation and official identification but these are logistical details and not dangerous situations. More difficult to negotiate are the interviews that require visits to potentially unsafe locations, in particular at night. Researchers may find themselves invited into potentially dangerous situations to meet informants who wish to speak off the record, outside of their official affiliation, or who may be based in communities or locations where foreigners do not regularly go. Access strategies based on snowball sampling depend on the interpersonal relationships that a researcher can establish with a potential gatekeeper. A gatekeeper is staking some part of her social, political or professional capital in introducing the researcher to their own personal or professional networks by vouching for the researcher in some way. Making an appropriate first impression on a potential gatekeeper is thus an essential element of the access strategy but this may often entail the researcher placing a degree of trust in a gatekeeper that can prove potentially dangerous.

\section{BOX 6.2 QUESTIONS TO ASK YOURSELF WHEN ENGAGING LOCAL EXPERTISE}

1 Who is your local informer? You need to have a sense of the life trajectory of the person you will be working with, their motivations and incentives. It is usually best to work with someone who has assisted external actors before because they will thus have a sense of what the researcher may need and the problems they may face (indeed, remain open to the fact that they may know this better than you do). It is a good sign if the person you consider working with can refer you to other individuals or organizations they have worked with in the past. 
2 Where do they stand politically? It is crucial to know if you are engaging someone who stands on one side or the other of a conflict constellation. This may be a matter of personal history or political conviction, but it may also be a matter of language and ethnicity of the individual, or even the place this person was born. Sometimes the realities of structural inequalities mean engaging someone with the relevant level of education, competence and experience also means engaging someone who stands clearly on one side or the other of a social divide which is a root cause of conflict. This can affect both the view of the political and security situation this person provides but also the strategies for access among local actors they will be able to engage in. The minimal requirement in such a situation is to at least be acutely aware of the bias this situation represents and seek ways to redress the balance during the research, for example, by working with multiple partners.

3 What dangers does your relationship with this person(s) pose to you? It cannot be taken for granted that everyone is who they say they are or that their motivations are always fully transparent. Researchers need to place trust in the person they work with but also need to verify information provided and to take steps for their own safety and that of the people they work with. Ask around about a person's record and do not become complacent about your own safety or theirs as conditions can change quickly. Ensure that the questions you are asking - and asking others to ask - do not expose anyone to undue risk.

4 What dangers does your relationship with this person(s) pose to them? Sometimes, having worked with foreign actors is enough to expose individuals to reprisals from security forces or political actors. Ask international contacts about their experiences working with locals; ask locals in contact with other international actors about their own sense of risks involved. There may be restrictions on your local partners movements or ability to engage that do not apply to you; you may need to work with several people to engage different communities.

In insecure contexts, staff of security institutions, multilateral organizations, and foreign embassies have access to privileged information that may otherwise be scarce or difficult to confirm. In the course of interviewing information may be offered that is otherwise sensitive, classified or officially secret. Occasionally, this may even extend to offers to share sensitive documents. While such material can be useful, especially for triangulating the veracity of information gathered otherwise, it entails specific risks for the researcher as well as the informant sharing such information. For one thing, receiving classified information is illegal under the laws of most countries and may expose both the person sharing as well as the person receiving such information to criminal or civil charges and even charges of espionage. Legal regimes covering information may extend from the country where the researcher is 
present or the country of nationality of the official/researcher concerned. The discovery that an informant has shared sensitive information either through electronic tracing, or through the publication of research results, can endanger the careers of informants and in extreme cases, their safety. Sharing and receiving sensitive information may be legally protected under whistleblowing regulations but such regulations are unlikely to be strong in many conflict-affected countries, and may or may not cover your research activities (see also Hughes and Garnett, this volume). It is the researcher's responsibility to fully understand the implications of sharing and receiving sensitive information. Yet it may be the case that the researcher is not entirely certain of the degree of sensitivity of information being shared. In any case, simple measures for data protection are prudent:

1 Keep a record of informant identities (names, dates, locations) separate from interview notes; do not include any identifying information in your notes and develop a code if necessary to disguise such information;

2 Ask informants directly what may or may not be shared and in cases of uncertainty check with them first (your research is not as important as someone's life);

3 Use end-to-end encrypted messaging and email services;

4 Make sure your computer and online backup accounts are all password protected using long passwords with a variety of cases, special characters and numbers;

5 If using an external hard drive for backups (a good idea where internet service is patchy), be careful to ensure you know where it is at all times.

Understanding how to frame potentially sensitive issues is a central element in adapting the research to protect informants. Part of this understanding must involve decisions about who not to engage with. In extreme cases, proscription regimes within the European Union or the United States list certain groups or individuals as suspected terrorists, which exposes to legal recourse anyone who chooses to engage with them as interlocutors. Moreover, these regimes have in some cases been used by national governments as a pretext to interfere with the work of humanitarian, development or peacebuilding practitioners (Dudouet 2010). Researchers need to be acutely aware of who they are engaging with and the effects of doing so.

Similarly, adapting research strategies to context also means developing a context-based understanding of what is prudent not to ask. For example, in interviewing local communities in Burundi about their experiences of security in an area known for a high level of penetration by political militia, the researcher in one case elected not to ask respondents about their own active roles in such groups. The researcher was unlikely to receive a candid response given the specific political context at the time and doing so could expose respondents to risk because it might have become known in the community that such questions were asked and recording such information could incriminate someone in an illegal act. Instead, the researcher chose to focus on experiences of victimization and to ask respondents what they had heard or believed about other people's experiences of violent political mobilization in the city. This line of questioning clearly undermined the integrity of the research in terms of its own initial purpose, and the theoretical 
analysis had to be adjusted as a result. However, these concessions to context were both necessary and justified to protect the interests of local respondents.

It is also pertinent for the researcher to reflect on the significance of silence and non-responses from an informant (e.g. Fujii 2010). For example, in an early interview with a relatively well-placed police official in Liberia, the researcher raised some questions about efforts to reduce corruption without knowing how sensitive this topic may be for the respondent. The interview was followed by complete silence and the official never replied to any further messages. What had been a promising entry-point for further interviews with police command became a deadend and also embarrassed the local contact who had facilitated the interview, in this case a journalist. Not only did the researcher's failure to understand the nature of the situation and adapt her interview questions ruin the opportunity for further introductions by means of the same well-connected conduit but it also potentially jeopardized the journalist's relationship with his source.

\section{Conclusions}

We have shown how gaining access to institutional knowledge and handling confidential and sensitive information appropriately, as well as the dynamics of gender, identity, insider-outsider status, and professional cultures particular to the security field can shape the research process in often unexpected ways. Decisions made during fieldwork can have direct and far-reaching consequences, not only for research design and methodology, but more importantly, for the safety and well-being of both the researcher and her respondents. Researchers in fragile contexts need to be especially attentive to the practical and methodological dilemmas that shape their own work and the experiences of those they work with. Indeed, it may be "one of the discipline's worst kept secrets that graduate students, in particular, feel practically unprepared for their fieldwork" (Lake and Parkinson 2017). This chapter has offered brief advice based on reflection of personal experiences. We discussed the dynamics of securityrelated research in conflict settings and potentially swiftly changing 'red lines'; the researcher's safety and well-being; and her responsibilities in keeping respondents and collaborators safe. Growing awareness of the deficiencies in graduate student training and ethical concerns have led to a recent proliferation of excellent discussions of fieldwork preparedness, data protection, and ethical concerns of research in conflict zones. The works listed below offer students further detailed advice and reflection on these issues before embarking on fieldwork in conflict settings.

\section{Suggestions for further reading}

- Lee Ann Fujii (2012) "Research ethics 101: Dilemmas and responsibilities", PS: Political Science \& Politics, 45 (4), 717-723.

- Marlies Glasius, Meta De Lange, Jos Bartman, Emanuela Dalmasso, Aofei Lv, Adele Del Sordi, Marcus Michaelsen, and Kris Ruijgrok (2017) Research, Ethics and Risk in the Authoritarian Field. Basingstoke: Palgrave Pivot. 
- Sarah Parkinson (2017) "Through the looking glass: Information security and Middle East research, memo, project on Middle East political science”, https://pomeps.org/2017/03/13/through-the-looking-glass-informationsecurity-and-middle-east-research/.

- Cyanne E. Loyle and Alicia Simoni (2017) "Researching under fire: Political science and researcher trauma”, PS: Political Science \& Politics, 50(1), 141-145.

\section{Note}

1 For more information on both cases, see Hedges (2019); Lynch (2018); Grimm (2018).

\section{References}

Cronin-Furman, Kate and Milli M. Lake (2018) "Ethics abroad: Fieldwork in fragile and violent contexts", PS: Political Science \& Politics, 51(3): 1-8.

Dudouet,Veronique (2010) "Mediating peace with proscribed armed groups", USIP Special Report 239, available at: https://www.usip.org/sites/default/files/SR239Duduoet.pdf (accessed 21 February 2019).

Fujii, Lee Ann (2010) "Shades of truth and lies: Interpreting testimonies of war and violence”, Journal of Peace Research, 47(2): 231-241.

Glasius, Marlies, Meta De Lange, Jos Bartman, Emanuela Dalmasso, Lv Aofei, Adele Del Sordi, Marcus Michaelsen, and Kris Ruijgrok (2017) Research, Ethics and Risk in the Authoritarian Field. Basingstoke: Palgrave Pivot.

Grimm, Jannis (2018) “Authoritarian Middle East regimes don't like academics - ask Matthew Hedges”, 22 November, https://www.opendemocracy.net/jannis-grimm/ policing-research-shifting-tides-for-middle-east-studies-after-arab-spring.

Hanson, Rebecca and Patricia Richards (2017) "Sexual harassment and the construction of ethnographic knowledge", Sociological Forum, 32: 587-609.

Hedges, Matthew (2019) "An ally held me as a spy - and the West is complicit", The Atlantic, 25 January 2019, available at: https://www.theatlantic.com/international/archive/2019/01/ matthew-hedges-uae-held-me-spy-west-complicit/581200/ (Accessed 21 February 2019).

Jamar, Astrid, and Fairlie Chappuis (2016) "Conventions of silence. Emotions and knowledge production in war-affected research environments", Parcours Anthropologiques, (11) DOI: $10.4000 /$ pa.513.

Krause, Jana (2018). Resilient Communities: Non-violence and Civilian Agency in Communal War. Cambridge, UK: Cambridge University Press.

Lake, Milli and Sarah Parkinson (2017) "The ethics of fieldwork preparedness", Political Violence@a Glance, 5 June 2017, available at: http://politicalviolenceataglance.org/ 2017/06/05/the-ethics-of-fieldwork-preparedness/ (accessed 21 February 2019).

Lynch, Marc (2018) "What the UAE's arrest of Matthew Hedges means for political science research in the Middle East", The Washington Post, The Monkey Cage, 29 November 2018.

Theidon, Kimberly (2014) “How was your trip?' Self-care for researchers working and writing on violence", Drugs, Security and Democracy Program Working Papers on Research Security, 2.

Wood, Elisabeth J. (2006) "The ethical challenges of field research in conflict zones", Qualitative Sociology, 29(3): 373-386. 
$\Longrightarrow$ Taylor \& Francis

Taylor \& Francis Group

http://taylorandfrancis.com 
PART 2

Mapping secrecy 
Section III: Reflexive methodologies 


\title{
WRITING SECRECY
}

\author{
Brian Rappert
}

- Research objective: This chapter will help researchers who struggle to find ways of writing about statecraft due to limits on what they can know and repeat.

- Research puzzle: How can what is not in our analysis become productive aspects of our research? I address this puzzle by outlining experimental forms of writing intended to examine the interplay between disclosure and concealment within security domains through writing with an interplay of disclosure and concealment.

When a meeting, or part thereof, is held under the Chatham House Rule, participants are free to use the information received, but neither the identity nor the affiliation of the speaker(s), nor that of any other participant, may be revealed. ${ }^{1}$

\section{Introduction}

The Chatham House Rule is one of the many kinds of the agreements commonplace in security-related settings that condition what can and cannot be repeated. While marking limits on disclosure, this rule simultaneously enables meetings to readily serve as sites of data collection. As scholars are as bound by such agreements as anyone, in undertaking research we become part of the security practices we are analysing.

Implicitly the Rule also speaks to the way practices of secrecy are enacted in localized, face-to-face interactions. Because of this, the meaning and relevancy of the Rule for those interactions is not something that can be settled in the abstract once and for all; instead they are matters worked through in relation to specific settings. From my experience of participating in international disarmament and 
arms control-related events for over 15 years, the following points are noteworthy observations about the Chatham House Rule:

- If you attended ten meetings where the Rule was invoked, it is likely that you would have encountered ten meaningfully different versions. While the official definition of the Rule specified by the London-based Chatham House policy institute is sometimes cited word for word, it far more common to hear a (simplified) gloss of 'the Rule' that differs in significant respects from the text quoted above. However, I have almost no experience of other meeting participants querying meaning of the Rule because of a specific wording or a lack of wording.

- Despite the indeterminacy of what 'identifying' means short of naming an individual, again, I have almost no experience of anyone seeking clarification about how to interpret the Rule.

- Although the Rule enables meetings to become sites for data collection, it is exceptionally rare to find references to these events in academic or official policy publications - at least in the disarmament areas I have worked. By contrast, within verbal exchanges within disarmament forums, who said what at which meeting is often shared.

While such observations might be read as criticisms, they only act that way when we think of the Rule as a context-free imperative that should definitively mark and police appropriate conduct. Instead of taking this approach, I would suggest the observations above can encourage us to turn towards how the Rule is made to matter. My experiences suggest the meaning and relevancy of the Chatham House Rule are inextricably bound up with notions of trust operating within communities (see also Walters and Luscombe, this volume). The Rule serves as a compact between those present, one that, through its very open-endedness, defines participants as members of a common group that can be ensured to act appropriately without being told exactly what that means.

The Chatham House Rule takes its place alongside other kinds of considerations bearing on determinations of what should and should not be disclosed by security researchers: legally enforced national security acts, personal bonds formed with close informants, signed nondisclosure agreements, conventions of tact, anticipations of media reception, etc. This chapter addresses how those engaged in fieldwork-based research can respond to the presence of disclosure limitations. It does so through posing the question: How can we skilfully write with and not just about secrecy? In other words, rather than outing secrets, or treating secrecy as a practice undertaken by others, can we embrace the ways in which intentional concealment characterizes social research? If we did so, what possibilities might open up?

I address these questions by surveying my attempts to produce experimental forms of writing intended to exemplify the interplay of disclosure and concealment in disarmament diplomacy (section three). Such techniques were not primarily intended as mechanisms for revealing 'what really happened', but rather as ways of engaging with the lived conditions of knowledge production within the 
communities under study, conditions that simultaneously facilitated and curtailed social research. Consideration of the prospects and dangers of exemplification in the 'Skilful edges' section will serve as the basis for addressing basic questions about the purposes of research. It is also intended as a way to query the meaning and the promises associated with seeking 'reflexivity'.

\section{Orientations to secrecy}

To begin, this section offers a characterization of some of common orientations to secrecy prevalent in social research. The aim is not to provide a systematic mapping of relevant literature - that is a task beyond the scope of this chapter (see the introduction to this volume). Instead, I wish to propose some of the commonplace commitments associated with how researchers position themselves and their topics of study in order to set up the next section.

I begin by noting that unmasking, revealing, uncovering, unearthing, or unveiling that which is hidden, unappreciated, lost, or obfuscated is a common trope rationale for research. While the world was hitherto understood in this way, scholarship often takes its task as providing alternative ways through uncovering evidence. Arguably this overall orientation is particularly prevalent in the study of national security and armed conflict because of the acknowledgement of the deliberate attempts undertaken by some to hide information from others, the concerted propaganda efforts by some to distort others' assessments, and the utility for belligerents to plead ignorance about the human consequences of warcraft. These considerations combined with the potential high stakes involved mean that scholars, journalists, activists and others investigating matters of national security often take as their central task exposing hidden truths, moving beyond appearances, or similar goals that to make publicly known what was previously publicly unknown.

Drawing on archival records, collecting informants' accounts, undertaking observations of sequestered places, requesting government documents and the like serve as key modus operandi in security research. An indication of the varied ways academics have laid claim to uncovering what is the case includes:

- Ascertaining the unappreciated institutional practices and organizational structures that result in blinkered and narrow security assessments of 'weapons of mass destruction' (e.g., Eden 2004; Vogel 2013).

- Detailing how compartmentalization and information control affect the ways scientists and engineers make sense of the moral and political consequences of their work (e.g., Gusterson 1996).

- Identifying the pragmatic, political and organizational processes that mean raw intelligence is never simply 'raw' (e.g., Räsänen and Nyce 2013).

- Revealing that the security measures that operate at the level of shaping impressions of security, without making anyone more secure (e.g., Schneier 2003).

- Depicting the processes that structure which types of suffering can be acknowledged (e.g., Mookherjee 2006). 
One of the conundrums of positioning security research as process of uncovering is the manner this invites a turning back on the claims of researchers. If the institutionalized practices in security agencies can lead to blinkered and narrow understandings of the world, for instance, cannot the same criticism be directed at those in universities, policy institutes, and elsewhere too? The risk of producing a partial and slant understanding is perhaps most evident in histories of war and conflict. The inequalities in whose experiences get recorded, the way in which some accounts eclipse others, the manner emerging facts are interpreted against the existing assumptions of orthodox disciplinary truths, and the reliance in crafting histories on official archives can each decidedly silence aspects of the past (Trouillot 1995). Even those means of inquiry particularly prominent in relation to researching statecraft, such as Freedom of Information requests, have come under scrutiny for how their partialness can result in a misleading picture (see Savage and Hyde 2014; also Hughes and Garnett, this volume).

It is important to keep in mind that while secrecy is often prevalent and high stakes in relation to national security, this is also the case for many other topics as well. Secrecy studies beyond matters of security have raised grounds for caution about how to respond to conditions of deliberate concealment. Taussig's (2003) warning to avoid "the craving for certainty that secrecy inspires" spoke to the manner that the pursuit of unearthing can lead scholars to overrate their claims. Van Maanen (2011) voiced a similar concern in analysing 'confessional tale' ethnographies. Herein, "[m]issing data, incompleteness, blind-spots and various other obscurities are admitted into the account. The avowed purpose, of course, is to lift the veil of public secrecy surrounding the fieldwork" (ibid.: 91). As he contends though, in purporting to lift a veil, confessions work to both bolster the appearance of disclosure as well as heighten the importance of what is disclosed.

As a related example about grounds for caution about exposing secrets, in the sub-field of auto-ethnography scholars take their own situated lives as a basis for studying society, politics, and culture. As I argued previously (Rappert 2010), though, much of auto-ethnographic writing has been characterized by a questionable orientation to revealing personal secrets. Despite otherwise widely acknowledging the tensions and contingencies of representing personal experience, when it comes to writing about secrets, many auto-ethnographic works adopt an orientation of straightforwardly outing, disclosing, or bringing into light what was previously hidden (e.g., Medford 2006; Poulos 2008). The telling of what was previously withheld thereby functions to give these accounts a solidity and coherence beyond that which is warranted.

As suggested by the preceding paragraphs, attempts to reflexively turn back and attend to the relevance of secrecy for social research raise a host of concerns. In relation to matters such as depicting lived experiences and writing history, we are faced with choices and tensions. How then might security researchers reckon with secrecy both as a topic of study and an underlying condition for our inquiry? ${ }^{2}$ 


\section{Exemplification}

In the remainder of this chapter, I want to suggest one orientation. A key starting point for this is the acknowledgement that intentional concealment is not just something we as security researchers write about. It is a condition that we so often undertake empirical research in, and therefore, importantly, our writing varyingly entails it. Against these multiple levels of relevance, a strategy I have pursued is to exemplify (see Mulkay 1985) the negotiation of revelation and concealment I have experienced in the field (between researcher-researched) within my accounts (between authorreaders). In other words, the orientation has been one of finding ways of conveying the place of secrets within security domains through what is in and what is left out of my writing. A central aim of exemplification has been to examine the lived conditions within security communities, particularly the conditions of knowledge production.

But to give such an overall depiction is to present a radically simplified and goal orientated rationalization to what were a set of emerging responses to situated troubles. In what follows, I want to provide an account of these troubles and the sensibilities that inspired my writing.

\section{Experimental secrets}

My first immersion into disarmament and arms control communities took place in the early 2000s. At the time I was examining international attempts (mainly inspired by the Biological Weapons Convention) to devise a code of conduct for civilian life scientists to prevent their research from inadvertently facilitating the development of biological weapons. My research questions included: What sort of codes and other mechanisms for controlling research have been or are being offered to reduce the threats associated with bioweapons? What threats are codes offered as a response against? How are and could they be embedded within the practices of scientists? In part because of good fortunes of timing and in part because of the absence of people who felt comfortable speaking across the security and science divide, I ended up being a reasonably prominent figure in the international discussions about codes. This was evident through being invited to numerous overseas open and closed meetings held by governments, professional associations, nongovernmental organizations, and others.

In this participant-observer role I experienced various uneases. One, though I had read many academic political and historical analyses associated with disarmament, very few offered any practical insights into the lived experience of researching within diplomatic-related settings (especially as an active participant). Another set of uneases stemmed from the pervasiveness but open-endedness of the web of informal and formal disclosure compacts in place. This led to basic questions about how to go on - both as a participant in international deliberations and as a researcher seeking to document them.

As part of my most substantial work on codes of conduct, a largely ethnographic account titled Experimental Secrets (Rappert 2009), I sought to evoke for readers 
experiences of fractured disclosure that I and the people I studied contended with as part deliberations about codes of conduct. As just a couple of examples of the kinds of writing techniques used:

\section{Glossing}

Condition: Participants in discussions about codes of conduct - civil servants, academics, diplomats, professional representatives, etc. - needed to contend with how to communicate about the content and outcomes of meetings under disclosure rules that they attended. We also had to give some sense of meaning to events that we were not able to attend that were conducted under (non)disclosure agreements.

Unease: The open-endedness of many disclosure rules as well as the implicit presumptions within communities of practice about their appropriate interpretation can make it difficult to be confident about what can be reported. Too much conjecture can take place about the relevance of events individuals did not participate in and such speculation can significantly affect the subsequent unfolding of events.

Response: What I sought to do was to topicalize what was missing from my analysis. For instance, one way this was done was by purposefully detailing what took place before and after a specific 'closed' event in order to encourage readers to partake in the same kind of inference and speculation I and others engaged in. At times, this 'in-between' space was re-visited in Experimental Secrets, at other times not. But more than just being relevant to conditions of managed disclosure, I sought to use such techniques to highlight how reading descriptions of any kind of lived experience necessarily requires readers to participate through supplying meaning, filling in blanks, and making inferences about the denotation of words.

\section{Snippets}

Condition: Just as is often the case with regard to academic conferences, in the meetings I attended the informal conversations surrounding the presentations, speeches and formal discussions were sites of a good deal of 'action'. Rumour, (at times wild) speculation, and re-hashings were rife as civil servants, academics, diplomats, professional representatives, etc. tried to assess others' motivations, expectations, and plans.

Unease: Despite the importance of 'backstage' interactions, such conversations didn't figure in any of the academic or policy analysis that I knew, even if the Chatham House Rule and other types of (non)disclosure agreements enabled representing these informal conversations.

Response: I sought to reproduce snippets of such settings, but also snippets without speaker identification details or further supplementary interpretations (see Box 7.1). The lack of qualifying information was meant to minimize 
any improper identification but also to underscore the confusing hesitations associated with making sense of diplomatic banter. Fleeting conversations about complex issues using professional vocabularies in which doubts about the extent of disclosure were commonplace occurrences in my experience. I aimed to represent these conditions in ways readers could experience the possibilities and confusions of trying to make sense of 'what is going on' for themselves.

\title{
BOX 7.1 SHORTENED RENDITION OF A SNIPPET
}

"We all know why we are in the situation we are in."

\begin{abstract}
"I am just saying that what people say in closed sessions is not what they say in the open one. No state said anything about fear of science being shut down in the closed sessions. Did you notice it was not in the final report?"
\end{abstract}

"How on Earth did you get

the idea that we did the IL-4

experiment on monkeypox?"

"Some who would be in a position to know told me."

"Who?"

"Well I cannot say. I remember it quite clearly, as he was reaching for a croissant."

"So the foxes are in charge of the coup now?"

"Haven't they always been."

"I am not like most scientists, I don't close my eyes to what happens in this country. Like my parents that didn't want to ask questions before the war. Nice people, but they avoided asking questions when their neighbours disappeared. I don't want to be like that, I want to ask questions."

"We joked about it as one code to rule them all."

"All of this talk about bioterrorism, it's all about fear." 
These two examples give a sense of the kinds of techniques employed; techniques that made what was absent from Experimental Secrets a defining feature of the book. It is worth pointing out the somewhat tension-ridden aims pursued. On the one hand, at times my hope was that experimental forms of writing provided a 'better description'; better in the sense of making bare the commonplace interactions, frustrations and confusions of diplomatic initiatives. I wanted to do so because these matters were often side-lined in abstracted political analyses. On the other hand, though, the techniques mentioned in the previous paragraphs were not intended to be judged according to their representational accuracy in detailing 'what happened'. Instead the primary goal was pragmatic; by giving a flavour of the conditions for knowledge production, I hoped to foster sensitivities for acting in circumstances of secrecy.

\section{Statecrafting ignorance}

Employing forms of writing involving crafted disclosure in order to engage readers with the secrecy that abounds in diplomatic processes was the overall strategy for another publication on disarmament diplomacy: "Statecrafting Ignorance", written by myself, Richard Moyes, and 'A.N. Other' (2011). Derived from campaigning and scholarship undertaken over many years, the chapter set out to speak to what we three knew regarding the process that led to the 2008 international convention banning cluster munitions, but felt had been blanked out of the then emerging policy and academic analyses of the convention: collaborations, machinations, complicities, and duplicities between governments, non-governmental organizations, academics and others as part of reaching a ban.

In order to do so, "Statecrafting Ignorance" was written in a conversational format; it is a dialogue between the three authors distilled down from discussions held over two days. A conversation format was chosen because small group conversations of just this sort were integral to the securing of the convention: persuasion, planning, de-briefing, and updating were just some of the many acts performed through these interactions. In relation to the possibilities for writing, informal multiple party conversations are often characterized by allusions, incomplete descriptions, varied threads of discussion, different viewpoints and arguments made at cross purposes. These features were in line with the partial and playful descriptions we wished to craft; for while setting out to discuss what could not be easily discussed, "Statecrafting Ignorance" sought to do so through marking the boundaries of what was absent from it. Even one of the author's pseudonym, 'A.N. Other', indicated the bounds of what was being acknowledged while we sought to bring unacknowledged matters to the fore.

One technique employed to evoke for readers the types of experiences that we encountered was the use of redacted text (something that looks like this:

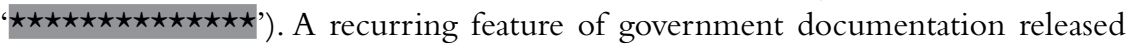
under Freedom of Information requests, such blacked out text is highly suggestive of what lurks below. In "Statecrafting Ignorance" (and Experimental Secrets), we 
redacted our own text to give a sense that - despite the aim of describing what was often left out of scholarly and popular accounts of disarmament diplomacy - we still held back some information from readers. We did this by first discussing and then writing out what we wanted to convey, and then went through the text blacking out the details we judged should be left out. Through this and other techniques, readers would at least have a sense of what was not be made available; matters that are often buried away beyond recognition in academic publications.

\section{The dis-eases of secrecy}

An interactive play between what was present and what was absent was also central to the make-up of another publication, the book The Dis-eases of Secrecy: Tracing History, Memory and Justice (Rappert and Gould 2017). Its topic was the apartheidera chemical and biological programme in South Africa titled 'Project Coast'. The histories told of Project Coast to date parallel many other kinds of human right transgressions: while details about some aspects of the programme are in general circulation, many are not. This is so because documents were destroyed, they remain sequestered in state archives, key individuals have refused to come forward, etc. Likewise, multiple and contradictory assessments about the rights and wrongs of Project Coast abound, each supported by a different set of facts and inferences.

These types of considerations are particularly pressing in the case of South Africa because truth as a basis for reconciliation has been a central plank of its transition from apartheid. In relation to Project Coast, the importance of truth was manifest in the Truth and Reconciliation Commission's (1998) special hearing on the programme. In light of the continuing social divisions within South Africa evident today, it seems reasonable to conclude that transitional justice efforts at 'truth telling' do not necessarily lead to the kinds healing once presumed, particularly intergenerational healing (Mandela Dialogues on Memory Work 2014).

Against concerns about what sort of histories have and can be written about Project Coast as well as their role in advancing justice, Chandré Gould and I set out to develop an appreciation of the fraught conditions for knowing about the programme in this book. We did so, in the main, through the manner claims and arguments were set out. The Dis-eases of Secrecy was organized through numbered entries given in roughly chronological order. While the book can be read front to back in the normal manner, the text was also organized into 11 themes. Through following numbered signposting between entries by flipping back and forth through the pages (as in a choose-your-own-adventure novel), readers are able follow threads of concerns related to topics such as 'victims', 'ignorance' and 'international relations'. In doing so, they will find themselves circling back on entries previously encountered, but situated in a different sequence of claims and therefore, at times, supporting different conclusions. The physical process of flipping back and forth between pages to read entries (and thereby passing over many others) provides an embodiment expression of how fashioning history entails making connections between some events and skipping over others. 
An intent of this format was to exemplify the process of researching secret and troubled pasts. We sought to place readers in the midst of the assemblage of a history to enable them to fashion connections anew. As we contended in the introduction (ibid.: xiii):

We wrote with absences and secrecy to alert readers to the processes of producing knowledge of the past. Through an argument in which what was missing was intended to be as much a feature of what was given, we sought to encourage readers to partake in a process of investigation - with the lures, dissatisfactions, and affects that this can entail. It is between the traces and fragmentations of our accounts that we hoped readers would be able to ask questions of themselves and others about the purposes of history and the potential of memory. In doing so, we hoped to engender sensitivities with the investments in the telling of history.

\section{Skilful edges}

In giving a flavour of some experimental varieties of exemplification, the previous section sought to provide possibilities for how security researchers can creatively engage with situations in which we have to be careful about what is disclosed. While a common hope for the writings outlined was to produce accounts that were accessible and engaging, my aim was not merely to fashion engrossing blanks as one might find in a detective novel. Instead, the kinds of reflexive 'turning back' outlined have sought to offer possibilities for responding to the knots and binds associated with investigating secrets.

The sensitivities informing the previously outlined attempts at exemplification included the importance of becoming curious about the academic conventions that enable but also constrict our writing. Against the temptation of treating security researchers' task as simply one of revealing what would otherwise be hidden, the overall orientation adopted was that of working through the importance of intentional concealment by partaking in it, while simultaneously bringing to the fore questions of what was being made available in that partaking. As part of this, instead of simply positioning security researchers as gaining authority by telling what happened in closed diplomatic processes, or by gaining credibility through evoking a sense that we could tell much but are barred from doing so, I and co-authors sought to inquire how the positioning of secrecy in security research shores up claims to authority and credibility.

It also follows, though, that the value of such efforts cannot not be assumed indeed it should be treated as beset by questions. As with attempts to be 'reflexive' more generally (Lynch 2000), what is gained through particular strategies and techniques depends on their adoption. At a general level, efforts to attend to what is not being attended to are always going to be partial. Unconventional forms of writing can offer novel configurations of the borders of our accounts, but there is no way this attending to can be total and complete. As such, the demand that follows is to engage thoughtfully with tensions and limits. 
The value of experimental writing with secrecy also depends on our purposes. As suggested above, my efforts were responses to particular practices: the consequential but unremarked upon social conventions of interactions in security domains and the ways in which histories over-delivered coherence and over-promised revelation. It follows that what counts as insightful, useful, etc. by way writing is not fixed in time, but depends on how individual interventions speak to the practice and scholarship of their day.

How then to engage skilfully with the limits of our writings? I would propose that at least one dimension for assessment is whether such writing prompts recognition of and empathy with the lived conditions of those we investigate. Although the more playful orientation outlined in the previous section might have seemed to imply researchers should adopt a nonchalant attitude towards what is included in our analyses, this was far from the case for me. Instead of being born from disengagement, what was included within Experimental Secrets, "Statecrafting Ignorance", and The Dis-eases of Secrecy was subject to considerable negotiation - with those being researched, my non-academic co-authors, and other collaborators. Certainly, this happened at a level far greater than comparable past publications of mine that took formal (and prosaic) ethical consent procedures as the over-riding criteria for deciding on the inclusion of empirical data.

The negotiations about what would be included provided an opportunity for connecting with others about the lived conditions within their communities of practice. For instance, as part of one of the 11 themes The Dis-eases of Secrecy, Chandré Gould and I set out to examine the reasons for a diplomatic silence widely known to many in disarmament but rarely acknowledged: namely the failure of South Africa to have declared an offensive programme under the Biological Weapons Convention (BWC). As background, States Parties to the BWC are meant to file so-called Confidence Building Measures (CBM) forms to promote transparency as well as to enable other states to assess their adherence to the convention. Of the many kinds of information included, states are meant to declare past offensive and defensive biological research and development programmes. Despite Project Coast having been subject to a host of formal investigations, widely reported in South Africa and abroad, no offensive biological research and development activities have ever been declared as part of South Africa's CBMs. More still, almost no mention has been made of this non-recognition within the official meetings and documentations of the BWC. And still more, South Africa is just one of several other states with highly questionable declarations that have also been subject to almost no attention within the BWC.

To paint an overall picture, Gould and I assessed the situation as follows:

- One of the repeatedly claimed purposes of CBMs was to promote transparency and confidence building;

- Yet many officials recognized the CBMs to be incomplete and inaccurate with regard to the declaration of past programmes. These faults though were not openly discussed within the BWC;

- And yet, for some of those Gould and I interviewed, the lack of declarations was said not to be a source of significant concern in relation to the levels of 
transparency or confidence placed in other governments (or the BWC as a whole) because the forms were invested with little significance;

- Despite this, the CBMs were still widely promoted as transparency and confidence builders and many initiatives have been conducted under the BWC to ensure governments fill in the forms.

In this arguably confused situation, in The Dis-eases of Secrecy Chandré Gould and I considered how consideration of the historical erasure of past programmes offered the potential for improving on-going international interactions (see Rappert and Gould 2014 as well). We did so by drawing on the experiences of anonymized prominent individuals associated with CBMs to develop a map of the kinds of defensive reasoning that they thought inhibited robust inquiry and encouraged antilearning practices within the BWC. On this basis of attending to their conditions of practice, we were able to identify and discuss with a wider range of officials in group setting the possible strategies for promoting greater confidence in the BWC.

Importantly, though in relation to the themes of this chapter, we recognized that many of the conditions of practice that inhibit robust discussion have also affected members of civil society - including academics participating in the BWC. Indeed, as elaborated in The Dis-eases of Secrecy, despite wishing to promote robust inquiry into CBMs, both in the underlying research and associated dissemination phases of this work, Chandré Gould and I repeatedly found ourselves falling into the same patterns of self-reinforcing delimited thinking and acting we associated with government officials. Attending to how this was so as part of The Dis-eases of Secrecy provided the basis for acknowledging the prevalence of intentional concealment in security research as well as the fraught conditions of being immersed in security communities. Through doing so, we hoped to develop a recognition of the lived conditions individuals were working under, conditions collectively constituted but not individually desired.

\section{Summing up}

In response to the tensions, binds, and uncertainties associated with what can and should be said about intentional concealment in disarmament diplomacy, this chapter has sought to offer some strategies and possibilities. The basic orientation advocated has been one of turning towards, rather than away from, the tensions, binds and uncertainties by making them topics for analysis. The central question raised has been this: how can social researchers skilfully write with and not just about secrecy?

In working through a response this question, I have sought to provide a kind of antidote to the commonplace commitment to reveal secrets. The overall orientation has been pragmatic. To paraphrase the philosopher Richard Rorty, in experimenting with forms of writing, I have set aside concern about definitely grasping the nature of statecraft in favor of attending to whether I was being imaginative enough to think up stimulating alternatives. In relation to my publications surveyed in this chapter, each sought to foster sensitivities for acting in circumstances of 
secrecy by using the mix of what was present and absent to speak to the conditions of knowledge production. As advocated, finding ways of writing with secrets and absences can be one approach for doing justice to both the subjects of our study and our engagements with them.

\section{Suggestions for further reading}

- Clare Birchall (2011) "There's been too much secrecy in this city: The False choice between secrecy and transparency in US politics”, Cultural Politics, 7(1): 133-156.

- $\quad$ Raymond M. Lee (2005) “The UK Freedom of Information Act and social research”, International Journal of Social Research Methodology, 8(1): 1-18.

- $\quad$ Steve Woolgar (ed.) (1988) Knowledge and Reflexivity. London: Sage.

\section{Notes}

1 See https://www.chathamhouse.org/about/chatham-house-rule

2 In relation to this question, a number of responses have been undertaken. For example, instead of orientating to official archives as warehouses of documents to be deciphered for the hidden stories they can tell, Stoler (2009) has sought to appreciate the taken for granted presumptions of officials that informed the production of officialdom records. Similarly, some have moved away from treating official documents as partial (and thereby faulty) historical texts to treating them as highly suggestive cultural images whose meaning should be deliberated (Office of Experiments 2013).

Relatedly, rather than treating transparency/secrecy, disclosure/concealment and publicity/secrecy as opposites, some have sought to show how they can co-constitute each one another (e.g., Bratich 2006). When these pairs are conceived of as inter-related, it no longer makes sense to envision the task of security researcher as being one of simply revealing what was hidden. In place of this approach, a more nuanced treatment is necessary.

\section{References}

Bratich, Jack (2006) "Public secrecy and immanent security", Cultural Studies, 20(4-5): 493-511.

Eden, Lynn (2004) Whole World on Fire: Organizations, Knowledge and Nuclear Weapons Devastation. Ithaca: Cornell University Press.

Gusterson, Hugh (1996) Nuclear Rites: A Weapons Laboratory at the End of the Cold War. Berkeley: University of California Press.

Lynch, Michael (2000) "Against reflexivity as an academic virtue and source of privileged knowledge", Theory, Culture \& Society 17(3): 26-54.

Medford, Kristina (2006) “Caught with a Fake ID”, Qualitative Inquiry 12(5): 853-864.

Mookherjee, Nayanika (2006) "'Remembering to forget': Public secrecy and memory of sexual violence in the Bangladesh war of 1971”, Journal of the Royal Anthropological Institute, 12(2): 433-450.

Mulkay, Michael J. (1985) The Word and the World: Exploration in the Form of Sociological Analysis. London: Allen and Unwin. 
Mandela Dialogues on Memory Work. (2014) Report on the Dialogue Series 26 November Johannesburg: Nelson Mandela Foundation.

Office of Experiments. (2013) "On being overt secrecy and covert culture," in Elizabeth Fisher and Rebecca Fortnum (eds). On Not Knowing. London: Kettle's Yard: 15-23.

Poulos, Christopher N. (2008) "Narrative conscience and the autoethnographic adventure. Probing memories, secrets, shadows and possibilities", Qualitative Inquiry 14(1): 46-66.

Rappert, Brian. (2009) Experimental Secrets: International Security, Codes, and the Future of Research. New York: University Press of America.

Rappert, Brian (2010) "Revealing and concealing secrets in research: the potential for the absent”, Qualitative Research 10(5): 571-588.

Rappert, Brian, Richard Moyes, and A. N. Other (2011) "Statecrafting ignorance: Strategies for managing burdens, secrecy, and conflict", pp. 301-324, in Susan Maret (ed.) Government Secrecy (Research in Social Problems and Public Policy, Volume 19). London: Emerald Group Publishing Limited.

Rappert, Brian and Chandré Gould (2014) Biological Weapons Convention: Confidence, The Prohibition And Learning From The Past. July ISS Paper 258.

Rappert, Brian and Chandré Gould (2017) Dis-eases of Secrecy: Tracing History, Memory and Justice. Johannesburg: Jacana.

Räsänen, Minna, and James M. Nyce (2013) “The raw is cooked: Data in intelligence practice”, Science, Technology, \& Human Values, 38(5): 655-677.

Savage, Ashley and Richard Hyde (2014) "Using Freedom of Information requests to facilitate research", International Journal of Social Research Methodology, 17(3):303-317.

Schneier, Bruce (2003) Beyond Fear: Thinking Sensibly about Security in an Uncertain World. Göttingen: Copernicus Books.

Stoler, Ann Laura (2009) Along the Archival Grain. Oxford: Princeton University Press.

Taussig, Michael T. (2003) "Viscerality, faith, and skepticism: Another theory of magic", pp. 272-306 in Birgit Meyer and Peter Pels (eds) Magic and Modernity: Interfaces of Revelation and Concealment. Stanford: Stanford University Press.

Trouillot, Michel-Rolph (1995) Silencing the Past. London: Beacon.

Van Maanen, John (2011) Tales of the Field (2nd edition). London: University of Chicago Press.

Vogel, Kathleen M. (2013) Phantom Menace or Looming Danger? A New Framework for Assessing Bioweapons Threats. Baltimore, MD: Johns Hopkins University Press. 


\title{
GENDER, ETHICS AND CRITIQUE IN RESEARCHING SECURITY AND SECRECY
}

\author{
Marijn Hoijtink
}

- Research objective: The aim of this chapter is to offer a reflective discussion of the gender-related opportunities and pitfalls associated with research on security and secrecy. This chapter helps researchers who want to reflect on questions of ethics and critique in research on security and military institutions.

- Research Puzzle: The puzzle the chapter addresses in relation to secrecy and methods is not simply to ask questions about how gender relations can help provide or limit access to information (although this will also be done), but to discuss how our research encounters with security professionals are shaped by our position as "insider"/"outsider" and by identity categories, among them gender.

\section{Introduction}

As feminist research has forcefully argued, the position and identity of the researcher are never irrelevant. It matters for the research process and research outcomes whether the researcher is male or female, black, white or brown, middle-class or working class, and so on. In research on security and war, gender dynamics have often been singled out as a particularly relevant factor influencing research outcomes. After all, in many ways, the domain of security continues to be a man's world. As Ann Tickner (2004: 44) writes, “the term 'woman' is still antithetical to our stereotypical image of a "national security specialist." Perhaps more so than any other domain, war and security are male-dominated and predominantly masculine areas, in which, as Tickner puts it, "it has been presumed that women have little important to say."

Over the course of my $\mathrm{PhD}$ research on security technology and corporate actors in European security, I became increasingly interested in and aware of the ways in which gendered power relations and dynamics have an impact on the 
research process and research outcomes. Sometimes, my gender presentation would provide access or information that I suspect I would otherwise not have had. For example, I noticed how during interviews many of my male interviewees would lecture me, or would try to impress me by sharing secrets. Other times, I would struggle to convince interviewees or participants to take me seriously. This was most obvious at the arms fairs and trade exhibitions that I visited as part of my fieldwork. The few women who were present at these events often worked as waitresses carrying champagne, wearing short skirts and high heels, or they were, as someone confessed to me in a private conversation at the Counter Terror Expo in London, the "excuse" woman that the company that they represented could display as a token of diversity. My own presence at these events confused, and sometimes even irritated, other participants, not only because I was a young woman alone at an arms fair, but also because I was a researcher - and, worse even, a social scientist and, hence, largely irrelevant to the exhibitors.

The aim of this chapter is to offer a reflective discussion of the gender-related opportunities and pitfalls associated with research on security and secrecy. Feminist work has long been concerned with shedding light on what is generally unseen and unacknowledged in academic research. A core objective of feminist research has always been to reveal the hidden or "private" experiences of women and to make their lives seen and their narratives heard. At the same time, feminists would stress that secrecy is not something that should always be uncovered. In research on, with and for vulnerable groups, secrets must often be kept to protect research informants. Moreover, feminist research has raised key questions about what it means to disclose secrecy or to know secrets. For example, to know secrets may allow us to build a relationship with "insiders," but it may also limit our ability to critique power relations in our research and beyond. A case in point is Carol Cohn's (1987) influential piece on the ethnographic research she conducted amongst "defense rationals" in the midst of the Cold War. Cohn observes how the men she spoke with and worked with in the context of her research used a highly abstract (and sexist) language to talk about nuclear weapons, what Cohn calls "technostrategic language." She soon finds that in her attempt to be taken seriously by these men, she too, begins to learn and adopt this "secret" language. Meanwhile, however, she recognizes that her ability to engage with these defense rationals in their own terms gets her "thinking inside their rules, tacitly accepting all the unspoken assumptions of their paradigms" (ibid.: 714).

In my own work, it was hard, as Cohn (ibid.: 688) put it, "not to notice the ubiquitous weight of gender, both in social relations and in the language itself." Gender relations had an impact on research access and my ability to navigate secrecy as I will discuss below, but my reflections on gender relations in my research also raised broader questions about reflexivity, ethics and critique. Drawing widely on feminist contributions to International Relations (IR), war, security and secrecy, this chapter addresses the following questions: How can we navigate the gendered impact of research access and research interviews, and how do we corporate this into our research findings in a reflective way? What does it 
mean to know secrets or to have gained close access? How do we write about, or critique security practices when we have established some sort of social bond with our research respondents? How far goes our responsibility for the people that we study or interview? And how do we navigate, what Gray (2016) calls, the "spaces between" engagement and disengagement with the secret institutions that we study?

In line with this edited volume and following a long-standing tradition in feminist research, I will address these questions while frankly writing about the realities of my own empirical work. The study upon which this chapter draws was conducted between 2011 and 2015 and focused on the growing commercialization of European security in the context of changing risk conceptions post-9/11. I asked: what motivates the growth market for security technology and the growing involvement of commercial security actors in Europe? In what way does the marketization of security in Europe change our understandings of current security institutions, practices, and forms of governance? How are commercial actors involved in (re)shaping (in)security and in the construction of preemptive risk? And how are these actors enrolled into the daily performativity of security, and with what effects for the relationship between public and private authority?

I used an in-depth and reflexive methodology, which was based on three principal means of data collection and data analysis: document analysis, interviews, and participant observation. A significant part of my fieldwork took place at three multiday trade fairs for armaments and security equipment: the Counter Terror Expo in London, the Milipol exhibition of internal state security in Paris, and Security Essen (see Box 8.1). In addition, I participated in a variety of stakeholder events across Europe, including a number of meetings organized in the context of an EU-funded research project on urban security. In the course of my fieldwork, I spent a great number of coffee breaks, lunches, and receptions speaking with contractors, engineers, and policy officials in the domain of European security. Fieldwork also included a bus tour with the consortium members of the research project that I studied to visit the touristic highlights of Bucharest. My observations at these events allowed me to study the emergence of new security technologies, as well as the specific discourses in which they emerged (Hoijtink 2014).

Participation in these events proved relevant for a third reason: while I engaged with high-level officials during most of my interviews, participant observation enabled me to have more informal conversations with mid-level security actors. Some of these conversations offered a messier picture of events than I would otherwise find in official discourse or in semi-structured interviews. As Hugh Gusterson (2008: 102) writes, my engagements with these mid-level security actors provided insights into the differences between "frontstage" and "backstage" narratives, or between what was officially said in public meetings and confessed in private conversations. It was precisely such informal moments that raised a number of questions about access, critique, and ethics that now inform this chapter. 


\section{BOX 8.1 SECURITY TRADE EXHIBITIONS AS RESEARCH SITES}

The growing number of security trade fairs are relevant sites to study trends and themes in war and security. Security trade fairs are not a new phenomenon, but, thus far, their relevance has been understudied (for recent contributions, however, see e.g. Jeandesboz 2016; Stockmarr 2016; Baird 2017).

All three trade exhibitions that I visited required some form of security clearance, and at all three exhibitions, visitors were subjected to security regulations, such as CCTV surveillance and security checks. All visitors were required to carry a photographic identity document and to visibly wear their personal visitor's badge. Photography was not allowed at these exhibitions, with the exception of Milipol. Apart from the requirement to preregister, admission to all three trade shows was relatively easy. However, entrance fees were high, around $€ 500$ for a two-day entrance ticket. The high costs involved in doing this type of fieldwork forced me to constantly think about my current data and about what a new fieldtrip would add to my narrative.

The trade exhibitions struck me as particularly masculine. For example, at the Milipol exhibition in Paris, visitors could test guns and robots and engage in a shooting competition at a provisional shooting range. Feminist literature on technology argues that technology is gendered in various ways, for example in the ways in which gendered assumptions about the user are designed into the technology, or in how technological artefacts, such as ultrasound technologies produce particular forms of knowledge about the female body, and structure relationships between the child and mother, or between the doctor and the mother in specific ways (see e.g. Faulkner 2001). Arguably, security and military technology is particularly gendered, because of the longstanding "popular masculine-please culture of war" among defense specialists (Dawson 2013).

The chapter proceeds in three steps. I will first examine feminist literature on secrecy and reflect on what a feminist lens allows us to see with regards to questions of navigating access and conducting field research in the context of secrecy and danger. Next, I offer a reflective discussion of how we can engage with questions of ethics and critique in the context of research on security and secrecy, drawing on recent work in the field of critical military studies in particular. I will conclude by means of providing three best practices that may guide further research. Throughout the chapter, I will draw on insights and empirical examples from my own work and that of others. 


\section{Secrecy in feminist research}

Secrets come in different forms and they affect our research in different ways: secrets may be kept by, from, or for research participants. We may keep secrets as a way of protecting our research informants, or, more instrumentally, as a way of protecting field access and the possibility of our research. Secrets are deemed exciting and, as such, they may be shared or disclosed to impress, even if, more often than not, secrets turn out to be surprisingly mundane, trivial, and unexciting. As studies of secret societies have pointed out, sharing secrets "is a powerful means of making and breaking social bonds" (Gusterson 1996: 80). Sharing secrets creates a sense of loyalty among those involved, as well as a stronger sense of separation from those who are excluded from the practices of secrecy.

What has been less often acknowledged is that secrecy is also highly gendered: secrecy has the ability to draw boundaries between the worlds of men and women, each with their own secrets (Herdt 1987). In national security and defense, to know secrets is often a right that is reserved for men. As Cynthia Enloe writes:

The most "manly" state policymakers and their academic advisors are the only ones rational enough to keep secrets. Less manly (i.e. less rational, less strategically “tough-minded") men - most (not all) elected legislators, most civil servants working in the more feminized departments of the state (e.g. health, culture, environment), most (not all) male journalists - and virtually all women can be excluded from the "top secret" inner circles of national security (Enloe 2016: 75).

Often, secrecy thus functions as a means of exclusion or oppression. "Secrecy," Gusterson (1996: 87) writes, "is a means by which power constructs itself as power." In this context, we reveal secrets, or seek to reveal secrets, to counter those that are in power and that hide information. The act of revealing secrets is itself subject to secrecy and power. Some forms of truth-telling are silenced or become delegitimized, because they do not fit our dominant understanding of proper truthtelling. A case in point, Linda Maxwell (2015) argues, is the way in which Chelsea Manning was attacked for leaking government documents out of what were supposedly private motives, for example, as retaliation for the fact that she was bullied in the military, or that she was living a secret life under Don't Ask Don't Tell in the US Army. As Maxwell points out, for many, the ways in which Manning connected her private struggles to the public act of leaking the documents disqualified her as a legitimate "whistleblower" - a figure, who is, according to the traditional model, animated by a concern with the public good only (see also Hughes and Garnett, this volume).

Feminist research has long objected to the putative separation between the public and private realm, the former associated with the official world of politics and the latter with the symbolically female private domestic sphere. Feminists 
have pointed out that the gendered nature of secrecy further reinforces the symbolic separation between the public and private sphere, even if the two domains are functionally closely interrelated. Indeed, important feminist work within the field of IR has shown that the predominantly masculine world of security, war and foreign policy relies on the hidden services and forms of support provided by women. Cynthia Enloe's (1990) book Bananas, Beaches and Bases: Making Feminist Sense of International Politics, tracing the experiences of women on the margins, working at the peripheries of military bases or serving in the military, points out that the delineation between the public and private realms is, in fact, one of the forms in which silence is sustained over the effects of militarism and women's marginalization. Enloe (1990: 195) famously argued that the "personal is international" and the "international is personal." To break these silences and give voice to women, Enloe insists that we study the international from the perspective of the lives of women and that we shed light on the seemingly normal and everyday interactions that take place in and around military and security institutions.

For Enloe, this approach has the potential to politicize the secret and supposedly private experiences of women; yet, recent feminist scholarship has also begun to problematize this preoccupation with voice and overcoming silence as a sign of agency, not in the least because the experiences of women differ, and because "the use and expressions of silence and secrecy intersect with class, race, ethnicity and other factors" (Palpart 2010: 24; see also Dingli 2015). In

\section{BOX 8.2 FEMINIST WRITINGS ON FIELD RESEARCH HAVE . . .}

- Problematized the notion of objectivity and the objective researcher: the researcher is a social actor, who is embedded in, and partaking in, social relations of power.

- Written frankly about the realities of empirical work, stressing the importance of 'writing in' the researcher and explicitly acknowledging the ways in which the positionality of the researcher, the research encounter, emotions, and struggles have an impact on the research process and outcomes (Ackerly et al. 2006).

- Strongly objected to the idea that the researcher leaves the field untouched without having an impact on respondents (Ryan-Flood and Gill 2010), calling attention to the ways in which existing social relations of power are reproduced in research relations and to how the research process might harm research participants. 
addition, secrecy can be a key means for resisting the marginalization of women (and men).As Jane Palpart (2010:25) writes, "to privilege voice over silence and secrecy as evidence of empowered agency ignores the transformative potential of a complex mix of choices," which may very well include the use of secrecy and silence.

Still, the broader feminist critique on the performed separation between the public and private domain has important implications for the study of secrecy. Firstly, feminism problematizes the idea that there is clear binary between secrecy and publicity. Along with contributions from queer theory, anthropology and cultural studies of secrecy, feminists have put forward the notion of the "public secret" or "open secrecy" to explore "that which is generally known, but cannot be articulated" (Taussig 1999: 6; see also Sedgwick 1990; Masco 2010). Open secrets govern the private lives of those who are silenced, but they also regulate public life in the sense that they reconfirm existing binaries of public/private, masculine/feminine and disclosure/secrecy, and the values and privileges that are associated with them.

Secondly, feminism allows us to see that secrets and silences are found in a variety of places, often on the margins of military and security institutions. This understanding provides a useful counterweight to a common assumption in political studies of secrecy that secrets are located primarily at the center of security institutions, in a clearly located 'chamber' of secrets. Such an understanding has implications for how we conduct our research. Rather than trying to extract or uncover secrets from the center of security institutions, feminist theory encourages us to conduct research on the margins and to navigate or work around secret institutions. Hugh Gusterson (1996) did so quite literally when he decided against applying for formal access to the Lawrence Livermore National Laboratory - he figured that the likelihood of being granted security clearance was simply too low and that, once denied, the management of the facilities would actively obstruct his research - and, instead, conducted his research outside the Laboratory fence. What Gusterson (2008: 101) calls his "enforced position on the margins of laboratory life," however, produced an ethnography that was particularly attentive to the constitutive effects of secrecy at Livermore, as well as to the role and experience of laboratory spouses.

Third, even if a main strategy of feminism, as put forward most forcefully by Enloe, is to give voice to women and to shed light on marginalized sites and subjects, feminist research has done much to problematize the imperative to reveal or make visible that we often find in (methodological) reflections on secrecy. I have already discussed how important new scholarship points to the transformative potential of silence and secrecy. More broadly, feminist research has argued that secrets must sometimes be kept in order to protect our research informants, particularly when those secrets and silences are key survival strategies. Other times, revealing secrets may simply be too dangerous for the researcher herself. This is particularly so when research focuses on 
violent institutions. For example, based on their experiences interviewing torturers and murderers in the Brazilian police and members of the Guatemalan Civil Police force respectively, Martha Huggins and Marie-Louise Glebbeek (2003) point out that in cross-gender research dealing with danger and secrecy, to eliminate or reduce power differentials between the researcher and the research informant may be a very dangerous strategy. While a common recommendation is that fieldwork should be approached as a collaborative effort, within the context of a study on danger, violence and secrecy "some interviewees," as Huggins and Glebbeek (2003: 365) write, "must remain objects of study, with hierarchy in such cases being necessary and legitimate" (see also Grassiani, this volume).

In my own research, physical danger or violence was never an issue, but there was always the risk not to be taken seriously. Access to information was sometimes openly denied, such as when I tried to access an annual conference on military and security technology in the Netherlands, but I was told that I "did not belong to the target group." More often, access to information was denied in more subtle ways. For example, interview requests were frequently ignored or they were sent to a colleague in the public relations department, who would then give a standard interview that did not go beyond what I would find online. Many of the people that I interviewed operated in a context in which they were actively "discouraged from veering off message" (Kuus 2013: 55). The challenge was to take my conversations with them "beyond the iteration of rehearsed talking points" (ibid.: 116).

One of the strategies that I used in my interviews was to ask a specific set of questions, what Gusterson (2008: 104) calls "branching” and "building" questions. I usually began by asking my respondents questions about their take on broader events and developments in European security. These questions served as icebreakers. I then asked more specific "branching" questions based on each interviewee's tasks, responsibilities, or concerns. As for "building," each interview built on interviews that were previously conducted, which allowed me to map and study the broader discursive field in which the commercialization of European security was taking place. I also used building questions to ask my respondents to reflect on my research interpretations and preliminary conclusions. "Branching" and "building" were important strategies to prevent my research respondents from getting bored. As Merje Kuus (2014: 56) points out "the question of how not to bore these professionals cannot be ignored." Arguably, this is particularly so in the context of studying elites, what anthropologist Laura Nader (1974) called "studying up." In the case of my research, most respondents were highly educated and intellectually curious, with some of them having PhD degrees. Quite a number of them had a background in engineering, so it was key to be able to explain to them why their perspectives were of interest to a social science research project. Often, as the work of Cohn also indicated, to be taken seriously meant being able to speak the very same technical language and to be prepared to display that 
ability, for example, by casually referring to the technical specificities of security systems or to use acronyms.

Some of my male colleagues, who worked on a similar topic, shared with me that they had very similar experiences and that they used similar strategies in interviews, although with an important difference: whereas they were often 'quizzed' by their interviewees and had to demonstrate that they knew what they were talking about, I was often 'lectured' during interviews. Most of the men whom I interviewed and spoke with seemed to be genuinely surprised that a woman was researching security and technology and some openly said so. Coincidentally, the fact that my name does not give away my gender (in the Netherlands, my name is given to both girls and boys) often added to the surprise when I showed up for an interview. Sometimes, my gender presentation opened up new avenues for information, such as when a high-level representative of the defense industry boasted about the different ways in which he had influenced EU policy-making in order to impress me. Admittedly, one of the strategies that I adopted at the time, but that I will problematize below, was that I would sometimes deliberately invoke the assumption that I was unthreatening, for example, by dressing in a way that is considered to be feminine and young. At the same time, as Harriet Gray (2016) explains, I was only able to adopt such a strategy, because, in many other ways, I still conformed with specific assumptions about what is a supposedly respectable and trustworthy academic subject - e.g. conducting my $\mathrm{PhD}$ research at a university that is perceived as reputable, within a larger research project that was funded within a prestigious funding scheme in the Netherlands. In other words, my identity - like all subjects' identities - is multifaceted and not only determined by my gender identity (Hansen 2000), and this mattered for my ability to gain research access and conduct research interviews.

As the above reflections about my positionality indicate, we ourselves, as researchers, keep or create secrets as well, including about who we really are or about what we really do in our research. For many feminists, this is a major concern. After all, an important question within feminist research methodology is how the researcher herself assumes a powerful position vis-à-vis the research object (see Box 8.2). How can we write about others without confirming existing power relations, or in ways that do no harm to the people that we study or interview? As a response, many feminists have argued the researcher's objective should be to eliminate power relationships between the researcher and the researched and even to establish a friendship with research participants (see e.g. Oakley 1981; see also Grassiani, this chapter). Accordingly, if academic research is about establishing a friendship with our research participants, then we must keep the secrets that they entrust us with and be truthful about our own motives.

In research on (security and military) elites, however, we often make the explicit decision to refuse such a social bond, because we aim to confront power and challenge those who hold power. As Cohn's work has shown, this is not 
always straightforward. Cohn finds that particular challenges are involved in conducting ethnographic research, while simultaneously disengaging from the security institutions that we are studying. "Reader, I liked them," she confesses when she discusses her encounters with the group of nuclear strategic analysts she studied (Cohn 1987: 690). Neither may the explicit denial of a social bond with political elites always be the most productive strategy for critique. Drawing on a recent body of scholarship in critical military studies, in the below I suggest that a more productive strategy for critique may be to foster openness in our research encounters with security elites.

\section{Reflections on ethics and critique in security research}

Halfway through my $\mathrm{PhD}$ project, I was invited to join a two-day stakeholder meeting in Bucharest, which was organized in the context of a large, EUfunded research project on urban security technology that I was studying. Included in the program was a bus tour with all the consortium members to visit the touristic highlights of the city. During the tour, I got the chance to speak with a number of the manufacturers and contractors in the project, one of them representing a large Israeli defense company. He asked me about my project and why I was there. I responded in the usual, neutral way: that I conducted my $\mathrm{PhD}$ research on the development of new security technologies post-9/11 and that I was interested in how new companies interact with public authority in the field of security. While this was certainly true, it was also only half of the story. What I left out was that I was mostly critical of how speculative understandings of risk and profit made new investments in security equipment and armaments possible. Of the companies and markets that I studied I was particularly critical of Israeli security and defense companies, because of the ways in which they have been marketing their experiences with (counter-)terrorism and war. When I explained what my project was about I was surprised to find that the person I was speaking with picked up on the critical underpinnings of my project immediately and was genuinely interested in them, asking me about the extent to which my project "was influenced by the work of Noam Chomsky and Naomi Klein" (two authors who have written widely and critically on private interests in the context of neoliberalism, see Chomsky 1999; and Klein 2007).

What followed was a very thought-provoking conversation about the role of his company and other Israeli defense companies in Israeli society and the Occupation, and about how he could possibly reconcile his own critical thinking with his work for the company. Back home in Amsterdam, thinking about my conversation with him, I asked myself a number of questions that I have been reflecting on since: am I deceptive if I do not tell my research participants the whole story, that is, if I leave out what I am actually interested in? Am I not re-constituting or legitimizing the dominant discourse if I do not challenge my research participants 
in our conversations? Am I not missing out on important moments of inconsistency, or resistance if I underestimate my research respondents? And is it possible or productive to challenge respondents when we "study up" or when we have little research access in the first place?

Recently, an emerging body of scholarship within feminist IR and the subfield of critical military studies has begun to engage with similar questions. Much of this literature calls for a commitment to openness in research encounters with military institutions, military personnel and militarism (see e.g. Baker et al.2016) - a commitment that, I suggest, we should extend to our encounters with security/secret institutions and processes of securitization (also Stavrianakis, this volume). Broadly, this commitment requires that we are attentive to the shifting and multifaceted positionality of the subjects that we study, or to the ways in which gender constructs are often contradictory and on the move (Duncanson 2009). To attend to this complexity, demands, as Basham and Bulmer (2017: 63) write "a methodological and epistemological commitment to situatedness and proximity to that which we study," which often, but not necessarily, takes the form of ethnographic fieldwork. Citing Donna Haraway, Basham and Bulmer write:

The point is to make a difference in the world, to cast our lot for some ways of life and not for other [and] to do that one must be in the action, be finite and dirty, not transcendent and clean. Knowledge-making technologies, including crafting subject positions and ways of inhabiting such positions, must be made relentlessly visible and open to critical intervention.

(Haraway 2004: 337; cited in Basham and Bulmer, 2017: 63).

Such a commitment to openness in our research encounters would also open up new forms of critique and resistance, what Rech et al. (2015: 56) call "engaged critique." This mode of engaged critique can take different forms. One way is to actively look for and allow for alternative voices in our research. As Basham and Bulmer (2017: 68) write in the context of their work on militarism, an engaged form of critique "necessarily means letting go of our comfortable beliefs that we already know who is resisting, and how they are doing it, and being brave enough to remain open to alternative possibilities from people and places we least expect." Such alternative voices and possibilities may come from veterans, as some authors in critical military studies have suggested (see e.g. Bulmer and Jackson 2015), but also from 'whistleblowers, or from dissident or alternative voices in the security industry, as my example in the above illustrates. The point is that we should not simply presume that the researcher has the sole claim to critique. Rather, the people who we engage in the research process "have their own critical capacities which they use to reflect on their experiences" (Basham and Bulmer 2017: 68). We should engage these 
potentialities for critique more explicitly in our research designs and when conducting and writing up our research.

Another way in which we can practice a different and more engaged form of critique is by acknowledging more explicitly, as feminist research encourages us to do, the ways in which we, as researchers, intervene in social and political processes when we conduct our research. Sarah Bulmer discusses in an article by Baker et al. (2016: 148-150) how in the process of her research she began to think differently about her own role as interviewer. She explains:

I realized that in asking questions about gender and sexuality I was reproducing the very discourse and subjectivities I wanted to change (...). I sought to actively destabilize the gendered terms I was using in my asking of certain questions and in gently challenging my interviewees on some of their responses.

(ibid.: 148)

Rather than viewing the interview as a source of data collection only, Bulmer suggests that we approach the research process as a political intervention in the context of which research participants (may) deconstruct their own positions. This implies "quite an active way of interviewing," which, she recognizes, "might have its own problems if that destabilizing of someone's identity or gentle challenging of their views is considered to be 'harmful' to the participant" (ibid.). Yet, she considers this way of interviewing to be more productive in terms of making a political difference beyond the original research and more honest and reflective of her actual intentions.

I have become increasingly intrigued by this idea of an engaged critique that is integral to the research process and I am planning to adopt this strategy more frequently in my future research projects. One may ask the (legitimate) question of how feasible and sensible such a strategy is in the context of research on secrecy and danger. Indeed, we risk losing research access or alienating our research participants if we challenge them or if we ask questions that are not what they expect. At the same time, as Rech et al. (2015: 56) argue, it is precisely in the context of secrecy, in-transparency and non-access that engaged critique is an important strategy to establish contact with gatekeepers and to gain access. For them, this may also involve that we actively seek to secure defense funding (or security research funding, as European scholars increasingly do in the context of the EU's framework program) - a strategy that feminist writers, such as Enloe and Cohn have earlier warned against because of the danger of scholarly militarization.

\section{Conclusions}

This chapter engaged with feminist literature to examine the gender-related opportunities and pitfalls associated with research on security and secrecy. Rather than providing us with a clear strategy for negotiating access or uncovering secrecy in an effective manner, feminist work encourages us to reflect on broader questions, including about how secrets manifest themselves, who can 
hide information or reveal secrets, or what it means to disclose secrecy. Let me, by means of a conclusion, nevertheless, identify three best practices that have been discussed in this chapter:

1 Develop an awareness for the ways in which identity categories, among them gender, affect the research process and your results.

2 Foster openness in your research and your relationships with research participants. Be open to surprise and unexpected voices.

3 Don't be deceptive and take your research respondents seriously. At the same time, reflect on where your ethical responsibility lies: is it with gatekeepers, research participants or with the "distant others" that are affected by your research (Wall 2011)?

\section{Suggestions for further reading}

- Brooke A. Ackerly, Maria Stern and Jacqui True (eds) (2006) Feminist Methodologies for International Relations, Cambridge, UK: Cambridge University Press.

- Catherine Baker,Victoria Basham, Sarah Bulmer, Harriet Gray and Alexandra Hyde (2016) "Encounters with the military", International Feminist Journal of Politics, 18(1): 140-154.

- Carol Cohn (1987) "Sex and death in the rational world of defense intellectuals", Signs, 12(4): 687-718.

- Cynthia Enloe (1990) Bananas, Beaches and Bases: Making Feminist Sense of International Politics, 1st edn., Berkeley, CA: University of California Press.

\section{References}

Ackerly, Brooke A., Maria Stern, and Jacqui True (eds) (2006) Feminist Methodologies for International Relations, Cambridge, UK: Cambridge University Press.

Baird, Theodore (2017) "Knowledge of practice: A multi-sited event ethnography of border security fairs in Europe and North America”, Security Dialogue, 48(3): 187-205.

Baker, Catherine,Victoria Basham, Sarah Bulmer, Harriet Gray, and Alexandra Hyde (2016) "Encounters with the military", International Feminist Journal of Politics, 18(1): 140-154.

Basham,Victoria and Sarah Bulmer (2017) "Critical military studies as method:An approach to studying gender and the military", pp. 59-71 in Rachel Woordward and Claire Duncanson (eds) The Palgrave International Handbook of Gender and the Military, London: Palgrave Macmillan.

Bulmer, Sarah and David Jackson (2015) "You do not live in my skin': Embodiment, voice and the veteran", Critical Military Studies, 2(1-2): 25-40.

Chomsky, Noam (1999) Profit over people: Neoliberalism and Global Order, New York, London, and Toronto: Seven Stories Press.

Cohn, Carol (1987) "Sex and death in the rational world of defense intellectuals", Signs, 12(4): 687-718.

Dawson, Graham (2013) Soldier Heroes: British Adventure, Empire and the Imagining of Masculinities, London and New York: Routledge.

Dingli, Sophia (2015) "We need to talk about silence: Re-examining silence in international relations theory”, European Journal of International Relations, 21(4): 721-742. 
Duncanson, Claire (2009) "Forces for good? Narratives of military masculinity in peacekeeping operations", International Feminist Journal of Politics, 11(1): 63-80.

Enloe, Cynthia (1990) Bananas, Beaches and Bases: Making Feminist Sense of International Politics, 1st edn, Berkeley, CA: University of California Press.

Enloe, Cynthia (2016) Globalization and Militarism: Feminists make the Link, Lanham: Rowman \& Littlefield.

Faulkner, Wendy (2001) "The technology question in feminism: A view from feminist technology studies", Women's Studies International Forum, 24(1): 79-95.

Gray, Harriet (2016) "Researching from the spaces in between? The politics of accountability in studying the British military", Critical Military Studies, 2(1-2): 70-83.

Gusterson, Hugh (1996) Nuclear Rites: A Weapons Laboratory at the End of the Cold War, Berkeley: University of California Press.

Gusterson, Hugh (2008) "Ethnographic research", pp. 93-113 in Audie Klotz and Deepa Prakash (eds) A Qualitative Methods in International Relations: a Pluralist Guide, New York: Palgrave Macmillan.

Hansen, Lene (2000) “The Little Mermaid's silent security dilemma and the absence of gender in the Copenhagen school”, Millennium:Journal of International Studies, 29(2): 285-306.

Herdt, Gilbert (1987) Guardians of the Flutes: Idioms of Masculinity, New York: Columbia University Press.

Hoijtink, Marijn (2014) “Capitalizing on emergence: The 'new' civil security market in Europe”, Security Dialogue, 45(5): 458-475.

Huggins, Martha and Marie-Louise Glebbeek (2003) "Women studying violent male institutions: Cross Gendered dynamics in police research on secrecy and danger", Theoretical Criminology, 7(3): 363-387.

Jeandesboz, Julien (2016) "Smartening border security in the European Union: An associational inquiry", Security Dialogue, 47(4): 292-309.

Klein, Naomi (2007) The Shock Doctrine: The Rise of Disaster Capitalism, New York: Palgrave Macmillan.

Kuus, Merje (2013) "Foreign policy and ethnography: A sceptical intervention”, Geopolitics, 18(1): 115-131.

Kuus, Merje (2014) Geopolitics and Expertise. Knowledge and Authority in European Diplomacy, West Sussex: Wiley Blackwell.

Masco, Joseph (2010) "'Sensitive but unclassified': Secrecy and the counterterrorist state", Public Culture, 22(3): 433-463.

Maxwell, Lida (2015) “Truth in public: Chelsea Manning, gender identity, and the politics of truth-telling”, Theory \& Event, 18(1).

Nader, Laura (1974) “Up the anthropologist: Perspectives gained from studying up", pp. 248311 in Dell Hymes (ed.) Reinventing Anthropology, New York:Vintage.

Oakley, Ann (1981) "Interviewing women: A contradiction in terms", pp. 30-61 in Helen Roberts (ed.) Doing Feminist Research, London and Boston, MA: Routledge \& Kegan Paul.

Palpart, Jane L. (2010) “Choosing silence: Rethinking voice, agency and women's empowerment”, pp. 15-29 in Róisín Ryan-Flood and Rosalind Gill (eds) Secrecy and Silence in the Research Process. Feminist Reflections, Abingdon \& New York: Routledge.

Rech, Matthew, Daniel Bos, K. Neil Jenkings, Alison Williams, and Rachel Woodward (2015) "Geography, military geography, and critical military studies", Critical Military Studies, 1(1): 47-60.

Ryan-Flood, Róisín and Rosalind Gill (eds) (2010) Secrecy and Silence in the Research Process: Feminist Reflections, Abingdon \& New York: Routledge. 
Sedgwick, Eve Kosofsky (1990) Epistemology of the Closet, Berkeley, CA: University of California Press.

Stockmarr, Leila (2016) “Security Fairs", pp. 187-196 in Rita Abrahamsen and Anna Leander (eds) Routledge Handbook of Private Security Studies. Abingdon and New York: Routledge, 187-196.

Taussig, Michael (1999) Defacement: Public Secrecy and the Labor of the Negative, Stanford, CA: Stanford University Press.

Tickner, J. Ann (2004) “Feminist responses to international security studies", Peace Review, 16(1): 43-48.

Wall, Tyler (2011) "Engaging empire at home and in the field: The politics of home-front ethnography in states of emergency", Cultural Dynamics, 23(2): 127-141. 


\title{
(IN)VISIBLE SECURITY POLITICS
}

\section{Reflections on photography and everyday security landscapes}

\author{
Jonna Nyman
}

- Research objective: This chapter will help researchers who want to use visual ethnographic methods in their research, focusing on ethnographic photography and participatory photography.

- Research puzzle: The chapter addresses the question of how and where we see security. By focusing on security practices that take place openly in public spaces, it challenges the ongoing link between security and secrecy.

\section{Introduction ${ }^{1}$}

Can we see security? The answer really depends on where we look, and what we consider relevant to security (studies). Security is closely associated with hidden, secret practices that are not in the open: with that which cannot be seen. But security work also takes place openly in public spaces. During my research on Chinese security politics, I engaged in participant observation in a wide range of sites, focusing on everyday security landscapes: in particular security checkpoints and street-level security services and personnel. Not only is access to these sites not a problem, it is a compulsory part of everyday life in contemporary China. These sites and practices have blurred into the urban landscape, becoming (in)visible mundane backdrops and routines of daily life. As my interest in these spaces and practices grew I began to reflect on and question what we see and how we see (as) security. These are not spaces or practices normally engaged with in security studies. ${ }^{2}$ Taken for granted and rarely questioned, my everyday security landscapes were also nebulous and hard to pin down. Drawing on visual ethnographic methods, I combined ethnographic photography with written notes to document and explore my own encounters with these spaces. I also undertook a small-scale participatory photography project with six participants in Beijing, who each took a series of photographs of their own encounters with security in everyday life. 
The chapter will help scholars interested in incorporating visual ethnographic methods in their research. In security studies engagement with visuality tends to focus on analysing widely circulated images, but my focus here is on answering research questions not "by examining images . . but by making them" (Rose 2012: 10). This poses different methodological challenges, but also opportunities. For instance, what if we want to reorient the visual lens towards practices rarely engaged with under the umbrella of security, how might we capture such practices? How can we use photography as a method for generating knowledge about security, and what happens when we do? What happens when we centre visibility to ask, when/where/how/what do we (and don't we) see (as) security? And when we 'see' security through the lens of a camera, how does this affect how and what we see, and how we think about it?

After briefly setting out some context, I will discuss my use of ethnographic photography and participatory photography, with some reflections and practical guidance for researchers thinking about incorporating similar methods in their research. I end with a few thoughts on the meaning of 'everyday' security and (in) visibility in security politics.

\section{Security paranoia and other methodological problems}

Researching security in authoritarian contexts poses its own particular challenges. China increasingly suffers from an extreme case of "security paranoia" (You 2016), which makes for difficult choices when it comes to what to research and how. But this was also what made me interested in the first place: government interest in security has proliferated in China in the last five years, with the creation of a range of new security-focused institutions, new security legislation, and even a new officially endorsed "comprehensive security concept" (Renmin Ribao 2014). These top-level policy changes have attracted a lot of interest, but there has been little focus on what this actually means in practical terms. For instance, how do these changes affect social and political life in China today? In trying to answer this question, I've become very interested in how security is practised and experienced in everyday spaces, and how this interacts with macro-level political changes. Ultimately I'm interested in the evolving meaning and practice of security in China today, and what the effects are. It's a mixed methods project, drawing on wideranging archival material, a series of elite interviews, and a range of ethnographic methods developed during eight months of fieldwork, which are my focus here. I was based in Beijing, but also travelled widely across China.

I knew that access would be a problem, so I had to think creatively to get useful and interesting data that would allow me to answer my research questions. For instance, while participant observation in a security organisation or government department would have provided fascinating data, this was not realistic in the context I was working in. Driven by previous experiences in China and my own growing interest in micro-politics and the everyday, I started to think about other ways to conceptualise and explore everyday security in China. My ethnographic approach 
drew on Geertz “deep hanging out” (1998), which involves more informal longterm immersion, distinct from interviewing or observing behaviour. One of the things that caught my attention was China's newly created "national security education day" (PRC Central Government 2015), which sees a wide range of activities and educational materials distributed to educate the general public about national security. Seeing these education campaigns play out in public spaces, I began to think about public space as another site for the everyday (re)production of security. My own everyday encounters with security check-points and street-level security services and personnel started to become more significant in my thinking about how security is 'made' in China. So I decided to proceed with a broad understanding of 'everyday security' (see also Crawford and Hutchinson 2016), focusing on the daily (re)production of security in public spaces.

This created a new problem: how do I document these encounters? Written notes seemed insufficient, failing to fully capture my experiences. Tentatively, I started to photograph whenever possible, to document more accurately what I was seeing, with a plan to use my photographs as a source of data alongside my field notes. But with time, photography grew into a bigger part of the research: it was no longer 'just' a method of data collection or documentation, it was a part of my analysis. As I photographed and deliberated with Chinese friends and colleagues, I came to realise that I wanted more. My position both as a foreigner and as a researcher already obsessed with security politics of course shaped both my experiences and what I would 'see' as security in the first place. All experiences are situated, and I wasn't looking for something 'objective' or neutral, but I did want a more structured in-depth insight into how Chinese people are experiencing security in the everyday, to compare with and analyse alongside my own experiences. This is when I stumbled on participatory photography, thanks to a chance encounter with a new colleague. ${ }^{3}$ I decided it was a worthwhile experiment.

\section{Photographing security}

Images are everywhere. Visuality and what we see shapes our experience and knowledge of security, but also how we represent that knowledge. My own use of photography fits within the broader heading of visual ethnography (see Pink 2013). Although ethnographic methods have slowly become more popular in critical security research, there has been little exploration of the role that photography might play in this. So the key question I want to tackle here is: how can we use photography to produce knowledge about security?

\section{Ethnographic photography: an ambulatory method}

When I started to take photos as part of my participant observation I wasn't really sure what I was actually going to do with the photographs. I had a desire to record and map everyday security landscapes - the actors, practices, and architectures I was encountering while 'hanging out' in public spaces. A desire to go beyond written 
words to capture some of the visual and material aspects of what I was experiencing, to use alongside my notes and reflections on the experiences/encounters themselves. It started as a more ad-hoc practice, as a way to try to 'fix' or pin down the many nebulous everyday "brief encounters" (Weismantel 2001: xvii) I had with security that I wasn't quite sure how to make sense of. With time it became more systematic and by the end of the project I had created a visual research diary, reflecting my own evolving responses to the security actors, practices, and architectures I was encountering on a daily basis. Photography served not just to record, but to sharpen my gaze by "framing the field in the viewfinder" (Emmel and Clark 2011).

I describe my method quite literally as wandering, because this is what I did. Photography is a mobile method: it happens in movement. This is also reflected in my photos, some of which are rather blurred by my attempts to catch something before the moment passes. I spent much of my time in the field walking around Chinese cities, thinking, observing, and photographing. Here I also draw on methods developed in urban studies and political geography where walking methods are more commonly used (see, for instance, Pierce and Lawton 2015; Ingold 2010; Lee and Ingold 2006; Adey et al. 2013). Some of the time I wandered in a very structured, formal way: doing 'urban transects' by tracing paths across the city and making notes and taking photographs (and in some cases recording video) along the way (see also Adey et al. 2013). These were sometimes interrupted by random ID checks or additional security check points, which I noted down as part of my records. But some of my 'best' data derives from more random photographic encounters: stumbling on a series of posters about national security in a small alleyway on my way to meet a friend for dinner, for instance. Ingold calls this 'ambulatory knowing', knowing by walking:

knowledge is grown along the myriad paths we take as we make our ways through the world in the course of everyday activities, rather than assembled from information obtained from numerous fixed locations. Thus, it is by walking along from place to place, and not by building up from local particulars, that we come to know what we do.

(2010: 121-122)

My ambulatory method was an important part of my own process of exploring and generating knowledge about everyday security landscapes in contemporary China: being-in, moving-in, everyday security landscapes and recording my experiences in written and photographic form. Of course this requires significant time spent in the field.

Places are created by routes, "by the shifting interaction of person and environment" (Lee and Ingold 2006: 68) and movement helped me to get a sense of how security practices map out across the city: where security checkpoints are more concentrated and where they are sparsely distributed, where different kinds of security personnel are concentrated, and so on, which helped me to develop a broader picture of how the network of urban security practices fits together. Moving between and in these spaces was crucial to my understanding of security-in-place, 
the situatedness of my security practices in their physical context. Hagmann similarly uses a "spatial heuristic" to investigate security ensembles within a space and how they fit together (2017: 7) rather than focusing on particular kinds of security practices or actors, as is more common. He stresses a need for "contextualised accounts of contemporary control" to understand how security varies in different spaces even in the same city, noting that because different spaces have different "architectural, societal, and political characteristics" they work differently, as does the securing of those spaces (Hagmann 2017: 12). In China there is also huge regional variation. Some spaces are highly securitised in a more uniform way across different provinces, such as high speed rail stations, while others vary depending on historical significance and political relevance: it makes little sense to compare security ensembles in a public park in Kunming with those of a park in Kashgar, for example. Spending a longer period in China also allowed me to trace temporal variation in security practices, observing how moments of national significance and/or tension such as key political meetings, international summits, and key anniversaries were reflected in the ebbing and waning presence of security personnel, practices, and architectures in different sites.

Photography is not always a suitable research method. Its suitability depends on your identity and its relation to your field of research, but also on how photography is used in the context in which you're working. Amateur photography is immensely popular in China today, and so my photography did not really stand out as inappropriate, suspicious, or out of place. At the same time, my role as a white Swedish woman travelling (and wandering) in China made me a constant object of interest. I was myself frequently the subject of photography by other interested photographers, especially in more rural areas where foreigners are less common. Including, on one memorable occasion, when I was 'surreptitiously' photographed by a uniformed police officer in Western China, who, after realising I'd noticed, somewhat sheepishly told me he thought I was beautiful and asked if I was Russian. This and similar experiences opened doors to many interesting encounters (and a vast number of selfies!). Although I was never able to blend in, being perceived as an interested stranger opened many doors, and also permitted me extra leeway when it came to 'strange behaviour' like taking photos of security check-points and personnel.

Making research decisions about photography is fundamentally shaped by the context in which you're working. In some spaces, photography is illegal. Photographing human beings poses its own challenges regarding consent, but also the safety of the people portrayed if you're working in authoritarian or otherwise sensitive contexts. As a result of my own concerns with such questions, I do not reproduce some of my photos where people are easily identifiable and/or engaging in activities which could get them into trouble, regardless of whether they've given their consent for me to do so. Your context may pose different challenges, which need to be reflected on before using photography as a research method. Here paying attention to what Rose terms "reflexive vigilance" is helpful:"the careful and consistent awareness of what the researcher is doing, why, and with what possible consequences in terms of the power relations between researcher and researched" (2012: 253). 
I photographed a wide range of things that I considered relevant to security, and the process of photographing opened my eyes to new things and made me 'see' security in new places. My starting point was security practices, but as I wandered, observed, and photographed the 'doings' of security I thought more and more about agency and participation, about who does the doings of security in China today. This led me to take a series of photographs of somewhat more unconventional security actors as they went about their daily doings. Figure 9.1 portrays a bored young security guard equipped with riot gear, stationed at Houhai lake in Beijing.

I spent much time observing the work of private security guards. Cheaper than regular police, they are hired by both private and public entities and perform a significant portion of police and security work in Chinese cities but are rarely accounted for in research on security in China (see Scoggins 2018). They wear formal uniforms and often carry police equipment, including riot gear, but they are usually young and lack police training. This bored young security guard sitting alone with his equipment propped up on the bench next to him made me rethink my own vision of the organised and well-oiled machine of the security state.

Who does security was a question that I kept coming back to, as I encountered more and more examples of unconventional security actors, including mass mobilisation of the civilian population. Figure 9.2 shows an anti-terrorism patrol on the streets of Kashgar, in Xinjiang, a province in the far North-West of China.

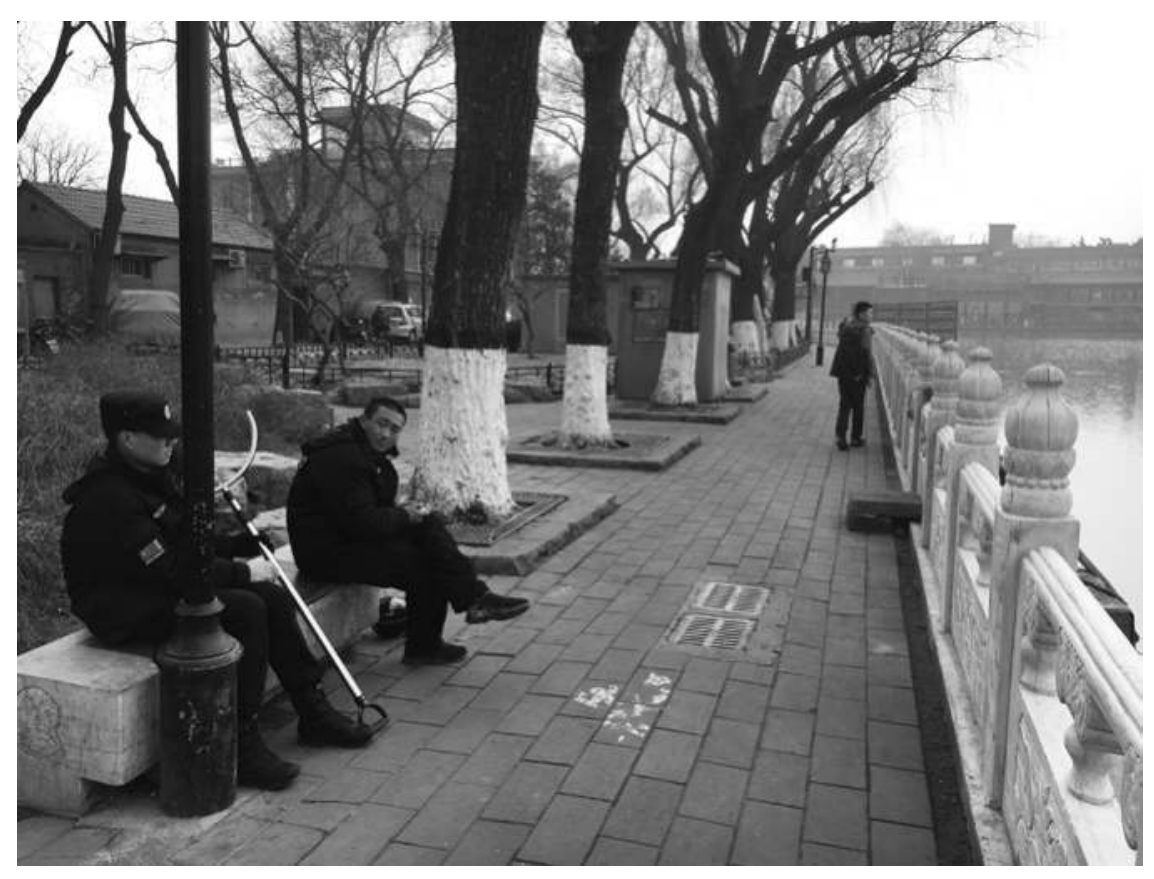

FIGURE 9.1 Security guard at Houhai lake, Beijing.

Source: Jonna Nyman 


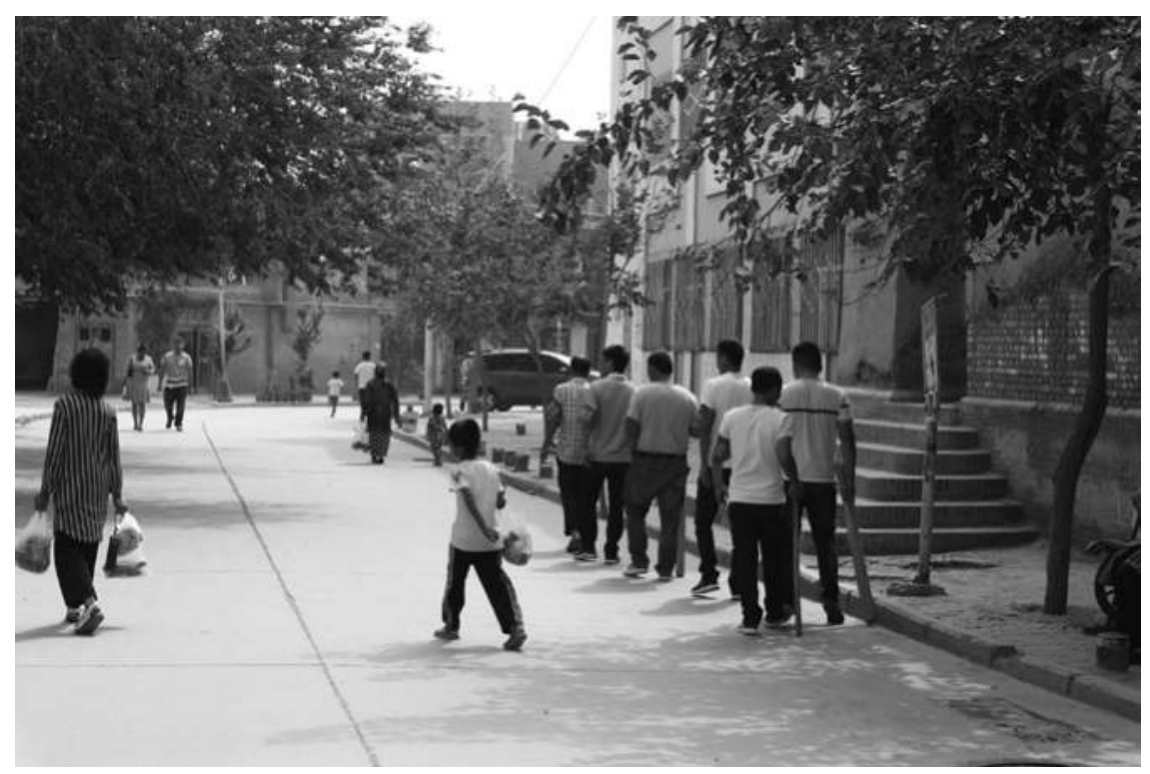

FIGURE 9.2 Anti-terror patrol in Kashgar, Xinjiang.

Source: Jonna Nyman

This was another chance encounter, stumbled upon while wandering around the city on foot. In the photo, six civilians are seen patrolling the streets with large wooden bats, which are used in anti-terror exercises across the province. They each wear a red armband to signal their status as civilian security volunteers. The story the photo does not tell, however, is that such participation is often compulsory. Again, these are not security actors that are considered relevant in contemporary studies on Chinese security politics, but their visual and material presence on the streets has effects (as does forced participation, of course).

My photographic encounters with everyday security actors made me think more deeply about the meaning of security in China today. The vast majority of the academic literature on Chinese security politics focuses primarily on foreign policy, China's relations with other states, or the armed forces. But my daily encounters with security told me something rather different: bored young security guards and civilians patrolling the streets have little to do with foreign policy and more to do with preserving domestic order and stability. In fact, since 2011 China's domestic security budget exceeds the budget for external defence (Guo 2012: 445). At the same time, there is growing journalistic and popular interest in China's increasingly high-tech surveillance systems, but in practice these are rarely as sophisticated or integrated as portrayed.

My photographs unpack and explore the mundane routine nature of security on the streets, highlighting everyday security landscapes and agents that are 
visible but rarely seen. In contrast, photographer and artist Trevor Paglen's work visualises that which is meant to be secret and covert, from surveillance to secret sites. His images portray the material artefacts of secrecy in order to bring that which is secret out in the open. They appear rather remote and mysterious, and are frequently taken from a great distance. My use of photography is purposefully mundane, exploring materiality and agency by placing not just the material objects, processes, and architectures but also the people doing the work of security in the photographs themselves. But there are also similarities in the ways in which Paglen works to make things visible. He emphasises the materiality of often abstract phenomena or happenings by emphasising their material presence: for instance, while we may talk of the internet in abstract terms, "the Cloud is buildings with servers in them" (Paglen, in Jobey 2015). In the same way, we may think of security as what happens behind the closed doors of the Chinese Ministry of State Security, but it is also enacted when civilians patrol the streets with wooden bats on the streets of Kashgar.

I used photography to document my everyday encounters with security, but the process of photographing also served to generate knowledge about who does security, how, and where. It served to 'sharpen my gaze' and force my own conception of what is relevant to study as 'security' to evolve as I encountered things I did not initially see. It made me reflect more on the visual logics of security, what we 'see' as relevant to security as well as what might not fit within those visual logics but nevertheless be relevant, and gave me a medium through which I could explore that. I refer to my method as ethnographic photography to distinguish it from photo documentation (eg Rose 2012: 301) since it is part of my interpretivist ambulatory ethnographic approach and an analytical strategy rather than purely a form of documentation.

Photography also forces reflection on the visuality of security more broadly: how our perception of security agents change when we visually encounter private security guards with formal police equipment, for instance. No experiences are purely visual, the security practices I observed were also material, sensory, and embodied. Similarly, the affective atmospheres produced by security ensembles in different spaces are deeply shaped by positional dynamics (Fregonese 2017: 4). Photography (and video) together with written notes helped to capture some, but not all, of this. For instance, it served to capture something about the materiality of security in everyday life, such as the materiality of civilians being forced to patrol the streets with wooden bats. Or the embodied and affective experience of facing a park now closed to the public because of security concerns, complete with a high perimeter metal fence topped with barbed wire and a padlocked gate, as I did in Ürümqi. So photography can be used to document, but it can also generate knowledge and capture some of the visual, material, sensory, and embodied aspects of security practice that the written word cannot. 


\section{BOX 9.1 QUESTIONS TO REFLECT ON WHEN USING PHOTOGRAPHIC METHODS}

- What's the purpose of photography in this research?

- Who or what are you photographing, where, and why?

- What's the link between your photos and your research question/s?

- What are you trying to capture, and is photography the most suitable method for capturing it?

- What aspects of your own identity (gender, race, class, age, dis/ability, etc.) might help or hinder your ability to use photography to produce knowledge in the contexts in which your working?

- What is the role of photography in your cultural context? What are the conventions and common practices?

- What ethical and legal questions do you need to consider?

- What technologies are most suitable for you to use? Do you need training to use them?

- What approach and technologies are safest to use in your context? I photographed very openly with a large DSLR camera for instance, to avoid the appearance of undertaking some kind of covert activity.

\section{Participatory photography: auto-photography and photo-elicitation}

Participatory photography is one of many methods that broadly come under the heading of collaborative visual methods. In this research I combined autophotography and photo-elicitation (see Alam et al. 2017: 2). Broadly speaking, this involves asking participants to take photos as part of a research project (autophotography) to gain insight into participants' life worlds and experiences. It is usually combined with interviews, and in many cases the emphasis is on using participants' photos as a prompt during interviews to elicit responses (photoelicitation). It is particularly useful as a method for understanding the experiences of non-elites, since it offers a way to understand "how ... less powerful people see their place in the world" (Rose 2008: 154). For me, it was a way to get out of my own experiences of and encounters with everyday security. Protected by a foreign passport and a visibly 'foreign face', my encounters with security are shaped by my own position of relative privilege. In some situations I may be more likely to be read as a threat, but at the same time I may experience different treatment by security staff. For instance, as a foreign citizen I had to regularly register my residence with the police and was unable to travel to some places without applying for the relevant permits. At the same time, on some occasions local security personnel avoided asking for my ID documents during spot-checks on the assumption that I did not speak Mandarin to avoid a potentially awkward situation. Participatory 
photography allowed me to access and gain some understanding of how six ordinary Beijingers from a range of backgrounds experience and encounter security in their daily lives and to generate knowledge about their experiences. I'm going to focus here on what I've done, with some examples and reflections on the experience as a guide to others interested in exploring similar methods.

Exploring "the everyday lived experiences of security ... how they are felt, lived through, sensed and borne by individuals and groups - is vital for understanding security governance writ large", but this has been largely overlooked (Crawford and Hutchinson 2016: 1186). Participatory photography captures "vignettes of social life as it happens by encouraging the direct involvement of research participants in responding to and interpreting their everyday places and practices through the production of images" (Alam et al. 2017: 2). Used in this way, photography is "closely aligned with lived experience, and consequently more representative of how participants themselves interpret their context, relationships, decisions and realities" (Winton 2016: 432). It is also a way to subvert the traditional researcherparticipant hierarchy, and tends to be relatively open-ended to give participants space to develop their own interpretations (in this case of security) by producing photographs that they see as relevant to the topic being studied. Likewise, interviews focus on participants' motives behind choosing particular subjects to photograph rather than the researcher's interpretations (see Lombard 2013: 23-24): the narrative participants create around their photos is central to understanding their experience. In this way the process works to flip the 'subjects' and the 'field' as absent foreign objects of study, to privilege not the viewers but the producers of the images, and their interpretations and embodied and affective responses to their own images and their own process of image-making. At the same time, it offers an alternative to purely verbal communication, opening doors to talking about subjects that might otherwise be difficult to voice.

I asked six participants to create photo-diaries of their own encounters with and experiences of security during a roughly week-long period in the spring of 2018. I also undertook two interviews with each participant, one at the start of the experiment to provide some instructions and talk through any questions they might have, and one at the end to go through their photos and discuss their experiences. Interviews were conducted largely in Mandarin. I hired a local research assistant to help me guide the interviews, and together we drew on pre-existing relationships and connections (see Lombard 2013:24) to recruit as mixed a group as possible to represent a wide range of experiences. ${ }^{4}$ We asked each participant to take around ten photos. Beyond this, we gave little guidance beyond suggesting that the photos "could be of people/places/activities/things that you consider relevant to security" and asked them to reflect in the process on the question of what "security" means to them and how security intersects with their daily life.

Our instructions were purposefully vague, to give participants space to explore what they themselves considered to be relevant. Some participants found this disconcerting, and checked in several times to make sure they were "doing it right", despite my efforts to reassure them that there was no wrong answer. The interviews 
were guided by the photographs each participant had produced: we largely talked through the photos and their experience and reflections on the process. The photos were invaluable, serving as prompts and reminders of participants own experiences and thoughts, in many cases eliciting new interpretations and "unintended connections" (Lisle 2011: 874), starting off new trains of thought as they remembered previous encounters with security. They opened up conversations about things that would normally be difficult to express. Here the presence of my research assistant was invaluable, since these are topics some participants may have been reluctant to discuss with a foreigner, however embedded: they often openly looked to him for reassurance both that what they were saying was relevant and that it was 'ok' to say.

Some of the photographs and experiences overlapped with my own: security check-points and street side security personnel featured in many images. Others explored things I had not considered, portraying a much broader conception of security. For example, one participant included a photo of a close friend in hospital, and told us about her struggles with ovarian cancer. He raised concerns about healthcare cost and access, but also about the breakdown of traditional family networks: "none of her family came [to visit], they were all too busy. People who work in big cities away from home, it's very hard for the family to visit and look after them, I think they are very vulnerable".

What participants themselves saw as relevant to their experiences with/of security evolved throughout the process of photographing, but also as they talked about their photos in the interviews. Forced to focus through the lens of a camera, photography became an explorative creative process as they started to focus in on different encounters and experiences, provoking continual reflection and profoundly shaping the interviews. Asking participants to take photos can be particularly helpful for "exploring everyday, taken for granted things" (Rose 2012: 307). Placing them in the role of experts also made them confident to talk more widely about their life worlds and experiences relating to security, and here broader themes that came up spanned topics including poverty and inequality, access to affordable healthcare, a feeling of powerlessness, and concerns about future security. Several expressed approval of the state's security governance, some were quite critical, and others were ambivalent.

My participants were incredibly generous with their time and participation. Most of them found the task interesting but curious, and they patiently bore with my peculiar questions: one commented that although she considered my research interesting and important, "it would never be done by a Chinese researcher because they are not interested in what ordinary people think". Several were surprised by how much they had to say once we got started. Although my participants freely volunteered their time and did not gain anything tangible from participating, some found it cathartic: one participant voiced her anger at not being able to talk openly about some of the more sensitive issues we discussed, stating "I'm so grateful to be able to talk about all of this".

Lastly, a note on language and culture. Critical security studies originates largely from the study of Western political systems and cultures and tends to take the meaning of security for granted. But security is not a concept that always translates easily into 
other linguistic or cultural contexts. Translation is often fraught with difficulties, posing particular methodological challenges for researchers working in different language or cultural contexts. Moving between different analytical levels also poses problems here: security does not always mean the same thing to an ordinary citizen as it does to a national-level policy maker, even in Western contexts. There is significant linguistic ambiguity in the Mandarin term for 'security' (安全/anquan), which can be variously translated as security or safety, which I am also exploring further in my research. Wilkinson's research in Kyrgyzstan faced similar challenges: she had little problem 'finding' security, the challenge, rather, "was how to study it in way that was meaningful to the people whom I met” (Wilkinson 2013: 138). In this part of the research, my solution was to keep the concept more open, in order to get more insight into my participants own interpretations of what is relevant to security.Visual methods served as a helpful springboard here, allowing participants to visually portray what they consider or experience as security/safety, but this also had some limitations, since security also brings up more abstract feelings that are hard to portray in a visual format. Several participants reflected explicitly on this during our conversations, and used their interviews to 'fill in the gaps'. For projects that investigate particular aspects of security it might be useful to provide a list of qualifiers in order to get the data needed, to narrow down and avoid cross-cultural mistranslation and misunderstandings.

Using participatory photography helped me to begin to understand how people experience security in their everyday lives and how this has changed over time: an important part of my research which I had struggled to operationalise. It provided me with a means to explore what meanings they attach to macro-level political processes (see Bayard de Volo 2009: 222), but also their own everyday experiences, and the connections between the two. It also allows me to place my own photographic encounters alongside those of my participants, to recognise my own experience as an 'outsider' but also not as privileged above or below the experiences of my participants. One of the biggest benefits of combining my own photography with participatory photography was to bring up differences and similarities in what is considered to be relevant to 'security'. Although there were significant overlaps, my participants' photographs often challenged my own implicit understanding of security, exploring experiences far beyond what we would usually consider to be relevant to security studies.

\section{BOX 9.2 QUESTIONS TO CONSIDER WHEN THINKING ABOUT USING PARTICIPATORY PHOTOGRAPHY}

- Who are you going to ask to take photographs, and what is their previous experience of photography?

- What instructions are you going to provide and how will that shape the outcomes? 
- What is your role as researcher: how can you employ reflexive vigilance?

- How is the research process shaped by the relationship between you as researcher and your participants?

- Is it safe to ask participants to take photos? Is there anything you should ask them not to photograph?

- Will participating put them under any risk (particularly relevant in authoritarian contexts), and if so, how can you a) remove or minimise that risk, and b) create conditions for informed consent?

- What can you do to protect participants? Guaranteeing anonymity is not always possible, for instance.

- What technologies are most suitable, and will participants need training to use them? You may also need to consider cost and appropriateness of different technologies in your context: I asked participants to use their camera phones because that made sense in my context, other projects have used disposable cameras or digital cameras.

\section{Everyday security landscapes and (in)visible security politics}

When security studies has engaged with everyday practices, it has largely focused on the daily practices of security professionals (for exceptions, see VaughanWilliams and Stevens 2015; Ochs 2011; Eschle 2018). 'Everyday' has both spatial and temporal connotations: it is about where security happens as well as when. If we take this focus on routine daily practices but shift our gaze to ordinary people's encounters with security in public spaces, how does that shape how we think about everyday security politics? This is not just a question about whose experiences matter, but also about where security happens and what (and whose) experiences are considered relevant. My aim in this project was to understand how security is (re)produced and practiced at different levels in China, and what the effects are. My participatory photography project with ordinary Beijingers provided some fascinating and original answers to my questions, but these answers would likely not be considered relevant in much of mainstream security studies. So to answer how we can 'know' about security in secretive contexts we need to also think about what we consider to be valuable knowledge in the field of security.

The photographs produced in this project centre the mundanity of security. In contrast to Paglen's work on visualising secrecy, it reflects explicitly and visually on the things we do not normally see as security, precisely because they are not hidden. Photography also raises the question of that which we cannot see, what different photographs allude to, what is not in the frame (see Lisle 2011:877). In authoritarian contexts in particular there will always be things hidden from sight. The photographs from my participatory project are intertwined with the narratives woven by the participants, who often reflected on this question, in particular in more abstract 
images. My own photographs are accompanied by field notes recording my own reflections on that which is present and absent in different security landscapes. In this way, photography can also be used to question and problematise the reification of that which is secret or covert as constitutive of security, what we might call '007-syndrome' thanks to ongoing popular fascination with the hidden world of espionage and covert elite activities personified by James Bond (who, as it happens, also features in one of China's state sponsored national security education videos). ${ }^{5}$

We also need to consider what is do-able and what is not do-able in the context in which you're working. I was told on more than one occasion by security personnel to delete photos I had already taken, which I did. My own position as a foreign researcher provided me with some protection and made me comfortable taking photos in sites where I specifically asked my participants in the participatory photography project not to take photos. Photographing security comes with ethical and practical challenges, many of which are profoundly shaped by positional dynamics. I spent a relatively long period in the field, I speak Mandarin, and have worked on China for nearly ten years. But I do not blend in. That said, while being visibly foreign closed some doors it also opened others. It also meant I had to be particularly careful when working with local participants, who are much more likely to be at risk than me: here, exercising reflexive vigilance was crucial.

As a method, photography can be an additional form of documentation (to be used alongside field notes), a way to record experiences in the field, but the act of photography itself can also be part of the analysis: this makes ethnographic photography different from photo documentation. By forcing us to make choices about what we do and do not photograph, it sharpens the gaze and pushes analytical questions about what is 'relevant' to the research in question to the fore, and can therefore develop and deepen our understanding. In the words of Winton, "[the] act of looking can change the way the world is seen" (2016: 432). Photography is a process of generating knowledge about security. Like any method, it has limitations. Most importantly, we cannot forget the hidden things, the things we do not see. After all, "there is politics beyond the edge of sight" (Van Veeren 2018: 200). Photography can sharpen our gaze and help us see security where we previously did not. But where we see security also depends on where we look, and looking is a political act.

\section{Some suggestions for further reading}

- $\quad$ Sarah Pink (2013) Doing Visual Ethnography. London: Sage.

- Gillian Rose (2012) Visual Methodologies:An Introduction to Researching with Visual Materials, SAGE (in particular Chapter 12, "Making images as research data”).

- Roland Bleiker (ed.) (2018) Visual Global Politics. London and New York: Routledge.

- Melanie Lombard (2013) "Using auto-photography to understand place: Reflections from research in urban informal settlements in Mexico", Area, 45(1), 23-32. 
- Ashraful Alam, Andrew McGregor, and Donna Houston, (2017) "Photoresponse: Approaching participatory photography as a more-than-human research method", Area, 50: 256-265.

\section{Notes}

1 Thanks to Jared Marguiles, Rhys Crilley, and Linda Åhäll for advice and support during the research and writing process, and to Zuosi for invaluable research assistance.

2 For an exception, see Hagmann (2017). There is more literature on this in other disciplines, such as urban studies, geography, and criminology - see, for instance, Scoggins and O'Brien (2016) on policing in China.

3 Thanks to the fantastic Jared Marguiles: see also Marguiles (2019).

4 My participants were all long-time residents of Beijing, half were women and half were men, age groups ranged from early 20 s to mid-50s. Four out of six were from Beijing originally (with Beijing hukou). They had mixed educational backgrounds.

5 This video was originally posted online but later removed, see Beijing State Security Bureau (2016).

\section{References}

Adey, Peter et al. (2013) "Pour votre tranquillité: Ambiance, atmosphere, and surveillance", Geoforum, 49: 299-309.

Alam,Ashrafu,Andrew McGregor and Donna Houston (2017) "Photo-response:Approaching participatory photography as a more-than-human research method", Area, 50: 256-265.

Bayard de Volo, Lorraine (2009) "Participant observation, politics, and power relations: Nicaraguan mothers and US casino waitresses", pp. 217-237 in E. Schatz (ed.) Political Ethnography: What Immersion Contributes to the Study of Power. Chicago and London: University of Chicago Press,.

Beijing State Security Bureau (2016) National security public education: Anti-spy law [国家 安全普法宣传教育: 反间谍法]. Educational video produced by Beijing State Security Bureau [北京市国家安全局] and originally published online.

Crawford, Adam and Steven Hutchinson (2016) "Mapping the contours of 'everyday security':Time, space and emotion”, British Journal of Criminology, 56(6): 1184-1202.

Emmel, Nick and Andrew Clark (2011) "Learning to use visual methodologies in our research: A dialogue between two researchers", Forum Qualitative Sozialforschung/Forum: Qualitative Social Research, 12(1): 1-15.

Eschle, Catherine (2018) "Nuclear (in)security in the everyday: Peace campers as everyday security practitioners", Security Dialogue, 49(4): 289-305.

Fregonese, Sara (2017) "Affective atmospheres, urban geopolitics and conflict (de)escalation in Beirut", Political Geography, 61: 1-10.

Geertz, Clifford (1998) "Deep hanging out”, The New York Review of Books, 45(16): 69.

Guo, Xuezhi (2012) China's Security State: Philosophy, Evolution, and Politics. New York: Cambridge University Press.

Hagmann, Jonas (2017) "Security in the society of control: The politics and practices of securing urban spaces", International Political Sociology, 0: 1-21.

Ingold, Tim (2010) "Footprints through the weather-world: Walking, breathing, knowing", Journal of the Royal Anthropological Institute, 16(s1), 121-139.

Jobey, Liz (2015) “Trevor Paglen: What lies beneath", Financial Times, published online at https://www.ft.com/content/beaf9936-a8ff-11e5-9700-2b669a5aeb83, accessed on 20 December 2018 
Lee, Jo and Tim Ingold (2006) "Fieldwork on foot: Perceiving, routing, socializing" pp. 67-86 in P. Collins and S. Coleman (eds) Locating the Field. Space, Place and Context in Anthropology. Oxford: Berg.

Lisle, Debbie (2011) "The surprising detritus of leisure: Encountering the late photography of war", Environment and Planning D: Society and Space, 29: 873-890.

Lombard, Melanie (2013) "Using auto-photography to understand place: Reflections from research in urban informal settlements in Mexico", Area, 45(1): 23-32.

Marguiles, Jared (2019) "On coming into animal presence with photovoice", Environment and Planning E: Nature and Space, OnlineFirst: 1-24.

Ochs, Juliana (2011) Security and Suspicion: An Ethnography of Everyday Life in Israel. Philadelphia: University of Pennsylvania Press.

Pink, Sarah (2013) Doing Visual Ethnography. London: SAGE.

Pierce, Joseph and Mary Lawhon (2015) "Walking as method:Toward methodological forthrightness and comparability in urban geographical research", The Professional Geographer, 67(4): 655-662.

PRC Central Government (2015) “中华人民共和国国家安全法（全文）[National Security Law: full text]", Ministry of National Defence of the People's Republic of China, published online at http://news.mod.gov.cn/headlines/2015-07/01/content_4592594.htm, accessed on 6 December 2017.

Renmin Ribao (2014) “走中国特色国家安全道路 [Follow the path of security with Chinese characteristics: Xi Jinping]2, Renmin Ribao 16 April 2014, published online at http://paper.people.com.cn/rmrbhwb/html/2014-04/16/content_1415585.htm, accessed on 22 February 2016.

Rose, Gillian (2008) "Using photographs as illustrations in human geography", Journal of Geography in Higher Education, 32: 151-160.

Rose, Gillian (2012) Visual Methodologies: An Introduction to Researching with Visual Materials. London: SAGE.

Scoggins, Suzanne E. (2018) "Policing modern China", China Law and Society Review, 3: 79-117.

Scoggins, Suzanne and Kevin O’Brien (2016) “China's unhappy police”, Asian Survey, 56(2): $225-242$.

Van Veeren, Elspeth (2018) "Invisibility", pp. 196-200 in R. Bleiker (ed.) Visual Global Politics. London and New York: Routledge.

Vaughan-Williams, Nick and Daniel Stevens (2015) "Vernacular theories of everyday (in)security: The disruptive potential of non-elite knowledge", Security Dialogue, OnlineFirst, 1-19.

Weismantel, Mary J. (2001) Cholas and Pishtacos: Stories of Race and Sex in the Andes. Chicago: University of Chicago Press.

Wilkinson, Cai (2013) "Ethnographic methods", pp. 129-145 in L. J. Shepherd (ed.) Critical Approaches to Security: An Introduction to Theories and Methods. London and New York: Routledge.

Winton, Alisa (2016) "Using photography as a creative, collaborative research tool", The Qualitative Report, 21(2): 428-449.

You, Ji (2016) “China's National Security Commission: Theory, evolution and operations”, Journal of Contemporary China, 25(98): 178-196. 
Section IV: Ethnographies of technologies 


\section{0}

\section{THE BLACK BOX AND ITS DIS/CONTENTS}

\section{Complications in algorithmic devices research}

\section{Till Straube}

- $\quad$ Research objective: This chapter will help researchers in the social sciences at all levels of technical expertise who want to investigate digital devices such as algorithms. The figure of the black box suggests itself as a framing device for such inquiries, but put into practice it is fraught with difficulties and potential for complications and misunderstandings. I explore practical and conceptual sources of frustration and trace them back to the black box's origin as engineering practice before suggesting ways to productively enroll the black box in researching algorithmic devices.

- Research puzzle: The chapter's arguments are developed through an illustrative example of a real-world research puzzle: starting from the observation that face detection algorithms exhibit racial bias, various possibilities of approaching an investigation into the issue are explored. While hypothetical, the research project highlights a set of real-life roadblocks to which algorithm studies are prone, and proposes ways to mitigate these.

\section{Can algorithms be racist?}

When the iPhone X was released in late 2017, one of its most prominent innovative features was its "Face ID" technology that can be configured to unlock the screen automatically when the phone's owner was looking at it. While this specific biometric authentication system relies on three-dimensional images captured by its front-facing "TrueDepth" camera (really a combination of infrared emitter, infrared camera, and conventional sensors), there are a variety of comparable systems that are based on conventional two-dimensional photo and video imaging technologies. The latter are an illustrative starting point for the methodological considerations in this chapter. 
The most prolific uses of these biometric recognition devices are in social media platforms (e.g. when Facebook suggests that you tag a friend whom their algorithm has identified in a photo), in border security (e.g. where biometric passports are employed to automate inspection processes at the airport), and in law enforcement (with the FBI, Interpol, and some police forces in the UK and China routinely employing face detecting technologies to identify unknown persons of interest, and police departments elsewhere - notably in Russia and Germany - experimenting with these technologies). But current and projected applications for face-recognizing technologies also include private security, marketing, entertainment, medicine and healthcare services. For example, Walmart experimented with matching video footage of shoppers against "an existing gallery of alleged [shoplifting] offenders" (Roberts 2015), and the company AiCure aims to address the healthcare industry's challenge of "medical adherence" by deploying software that automatically verifies visually that patients ingest their prescribed medication (Gaskell 2017).

Abstractly speaking, face-detecting systems are employed to routinely and automatically establish a link between someone's outward appearance and digital records about that person in specific contexts - to tie a body to its "data double" (Haggerty and Ericson 2000). As such - even if it can be argued that the use of facial recognition technology is marginal in everyday applications today - it is widely believed to fill an important role in the data regimes of the future.

The rise and sophistication of face-detection devices have long been accompanied by various criticisms from Surveillance Studies scholars and beyond. One concern is with the technologies' implications for citizens' privacy in public spaces, their potential for suppressing civil liberties and their incompatibilities with current jurisdiction (Prabhakar et al. 2003; Jain et al. 2004; Bowyer 2004; Carlo et al. 2018). When Stanford researchers found that face recognition software was "more accurate than humans at detecting sexual orientation from facial images", the authors saw fit to include a prominent warning in the paper's abstract: "[G]iven that companies and governments are increasingly using computer vision algorithms to detect people's intimate traits, our findings expose a threat to the privacy and safety of gay men and women" (Wang and Kosinski 2018: 246).

A second, distinct avenue of critique that is often pursued by opponents of facedetection devices is the concern over whether or not they are working reliably. For example, Sharif et al. (2016) were able to show that specially designed eyeglasses allowed impersonation or dodging the biometric algorithm altogether. A study in the UK found that "95\% of 'matches' [in face detection by UK police] wrongly identified innocent people" (Carlo et al. 2018), and commercial applications also seem to have issues yet to be worked out; Walmart abandoned early experimentation with face detection technologies citing little or no return on investment (Roberts 2015) - but has since joined the ranks of American retail chains refusing to comment on the use of facial recognition software (Bitar and Stanley 2018).

Adding to concerns over error rates, studies have found that face detection systems "show signs of bias" (Garvie et al. 2016:53). When the accuracy of commercial face detection solutions were tested along the dimensions of age, race and gender, 
Klare et al. (2012) found that "algorithms consistently have lower matching accuracies on the same cohorts (females, Blacks, and age group 18 to 30)." In a recent study, Buolamwini and Gebru (2018:1) also found that "darker-skinned females are the most misclassified group."

The biases found by these studies were taken up by a wide range of media reports and has received attention far beyond the scientific community. The media echo continues to be substantiated by 'viral' images and videos of face detection software failing to identify or even find the faces of people of color. When the American Civil Liberties Union (ACLU) tested Amazon's face detection service with pictures of members of congress, "[t]he false matches were disproportionately of people of color" (Snow 2018).

The empirical racial bias of face-detection technologies is just the sort of phenomenon that is intriguing to scholars of the social sciences who engage critically with digital technologies. It lends itself to explore some far-reaching questions that disciplines like sociology, anthropology, political science or human geography are increasingly engaging with: what does it mean for an algorithm be racist? What are the ethical implications of such a statement? What are the problematic aspects of machine learning and artificial intelligence? How are digital technologies reshaping security assemblages and public space?

This chapter will not, however, try to answer the above questions. Instead, the racial bias of face-detection software will serve as an illustrative example for some methodological considerations: if we were to give an account of biometric recognition systems and its biases, how should we go about it? And what would be some of the pitfalls to avoid? Setting out on this hypothetical inquiry, this chapter will first discuss the black box - a common trope in such endeavors - and highlight some of the practical and conceptual problems that arise when we try to enroll it in our research. In the second half of the chapter, I will give advice on how to successfully integrate the black box into the ethnographic toolkit before ending with a note on interfaces.

\section{The trouble with opening the black box}

When the social sciences or popular media engage with digital technologies (and "algorithms" specifically), the black box figures prominently. The image often conjured in these accounts is that the inner workings of the algorithm are packed into an opaque container and thus obscured from public scrutiny:"[A]lthough algorithms are imbued with the power to act upon data and make consequential decisions (...) they are largely black boxed and beyond query or question" (Kitchin 2017).

For those interested in researching algorithms with qualitative methods, the primary challenge seems to be to find ways to pry open the black box and to reveal its source - to expose the secret mechanisms of the algorithm. This way, we tell ourselves, we will be able to identify its problems and subject them to critique. As Diakopoulos (2018) succinctly puts it, "[w]e need to get inside that black box, to understand how they may be exerting power on us, and to understand where they might be making unjust mistakes." 
To be sure, a variety of research exists that expertly employs the black box as a device to problematize politics of visibility and facilitate insightful accounts (MacKenzie 2006; Lenglet 2011; Wesseling et al. 2012). What is more, these texts thoughtfully engage with the conceptual underpinnings of the black box and are aware of its limits.

However, putting the method of the black box into practice as a researcher is a perilous undertaking. This is true of all scientific concepts (Pickering 1993; Law 2004) - but compared to other methodological fragments, the black box has a distinct tendency to appear in our accounts as an oversimplified image, stripped of its rich affordances. All too often, the black box is taken to be a thing that we can encounter out there in the field (rather than a practice or method) - many times our object of inquiry itself appears as a black box. This chapter is concerned with the pitfalls involved in such an approach.

Invoking the black box is so seductive because it appeals to the researcher's fantasy of bringing the (dark) secrets of an elusive object to light: It seems to conveniently contain all the answers we are looking for, right there within our grasp. Now, if we can only get it open ...

The often-repeated imperative to straightforwardly 'open the black box' will be complicated and challenged along the illustrative example of the facial recognition system. In this section, I lay out some of the inevitable obstacles that researchers face when they set out to reveal the inner lives of secret algorithms. The problems here are twofold: On the surface, we are confronted with a set of practical hurdles that impede our inquiry at every step. But these problems only conceal deeper conceptual issues with the endeavor. I will discuss both sides in turn.

\section{Practical problems; or, when the black box resists opening}

When looking at facial recognition software and its racial bias, 'opening the black box' would mean to reveal how the algorithm works and how racial bias is introduced.

However, one of the more imminent practical problems becomes immediately apparent: the most advanced biometric identification algorithms, like most stateof-the-art software, are strictly proprietary and the companies or governments that own the intellectual property rights to the source code are not willing to share it with anyone. This is especially true for those algorithms that are employed in security contexts. As Kitchin advises researchers:

Coding often happens in private settings, such as within companies or state agencies, and it can be difficult to negotiate access to coding teams to observe them work, interview programmers or analyse the source code they produce.

(Kitchin 2017: 20)

To illustrate: Unlike many of the algorithms employed by law enforcement, some advanced face recognition systems (like Amazon's "Rekognition” service) 
are commercially available to the public, which is how the ACLU was able to test it against profile pictures of members of congress. However, the proprietary software only exposes an interface - in the case of "Rekognition" an application programming interface or API. What happens between the moment when an image or a video is supplied to the service (input) and when matches are returned (output) remains hidden from view to anyone but the engineers working on the system at Amazon. This is precisely what it means for an algorithm to be black-boxed: We can see what goes in, we can see what comes out, but the inner workings of the black box are obscured. In many cases, this circumstance immediately thwarts the researcher's best efforts to reveal the secrets of the black box.

But what about open-source software? Can we not avoid this issue by choosing a collaborative project that publishes its codebase? Kitchin continues:

Access is a little easier in the case of open-source programming teams and open-source programmes through repositories such as Github, but while they provide access to much code, this is limited in scope and does not include key proprietary algorithms that might be of more interest with respect to holding forms of algorithmic governance to account.

(Kitchin 2017: 20)

What does this mean for our hypothetical research project? As it happens, the software "OpenFace" is a facial recognition system that can be used, read and modified by anyone as per its open-source Apache 2.0 license (Amos et al. 2016). If we decide to turn here for answers, two additional problems become apparent.

First is our literacy in this specific technical context: the project is easy enough to access on GitHub, but what we find (of course!) is the codebase for a software at the time of this writing, nearly 30,000 lines of code in different programming languages (with Python at its core). If we are serious about 'opening the black box' and exposing its biases, would we not first have to learn to understand how these pieces relate to each other - to navigate this text, our site - so we can look for the source of the bias? A daunting task for anyone, let alone researchers not trained in computer science. Just because the source code is open for anyone to read, this doesn't mean that we can understand it.

The second issue here is that even if we were to start learning the relevant languages, study the codebase and become proficient enough to trace function calls through the various libraries and pieces of code - to read the device's inner workings - we would soon realize that the interesting parts of the software are still not legible. The crucial functionalities - extracting faces from images, representing them within the logic of the software, and 'recognizing' faces by matching them against other representations - are implemented through pre-trained artificial neural networks (Kim 2018). These 'neural nets' are very good at pattern recognition whether in language, medical scans, or pictures of faces - and they warrant a short explanation here. 
Very simply put, neural networks are a programming technique that takes a decision that is very difficult to formalize in computer language ("Are these two images representations of the same person?"), breaks it apart into many combinations of decisions that are easier to formalize ("Is this region of pixels darker than that one?") and chains them together in layers of ever more abstract combinations of modular decisions. The neural network distills these decisions down at each step to arrive at a simple answer to a complex problem. The conceptual layout of these machine learning algorithms mimics microscopic processes in animal brains (hence "neural"), although many insist that this is only a metaphor.

The trick is that these abstract networks are trained with hundreds of thousands of data points where the desired outcome is known, so that the correct 'neural' decision paths are formed. In practice, training the algorithm also means that engineers iteratively fine-tune their parameters and weightings until the results are satisfactory. After training, a neural network may be very good at making specialized decisions (such as matching faces), but even those who assembled and trained it are no longer able to trace the causalities of its decision paths - in other words, it is impossible for such an algorithm to meaningfully justify why it came to a given decision (Heaven 2013; Edionwe 2017).

In this sense, the neural net is a black box not because business interests or governments want to keep its mechanisms a secret, but because it is a complex problem-solving apparatus that is put to work not through inscription of premeditated processes, but by putting input and output in direct relation through feedback loops and modulation of abstract parameters.

If going into our hypothetical inquiry, our fantasy was to be able to put our finger on the one line of code that was guilty of introducing racial bias into the algorithm, then disappointment was inevitable. Opening the black box of facial recognition software and exposing the source of its racial bias was never going to work. We may blame this on circumstance, or on a poor choice of a research object, and hope for better results next time. As far as methods are concerned, we may abandon the source code as a site and rely on a more traditional ethnographic toolkit: talking to engineers about their code, or to users of the software about their experiences.

But these practical obstacles that we might encounter in the field only obscure the underlying conceptual problems with the widespread fantasy of opening the black box.

\section{Conceptual problems; or, when the black box explodes}

The figure of the black box is invoked in various scientific and non-scientific contexts (see Box 10.1). But it is predominantly in reference to Science and Technology Studies (STS) and Actor-Network-Theory (ANT) literature that social scientists today invoke the black box as a mode of investigation, so its purchase within these scholarly traditions warrants a closer look. 


\section{BOX 10.1 VARIATIONS ON THE BLACK BOX}

As a metaphor, the "black box" is employed in everyday speech to point to the hidden mechanisms and complex inner workings of devices that are concealed from view. It carries negative connotations of corporate or state secrecy, questionable algorithmic practices, and likely violations of privacy. These themes resonate in Pasquale's (2015) broadly received book, The Black Box Society, which outlines a political and legal project to reign in corporate algorithms.

The origins of the black box, however, can be traced back to an engineering technique (Cauer et al. 2000): when thinking about complex devices such as electronic circuits, and when representing them in technical drawings, it is often useful to group some elements together and think of them as a "black box" - this means to disregard their precise workings and only think of them in terms of in- and output. This way, the black box hides complexity through abstraction.

As a technical concept, it informed the way of thinking that Cybernetics sought to apply to all systems: be they mechanical, organic, political, organizational or economic in nature (Ashby 1957; Wiener 1961). We tend to think of Cybernetics today as an academic movement, but Pickering (2002) reminds us that the cybernetic project was deeply rooted engineering practice.

The black box was further explored and formalized in Philosophy of Science (Bunge 1963), and it is said to be the guiding principle in the formation of behaviorist psychology where the inner workings of the mind are left untouched (Graham 2017). Niklas Luhmann in his articulation of a universal systems theory relies on the black box to elide the differences between different sorts of systems: When their inner workings are black-boxed, "psychic" or "social" systems all behave the same way (Luhmann 1987: 156).

Arguably, however, the black box has entered the methodological toolkit of contemporary social sciences by way of some seminal research in Science and Technology Studies (STS) that closely followed the practices of scientists and engineers. These themes are explored in this chapter in more detail.

I want to highlight two characteristics of the black box as articulated in early texts in the ANT school of thought that are sometimes neglected when the figure is invoked in the methodological considerations of contemporary research projects.

First, Bruno Latour writes:

The assembly of disorderly and unreliable allies is thus slowly turned into something that closely resembles an organised whole. When such a cohesion is obtained we at last have a black box. 
As this passage shows, the black box is not simply something 'out there' that as researchers we encounter in the field (and proceed to open to reveal its secrets). The focus here is on the process of assembly: there is substantial work that goes into "obtaining the cohesion" of the black box. It may be helpful, then, to think of black-boxing as an active verb rather than a (metaphorical) object.

Secondly, Michel Callon states that

[e]ach element is part of a chain that guarantees the proper functioning of the object. It can be compared to a black box which contains a network of black boxes that depend upon one another both for their proper functioning as individuals and for the proper functioning of the whole.

(Callon 1986: 31)

This image of nested black boxes is a crucial point that speaks to the empirical difficulties of revealing what is black-boxed: even when we succeed, what we usually find is more black boxes.

We can experience this conundrum first-hand when working with computer code. Even in the rare cases where we do gain access to the source code (say, with open-source projects or through an exceptional level of field access), and the software is written in a programming language that we are literate in, the argument can be made that, strictly speaking, we still cannot learn anything about the 'true' inner workings of the device for two reasons.

First, at every turn we can expect the code to include references to libraries (i.e. collections of pre-defined routines and data structures) that are maintained elsewhere, and to data points that depend on the precise contexts of individual instances of the program. These can be understood as pointers to more black boxes that may or may not give way to further opening attempts. In the case of "OpenFace," part of what we found were pre-trained neural nets that are beyond meaningful reading.

The second and more conceptual point here is that even the most banal syntactic elements of the code are never executed directly - the human-readable code first has to be translated (compiled) to machine code - a precisely arranged stream of ones and zeroes - which in turn are instructions for the hardware that executes them. So between the human-readable computer code and the actual 'production environment' of the algorithm there are - by necessity - a series of cascading blackboxed mediations; a circumstance that impedes any definitive 'opening'.

The inscriptions of digital devices are composed of references to black-boxed mechanisms, and "the [digital] artifact is composed of writings all the way down" (Latour 2008: 4). If our mission were indeed to find answers by opening black boxes, we would be in for a world of pain - this is why Latour refers to "Pandora's black box" (Latour 1987: 1; emphasis added).

ANT literature encourages us to think of algorithms as black-boxed entities, and to "deploy their networks," or "trace their associations" (Latour 2005; see also Dijstelbloem and Pelizza, this volume). However, when these concepts are put into 
practice, we need to be careful not to misunderstand them as an imperative to 'open the black box of the algorithm' and to expose its secret mechanisms - this would likely render our findings banal where they are not unobtainable.

\section{Getting lost in the black box}

After failing to open the algorithm's black box directly by reading its code, the most feasible alternative is to trace the associations, or "unpack the full socio-technical assemblage of algorithms" through a variety of ethnographic tools such as talking to experts and software engineers, document analysis, or attending conferences (Kitchin 2017: 25).

With a social science training, we are likely to have a good idea of what we mean when we talk about bias: an unjust asymmetry along the lines of demographic markers like race or gender, rooted in violently asserted cultural hegemonies and deeply ingrained in scientific practice (Bhaba 1983; Longino and Doell 1983; Harraway 1988). Precisely the sort of "machine bias" then, that Angwin et al. (2016) exposed in judicial risk assessment software "likely to falsely flag black defendants as future criminals."

If we asked an engineer working on face detection systems about bias, however, there may be a misunderstanding at first: "bias" is a narrowly defined technical term when talking about machine learning and predictive models: it is a type of error that happens when (very simple) models underfit the data, and to add to the confusion, bias is precisely the error source that neural networks are very good at avoiding.

But even after we specified the phenomenon that we are interested in more precisely - algorithms being wrong more often when trying to read or identify the faces of people of color than with white faces - very likely we would be told that this is not an issue with the algorithm at all, but with the training data.

The source of the problem, many critics of facial recognition software are quick to point out, is that the galleries of photos with which the algorithms have been trained contain mostly white faces (Edionwe 2017; Harris et al. 2016; Klare et al. 2012).

Crucially, proponents of facial recognition software readily agree that any observed bias - racial or otherwise - is not due to a faulty algorithm but simply an effect of insufficient training. Consider this passage from an interview with the CEO of FaceFirst, a company supplying facial recognition software to retailers:

Still there are critics of the software. Among the most vocal have been those who maintain the technology makes a higher number of misidentifications when dealing with people of color, women and especially women of color.

"We do not see these issues with our customers," Trepp says. By way of explanation, he notes that an algorithm is at the center of facial recognition technology. When faulty identifications based on gender or color are made, it means "these algorithms were not trained sufficiently," he says. 
At FaceFirst, after developing the algorithm, "We begin training the machine, giving it millions of images. Hundreds of thousands of images won't do, it has to be millions," he says. "If you don't train with images of women, people of color, women of color," the system is not well trained.

(Schulz 2018)

The same argument is being made by proponents of facial recognition technology in the security context: The algorithm itself "does not see race, sex, orientation or age. The software is matching distance and patterns only, not skin color, age or sex of an individual" (Seattle Police department, cited in Garvie et al. 2016: 53).

What we are witnessing here is a double motion of opening a black-boxed system with the one hand, and defining two black boxes with the other: the algorithm is working fine, but maybe the data is flawed. This separation of a device into a 'neutral' algorithm and 'problematic' data can be found in many text discussing the political dimension of digital devices, and is often brought up in connection with the racial bias in face detection (Chander 2017).

This sounds sensible on the surface, but it is a troubling statement if we consider that training the neural network is a vital process in authoring a working algorithm. The fallacy lies with isolating the problem (of racial bias) to the seemingly minor issue of training data, thereby exonerating the algorithm 'itself'. Without training, a neural net is just an abstract formulation of a technique - in a very concrete way, the algorithm is made of its training data. Articulating "the algorithm" and "the training data" as if one could look at these two objects side-by-side may make sense from an engineering standpoint, but it is misleading rhetoric when considering an algorithm's political implications.

In our hypothetical research project, we can imagine following up on this claim of bad data and finding, as researchers at Georgetown Law did, that the problem persists even where it cannot be explained by the predominance of white faces in the training data:

Racial bias intrinsic to an algorithm may be compounded by outside factors. African Americans are disproportionately likely to come into contact with - and be arrested by - law enforcement. This means that police face recognition may be overused on the segment of the population on which it underperforms. It also means that African Americans will likely be overrepresented in mug shot-based face recognition databases.

(Garvie et al. 2016)

But there are more black boxes to be opened: a subsequent approach to explaining the phenomenon might be that the problem does not lie with the selection of the training data, but with the history of photography itself - with exposure times, sensors and other materials developed specifically to capture white faces (Roth 2009; Buolamwini 2017). Considering that preprocessing of photo galleries for 
faster training of neural networks includes conversion to grayscale (Kim 2018), it seems especially plausible that factors like lighting and contrast are crucial when it comes to the precision of these applications.

To speculate even further, what if physicists told us that the problem did not lie with the photographic equipment, but with the properties of photons themselves the very quantum particles that light is made of? Would we then be satisfied with having opened the last black box and finding the root of the problem? Much more likely, we would realize that by employing the rhetoric of the black box - by entering the discursive terrain of the engineer - we had reduced the political issue of racial bias to a purely technical problem (Amaro 2017).

Finally, at the level of quantum mechanics, we are in no position to even consider what should be one of the most pressing questions: is it even desirable to 'improve' face recognition systems so that they correctly identify persons of color (Hassein 2017)?

This example shows that the discursive privilege to define the shapes of black boxes can be deployed to focus attention on some problems, elide others, and make narrow technical expertise a prerequisite for being part of the conversation. In this regard, the black box's origin as an engineering practice still carries weight. In the next section, I will offer advice on how to give this circumstance due consideration in the approach to our own research.

\section{Deploying the black box in researching digital devices}

Some argue that the black box is a misleading rhetorical device to begin with. As logistics scholar Brett Neilson points out,

the metaphor of "opening the black box" is very rhetorical because it does not mean that we can and even want to understand the techniques, technologies and codes that make logistics work. It simply indicates that all these factors are important. I do not very much agree with the use of this metaphor because it allows us to project fantasies and paranoia within our analysis.

(Neilson cited in Cuppini et al. 2018)

Should we therefore abandon the black box and strike it from our vocabulary entirely? In the following I want to lay out how we can still render the black box productive in our research while avoiding some of the pitfalls.

\section{Understand the black box as an engineering practice}

Apart from the ways in which the black box has been deployed as a theoretical or methodological concept, there exists a parallel cultural history of the black box as an applied engineering technique. The practice of black-boxing single elements of complex systems has been a prerequisite for many technological advancements 
based on modularity, a concept that computing historian Andrew Russell traces back to architecture and the military:

Modules feature standardized interfaces, which facilitate their integration with the overarching system architecture. A key feature of each module is that it should encapsulate (or "black-box") its messy internal details, thus masking technical, organizational, cultural, and political conflicts to display only a consistent interface.

(Russell 2012: 257f)

As such, the black-boxed module is "kind of a characteristic of modernity" (Russell cited in Posner 2018), and a fundamental principle for the development of devices ranging from weapons systems and cargo containers to computer hardware.

In this sense, software engineers are experts in black-boxing. When programmers sketch out architectures or write loosely structured 'pseudo-code,' they design systems made of black-boxes to be fleshed out later. When they argue among themselves about the benefits of object-oriented programming versus functional programming paradigms (two competing 'philosophies' about how computer code should be structured), they are really disagreeing over what shape the code's black boxes should have: that of an object or that of a function. And everyday programming tasks like debugging (i.e. finding the sources of errors) or refactoring code (i.e. rewriting for usability or legibility) are exercises in selectively dissolving systems of black boxes and putting them back together in different ways.

The point is that technical professionals routinely deploy and arrange black boxes constantly to articulate, isolate and solve problems. So when in our research we have the opportunity to sit down with programmers willing to talk about their code, we should be aware that the black box is much more part of their toolkit than of ours - even though they may never use the term.

When engaging with the technical side of things, social scientists do well to question at every turn whether the borders being drawn between abstract entities are conducive of their inquiry. There is merit in avoiding language that specifies "an algorithm" or "(big) data" as an object of inquiry, since neither does work in the world by itself (Kitchin 2017), and acknowledging the connectedness of hard- and software, organizational environments and so on through terms such as "digital systems" or "devices".

\section{Accept arbitrariness and uncertainty}

When we trace the associations of a digital device, there are countless possible paths we could follow. The codebases of included libraries, specific datasets that the device is put to work on, the stories of the people involved in authoring the software, the manufacturing process of specialized hardware - these are just a few examples of equally valid avenues of investigation.

It is helpful to recognize that many factors contribute to which specific paths our account follows and which it leaves out: our training and experience as researchers, 
field access and circumstance, or the interests and expertise of those we talk to, just to name a few. In her insightful critique of ANT, Anna Tsing calls this process "worlding" (in reference to Gayatri Spivak):

All researchers, including both natural and social scientists, use worlding to assess their research materials, that is, to place them in what seem to be relevant webs of relationality. Scientists use worlding, for example, to consider the potential relationships among observable bits of data. (. . .) To understand scientific storytelling practices, it is necessary to appreciate the work of worlding, even where it is downplayed or denied in lavish descriptions of formal methods.

(Tsing 2010: 50)

A very practical lesson for researchers here is to second-guess the focus of our inquiry at every turn: Is it really necessary to understand the inner workings of this object to give a good account of it? Or are there other ways to situate the device, other paths of inquiry to follow? How else can this thing be worlded?

A good account of a digital (or other) device is attained by tracing some of its associations that are chosen with care, and is self-reflexive enough to acknowledge and sustain the fundamental arbitrariness of the path followed.

The misconceived project of opening the black box and definitively revealing its mechanisms has to fail because it strives for an unattainable objective result. What is more, its gesture is in line with scientific traditions that search for definitive answers and - like Geography in service of colonialism - look to map out all the blank spots left on the face of the earth. Digital devices demonstrate more clearly than ever that it is time to give up the search for a "vantage point" from which to "look down upon new scenes to be described" (Sharp 2009), and instead to develop methods and strategies to deal productively with doubt and uncertainty.

\section{Add specialized methods to the toolkit}

When researching digital devices, our toolkit includes many ethnographic methods that are not specific to the field. Gathering data through interviews with experts and professionals, attending conferences and other observations, and discourse analysis of policy papers or journalistic texts will lead to valuable findings just as with most other objects of inquiry. But insights can also be gained through some methods that are specific to digital devices.

There is a growing body of literature on digital ethnographic methods, ranging from the enrolment of digital tools in data gathering process (Murthy 2008; Kozinets 2015) to instructive texts on how to render digital devices legible as object of inquiry (Bowker and Star 1999; Diakopoulos 2013; Kitchin 2017). Inspiration can also come from the methods employed in seminal or especially convincing accounts of technological systems (Suchman 2007; Knorr Cetina and Bruegger 2002; Woodward et al. 2015). In the end, the most helpful methodological toolkit 
depends heavily on the precise context of the research and the affordances presenting themselves in the field. In the following I briefly highlight three approaches to researching digital devices that have worked well for my research in the past.

First, even though getting access to source code is not the definitive solution it is often made out to be (and by no means necessary), there is value in getting an overview of the technical side of things. If, for example, external libraries are used for crucial functionalities, this can lead to more texts to include in analysis and more people to talk to. Software engineers are usually very good at sketching out the functionality of a system (from their point of view), so even when the code is inaccessible or prohibitively complicated, it can be helpful to ask for a schematic mapping of how the device works - this map can be read as an articulation of the black-boxing that guided authoring of the system.

Second, some of the most insightful moments can come from listening to the users of a device. This can be as simple as sitting down in front of a computer and having users talk about the steps that they take when using an application. For many programming languages, frameworks or specific programming techniques, there are regular meetups of user groups in some cities. Informal gatherings like un-conferences are another way to meet people who use specific technologies and listen to their exchanges. Finally, if tutorial videos or technical talks are publicly available, they can shed light on the way that technologies are (intended to be) put to work and interfaced.

Third, all digital devices come with a plethora of technical documentation. There are sometimes manuals geared towards different levels of expertise (e.g. the 'developer platforms' of Google, Twitter, etc.), and it can be insightful to look at the different interfaces exposed at each level. Even for proprietary software that hides its mechanisms, bug reports can be revelatory: when a system breaks down, it loses its black-boxedness. Finally, the archives of developers' mailing lists document all the interesting moments in the lifetime of a piece of software, and can bring to life past controversies and important decision points that have long been resolved and receded into the background (Straube 2016).

All of these instances closely echo Latour's very helpful list of "occasions where [an object's] momentary visibility is enhanced enough to generate good accounts" (Latour 2005: 80). The general aim of algorithmic research should be to treat computer code not only as an object of interest or a source of information, but as a lively "social site" (Marston et al. 2005: 425) imbued with meaningful associations and full of possibilities - a site where we can do ethnography (see also Bosma, this volume).

\section{Conclusion: from black boxes to interfaces}

Along the illustrative example of face detection systems, I highlighted some of the practical and conceptual problems with the ubiquitous imperative to 'open the black box' of algorithms. It was the goal of this chapter to show that the fantasy of revealing the secret inner workings of 'the algorithm' does more harm than good for critical social science research dealing with digital devices. 
I suggest understanding the black box instead as a routine engineering practice, instances of which should themselves be made visible and submitted to scrutiny in critical accounts of digital systems. If the black box is to be invoked at all in our methodological considerations, we should furthermore acknowledge the irreducible uncertainties and subjectivities tied up with its unpacking, and employ targeted methods to make visible the concealed contours that facilitate our deliberate account.

In conclusion, I want to point out that all of the aspects of the black box that I suggest can be rendered productive in critical research pertain to its interfaces. Any black box is necessarily defined by its interfaces that can take many shapes: user interfaces, application programming interfaces, function calls, protocols or object data models. Even the source code is nothing more but an interface between the system and its authors. Where the black box is at risk of being seen as a static object, the interface "actively extends into and conditions that which it separates" (Hookway 2014: 9). The interface of a black box is always accessible because it is what connects the black box to the outside world - more than that, it defines what that outside world looks like from inside the box.

The interface is a lively site of constant translation, and therefore lends itself to tell more interesting accounts than the black box. If we take interfaces to mean more than those between human and machine, there is much to learn about them. It can only be hoped that, as a rhetorical and methodological device, the interface receives even a fraction of the interest that is bestowed upon the black box.

\section{Suggestions for further reading}

- Geoffrey C. Bowker and Susan Leigh Star (1999) Sorting Things Out: Classification and Its Consequences, Cambridge, MA: MIT Press.

- Vikram Chandra (2014) Geek Sublime. The Beauty of Code, the Code of Beauty, Minneapolis: Graywolf Press.

- Nicholas Diakopoulos (2018) “The algorithms beat: Angles and methods for investigation", The Data Journalism Handbook, URL: https://datajour nalismhandbook.net/handbook/two/investigating-data-platforms-andalgorithms/the-algorithms-beat-angles-and-methods-for-investigation [accessed 2019-01-27].

- Rob Kitchin (2017) “Thinking critically about and researching algorithms”, Information, Communication \& Society, 20(1): 14-29.

- Bruno Latour (2005) Reassembling the Social: An Introduction to Actor-NetworkTheory. Oxford: Oxford University Press.

\section{References}

Amaro, Ramon (2017) "Decolonising design", Het Nieuwe Instituut, URL: https:// thursdaynight.hetnieuweinstituut.nl/en/reports/thursday-night-live-decolonisingdesign-ii-ramon-amaro [accessed: 2017-07-11]. 
Amos, Brandon, Ludwiczuk Bartosz and Mahadev Satyanarayanan (2016) OpenFace: A General-Purpose Face Recognition Library with Mobile Applications, Pittsburgh: CMU School of Computer Science.

Angwin, Julia, Jeff Larson, Surya Mattu and Lauren Kirchner (2016) "Machine Bias", Pro Publica, URL: https://www.propublica.org/article/machine-bias-risk-assessments-incriminal-sentencing [accessed 2018-10-18].

Ashby, W. Ross (1957) An Introduction to Cybernetics, London: Chapman \& Hall.

Bhaba, Homi K. (1983) “The Other Question ... Homi K Bhaba Reconsiders the Stereotype and Colonial Discourse", pp. 18-36 in Francis Barker (ed.) The Politics of Theory, Essex: University of Essex.

Bitar, Jenna and Jay Stanley (2018) "Are stores you shop at secretly using face recognition on you?”, $A C L U$, URL: https://www.aclu.org/blog/privacy-technology/surveillancetechnologies/are-stores-you-shop-secretly-using-face [accessed 2018-10-17].

Bunge, Mario (1963) “A general black box theory”, Philosophy of Science, 30(4): 346-358.

Buolamwini, Joy (2017) Gender Shades: Intersectional Phenotypic and Demographic Evaluation of Face Datasets and Gender Classifiers (M.Sc. Thesis), Cambridge: MIT.

Buolamwini, Joy and Timnit Gebru (2018): “Gender shades: Intersectional accuracy disparities in commercial gender classification”, Proceedings of Machine Learning Research, 81(1): 1-15.

Bowker, Geoffrey C. and Susan Leigh Star (1999) Sorting Things Out: Classification and Its Consequences. Cambridge, MA: MIT Press.

Bowyer, Kevin W. (2004) “Face recognition technology: Security versus privacy”, IEEE Technology and Society Magazine, 23(1): 9-20.

Callon, Michel (1986) "The sociology of an actor-network: The case of the electric vehicle", pp. 19-34 in Michel Callon, John Law and Arie Rip (eds) Mapping the Dynamics of Power and Technology, Basingstoke: Palgrave Macmillan.

Carlo, Silkie, Jennifer Krueckeberg and Griff Ferris (2018) "Face off: The lawless growth of facial recognition in UK policing“, Big Brother Watch, URL: https://bigbrotherwatch.org. uk/wp-content/uploads/2018/05/Face-Off-final-digital-1.pdf [accessed 2018-10-16].

Cauer, Emil, Wolfgang Mathis and Rainer Pauli (2000) "Life and work of Wilhelm Cauer (1900-1945)", Proceedings of the International Symposium of Mathematical Theory of Networks and Systems, 14(1): 1-10.

Chander, Anupam (2017) “The racist algorithm?”, Michigan Law Review, 115(6): 1023-1045.

Cuppini, Niccolò, Mattia Frapporto, Giorgio Grappi, Brett Neilson and Ned Rossiter (2018) "The logistics of global capitalism: A dialogue with Giorgio Grappi, Brett Neilson and Ned Rossiter", Zapruder World, URL: http://zapruderworld.org/2018/10/the-logisticsof-global-capitalism-a-dialogue-with-giorgio-grappi-brett-neilson-and-ned-rossiter/ [accessed 2018-11-02].

Diakopoulos, Nicholas (2013) Algorithmic Accountability Reporting: On the Investigation of Black Boxes, New York: Tow Center for Digital Journalism.

Diakopoulos, Nicholas (2018) "Algorithmic accountability \& transparency", Musings on Media, URL: http://www.nickdiakopoulos.com/projects/algorithmic-accountabilityreporting/ [accessed 2019-01-27].

Edionwe, Tolulope (2017) “The fight against racist algorithms”, The Outline, URL: https:// theoutline.com/post/1571/the-fight-against-racist-algorithms [accessed 2017-07-11].

Garvie, Claire, Alvaro M. Bedoya and Jonathan Frankle (2016) The Perpetual Line-up: Unregulated Police Face Recognition in America, Washington, DC: Georgetown Law Center on Privacy \& Technology.

Gaskell, Adi (2017) "Using AI to prove you've taken your medicine”, Huffington Post, URL: https://www.huffingtonpost.com/adi-gaskell/using-ai-to-prove-youve-t_b_9658188. html?guccounter=1 [accessed 2018-10-14]. 
Graham, George (2017) “Behaviorism”, The Stanford Encyclopedia of Philosophy, URL: https:// plato.stanford.edu/archives/spr2017/entries/behaviorism/ [accessed 2019-01-27].

Haggerty, Kevin D. and Richard V. Ericson (2000) “The surveillant assemblage”, British Journal of Sociology, 51(4): 605-622.

Hassein, Nabil (2017) "Against black inclusion in facial recognition", Digital Talking Drum, URL: https://digitaltalkingdrum.com/2017/08/15/against-black-inclusion-in-facialrecognition/ [accessed 2017-08-19].

Harraway, Donna (1988) "Situated knowledges: The science question in feminism and the privilege of partial perspective", Feminist Studies, 14(3): 575-599.

Harris, Meena, Duretti Hirpa, Erica Baker, and Megan Anctil (2016) "Talking with black women engineers about diversity in Silicon Valley”, Lenny, URL: https://www.lenny letter.com/story/talking-with-black-women-engineers-about-diversity-in-siliconvalley [accessed 2017-07-11].

Heaven, Douglas (2013). "Not like us: Artificial minds we can't understand", New Scientist, 2929: 32-35.

Hookway, Brandon (2014) Interface, Cambridge, MA: MIT Press.

Jain, Anil K., Arun Ross and Salil Prabhakar (2004) "An introduction to biometric recognition", IEEE Transactions on Circuits and Systems for Video Technology, 14(1): 4-20.

Kim, Stephanie (2018) "Understanding facial recognition through OpenFace", Algorithmia, URL: https://blog.algorithmia.com/understanding-facial-recognition-openface/ [accessed 2018-10-16].

Kitchin, Rob (2017) “Thinking critically about and researching algorithms”, Information, Communication \& Society, 20(1): 14-29.

Klare, Brendan F., Mark J. Burge, Joshua C. Klontz, Richard W.Vorder Bruegge and Anil K. Jain (2012) "Face recognition performance: Role of demographic information", IEEE Transactions on Information Forensics and Security, 7(6): 1789-1801.

Knorr Cetina, Karin and Urs Bruegger (2002) "Global microstructures:The virtual societies of financial markets", American Journal of Sociology, 107(4): 905-950.

Kozinets, Robert V. (2015) Netnography: Redefined, London: Sage.

Latour, Bruno (1987) Science in Action: How to Follow Scientists and Engineers through Society, Cambridge, MA: Harvard University Press.

Latour, Bruno (2005) Reassembling the Social:An Introduction to Actor-Network-Theory, Oxford: Oxford University Press.

Latour, Bruno (2008) "A cautious Prometheus? A few steps toward a philosophy of design (with special attention to Peter Sloterdijk)", Proceedings of the International Conference of the Design History Society, 2(1): 2-10.

Law, John (2004) After Method: Mess in Social Science Research, Oxon: Routledge.

Longino, Helen and Ruth Doell (1983) "Body, bias, and behavior: A comparative analysis of reasoning in two areas of biological science", Signs, 9(2): 206-227.

Lenglet, Marc (2011) "Conflicting codes and codings: How algorithmic trading is reshaping financial regulation”, Theory, Culture \& Society, 28(6): 44-66.

Luhmann, Niklas (1987) Soziale Systeme: Grundriss einer allgemeinen Theorie, Frankfurt: Suhrkamp.

MacKenzie, Donald (2006) “Opening the black boxes of global finance”, Review of International Political Economy, 12(4): 555-576.

Marston, Sallie A., John Paul Johnes III and Keith Woodward (2005) "Human geography without scale", Transactions of the Institute of British Geographers, 30(4): 416-432.

Murthy, Dhiraj (2008) "Digital ethnography: An examination of the use of new technologies for social research", Sociology, 42(5): 837-855. 
Pasquale, Frank (2015) Black Box Society: The Secret Algorithms That Control Money and Information, Cambridge, MA: Harvard University Press.

Pickering, Andrew (1993) "The mangle of practice:Agency and emergence in the sociology of science", American Journal of Sociology, 99(3): 559-589.

Pickering,Andrew (2002) "Cybernetics and the mangle: Ashby, Beer and Pask", Social Studies of Science, 32(3): 413-437.

Prabhakar, Salil, Sharath Pankanti and Anil K. Jain (2003) "Biometric recognition: Security and privacy concerns", IEEE Security \& Privacy Magazine, 1(2): 33-42.

Posner, Miriam (2018) "See no evil”, Logic, URL: https://logicmag.io/04-see-no-evil/ [accessed 2018-10-16].

Roberts, Jeff John (2015) "Walmart's use of sci-fi tech to spot shoplifters raises privacy questions", Fortune, URL: http://fortune.com/2015/11/09/wal-mart-facial-recognition/ [accessed 2018-10-16].

Roth, Lorna (2009) "Looking at Shirley, the ultimate norm: Colour balance, image technologies, and cognitive equity”, Canadian Journal of Communication, 34(1): 111-136.

Russell, Andrew (2012) "Modularity: An interdisciplinary history of an ordering concept", Information \& Culture, 47(3): 257-287.

Schulz, David P. (2018) "Facial recognition is becoming a competitive tool in the fight against fraud", Stores, URL: https://stores.org/2018/10/30/nice-to-see-you-again/ [accessed 2018-11-02].

Sharif, Mahmood, Sruti Bhagavatula, Lujo Bauer and Michael K. Reiter (2016) “Accessorize to a crime: Real and stealthy attacks on state-of-the-art face recognition", Proceedings of the ACM Conference on Computer and Communications Security 23(1): 1528-1540.

Sharp, Joanne (2009) Geographies of Postcolonialism: Spaces of Power and Representation, Los Angeles: Sage.

Snow,Jacob (2018) “Amazon's face recognition falsely matched 28 members of Congress with mugshots”, ACLU, URL: https://www.aclu.org/blog/privacy-technology/surveillancetechnologies/amazons-face-recognition-falsely-matched-28 [accessed 2018-10-17].

Suchman, Lucy A. (2007) Human-Machine Reconfigurations: Plans and Situated Actions, New York: Cambridge University Press.

Straube, Till (2016) "Stacked spaces: Mapping digital infrastructures", Big Data \& Society, $3(2): 1-12$.

Tsing,Anna (2010) "Worlding the Matsutake diaspora. Or, can actor-network theory experiment with holism?”, pp. 47-66 in Ton Otto and Nils Bubandt (eds) Experiments in Holism: Theory and Practice in Contemporary Anthropology, Malden: Wiley-Blackwell.

Wang, Yilun and Michal Kosinski (2018) "Deep neural networks are more accurate than humans at detecting sexual orientation from facial images", Journal of Personality and Social Psychology, 114(2): 246-257.

Wesseling, Mara, Marieke de Goede and Louise Amoore (2012) "Data wars beyond surveillance: Opening the black box of swift", Journal of Cultural Economy, 5(1): 49-66.

Wiener, Norbert (1961) Cybernetics: Or the Control and Communication in the Animal and the Machine, Cambridge, MA: MIT Press.

Woodward, Keith, John Paul Jones III, Linda Vigdor, Sallie A. Marston, Harriet Hawkins and Deborah P. Dixon (2015) "One Sinister Hurricane: Simondon and Collaborative Visualization", Annals of the Association of American Geographers 105(3): 496-511. 


\title{
11
}

\section{MULTI-SITED ETHNOGRAPHY OF DIGITAL SECURITY TECHNOLOGIES}

\author{
Esmé Bosma
}

- Research objective:This chapter will help researchers explore how they can study complex digital security technologies. The chapter delineates a multisited ethnographic approach around 'sites of experimentation'. It offers two methodological starting points: (i) following technology from design to use, and (ii) observing human-computer interaction.

- Research puzzle:The puzzle the chapter addresses in relation to secrecy and methods is: how can researchers make strategic use of their limited resources in order to understand, analyse and communicate to a wider audience the sociopolitical role of digital security technologies?

\section{Introduction}

"Who or what is responsible for the act of killing? ... Which of them, . . the gun or the citizen, is the actor in this situation?" (Latour 1999: 178-179). Bruno Latour, one of the main proponents of Actor-Network-Theory (ANT), famously mobilised the example of the gun to argue that technology is never just "a neutral carrier of human will" nor are we rendered powerless by its force. The mistake in both argumentations, argues Latour, is that they "start with essences, those of subjects or those of objects" (ibid.: 180). The outcomes of events are not entirely dependent on human or technological action. Rather, such outcomes lie at the intersection between human and non-human agency.

My research into counter-terrorism financing by banks is centred around the proposition to take seriously the role of 'non-humans' in security practice (see Box 11.1). I go beyond utopian and dystopian visions on technology to study: who and what is at work to counter terrorism financing? Security decisions are increasingly enacted via a combination of human and technological elements; they "transform, translate, distort and modify" the state of security affairs (Latour 2005: 39). 
How does technology mediate decision-making by compliance professionals in banks when they anticipate, monitor, detect and report suspicions in the context of terrorism financing? In other words: how do banks know when money may be intended for facilitating a terrorist attack?

Banks make use of automated transaction monitoring systems to filter suspicious transactions. It is of increasing academic and societal relevance to provide more insights into the transaction monitoring and reporting practices of banks. This is because they are part of a chain of activities that may lead to security facts with powerful consequences (Amicelle and Iafolla 2017; De Goede 2018). Although they may eventually lead to the prevention and prosecution of terrorism financing, only a very small number of suspicious transaction reports actually lead to court convictions (Europol 2017). Critical questions have been raised about the effectiveness and effects of financial transaction monitoring such as financial exclusion and de-risking by banks of 'risky' regions, populations and non-profit organisations (De Goede and Wesseling 2018; HSC and ECNL 2018).

A growing body of literature at the intersection of International Relations (IR), (critical) security studies (CSS) and Science and Technology Studies (STS) has illuminated how security technologies, such as body scanners (Bellanova and Fuster 2013) and border detection devices (Bourne et al. 2015), transform how security expertise is being practiced and produced (Berling and Bueger 2015). As Bruno Latour points out:

we have to accept that the continuity of any course of action will rarely consist of human-to-human connections (for which basic social skills would be enough anyway) or of object-object connections, but will probably zigzag from one to the other.

(Latour 2005: 75)

This chapter draws on the ontological and epistemological insights from ANT, a strand of literature in STS, to outline a 'situated methodology' (Dijstelbloem and Pelizza, this volume). It will do so by suggesting some starting points for conducting detailed empirical investigation into digital devices across multiple "sites" (Latour 2005: 219).

I delineate a multi-sited ethnographic inquiry of digital security technologies centred around sites of experimentation. Within this chapter, I refer to these sites as settings in which the (potential) role, as well as the ethical, technical and practical dilemmas of the design, implementation and use of digital security technologies are openly discussed. Digital security technologies pose particular secrecy challenges for researchers. They are often privately owned, localised in numerous sites and are used in combination with sensitive data. Moreover, it requires specialised knowledge to elucidate technologically-mediated security practices (Van Veeren 2018; see introduction to this volume). Although an abundance of studies have demonstrated the crucial role and political effects of digital and material security devices (see, for example, Amicelle et al. 2015 or Suchman et al. 2017), the methodological choices and challenges of conducting a detailed empirical analysis of these complex 
technologies often remain implicit. The main question that this chapter aims to answer is: how can we account for the productive role of digital security technologies in effecting judgments and decisions in the security realm?

For researchers with a non-technical background, it is especially difficult to decide how much understanding of the actual workings of these complex technologies is needed in order to be able to attain a realistic impression of the dynamics of human and non-human agency that make up security practices. The chapter will help researchers to make strategic choices to align background knowledge and expertise with research objectives. It offers theoretical and practical suggestions to understand, analyse and communicate to a wider audience the socio-political role of digital security technologies.

The chapter commences by delineating a methodological approach for studying digital security technologies. The chapter consists of three parts. The first part discusses the secrecy challenges of digital security technologies and outlines how a multi-sited ethnographic approach centred around sites of experimentation can help to study them, but also what the challenges might be. In the second and third parts, I draw upon my personal research experiences to develop and illustrate two methodological avenues - or rather starting points - for conducting ethnographies of digital technologies: (i) following technology from design to use and (ii) observing human-computer interaction.

\section{BOX 11.1 COUNTER-TERRORISM FINANCING BY BANKS}

Starting in 2017, my research has primarily focused on counter-terrorism financing efforts by major banks in Europe. By conducting ethnographic research in and around banks, the study addresses how compliance professionals navigate the complex and occasionally competing responsibilities of their security, commercial and societal roles. My research not only analyses how human backgrounds, expertise, habits, routines and inclinations come to matter in a daily context, but also incorporates human interaction with security technologies and the subsequent ethical, technical and practical dilemmas practitioners face.

Inspired by insights from STS and CSS, the study foregrounds the role and reliance on - digital technologies in the production of security expertise by compliance officers and intelligence analysts in financial institutions. Following what Latour has called the "making of" (Latour 2005), I investigate suspicious transaction reports through combined action by humans and nonhumans. Deploying the notion of de-scription (Akrich 1992), furthermore, my aim is to follow - non-sequentially - the evolution of transaction monitoring software and/or machine learning algorithms, from its very design to use in practice. 
My research has (so far) been conducted in the Netherlands and United Kingdom. It includes 60 interviews - ranging from long formal conversations to semi-structured interviews - with amongst others compliance professionals, consultants, law enforcement representatives and regulators. I have also interviewed IT experts, data scientists, software engineers, product developers and analysts that were somehow involved in the workings of the transaction monitoring system - either by inscribing its input or processing its output. I have undertaken fieldwork at a wide range of information and stakeholder sessions about financial crime including three national workshops and one international anti-money-laundering conference.

A considerable part of my ethnographic data derives from one Dutch bank, where I have conducted a three-month research internship between March and June 2018. Following extensive negotiations concerning, for example, the objectives of my research and anonymity and confidentiality (see De Goede, this volume), I received access to experience first-hand the professional lives of compliance professionals. For three months I was an 'intern' observer, slowly mapping and developing an in-depth understanding of the dilemmas practitioners face concerning the countering of terrorism financing. I was based at the compliance department, from where I 'snowballed' through various other departments of the bank, conducting observations and interviews as I went.

\section{Studying digital security technologies}

In an increasingly data-driven world, the innovations of Artificial Intelligence (AI) and computer science have led to new ways of securing and governing populations. Security and intelligence professionals in law enforcement, border control and in private contexts such as banks make discretionary decisions in dialogue with security devices (Amicelle et al.2015). This part discusses the methodological challenges and opportunities of studying digital security technologies. In the first section I briefly present the case of transaction monitoring systems. Then I discuss which secrecy challenges digital security technologies pose. In the last two sections I delineate a multi-sited ethnographic approach focusing on sites of experimentation.

\section{The case of transaction monitoring by banks}

Financial institutions such as banks have the legal obligation to act on "the prevention of the use of the financial system for the purposes of money laundering or terrorist financing" (Directive (EU) 2018/843). They need to comply with international 'customer due diligence' (CDD) standards to know, identify and verify customers and beneficial owners of companies and conduct a risk assessment before 
accepting customers. On a regular basis they have to monitor and review whether clients behave according to their 'risk profile' by checking their accounts and monitor transactions for unusual and suspicious financial behaviour. Unusual and/or suspicious transactions have to be reported to Financial Intelligence Units (FIUs).

To identify terrorism financing, transaction monitoring systems are used, that need input in the form of 'scenarios' (DNB 2017b). For a 'terrorism financing scenario', one has to formulate certain indicators. Based on scenarios and threshold values, the transaction monitoring system filters out unusual (or suspicious) transactions and generates alerts. Indicators, for example, could be formulated according to the type of customer, customer segment, the earlier formulated 'risk profile', geographical location and cash or wire transactions. An example of such a 'business rule' in the retail segment of banks is: "customers within a specific age group, e.g. 18-25 years, crossing certain limits with respect to the size and frequency of noncash transactions" (DNB 2017b: 23). Major banks employ hundreds of analysts who manually process the automatically generated alerts. They conduct research into the customer's or company's general profile, bank accounts and transaction behaviour and possibly report it as unusual.

Despite the implementation of automated transaction monitoring systems, the Dutch Central Bank (DNB) concludes that "financial institutions in all sectors manage the risk to become involved in terrorist financing insufficiently", stating that "the transaction monitoring systems are often insufficiently tailored to detect terrorist financing and deficiencies are regularly found in client research" (DNB 2017a). For banks, failing to report or reporting too quickly can have financial but also reputational consequences. Many major banks have paid millions in fines or settlements after allegations of insufficient anti-money laundering controls (for example De Clerck and Bové 2017; FCA 2017; Klumpenaar 2015; OM 2018).

The identification of unusual or suspicious transactions in relation to terrorism financing creates difficulties as they are often small, mundane transactions that do not stand out (De Goede 2017; NVB 2017). There is a lack of concrete indicators for terrorism financing that can be translated into scenarios and business rules. A problem often mentioned in the compliance sector is that the monitoring system generates too many transactions that are falsely flagged as unusual or suspicious ("false positives"). This creates a compliance overload:

The whole movement in the market simply indicates, that in the traditional model, of "we set the scenarios, and we process the alerts", everyone gets swamped. It does not work. So everyone is looking at alternative solutions such as algorithms and machine learning algorithms. That is really unavoidable.

(Interview bank employee, 2018)

AI and machine learning technologies are increasingly seen as an answer to the growing pressure on banks and relating compliance personnel costs. They are advertised in practitioners' magazines with covers like "Look past 'wow' and see hope for compliance overload" and "Up to speed on Artificial Intelligence?" (Banking 
Exchange 2017). Companies offer machine learning tools for financial crime professionals promising "compliance by design", "greater operational effectiveness" and "advanced analytics". Researchers who aim to analyse the role of these complex technologies may be confronted with practical and technical challenges.

\section{Secrecy and digital security technologies}

Numerous scholars have deployed STS insights into their respective fields to study the complex socio-material nature of digital technologies. Intersecting STS with law and philosophy (Hildebrandt and Rouvroy 2011), communication and media studies (Gillespie 2014), surveillance studies (Kroener and Neyland 2012), and Human Computer-Interaction studies (Suchman 2007), they have successfully shown how the study of algorithms, autonomic computing, software and technological change can provide an entry-point to study power, agency, accountability and human autonomy. In security studies too, it has been shown that the deployment of algorithmic techniques for security entails important political and ethical stakes that should be described and analysed (Amoore and Raley 2017; Aradau and Blanke 2015; Grommé 2016; Kaufmann et al. 2019). But digital security technologies may be hard to comprehend. Whether there is an interest to study technology from the start, or whether awareness of mediating technologies arises later on in the research process, one can get easily overwhelmed by the technological jargon, buzzwords and rapid innovation in the tech-world (see Box 11.2). In particular for researchers with limited technical expertise, this is a time-consuming challenge.

\section{BOX 11.2 AN ETHNOGRAPHY OF WHICH TECHNOLOGY?}

Ethnographic research can seem deceptively simple. "It may appear to require only that one 'act naturally', putting aside any methodological rules and constraints" (Hammersley and Atkinson 2007: 21). For researchers who are not trained in anthropology and perhaps have received limited ethnographic training, it is important to reflect upon some of the common problems within ethnographic research designs, such as defining a viable research problem (ibid.: 21-40).

According to Bruno Latour: "any thing that does modify a state of affairs by making a difference is an actor" (Latour 2005: 71, emphasis in original). Although I was interested in the automated software that makes a selection of potential suspicious transactions, I encountered many other technologies that were potentially mediating security practices by banks.

That is when I started to perceive many more actors. Questions arose such as: what is an algorithm? What is a transaction monitoring system? What is 
machine learning and Artificial Intelligence and what are the differences? How can they be used to spot terrorist activity within financial data? Can they? Who is making this software? What does a data scientist do? What is blockchain? What are cryptocurrencies?

Posing and answering such questions may be helpful for understanding the technology under investigation and may lead to surprising research opportunities and findings. When explored exhaustively, however, one might face the danger of drowning in technical details, losing focus and being distracted from the initial research question.

Banks may develop their own in-house transaction monitoring systems, yet often buy (expensive) software packages from external vendors such as LexisNexis, Oracle, Palantir, SAS or Worldcheck. Private actors will often guard the precise workings of the algorithms as a secret, as they are a fundamental part of the company's business model which enables them to develop a competitive advantage (Gillespie 2014). Even if one would have access to the algorithmic codes, it requires specialised knowledge to be able to understand them. Furthermore, it is nearly impossible to know how they would work in practice as their productivity only becomes apparent after implementation and in combination with data.

Other chapters in this volume discuss challenges around gaining access, confidentiality and research ethics in different settings (see De Goede, this volume, about the process of gaining access to the bank). It should be noted here, however, that working in the context of counter-terrorism is particularly challenging; a blue-print of counter-terrorism financing policies and practices cannot end up in the public domain. Hypothetically though, one can wonder to which extent the often partial and situated knowledge could pose a security risk. Although scattered, much information already exists in the public domain in policy reports, conference presentations, published minutes, user guides of technologies and so on. During my fieldwork I was open to my respondents about my research interests as well as in which I was not interested. Every time I explicated that I was not interested in personal and sensitive customer data, but in dilemmas and daily practices. Still, encountered sensitive data as well as working practices too precise to publish can function in different ways, for instance as background information to make sense of processes.

One of the challenges of studying digital technologies is that they consist of more than computer codes; they are made of "stuff” too (Dourish 2017). For instance, the material infrastructures supporting the virtual or the data (like computers, screens, cables, servers and electricity networks) can either enable or constrain the workings of a software programme (Amoore 2016). Understanding, perhaps even finding the technologies, is further complicated by the emergence of sophisticated security devices such as surveillance cameras, biometric identification and verification 
systems and transaction monitoring systems that operate through AI and machine learning algorithms such as anomaly detection or 'neural networks' (Vayre 2018; see also Straube, this volume).

In his ethnographic study of risk-calculation and data-driven governance by the British Fire and Rescue Service (FRS), Nathaniel O'Grady (2015) demonstrates how data and digital technologies can simultaneously be free-floating, as well as dispersed and localised into various contexts. The analysis software MOSAIC, previously used by credit checking company Experian to profile populations in terms of consumer behaviour, was acquired and redeployed by the FRS to establish risk profiles of people most vulnerable to fire. Through conducting detailed empirical investigation into the "processes of appropriation, localisation and redeployment", O'Grady shows how digital risk calculation technologies "must undergo transformation to adapt to new organisation sites and spaces before enacting new modes of governance" (2015: 82). A digital security technology can be appropriated and transformed into numerous sites such as the military, intelligence agencies, police departments and private security actors across the globe. Although the dispersed nature of data and their associated software appears to add to their ungraspable nature, I argue that the moments in which the technology travels to new contexts offer opportunities for ethnographic research accounts of digital devices. As noted by O'Grady: “[c]ritical accounts of data-driven governance (...) must examine the mundane organisational routines, practices and processes that facilitate technological redeployment" (ibid.).

\section{Multi-sited ethnography}

How can complex digital security technologies be incorporated into an ethnography? And in which field should the fieldwork take place? There is a growing literature on digital ethnographic methods. Some studies focus on data collection in the "virtual field" (Hammersley and Atkinson 2007: 137; Lazar et al. 2017: 252), others make the digital device the prime object of analysis (Amoore and Raley 2017; Aradau and Blanke 2018; Ziewitz 2016).

In a "multi-actor and multi-level technopolitical context" new political entities arise that transcend the 'state' (Dijstelbloem and Pelizza, this volume). Terrorism financing is a security problem that transcends national borders as well as boundaries between the public and private realm. Most banks are transnational corporations operating within multiple jurisdictions. Financial anthropologists have studied global financial processes of localisation and appropriation: "financial practices do not diffuse globally in a uniform manner, but are instead utilised locally in a specific way" (Lagerwaard 2015: 575). Transaction monitoring systems are being produced by major technology firms that compete in the global market and are localised into many contexts. This dynamic context asks for a flexible approach that combines multiple ethnographic methods of data collection at multiple sites (Baird 2017; Cohn 2006; Marcus 1995; Schwell, this volume).

In order to develop an initial understanding of the security responsibilities of financial institutions before my internship in the bank, I used techniques of 
unstructured observation. Researchers using unstructured observation "are seeking to be taught by the world and want to get as close to the reality of the events as possible without being so constrained by preconceived notions of how things work that they overlook some important aspects" (Manheim et al. 2012: 333). Unstructured observation may seem trivial, but it allowed me to gain a sense of the field, as well as to have many conversations with bankers, compliance professionals and tech-companies - thereby making it a part of my ethnography as well as a snowball-sampling method. Although I was attentive to the role of security technologies from the beginning, my research does not focus exclusively on technologies (see Box 11.1).

In the beginning of my ethnography in the bank I spent a considerable amount of time just 'being' in the bank to learn about the myriad of security issues the bank deals with next to terrorism financing: various types of fraud, money laundering, corruption, violence to ATM machines, information security, the safety of employees at the office as well as abroad, data leaks and so on. I engaged with compliance professionals around me, read reports and guidance documents and followed online training. Taking the opportunity to experience the daily life at a compliance department, I spent most of my time sharing coffees with employees, joining and observing meetings whilst arranging a series of interviews.

I read secondary academic literature, policy reports, media-articles and practitioners' magazines about compliance and banking and I also signed up for forums, blogs, newsletters and event alerts of relevant public actors, companies and antifinancial economic crime organisations. This created a constant stream of information about issues and events at the intersection of security, technology and finance. Sometimes I went to rather generic technical workshops, for instance on blockchain technology. Other times, I went to more specialised events around my topic such as one on detecting financial crime with machine learning for financial institutions. At such meetings I often asked technical experts to explain in clear language the workings of digital technologies. Although this led to a general understanding of the technologies at play, I felt that in order to show how the transaction monitoring system 'acts', a more detailed understanding of the inner workings of the technology was necessary.

In a first attempt to studying machine learning algorithms that are being used to identify financial economic crime, I tried to "reflexively produce code", an approach of researching algorithms whereby the "researcher reflects on and critically interrogates their own experiences of translating and formulating an algorithm" (Kitchin 2017: 23). In short, I learned quickly that this was not feasible. Because of the variety of algorithms, programming languages and strands of computer and data science, it was unclear which 'code' to study and where. This problem was even further complicated by my limited experience in programming or coding and pre-existing technological knowledge. Till Straube (this volume) convincingly problematises 'opening the black box of algorithms'. In the next section I show that there are indeed "other ways to situate the device, other paths of inquiry to follow" than to study the inner workings of the algorithm (Straube, this volume). 


\section{Sites of experimentation}

Where can digital technologies be observed and analysed? Based on theoretical and methodological perspectives originating in ANT research, I propose to conduct ethnographic research at sites of experimentation, termed as settings in which the (potential) role, as well as the ethical, technical and practical dilemmas of the design, implementation and use of digital security technologies are openly discussed. Although they shape our lives in numerous ways, most technologies run 'silently' (Latour 1992) in the background. We do not treat them as mediators that do something (Latour 2005: 128), but as intermediaries or black boxes; "defining its inputs is enough to define its outputs" (Latour 2005: 39).

ANT accounts therefore study occasions during which facts or artefacts are not (yet) stable and taken-for-granted (Latour 2005: 79). It is during the moments that the technology is being developed or breaks down - or indeed as O'Grady demonstrated, when it is being appropriated, redeployed or localised into new contexts that technologies are present and visibly active. Traditionally, much STS and ANT research has therefore revolved around experiments and in the laboratory (Latour 1999; Sismondo 2010). Daniel Neyland illustrates how projects of experimentation with technology can provide fruitful terrain for ethnographic research into digital devices: "algorithms and their system are continually inspected and tested, changed and further developed" (2018: 22). He argues that to study the "everyday life of algorithms', one should "pay attention to the everyday work required for algorithmic conditions and consequences to be achieved" (Neyland 2018:32).

Digital security technologies are actually continuous objects of experimentation: there are many people at work in the design, implementation, 'tuning' and use of the technology (Weber 2016). It is in these moments of experimentation that the technology and the way in which it transforms of modifies a state of affairs becomes less taken-for-granted and opaque; the technical characteristics, practical dilemmas and often ethical issues are openly discussed. As I show in this chapter, the transaction monitoring system too, is a continuous object of experimentation. There are many people at work that aim to optimise the filtering of suspicious transactions out of millions or regular commercial transactions. According to Annemarie Mol,ANT researchers do generally emphasise the work involved in ordering. Mol argues that "when norms have been set, 'normalisation' does not automatically follow" (Mol 2010: 263). Building on insights from Michel Foucault, forms of ordering are not the 'product of centralised deliberation' or a 'strategic subject', but "spread themselves through and pattern the fabric of the social to operate as a microphysics of power" (Law and Ruppert 2013: 231).

In the following two sections of this chapter I describe two methodological starting points for researchers who are interested in conducting ethnographies of digital technologies. In the next section I suggest that in order to identify sites of experimentation, a methodological starting point could be to follow technology from design to use. This will enable to see who and what is at work in ordering society. In the final section, I provide practical tips for studying the use of digital technology at a specific 
site; for observing human-computer interaction. Finding instances and 'sites' of experimentation around your digital technology of interest is a way to identify moments in which the workings and dilemmas of the digital technology may become apparent.

\section{Digital security technologies from design to use}

Studying technology from design to use allows to study the different human and non-human actors involved in the enactment of security decisions and to identify sites of experimentation; the moments in which the technology becomes visible. In The De-scription of Technical Objects, Madeleine Akrich famously shows how technical objects form part of a chain: "although they point to an end, a use for which they have been conceived, they also form part of a long chain of people, products, tools, machines, money, and so forth" (1992: 205). ANT has shown how beneficial it is to conduct ethnographies of technologies during the "making of" phase (Latour 2005: 89), when the facts and artefacts have not yet been stabilised. In the previous section, I argued that sites where technologies are being 'tuned' and used can be equally interesting and useful. However, "construction sites" (Latour 2005: 88) or sites of experimentation are not always easy to locate. How does one go about research when they are not clearly demarcated in the form of an experimental project around the development of a new technology? In this section, I suggest a non-sequential approach through which to follow the technology from design to use, moving through different phases of experimentation.

In order to know about the 'making-of' transaction monitoring software systems, one would have to "loop back" (Bourne et al. 2015) to the designers (i.e. software developers) of large companies. As banks employ often thousands of people, it is difficult to know which forms of transaction monitoring they use, who designed it, and who uses it. Like many other (digital) security technologies, financial transaction monitoring systems are often being sold in the form of a finished product whereby it is difficult to recognise the original designers or engineers. This poses challenges around access and secrecy and to the feasibility and scope of the research project. Likewise, it may be complicated to find out if and where banks are developing in-house transaction monitoring systems or machine learning tools.

As previously mentioned, the localisation of digital security technologies into different organisational contexts raises questions about where an ethnography of the digital might take place. One of my solutions to identify sites of experimentation was to visit a specialised conference on anti-money laundering and counterterrorism financing. Attending the panels and workshops provided more insights into the socio-technical characteristics, possibilities, and challenges of transaction monitoring systems. In a specific area of the conference, numerous software companies and vendors advertised their products to the bankers and compliance officers attending the conferences (see also Baird 2017; Hoijtink, this volume). I collected sales folders, spoke with salespeople about the possibilities of their products, saw demos, shared and 'tested' my research interests, assumptions and understanding of technicalities with a technical crowd. 
Security conferences and fairs are useful sites where one can learn about the different stakeholders who are involved in designing, developing, selling, acquiring, implementing, maintaining or 'tuning' of transaction monitoring systems: lawmakers, software vendors, directors and managers of financial institutions, consultants, compliance officers, IT experts, data scientists and so on. Rather than studying one project, I learned about the plethora of instances - of tuning and experimentation - in which sovereign decisions are inscribed into transaction monitoring systems. Multiple times I encountered 'product owners' of transaction monitoring systems. 'Product owner' is a term that is often being used in (tech) companies, start-ups and IT development frameworks. Although they may have different tasks, product owners are often in charge of a certain (IT) 'product'; they keep oversight, supervise a team responsible for development and implementation and communicate with customers and/or stakeholders. Product owners of transaction monitoring systems in financial institutions are responsible for the operational workings of the system; they implement and 'tune' scenarios and maintain and evaluate the systems. Interviewing product owners can provide a good insight into the technical workings of the system as well as the socio-political dilemmas of detecting financial crime.

Instead of sticking narrowly to a sequential approach from design to use, I propose to use it as a thought construct to help identify sites of experimentation (see Box 11.3). The methodological starting point is to put the socio-technical characteristics of the digital security technology center stage. From there we can "loop back" (Bourne et al. 2015) into the processes of technological development and 'loop forward' into its appropriation by end-users in practice. Moreover, "[r]ather than holding stable and separate the identities of 'designer' and 'user'", as Lucy Suchman has argued, they should work as "categories describing persons differently located, at different moments, and/or with different histories and future investments in projects of technology development" (2012: 57). This will help researchers to map the socio-technical assemblage (Kitchin 2017) of digital security technologies.

\section{BOX 11.3 QUESTIONS TO CONSIDER WHEN FOLLOWING TECHNOLOGY FROM DESIGN TO USE}

- What is the socio-political context of the digital device? For which problem should it offer a solution?

- Who are or have been involved in designing, developing, selling, acquiring, implementing of the technology and who uses it?

- In which organisational context is the technology being appropriated, redeployed and localised? 
- What are the socio-technical characteristics of the digital device? (What does it do and when does interaction with humans take place?)

- Which ethical, technical and practical dilemmas of the security technology do designers, users and other stakeholders mention?

\section{Observing human-computer interaction}

One instance in which the workings of digital security technologies may become visible is in its use by security professionals. To study technology in use (especially new users) has been a long tradition in STS and ANT to unpack routine and taken-forgranted technologies (Verbeek and Slob 2006). Analysts can temporarily create the same type of novelty through "irruption into the normal course of action of strange, exotic, archaic, or mysterious implements" (Latour 2005: 80). One way for irruption into the normal course of security decision-making is to make this interaction between the human and computer - the use of a technology - a primary ethnographic focus; to regard the security professional behind a computer as a site of experimentation. Transaction monitoring systems can be considered as continuous objects of experimentation because the system is constantly adapted to evolving security threats, technological innovation as well as feedback from analysts about the effectiveness of the output. Periodic feedback offers incentives to 'tune' the system in other ways.

The human-computer interaction (HCI) literature, of which a comprehensive overview cannot be given here, presents empirically rich and interesting accounts of the human-machine interface. Although a part of HCI specifically explores design and use of technologies and interfaces for purposes of product development - not necessarily a research goal for security researchers - the wide variety of methods such as interviews, research diaries, focus groups, case studies, ethnographies and 'userresearch' deployed in HCI can provide inspiration to study human-computer interaction in security contexts (see for an overview Lazar et al. 2017). Consider for instance Lucy Suchman's (2007) - originally published in 1987 - seminal ethnographic study of user interaction with a newly developed photocopy machine. Also, her later work on tracking and targeting technologies should be noted here (Suchman et al. 2017). This chapter focuses on the observation of human-computer interaction behind a desk. Sometimes, the observation of human-computer interaction can happen unexpectedly, when respondents spontaneously show things on the screen. At other times, the interaction in itself can become the object of longer ethnographic research (see the chapters on 'case studies' and 'ethnography' in Lazar et al. 2017). In my case, it was a small part of a broader ethnographic study of the security responsibilities of banks.

\section{Observing 'the processing of alerts'}

In order to understand the possibilities and difficulties in detecting terrorism financing by banks, the transaction monitoring system had become an object of 
interest for my research. The accuracy of the alerts - the output of the system provides input for the those with the task to 'tune' the system. The processing of alerts can therefore be considered as continuous experimentation. As one bank employee put it during an interview:

The moment you set your thresholds too weak, you miss out on a lot and are not doing well. Of course we have a moderate risk appetite, so we prefer to set our thresholds too tight, so we get a lot of alerts, but if you have so many alerts that at a given moment, to say it very directly, you drown in the alerts, [...] that is also not the aim. That is really a dilemma, how do I set my thresholds, how do I optimally tune.

(Interview bank employee, 2018)

Through observing the output of transaction monitoring systems and the processing thereof, I aimed to learn more about the supposed difficulties in detecting financial economic crime and terrorism financing in specific, as well as about the daily dilemmas of compliance professionals. Inspired by often empirically rich ANT studies of 'chains of translations' (Latour 1999), my aim was in addition to observe and document a typical step-by-step processing of an alert; the analyst 'in dialogue with' the transaction monitoring system. One day, a manager arranged for me to sit next to an analyst for the day.

With quick mouse-clicks switching into different interfaces, it was hard to follow the different steps in the process and the discretionary choices that were made. Next to the transaction monitoring system, analysts use a variety of software programmes and tools to assess if the alert on the unusual transaction is an example of unusual or suspicious behaviour that should be reported. It was impossible just to be an observer. I felt like a nuisance since I interrupted the analyst with numerous questions about every little step.

A lot of work in banks takes place behind a computer, tablet or cell phone. What is being viewed, decided or done is not easily observable. Whereas the use of some mundane technical objects (like the photocopy machine) is clearly visible, this is not the case when financial analysts and compliance officers in banks interact with their screens. After all, how would an ethnographer be able to study me when I do research? Although a large part of it takes place behind a computer, one would get a very partial idea of my daily practices by just sitting next to me for an afternoon, or even a week.

Looking back at my extensive field notes of that day, it is clear that the observation has been crucial to my understanding and analysis of daily security practices in banks. For instance, through observing interaction with the screen I learned about the various software programmes that are being used, the types of data that analysts work with and typical actions to process alerts. In addition to the interaction with the screen, I documented the daily life and routines of analysts, the communication lines and the differences between departments within the bank (i.e. compliance, the 
business lines etc.), the frequency and nature of unusual transactions in relation to various financial economic crime profiles, the challenges of analysts and their recommendations for improvement. In combination with other interviews, it allowed me to gain a broad sense of the technological possibilities and challenges in detecting terrorism financing.

However, given the fact that I had only one day for observation, it had been unrealistic to expect to document a precise step-by-step processing of an alert in addition to the wider social context of the analysts. First, human-computer interaction is a quick and fleeting moment that is difficult to capture. It was impossible to document the sequence of interaction as there were too many interactions with too many software programmes. To document one's own first encounter with a security technology at the same time is challenging at the least. Second, with unrealistic research objectives and by sticking frenetically to Latour's lesson on taking field notes and research diaries and his warning that "everything is data" (2005: 133), I had put both myself as well as the analyst under pressure to capture every little detail.

It is important to reflect on such research 'failures' as it can be revealing in itself to document the complexity of security technologies and the ways in which secrecy has a productive effect on researcher and researched (see introduction to this volume).Also, it contextualises the data that was obtained as well as the credibility of the research account. Whereas in human-centred ethnographies one can go back to the respondents to verify constructed realities (Guba and Lincoln 1989), this is not the case when interaction is the research objective. In my case, it was only the combination with ethnography of the human part of the interaction and the wider social context that provided insights into the enabling or constraining potential of transaction monitoring systems. With sufficient preparation, realistic expectations and a research design that balances structured and unstructured elements however, there is much to be gained from observing human-computer interaction (see Box 11.4).

\section{BOX 11.4 QUESTIONS TO CONSIDER WHEN THINKING ABOUT OBSERVING HUMAN- COMPUTER INTERACTION}

- What are you interested in precisely? In the perspective of the human, their interaction with the computer, or the socio-technical characteristics of a specific programme?

- How will you communicate your research interests to your respondent?

- Who will you observe and "how is the research process shaped by the relationship between you as a researcher and your participants?" (Nyman, this volume) 
- In which setting will you observe human-computer interaction? (the respondent's role in the organisation and physical location might influence your observations: sounds, privacy, visibility, other colleagues, etc.)

- Which role (participant and/or observer) will you take?

- How much time will you have for observation and what is a realistic research goal for this duration?

- How are you going to take notes and what kind of notes will help you answer your research questions at a later stage?

- Will you encounter sensitive data? Is there privacy-sensitive or confidential information that you should leave out of the analysis/anonymise?

- Would it be useful and possible to have a preparatory meeting with the person behind the computer?

- Will you be able to do "member checks" to verify your assumptions and descriptions in the form of a debrief or interview afterwards and if so, what will you check? (Guba and Lincoln 1989: 239).

\section{Conclusion}

This chapter has shown why it is fruitful to conduct an ethnographic investigation of digital security technologies. Studying digital security technologies poses particular challenges of secrecy, because they are often privately owned, localised and embedded in many different contexts. Multi-sited ethnography can help to account for the productive role of complex and digital security technologies. Drawing on my own research experiences of studying transaction monitoring systems used by banks to counter-terrorism financing, I have illustrated how sites of experimentation can be fertile grounds for ethnographies of technologies. An iterative and (un)structured research process becomes even more rewarding when combined with continuous reflection on research objectives and scope. The chapter offers two concrete ways in which one might approach and study obfuscated digital technologies, being (i) to follow digital security technologies from design to use and (ii) to observe human-computer interaction. These methodological starting points will help researchers to conduct detailed empirical inquiry into the role of non-human actors in security practices. However, when putting technology centre stage, we should keep in mind not to be glued to it, but to trace its connection through and into the world.

\section{Suggestions for further reading}

- Madeleine Akrich (1992) “The de-scription of technical objects”, pp. 205224 in Wiebe. E. Bijker and John Law (eds) Shaping Technology/Building Society: Studies in Sociotechnical Change. Cambridge, MA: MIT Press. 
- Mike Bourne, Heather Johnson, and Debbie Lisle (2015) "Laboratizing the border:The production, translation and anticipation of security technologies", Security Dialogue, 46(4): 307-325.

- Bruno Latour (2005) Reassembling the Social. An Introduction to Actor-NetworkTheory. Oxford: Oxford University Press.

- Edwin Sayes (2014) "Actor-network theory and methodology: Just what does it mean to say that nonhumans have agency?", Social Studies of Science, 44(1): 134-149.

- Malte Ziewitz (2016) “Governing Algorithms: Myth, Mess, and Methods", Science, Technology, \& Human Values, 41(1), 3-16.

\section{Note}

1 Acknowledgements: thanks to Tasniem Anwar, Rocco Bellanova, Marieke de Goede, Hendrik Ike, Pieter Lagerwaard and Polly Pallister-Wilkins for the reading tips, helpful comments and support during the research and writing process. My sincere gratitude goes out to the many employees at The Bank for the kindness, trust and support during my fieldwork period and to all the other respondents who shared their valuable perspectives.

\section{References}

Akrich, Madeleine (1992) "The de-scription of technical objects", pp. 205-224 in Wiebe. E. Bijker and John Law (eds) Shaping Technology/Building Society: Studies in Sociotechnical Change. Cambridge, MA: MIT Press.

Amicelle, Anthony, Claudia Aradau, and Julien Jeandesboz (2015) “Questioning security devices: Performativity, resistance, politics”, Security Dialogue, 46(4): 293-306.

Amicelle, Anthony and Vanessa Iafolla (2017) "Suspicion-in-the-making: Surveillance and Denunciation in financial policing", The British Journal of Criminology, 58(4): 845-863.

Amoore, Louise (2016) "Cloud geographies: Computing, data, sovereignty", Progress in Human Geography, 42(1): 4-24.

Amoore, Louise and Rita Raley (2017) "Securing with algorithms: Knowledge, decision, sovereignty", Security Dialogue, 48(1): 3-10.

Aradau, Claudia, and Tobias Blanke (2018) "Governing others: Anomaly and the algorithmic subject of security”, European Journal of International Security, 3(1): 1-21.

Baird, Theodore (2017) "Knowledge of practice: A multi-sited event ethnography of border security fairs in Europe and North America”, Security Dialogue, 48(3): 187-205.

Banking Exchange (2017), June/July edition, available on: https://issuu.com/bankingexchange/docs/banking_exchange_june_? $=16540037 / 49780807$ (accessed 8 February 2019).

Bellanova, Rocco and Gloria G. Fuster (2013) "Politics of disappearance: Scanners and (unobserved) bodies as mediators of security practices", International Political Sociology, 7(2): 188-209.

Berling, Trine V. and Christian Bueger (eds) (2015) Security Expertise: Practice, Power, Responsibility. New York: Routledge.

Bourne, Mike, Heather Johnson, and Debbie Lisle (2015) "Laboratizing the border: The production, translation and anticipation of security technologies", Security Dialogue, 46(4): 307-325. 
Cohn, Carol (2006) "Motives and methods: Using multi-sited ethnography to study US national security discourses", pp. 91-107 in Brooke A. Ackerly, Maria Stern and Jacqui True (eds) Feminist Methodologies for International Relations. Cambridge, UK: Cambridge University Press.

De Clerck, Gwend and Lars Bové (2017) “Arrest zet witwasmeldingen banken op de helling”, De Tijd, 20 May 2017, available at: http://www.tijd.be/ondernemen/banken/Arrest-zetwitwasmeldingen-banken-op-de-helling/9896319 (accessed 8 February 2019).

De Goede, Marieke. (2017) "Banks in the frontline: Assembling space/time in financial warfare", pp. 119-144 in Brett Christophers, Andrew Leyshon and Geoff Mann (eds) Money and Finance After the Crisis: Critical Thinking for Uncertain Times, Hoboken, NJ: John Wiley \& Sons.

De Goede, Marieke (2018) “The chain of security”, Review of International Studies, 44(1): 24-42.

Dourish, Paul (2017) The stuff of bits: An essay on the materialities of information. Cambridge, MA: MIT Press.

DNB (De Nederlandsche Bank) (2017a). Position paper for the roundtable discussion on countering terrorism financing, Committee on Finance, Dutch House of Representatives, The Hague, 7 February 2017, available at: https://www.dnb.nl/binaries/PPterroris mefinanciering_tcm46-352386.pdf?2018090513 (accessed 7 February 2019)

DNB (2017b) "Post-event transaction monitoring process for banks", Guidance, pp. 1-48, Amsterdam, 30 August 2017, available at: http://www.toezicht.dnb.nl/en/binaries/ 51-236846.pdf (accessed 7 February 2019).

Directive (EU) 2018/843 of the European Parliament and of the Council, "The Fourth Anti-Money Laundering Directive" (AML4), 30 May 2018, available at: https://eurlex.europa.eu/legal-content/EN/TXT/?uri=CELEX\%3A32018L0843 (accessed 7 February 2019).

Europol (2017) "From suspicion to action. Converting financial intelligence into greater operational impact", pp. 1-44, Luxembourg: Publications Office of the European Union.

Financial Conduct Authority (FCA) (2017) "FCA fines Deutsche Bank א163 million for serious anti-money laundering controls failings", Press Releases, 31 January 2017, available at: https://www.fca.org.uk/news/press-releases/fca-fines-deutsche-bank-163-millionanti-money-laundering-controls-failure (accessed 20 February 2019).

Gillespie, Tarleton (2014) "The relevance of algorithms", pp. 167-194 in Tarleton Gillespie, Pablo J. Boczkowski, and Kirsten A. Foot (eds) Media Technologies: Essays on Communication, Materiality, and Society. Cambridge, MA: MIT Press.

Grommé, Francisca (2016) "Provocation: Technology, resistance and surveillance in public space”, Environment and Planning D: Society and Space, 34(6): 1007-1024.

Guba, Egon G. and Yvonne S. Lincoln (1989) Fourth Generation Evaluation. Newbury Park etc.: Sage.

Hammersley, Martyn and Paul Atkinson (2007) Ethnography: Principles in Practice (3rd ed). London \& New York: Routledge.

Hildebrandt, Mireille and Antoinette Rouvroy (eds) (2011) Law, Human Agency and Autonomic Computing. The Philosophy of Law Meets the Philosophy of Technology. Oxon: Routledge.

HSC (Human Security Collective) and ECNL (European Center for Non-for-profit Law) (2018) "At the intersection of security and regulation. Understanding the drivers of 'de-risking' and the impact on civil society organizations", March 2018, pp. 1-106, available at: https://www.hscollective.org/wp-content/uploads/2018/05/Understandingthe-Drivers-of-De-Risking-and-the-Impact-on-Civil-Society-Organizations_1.pdf (accessed 7 February 2019).

Kaufmann, Mareile, Simon Egbert and Matthias Leese (2019) "Predictive Policing and the Politics of Patterns”, The British Journal of Criminology, 59(3), 674-692. 
Kitchin, Rob (2017) “Thinking critically about and researching algorithms”, Information, Communication \& Society, 20(1): 14-29.

Klumpenaar, Sjoerd (2015) “ABN Amro krijgt boete voor misstanden Dubai”, NRC Handelsblad, 4 November 2015, available at: https://www.nrc.nl/nieuws/2015/11/04/ abn-amro-krijgt-boete-voor-misstanden-dubai-a1411763 (accessed 8 February 2019).

Kroener, Inga and Daniel Neyland (2012) "New technologies, security and surveillance", pp. 141-148, in Kirstie Ball, Kevin D. Haggerty and David Lyon (eds) Routledge Handbook of Surveillance Studies. New York: Routledge.

Lagerwaard, Pieter (2015) "Negotiating global finance: Trading on Dalal Street, Mumbai", Journal of Cultural Economy, 8(5), 564-581.

Latour, Bruno (1992) "Where are the missing masses? The sociology of a few mundane artifacts", pp. 225-258 in Wiebe. E. Bijker and John Law (eds) Shaping Technology/Building Society: Studies in Sociotechnical Change. Cambridge, MA: MIT Press.

Latour, Bruno (1999) Pandora's Hope. Essays on the Reality of Science Studies. Cambridge, MA: Harvard University Press.

Latour, Bruno (2005) Reassembling the Social. An Introduction to Actor-Network-Theory. Oxford: Oxford University Press.

Lazar, Jonathan, Jinjuan Heidi Feng and Harry Hochheiser (2017) Research Methods in Human-Computer Interaction (2nd ed.). Cambridge, MA: Morgan Kaufmann.

Law, John and Evelyn Ruppert (2013) "The social life of methods: Devices", Journal of Cultural Economy, 6(3): 229-240.

Manheim, Jarol B., Richard C Rich, Lars Willnat, Craig Leonard Brians and James Babb (2012). Empirical Political Analysis: An Introduction to Research Methods. Harlow: Pearson

Marcus, George E. (1995) "Ethnography in/of the world system: The emergence of multisited ethnography", Annual Review of Anthropology, 24(1): 95-117.

Mol, Annemarie (2010) "Actor-network theory: Sensitive terms and enduring tensions", Kölner Zeitschrift Für Soziologie Und Sozialpsychologie. Sonderheft, 50: 253-269.

Neyland, Daniel (2018). The Everyday Life of an Algorithm. Open Access: Palgrave Macmillan, available at: https://doi.org/10.1007/978-3-030-00578-8

NVB (Nederlandse Vereniging van Banken) (2017) "Position paper. Tegengaan terrorismefinanciering kan effectiever", Committee on Finance, Dutch House of Representatives, The Hague, 7 February 2017, available at: https://www.nvb.nl/media/document/001335_ tegengaan-terrorismefinanciering.pdf (accessed 7 February 2019).

O'Grady, Nathaniel (2015) "A politics of redeployment. Malleable technologies and the localisation of anticipatory calculation", pp. 72-86, in Louise Amoore and Volha Piotukh (eds) Algorithmic Life: Calculative Devices in the Age of Big Data. London and New York: Routledge.

OM (Openbaar Ministerie) (2018) “ING betaalt 775 miljoen vanwege ernstige nalatigheden bij voorkomen witwassen”, Openbaar Ministerie, 4 September 2018, available on: https:// www.om.nl/@103953/ing-betaalt-775/ (accessed 7 February 2019).

Sismondo, Sergio (2010) An Introduction to Science and Technology Studies (2nd ed.). Chichester, UK and Malden, MA: Wiley-Blackwell.

Suchman, Lucy A. (2007) Human-Machine Reconfigurations: Plans and Situated Actions. New York: Cambridge University Press.

Suchman, Lucy (2012) “Configuration”, pp. 48-60 in Celia Lury and Nina Wakeford (eds) Inventive Methods: The Happening of the Social. Oxon and New York: Routledge.

Suchman, Lucy, Karolina Follis, and Jutta Weber (2017) “Tracking and targeting: Sociotechnologies of (in) security”, Science, Technology, \& Human Values, 42(6): 983-1002.

Van Veeren, Elspeth (2018) "Invisibility", pp. 196-200 in Roland Bleiker (ed.) Visual Global Politics. London and New York: Routledge. 
Vayre, Jean-Sébastien (2018) "Comment décrire technologies d'apprentissage artificiel? Le cas des machine à prédire”, Réseaux, 5(211): 69-104.

Verbeek, Peter-Paul and Adriaan Slob (eds) (2006) User Behavior and Technology Development. Dordrecht: Springer.

Weber, Jutta (2016) "Keep adding. On kill lists, drone warfare and the politics of databases", Environment and Planning D: Society and Space, 34(1): 107-125.

Wesseling, Mara and Marieke de Goede (2018). Beleid Bestrijding Terrorismefinanciering. Effectiviteit en Effecten (2013-2016). University of Amsterdam commissioned by The WODC (Research and Documentation Centre) of the Dutch Ministry of Justice and Security, Amsterdam, December 2018.

Ziewitz, Malte (2016) "Governing Algorithms: Myth, Mess, and Methods", Science, Technology, \& Human Values, 41(1): 3-16. 


\title{
12
}

\section{RESEARCHING THE EMERGENT TECHNOLOGIES OF STATE CONTROL}

\section{The court-martial of Chelsea Manning}

\author{
Sarah M. Hughes and Philip Garnett
}

- Research objective: This chapter has two objectives. The first is to critically analyse the multiple technologies by which state actors work to influence a narrative surrounding an event or process. The second is to attempt to ground this analysis within the context of leaked data, through the court-martial of Chelsea Manning.

- Research puzzle: This chapter helps researchers who want to navigate the challenges of working with state secrets that are leaked and therefore in the public realm, but which are technically still classified.

\section{Introduction}

The number of high-profile cases of whistle-blowers in recent years presents a novel challenge for security researchers. What methods can be applied in order to research leaked state secrets that are now in the public realm? This chapter will help researchers who are confronted with the particular methodological difficulties associated with obtaining or publishing publicly accessible data that the state (or other organisations) may wish to obscure. Such data may be leaked, readily available on the Internet, and yet never have been declassified. The data may also have been released through Freedom of Information Act requests (FOIA) and be redacted or hidden on poorly implemented websites that are not easily searched. For this chapter we adopt an ethnographic approach to the research of these digital technologies, which include: large document datasets, website security certificates, search engine algorithms, and redacted FOIA documents.

Drawing upon our own research dilemmas whilst researching the court-martial of whistle-blower Chelsea Manning, in this chapter we map out a series of obfuscating emergent technologies of state control, (the difficulties that surround accessing publicly 'available' data via poorly constructed FOIA reading rooms, redactions and files 
downloads) and we comment upon the implications of these for security researchers in this field. Our ethnographic approach to the digital technology in the context of state secrets allows us to map our encounters with the inconsistent and emergent actors involved within the obfuscation of this data. We therefore detail to other researchers the challenges we faced, and the methods we arrived at to critically interrogate public access to information about Chelsea Manning's court-martial.

This chapter therefore engages with the following questions:

- What ethical, practical and technological challenges do researchers face when they wish to use leaked materials for their research?

- What tools can researchers use to map secrecy through an attention to technologies of state control?

- What methodological challenges face researchers who aim to access public data that the state wishes to hide?

- How can researchers navigate such a complex, ethically and politically charged field?

- What strategies can researchers deploy to avoid paranoia when researching secret state technologies?

- How can, or should, researchers publish their findings from this data?

\section{BOX 12.1 THEORISING THE STATE}

- Emergent technologies of state control: We understand the state to be multifaceted and inconsistent (Gill 2010; Mountz 2013), continually performed through the dynamic interplay of multiple actors. Therefore when exploring the technologies of state control, we see these systems, procedures and programs in the context of an always-already incoherent and emergent state persisting beyond the duration of the actors that comprise it.

- Obfuscation: A clouding over, a procedural darkness and/or a lack of clarity over the access to legally available data. Obfuscation differs from obstruction, as there may be no singular point or moment of refusal, rather a series of emergent practices that arise through an assemblage of state actors.

\section{The court-martial of Chelsea Manning}

Private Chelsea Manning was arrested by the US government in May 2010, charged with leaking classified military material to Wikileaks. Intelligence analyst Manning was later convicted in 2013 of a series of offences, including violating the 1917 Espionage Act and stealing government property. Initially sentenced to 35 years in military prison, Manning was released on 17 May 2017 after her 
sentence was commuted to time served in the final days of the Obama presidency. Between January and May 2010 Manning leaked approximately 750,000 documents to WikiLeaks. Among this material was the 2007 Baghdad airstrike video showing the killing of two Reuters correspondents (which has subsequently been termed 'collateral murder'), the 2009 Granai airstrike in Afghanistan, and 400,000 documents that came to be known as the Iraq War Logs (James 2014). Constituting one of the largest ever data leaks in the military/security realm, over a million documents. These documents ranged in classification from UNCLASSIFIED up to SECRET/NONFORN (not to be shared with foreign nationals) (US Department of Defence 2011). No TOP SECRET information was released. These documents, including state department diplomatic cables, provide evidence of the officially sanctioned cover-up of rape and sexual torture (including of children) by military contractors, and the indiscriminate shooting of Iraqi civilians and those attending to their injuries.

Manning was convicted by courts-martial; under military rather than civilian law (the Uniform Code of Military Justice). This is important to consider methodologically as the proceedings of courts-martial are not routinely published; and although the judge has some discretion to release records it is the prosecution that is responsible for the release of information. Therefore, for full access it is necessary for the media to be physically present to report on trial proceedings, for which they need accreditation from the military before entering the court room. In the case of Chelsea Manning, one journalist, Alexa O'Brien, took and published detailed notes of the proceedings online (O'Brien 2017). She was able to file over 100 FOIA requests for official documents and transcripts of the court-martial, which have been uploaded to the US Army's FOIA reading room. However, many challenges remain for the researcher in accessing this unclassified data on the trial which is now 'publicly available', and yet obfuscated through a series of emergent technologies of state control which we will continue to unpack later in this chapter.

\section{BOX 12.2 FROM THE PENTAGON PAPERS TO WIKILEAKS: LEAKED DATA IN AN INTERNET AGE}

One of the most famous large scale leaks of the twentieth century was the Pentagon Papers in 1971 (Ellsberg 2003); a 47 volume largely 'Top Secret' report produced by the United States Department of Defense as a history of the US's political and military involvement in Vietnam from 1945 to 1967. In order to leak the documents US military analyst Daniel Ellsberg manually photocopied all 7000 pages, a process that took weeks to complete (Ellsberg 2003).

Since the Pentagon Papers, the advent of the Internet has fundamentally changed the scale and nature of document leaks. The digitisation of state processes has significantly changed the conditions through which data is 
released, as (access permitting) it is possible to make perfect digital copies of documents and other materials. Further, this data can be disseminated via online platforms, including the WikiLeaks website, a cryptographically secured leaks platform that takes advantage of this relative ease with which documents can be copied and transported electronically (WikiLeaks 2015). Leakers anonymously access the 'dark web' service submission website using The Onion Router (TOR) (Dingledine, Mathewson, and Syverson 2004), and deposit files for WikiLeaks to publish.

We can assume that the WikiLeaks dark web submission point was how Chelsea Manning was able to transfer 750,000 files from two databases to Wikileaks. A leak on this scale would have been practically impossible in 1971, as it would have taken months to photocopy 750,000 pages of documents, and physically moving them would be challenging. In contrast, Manning was able to copy an entire database onto a single CD-ROM, marked Lady Gaga, and walk out with it in a portable CD player (Leigh 2010).

The Internet brings further opportunities and constraints for disseminating leaked data. As the Pentagon Papers were classified, the New York Times and later the Washington Post had to go through the courts to publish with them. To further safeguard the possibility of public debate about the content of the papers then US Senator Mike Gravel asked Howard Zinn and Noam Chomsky to produce an edited portion of the papers (United States Department of Defense et al. 1971). This resulted in 4,100 pages of the papers being entered into the record of his Subcommittee on Public Buildings and Grounds (Gravel 1972); the full 7,000 pages were only declassified by the US Government in 2011 ("Pentagon Papers" 2016). In contrast, all the data leaked by Manning remains intact and available, if somewhat in limbo; it remains classified and is accessible on the WikiLeaks website. However, as we have written elsewhere (Garnett and Hughes 2019) it is not entirely clear how easy it would be to publish with the data which has not been declassified.

The recent Paradise and Panama Papers released by the International Consortium of Investigative Journalists (ICIJ) are different again in their scale (11.5 million and 13.4 million documents respectively). Impossible to photocopy, and significantly beyond the capacity of CDs, and most flash drives, these datasets present additional challenges to researchers with respect to access, raising questions of how to effectively approach, analyse, publish data of this scale.

\section{Research design and methodology}

Our research emerged from a recognition that Manning's court-martial, and the data that she leaked to Wikileaks have received scant attention within the academy (see Garnett and Hughes 2019). This is, however, important to explore, in the context 
of claims reported by Julian Assange that: "the ISA has banned the single most significant US foreign policy archive from appearing in its academic papers ..." (Assange and Others 2015: 10). We were not interested in 'testing' Assange's claims here; instead we focused upon the politics of knowledge curation in the context of an ambiguous and incoherent state.

We therefore draw a distinction between the two forms of data concerning state secrets that are relevant here: first, data that has been leaked by a whistle-blower and has not been declassified; second, data that the state has been forced to release, but otherwise would not have done so (e.g. through a FOIA request). In the case of Chelsea Manning, both forms of data are relevant here; the files that were leaked to Wikileaks, and the subsequent FOIA requests regarding her court-martial and treatment by the US military. This distinction is important; whilst both state secrets that are now in in the public realm, the technologies of state control used to obfuscate access to, or publishing on this data are different.

With this in mind, we depart from mainstream approaches for engaging with the state in security research. The information is publicly accessible; it is just not readily so. Indeed, we understand 'the' state to be emergent, and comprised of multiple actors (see also Dijstelbloem and Pelizza, this volume). There are many US government actors enrolled into Manning's case including: the military tribunal staff at Fort Leavenworth; staff at the FOIA request department and website maintenance staff. Individuals people the state (Medby 2016). In addition, the state is also comprised of multiple material actors. These lively, agentic materials exceed and extend the spaces of politics beyond the traditional sites of the state. For example, the contents of the US army's FOIA reading room cannot be picked up by a search engine, providing additional challenges for the security researcher. Splintering the definite article of 'the' state reveals an emergent and inconsistent assemblage that cannot be determined a priori. For security researchers attempting to access publicly available state secrets, this means starting from an acknowledgement that there is no singular point of refusal. In short, questions about 'access' raise important epistemological, ethical and political questions about the place of research in, on and with public state secrets. The state has obfuscated aspects of the production and release of this data and therefore the research is approached obliquely. By framing this research as oblique we are not claiming that access would a give a researcher a 'full view', for in some way most research is from an oblique angle (see Belcher and Martin, this volume).

We therefore adopted an ethnographic approach (including interviews, observation and auto-ethnographic reflections) to researching Manning's court-martial. We chose this methodological approach to allow for a commitment to an inductive and iterative epistemology and to align with our understanding of an emergent state. Ethnographic methods can be considered more of an approach to research rather than a specific set of methodological practices. We conducted an auto-ethnography of our own interactions with state technologies and semi-structured interviews with actors involved within Manning case. This aligns with the framing of this research process as oblique; in the knowledge that we were encountering fragments 
of 'the' state which were already obfuscated. An ethnographic approach allowed us to these map obfuscating practices as they emerged and were encountered.

In the following sections, we unpack how these approaches played out during our research, and make suggestions for future researchers encountering the emergent technologies of state control. We look at this through the nuances of access to the US Army's FOIA Reading Room website.

\section{Example: access to the US Army's FOIA Reading Room website}

As previously mentioned, when courts-martial are undertaken by the US military there is no public record of the trial; the prosecution can decide what is released. This does not mean, however, that there is no way for a researcher to access a transcript, for requests in the US can be made under FOIA. It is important for researchers to note, however, that FOIA requests have to be very specific (e.g. asking for documents that are known to exist) to avoid being rejected for being too broad. This requires a clear and detailed understanding of the form of the materials requested (e.g. in the US you usually require the subject, timeframe, individuals involved and a reason why that department will have that information). As a journalist who had attended the trial submitted 25 FOIA requests for access to the court-martial transcript specifically, and more than 100 requests for the proceedings as a whole, we did not submit our own FOIA requests. It is standard practice with US FOIA requests that the data that was permitted to be released was redacted to protect state secrets before being uploaded to the US Army's FOIA Reading Room website.

Our ethnographic research on encountering technologies of state control, identified a tension between democratic public accountability and obfuscating practices in our attempts to access the US Army FOIA website. At the time of writing this chapter, we note that there are elements of the construction of this website that make it appear risky for the researcher (or any member of the public) to access. We documented this as part of our auto-ethnographic research methods. When arriving at the website, the visitor is warned of a lapsed certificate with an alert stating that "Your connection is not private" and an additional warning that there is the possibility that the site may be being used by 'attackers' to steal the visitor's information and potentially their identity (see Figure 12.1) . $^{1}$

This warning, we suggest, is likely to encourage many users to leave the site, nor attempt or know how to go any further. Previously, when using Chrome to get beyond this warning the user had to select the 'advanced' button, which is concealed on the left-hand-side of the alert message and greyed out. After selecting this 'advanced' option could user create a security exception and accept the expired security certificate, however this was accompanied by an additional warning about the potential hazards of proceeding to the site (Figure 12.2, Garnett and Hughes 2019). Only then can a user proceed to the website and the location of the documents. At the time of writing however, it has not been possible to access the US Army's FOIA Reading Room via Chrome ${ }^{2}$ for at least six months (see Figure 12.3). 


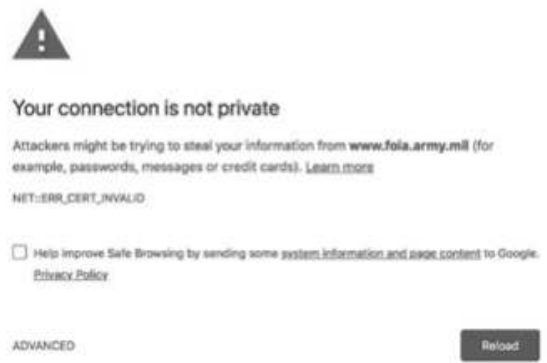

FIGURE 12.1 Screenshot of attempt to access the US Army's FOIA website [28 November 2018]

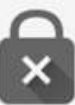

\section{Your connection is not private}

Attackers might be trying to steal your information from www. foia. army. mil (for example, passwords, messages or credit cards).

NET:ERR_CERT_AUTHORIT_INVALID

HIDE ADVANCED

This server could not prove that it is www. foia. army. mil; its security certificate is not trusted by your computer's operating system. This may be caused by a misconfiguration or an attacker intercepting your connection. Find out more.

Proceed to muw foia armymil (unsafe)

FIGURE 12.2 Screenshot of attempt to access US Army's FOIA website [24 November 2016] 


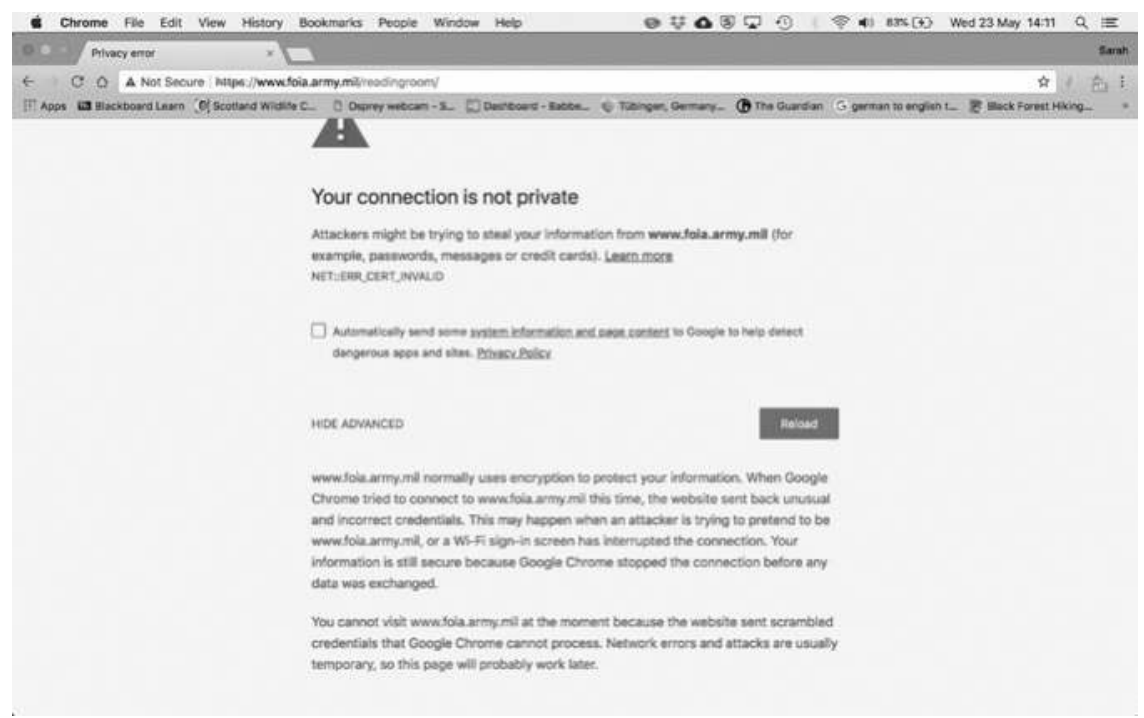

FIGURE 12.3 Screenshot of attempt to access US Army's FOIA website [23 May 2018]

The FOIA website itself has a clear layout and information on the documents filed there (e.g. the title, filename and some metadata). Yet attempting to download documents on the website reveals further difficulties; whilst the website does list individual documents that can be searched from within the site, the functionality is limited, for the searchable metadata (such as keywords) is restricted.Additionally, many of the documents (although, not all of them) are stored in ZIP files that are frequently in excess of 1 gigabyte. The files do not report their size to the web browser, which means that a visitor is unable to determine how long the download will take, nor the final size of the download (see Figure 12.4). When downloaded the files are redacted and difficult to search, for they are frequently images embedded within PDFs. We suggest that some visitors may consider abandoning the download due to the previous warnings cultivating a fear that the files are somehow corrupted.

Our auto-ethnographic reflections on attempting to access the US FOIA website, are an example of where our reflections on government (in)actions could be labelled as aligning with conspiracy. However, as this is a website where the US Army disseminates information released in response to a FOIA request, it is not unreasonable to make the assumption that this is information that they would not willingly release. Perhaps it is in their interest to obscure access to this information; to make it harder for interested parties to research this data? Clearly, making their website easily accessible is not a high priority; for this has been the case since at least March 2016.

Importantly, however, that does not necessarily mean that these difficulties in accessing the files have been intentionally created. For example, the website's security certificate may once have been valid, and when it expired its renewal may have been caught between the multiple actors comprising an (in)coherent bureaucratic 
Today

Separate_Exhibits.zip

https://www.fola.army.mil/ReadingRoom//ReadingRoom/FileDownload.dl?docl...

$281 \mathrm{~KB} / \mathrm{s}=4.6 \mathrm{MB}$

PAUSE CANCEL

FIGURE 12.4 Screenshot of file downloading from the US Army's FOIA website [24 November 2016

assemblage. Similarly, the large ZIP files may be a reflection of the amount of time the creator of the content was willing to spend on building the database. This is therefore not likely to be a deliberate attempt to put people off downloading the files, for to create metadata for and upload every file individually would be a significant task. Perhaps therefore the state of the website reflects convenient neglect. As consequence of this complication, however, access to this data becomes obfuscated.

\section{BOX 12.3 RESEARCHER IN PRACTICE: ON FEELING LIKE A CONSPIRACY THEORIST}

From our experiences, the work of researching technologies of state control over publicly available data can make you feel paranoid. The lack of clear refusal of access, the delays, lack of responses and bureaucratic confusion can be helpfully understood through an understanding of 'the' state as inconsistent and emergent. However, this did not necessarily negate our concerns of being labelled as 'conspiracy theorists', joining dots into phantom shapes to make unsubstantiated claims about state practices.

We follow Hyndman (2001: 265) who argues in her feminist critique of traditional conceptions of Geographical fieldwork, that "there is value in working through the messiness, engaging in fieldwork in a careful manner, rather than writing it off as too fraught with difficulties and dangers. Imperfect engagement is better than no engagement, or a paralyzing angst". In recommending that researchers remain with this discomfort and unease, we are not arguing for grand claims about illicit state practices, but instead suggesting the value in making these moments of obfuscation and confusion visible. This is important, first, because it is through encounters with state actors that researchers can come to learn about the technologies of state control and secondly, as it is through making this visible that we can hold democratic public institutions to account (Belcher and Martin 2013). 


\section{Implications and suggestions for security researchers: politics, ethics, practicalities}

What the above example from our research process reveals about researching the emergent technologies of state control is that an outright refusal of access, or a clear path of obstruction would likely be identifiable and therefore easier to write about. In contrast, the obfuscating practices that we were both researching and experiencing are emergent; they arise from encounters with facets of the state and its technologies. It is only through asking that you do not get a reply; only when attempting to access a website that you find difficulties. Technologies of state control are emergent, for they only arise when the researcher rubs up against, challenges or encounters aspects of the state apparatus. This makes these technologies hard to identify a priori and to capture through the research process.

In addition, and importantly for the academy, the data that Manning leaked has never been declassified. This raises a series of additional dilemmas for security researchers regarding the place of such data within academic journals. This is further complicated in the context of a series of claims made by Julian Assange, editor-in-chief of WikiLeaks that: ". . . the poverty of coverage in American international relations journals appears not merely odd, but suspicious." (Assange et al., 2015, p. 10), leading others to observe that " $[\mathrm{t}]$ here has been an effective embargo on the use of those materials for research by US academics who fear sanctions by US authorities if they as much as access them" (Mair, 2016). We have written elsewhere on the relative lack of attention given to Manning's case within International Relations and Political Geography and the possible reasons for this (Garnett and Hughes 2019). However, the International Studies Association (ISA) have responded to wider claims of this nature noting:

It has been discussed among the ISA journal editors in the context of any legal issues related to materials used from WikiLeaks. That discussion centered on the implications of publishing material that is legally prohibited by the US government ... But no policy has been made and the issue has not been widespread in journal submissions.

(Boyer, in Norton 2015)

There have been cases of high profile US universities activity discouraging students and staff from engaging with the materials; a leaked email from Columbia University's School of International and Public Affairs (SIPA) advised the below (see Figure 12.5).

This further demonstrates the relationship between the academy and the state; for this took the form of warning students that the use of leaked material might bring into question their suitability for handling government materials, and therefore by implication suggesting that they might damage their future employability (Figure 12.5). This advice, including the email from Columbia University's SPIA, was retracted soon after it was released (Gustin 2010). In short however, there is a lack of clarity for researchers as to the methodological possibilities and implications for research in this area that resonate beyond the specifics of this example. 


\section{From: Office of Career Services}

Date:Tue, Nov 30, 2010 at 3:26 PM

Subject: Wikileaks - Advice from an alum

To: "Office of Career Services (OCS)"

Hi students,

We received a call today from a SIPA alumnus who is working at the State Department. He asked us to pass along the following information to anyone who will be applying for jobs in the federal government, since all would require a background investigation and in some instances a security clearance.

The documents released during the past few months through Wikileaks are still considered classified documents. He recommends that you DO NOT post links to these documents nor make comments on social media sites such as Facebook or through Twitter. Engaging in these activities would call into question your ability to deal with confidential information, which is part of most positions with the federal government.

Regards,

Office of Career Services

FIGURE 12.5 Email from Columbia University's SIPA

Source: Gustin 2010

\section{Politics}

In the absence of any written guidelines on the publishing of publicly available classified material within academic journals, we got in contact with editors of Political Geography and International Relations journals to request whether they had any specific policies regarding this. For example, could a researcher publish a screenshot of the video of the Baghdadi airstrike 'collateral murder', which depicts the indiscriminate shooting of Iraqi civilians, Reuters' staff, and two children by US military forces in an Apache helicopter, including the audio recordings from the cockpit? This video is widely available on the Internet; a simple Google search will bring up a Wikipedia page with a screenshot and link to the video. Yet this material is classified and is therefore still technically a state secret. What then is the role of the researcher, and the wider academy in response to this?

Of those journal editors who replied, most expressed that they did not have a particular policy on this, and that individual cases were dealt with by the editorial board as they arose. They all stated that this was not a problem they commonly came across (if indeed, they did at all), and therefore it is likely that this situation 
does not merit a journal policy. One editor commented that they had not received a paper dealing with leaked material, but compared this discussion around the ethics of classified data to a conversation they had had regarding the (re)publication of the cartoon of Prophet Muhammed that had originally appeared in the Danish newspaper Jyllands-Posten.

\section{Ethics}

There are significant ethical implications to consider when attempting to engage with, or publish on leaked data. Those potentially impacted by this include: the whistle-blower, publisher of the leaked data, those named in the leaked data, the researcher, their research team, institution and colleagues. This is not to say that security researchers should not engage with leaked data, for this is a critical part of holding the state to account, yet this research is located within a constantly changing politically and ethically charged field.

What this means is that it becomes challenging to deploy a pre-existing ethical framework to work with leaked data (see in this volume Hoijtink; Amicelle, Badrudin and Tanner). Instead, we find it helpful to follow Butler's account that "ethics requires us to risk ourselves precisely at moments of unknowningness" (2005: 136). Ethics, Butler argues, begins at the edges of sensibility; it is only by acknowledging our own incoherence, the impossibility of being able to give an account of ourselves, that we can begin a "conception of ethics, and indeed, responsibility" (2005: 19). When framed in this way, ethics emerges at the point where the research route becomes unclear, where the researcher takes a step into the unknown. In the context of working with leaked data, has implications for the practical steps that can be taken by the researcher.

\section{Practicalities}

Working with leaked data requires starting the research with different and difficult questions. From our experiences with the Manning data, which cannot simply be extrapolated to other geopolitical contexts, we make the following recommendations for researchers intending to publish within this complex and political area of research:

1 The researcher must approach the topic in the realisation that their work is part of a wider process of knowledge curation, that they are working from an oblique angle whereby many aspects of traditional research design, ethics, methods and dissemination cannot simply be applied. For example from our research on Chelsea Manning, we started from the assumption that the researcher will likely encounter incoherent fragments of a dispersed and disparate state.

2 Prior to engaging with the leaked material, it is - of course - imperative to research the context of the data leaks. Why was this data leaked? What have the implications of this been for the whistle-blower, those named within the 
data, and the state institutions that have been impacted? What are the potential political and individual implications of further scrutiny of this data in the academy? Whilst the need to hold states to account for their actions may be the rationale for some critical security research, the researcher must think through the possible implications of their research in this field.

It can be challenging to conduct a project with the understanding that the research process is oblique. Further, it is hard to document the obfuscating technologies of state control whilst simultaneously recognizing that these technologies emerge and become visible as a result of the research process. We found that conducting auto-ethnographic research was beneficial for balancing this tension within the research design. In taking detailed, self-reflexive notes of our own thoughts and actions throughout the research process we were able to build up two research diaries that captured our own encounters with state technologies. We found this helpful to navigate what was at times a confusing and disorienting process. It was also useful to have a record of our own encounters with technologies of state control, for example the screenshots of website access.

Furthermore, as previously noted, the publication of classified data within academia books and journals is a grey area, both legally and ethically. Therefore, we suggest to future researchers who are aiming to publish their research, that they contact relevant journal editor(s) well before submitting. In particular, for those publishing classified data that has been leaked from non-democratic (or potentially hostile) states, we strongly recommend taking legal advice on the implications of this on your future travel, access and employment. In addition advice should be sought on the possibility of further reproductions on the leaker and those named in the leaks. Our advice here would be to consider whether you need to include the data within your work, or whether can you signal this to the reader to find themselves. This will depend, of course, upon the nature of your research, epistemology and methods used. In short however, whilst we do not think that critical security researchers should shy away from pushing the academy to have difficult conversations on the place of leaked data, the researcher must be proactive in taking measures to prevent the potential repercussions of this.

\section{Reflections}

The last decade has been characterized by whistle-blowers, with large deposits of publicly accessible, and still classified, state secrets. At the same time, the online documentation of FOIA requests has resulted in further repositories for redacted data that the democratic state has been forced to release. In this chapter we reflected upon these two forms of data: leaked classified data that has entered the public realm, and data that the state has been required to make public.

We explored the technologies of state control that emerge to control, curtail and obfuscate access to this data. Drawing upon our own research into the attention that the court-martial of Chelsea Manning has received in the academy, we reflected 
upon the ethical, political and practical dilemmas that we encountered, to give advice to future critical security researchers working in this field. First, we identified that it can be helpful for work in this area to theorize the state as multifaceted and inconsistent, an assemblage of multiple, heterogenous actors. This is because when conceptualizing the technologies of state control an understanding of these systems, procedures and programs as fragments of an emergent 'whole' can assist the researcher in processing their experiences. Technologies of state control are emergent; they arise through a researcher's interaction with disparate parts of the state apparatus. Second, we frame these emergent technologies as a form of obfuscation. By this we mean that the incoherent state does not act with a singular intention; there is no singular point of refusal of access to, or to publishing on this data. Instead, it is possible to map, or document these areas of procedural darkness to address the politics of the lack of clarity over the availability of this data for researchers.

We therefore adopted ethnographic methods, in particular auto-ethnography, as a means by which to chart these emergent technologies. We utilized autoethnographic reflections from our work attempting to access the US army's FOIA Reading Room. Commenting upon a series of what we term obfuscating technologies of state control, we note the difficulties accessing the website, the lapsed security certificates, lack of metadata, undisclosed file sizes and documents saved as redacted JPEGs saved within pdfs, making it challenging for the researcher to search. We drew out the implications of this for the security researcher, discussing the merits of framing these technologies as emergent and the consequent value of auto-ethnographic work within this area. From this we moved to examine the ethics, politics and practicalities of publishing classified data that has been leaked to the public. Utilizing our experiences and discussions with journal editors around the place of classified material within the academy, we advised future researchers to place their research within wider discussions of knowledge curation, to critically interrogate the context of the leaked data and to seek clarification from journal editors and - if necessary - lawyers before moving to publish in this field. We end by noting that mapping the emergent technologies of state control in the context of publicly available state secrets is a new and unchartered terrain. In a digital age, the rise of mass data leaks is likely to continue to increase, posing urgent and as-yet unaddressed challenges for critical security researchers.

\section{Suggestions for further reading}

- $\quad$ Pauline Maillet, Alison Mountz, and Keegan Williams (2017) "Researching migration and enforcement in obscured places: Practical, ethical and methodological challenges to fieldwork.” Social \& Cultural Geography, 21(7): 927-950.

- Gabriel J. Michael (2015). "Who's afraid of WikiLeaks? Missed opportunities in political science research.” The Review of Policy Research, 32(2): 175-99.

- John O'Loughlin, Pauliina Raento, Joanne P. Sharp, James D. Sidaway, and Philip E. Steinberg (2015) "Data ethics: Pluralism, replication, conflicts of interest, and standards in Political Geography." Political Geography, 44(1): A1-A3 
- $\quad$ Philip E. Steinberg (2010) "Professional ethics and the politics of geographic knowledge:The Bowman Expeditions.” Political Geography, 29(8): 413.

- Lucy Suchman, Karolina Follis, and Jutta Weber (2017) "Tracking and targeting: Sociotechnologies of (in)security." Science, Technology \& Human Values, 42(6): 983-1002.

\section{Notes}

1 It is worth noting that a SSL certificate for a multi-domain site such as the US government webpages could be purchased for roughly $\$ 600$ dollars a year (digicert.com 2017), so it is likely they have the capacity to install a valid certificate should they wish.

2 Similar situations play out - albeit with different wordings of the warning - in many other major browsers (e.g. Internet Explorer, Mozilla (Firefox) and UC Browser).

\section{References}

Assange, Julian, and Others (2015) The WikiLeaks Files: The World According to US Empire. London:Verso Books.

Belcher, Oliver, and Lauren L. Martin (2013) "Ethnographies of closed doors: Conceptualising openness and closure in US immigration and military institutions: Ethnographies of closed doors." Area, 45(4): 403-410.

Butler, Judith (2005). Giving an Account of Oneself. Oxford: Oxford University Press.

Digicert.com (2017) SSL \& PKI Made Easy. Digicert. https://www.digicert.com/ Accessed 6 December 2017.

Dingledine, Roger, Nick Mathewson, and Paul Syverson (2004). Tor: The Second-Generation Onion Router. Washington DC: Naval Research Lab.

Ellsberg, Daniel (2003). Secrets: A Memoir of Vietnam and the Pentagon Papers. Penguin: London.

Gill, Nick (2010). "New state-theoretic approaches to asylum and refugee geographies." Progress in Human Geography, 34(5): 626-645.

Garnett, Philip and Sarah M. Hughes (2019) "Obfuscated semocracy? Chelsea Manning and the politics of knowledge curation." Political Geography. (early edition)

Gravel, Mike (1972). The Pentagon Papers:The Defense Department History of United States Decision making on Vietnam. Critical Essays and an Index to Vol. 1-4.Vol. 5. Beacon Press: Boston.

Gustin, Sam (2010) Columbia University reverses anti-WikiLeaks guidance. Wired https:// www.wired.com/2010/12/columbia-wikileaks-policy/ Accessed 5 April 2018

Hyndman, Jennifer (2001) "The field as here and now, not there and then." Geographical Review, 91(1/2): 262-272.

James, Selma (2014) “Chelsea Manning joins the army - of whistleblowers.” QED: A Journal in GLBTQ Worldmaking, 1(1): 47-51.

Leigh, David (2010). "How 250,000 US Embassy cables were leaked." The Guardian, 28 November 2010. http://www.theguardian.com/world/2010/nov/28/how-us-embassycables-leaked.

Mair, Michael (2016) Viewpoint: Julian Assange and the "academic embargo" on Wikileaks revelations - news - University of Liverpool. University of Liverpool. February 5, 2016.

Medby, Ingrid Agnete (2016) "Peopling the state: Arctic state Identity in Norway, Iceland, and Canada." Doctoral thesis. Durham University, 2017. http://etheses.dur.ac.uk/12009/. Accessed 25 May 2018.

Mountz, Alison (2013) "Political Geography I Reconfiguring Geographies of Sovereignty." Progress in Human Geography, 7(1): 1-13. 
Norton, Benjamin (2015) Assange: US Academia Helps the State Department. Medium https:// medium.com/@BenjaminNorton/assange-us-academia-helps-the-state-departmentac66b4276778 Accessed 5 April 2018

O'Brien, Alexa (2017). Alexa O'Brien: Archive https://alexaobrien.com/archive Accessed 10 September 2017.

United States Department of Defense, Noam Chomsky, Mike Gravel, and Howard Zinn. (1971). The Pentagon Papers. (The Senator Gravel Edition.) The Defense Department History of United States Decision-Making on Vietnam. vol. 5. Critical Essays. Edited by Noam Chomsky and Howard Zinn, and an Index to Volumes One-Four. Beacon Press: Boston “Pentagon Papers." (2016). National Archives. 15 August 2016. https://www.archives. gov/research/pentagon-papers. Accessed 26 June 2018

US Department of Defense (2011) Final Report of the Department of Defense Information Review Task Force. https://assets.documentcloud.org/documents/3868778/WikileaksManning-Defense-Department-Damage.pdf Accessed 6 December 2017.

Wikileaks (2015) "What Is WikiLeaks." https://wikileaks.org/What-is-Wikileaks.html. Accessed 26 June 2018. 
PART 3

Research secrets 
Section V: Critique and advocacy 


\title{
13
}

\section{SEARCHING FOR THE SMOKING GUN?}

\section{Methodology and modes of critique in the arms trade}

\author{
Anna Stavrianakis
}

- $\quad$ Research objective: This chapter will help researchers who want to navigate secrecy, managed openness and partial (in)visibility in the study of security issues. It provides practical information on sources for studying the arms trade; how to engage in Freedom of Information requests; and how to combine methods iteratively, including both quantitative and qualitative methods. It discusses methods in the context of the relationship between scholarship and politics in critique.

- $\quad$ Research puzzle: The puzzle the chapter addresses in relation to secrecy and methods is how researchers can move beyond a static binary understanding of secrecy and openness, towards an understanding of the shifting dynamics of partial (in)visibility and managed transparency.

\section{Introduction}

Ask the UK government pretty much any question about its arms export decisions, and the answer you'll get is that it operates "one of the most robust export control regimes in the world" (see CAAT n.d.). Nonetheless, controversies continue: the UK regularly exports weapons and surveillance technologies to repressive, authoritarian and warring states around the world. In particular, exports to the Middle East - to states such as Bahrain and Egypt during the Arab Spring, to Israel for use in the Occupied Territories, to Saudi Arabia and the United Arab Emirates for use in the war in Yemen - have been criticised by non-governmental organisations (NGOs), campaigners and journalists for putting geopolitical and commercial interests ahead of the UK's publicly stated commitments to human rights and international humanitarian law (IHL). Yet the government rebuts criticism by pointing to its risk-based arms export policy, which is based on a set of criteria that include respect for human rights and IHL. Whilst the government claims - tautologically - that the existence 
of the policy and a process to implement it means that there are no problematic exports, this also means that controversial exports are not mistakes. It means that something happens during the licensing process that generates perverse outcomes: a system that is supposed to prevent human rights and IHL violations ends up facilitating exports that contribute to just such ills.

This chapter will help researchers who want to study the arms trade and other issues closely linked to national security, particularly in liberal democracies. The puzzle is how liberal democracies manage to export violence around the world and yet claim to be benevolent protectors of human rights and IHL, good governance and the rule of law. Critics say the government ignores its own commitments which suggests that better policies and processes would fix things. But the wording of the UK government's policy is quite progressive; and there is an extensive civil service licensing process and ministerial oversight. Thus, analysing the way policy and process operate in practice becomes important for figuring out how controversial arms exports continue and are justified.

Drawing on my own research experiences and dilemmas researching UK arms export policy towards Saudi Arabia since the start of the 2015 war in Yemen, the chapter outlines the main methods I have found productive, and addresses the practical, intellectual and ethical challenges that have surfaced. The chapter proceeds in three steps. First, it gives a brief outline of the contours of the political and methodological challenges at stake. Second, I outline some of the methods I have found productive in assessing the politics of a seemingly mundane bureaucratic process: the analysis of government licensing data; interviews and participant observation; and the use of Freedom of Information (FOI) requests. Finally, I turn to the relationship between methods, methodology and the mode of critique, discussing the challenges of moving between scholarship and activism. The chapter helps researchers find ways to study practices that are both facilitated and obscured by secrecy, partial visibility and managed openness; navigate the shifting boundaries between scholarship and activism; and reflect on modes of academic critique.

\section{Arming the Saudi-led war in Yemen: what is the (methodological) problem?}

\section{BOX 13.1 CONTROVERSY OVER ARMS SALES IN THE YEMEN WAR}

Since March 2015, a Saudi-led coalition of Middle Eastern and African states has been engaged in an aerial bombing campaign, naval blockade and ground manoeuvres in support of Yemeni President Abdrabbuh Mansur Hadi and against Houthi forces and loyalists to former President Ali Abdullah Saleh. 
The coalition is reliant on weapons and wider military (intelligence and logistical) and diplomatic support from the US and UK in particular. The coalition has been heavily criticised for IHL violations: attacks on civilian objects such as hospitals, schools and markets that have not obeyed the principles of distinction, necessity, proportionality and humanity. This criticism has extended to its weapons suppliers, for facilitating IHL violations and fueling the war.

The USA and UK are far and away the largest arms suppliers to Saudi Arabia and other Gulf Cooperation Council states. Their arms exports are part of larger packages of military aid and training, and diplomatic support stretching back to the formation of the Saudi state, and bound up with wider interests around oil, regional stability and counter-terrorism. This makes arms export policy a good case study of the ways in which liberal democracies manage their claims of promoting democracy and protecting human rights and international humanitarian law, whilst securing the national interest, defending national security and preventing terrorism (Erickson 2015; Stavrianakis 2016). Historically, arms production and transfers have long been deemed by states to be in the national interest and cloaked in secrecy under the banner of national security and commercial confidentiality.

Trying to conduct research into how arms export policy works in practice, one is immediately confronted by secrecy, managed information under the guise of transparency, and the dominance of logics of state security and commercial confidentiality as well as bureaucratic opacity and delay. There is a tight relationship between the state and arms industry regardless of a country's form of economy and political system. Even in capitalist states in which the arms industry is formally private, it is organically connected to the state through a revolving door of personnel, a privileged claim on the state budget, and the ideological power of discourses of defence and security. In the UK case, transfers to Saudi Arabia now account for almost half of all arms exports, and these exports are facilitated by a government-to-government arrangement in which the UK Ministry of Defence (MoD) contracts BAE Systems, the largest UK-headquartered arms company, to fulfil its obligations to the Saudi military.

This relationship is marked by secrecy and mutual deniability: the agreements governing the military relationship remain classified and while new information is sometimes released with the transfer of government records to the National Archives thirty years after their creation, most requests for disclosure of contemporary information are refused on the grounds that Saudi Arabia would view it as a breach of confidentiality. This is secrecy in its traditional national security guise, in which information is kept out of the public domain and is controlled in its circulation via processes of classification and restriction. Moreover, the arrangement allows BAE Systems to shield its reputation behind the sanction of the state, and allows the state to claim the company's actions are a commercial matter. This blurring of the 
public-private and domestic-foreign binaries, accompanied by the mobilisation of those very binaries for legitimation purposes, form one of the core methodological challenges that researchers must try to unpick.

At the same time as being a major military and diplomatic supporter of Saudi Arabia, the UK has long been a leading proponent of multilateral arms trade regulation. This is where one of the differences between the UK and USA becomes important. The UK operates a risk assessment framework and has more explicit commitments to protecting human rights and IHL in its arms export policy than the USA does. The UK was a leading actor in the 1990s in the development of what became the EU Common Position on Arms Exports; has been a vocal champion of the UN Arms Trade Treaty (ATT); and has commitments to human rights and IHL written into its legal and political commitments around regulating arms exports. The UK government is obliged to refuse transfers where there is a clear risk they might be used in violations of IHL or human rights (Cable 2014). The UK also has one of the most active NGO and campaign group communities (e.g. Amnesty International, Campaign Against Arms Trade, Oxfam, Saferworld, Stop the Arms Fair), as well as journalists keeping government on its toes, and a system of parliamentary scrutiny. The work of campaigners and journalists generate repeated controversies in which the extensive bureaucratic implementation of a stated policy leads to perverse outcomes.

Making research decisions about how to investigate the black box of policy making has political as well as methodological aspects that relate to accountability and modes of academic critique. One of the organising themes of this book is the move beyond a binary understanding of secrecy and visibility, beyond the secret as something to be uncovered, and towards an understanding of the shifting dynamics of partial visibility and managed information. What this case study demonstrates is some tactics for getting at these dynamics, providing tools for investigating the myriad ways a policy can both generate perverse outcomes and be claimed as effective. Nonetheless, whilst researchers should not assume "a coherence in action and a competence in ability which might well be unwarranted" (Rappert 2012: 43), there is also a point of decision that a named minister is responsible for: the decision to issue arms export licenses. This gives a point of accountability that remains politically important.

The question becomes, is it possible to search for a so-called smoking gun? There may not be an all-knowing centre or driver of policy, but are there points in the decision-making process where things do not go according to how they are presented? On the other hand, it can also be revealing - and politically effective - to map and analyse secrecy, practices of obfuscation and blurring. If government is not interested in allowing outsiders better access, scholars may never be able to pinpoint who made the decision or how it was made. So perhaps the task at hand is different: the question then becomes, what mode of accountability can we pursue if we give up the search for the smoking gun?

I consider a key task of research into the arms trade to be that of repoliticising debate about the circulation of the means of violence that has become 
depoliticised under discourses of national security, national interest and commercial interests, but also human rights and IHL. I thus pursue critical work in both senses of the term: work that is "informed by the core methodological principles of historicism, holism and reflectivism", and also oppositional - recognising that such pursuit is "inherently frictional and conflict-laden" (Selby 2018). Efforts to ask questions about arms export policy are shut down by the perpetual repetition of the claim of a robust control regime, partial economic claims about the employment benefits of arms manufacturing, and broader ideological tropes around the UK's place in the post-colonial world. Meanwhile, NGO efforts to reframe the arms trade as a human security, human rights or IHL issue is strategically understandable but also bring their own political challenges. That is, in seeking practical change, NGOs run the risk of reproducing wider frames of reference around North-South relations or the role of organised violence in world politics that are part of the problem they seek to challenge. So conducting research into how the licensing regime actually operates and translating the key lessons of that into policy-relevant language are core tasks. Yet scholarship and activism are distinct, if related, activities. There may be strategic reasons why activists cannot take up a particular strand of research or scholarly argument; and intellectual or political reasons why scholars may not be comfortable signing up wholeheartedly to activist efforts. Effective activism requires good research, but the translation is a form of labour in itself that it requires time and strategic thinking (Stavrianakis 2006). Translation for activism involves starting where practitioners are at, trying to shift the terms of debate, thinking about who allies and opponents are - and then being able to move back into scholarship.

The challenges of investigating arms export practices take different forms in different contexts. In the US, for example, the arms industry is formally private, but arms exports are more directly a matter of state policy being directed through the Foreign Military Sales programme, and the US government does not claim to operate a risk-based assessment process. In other leading exporting states such as Russia and China, meanwhile, the arms industry is state-owned, so the political economy is different, and they do not incorporate IHL or human rights concerns into their policy, nor do they have freedom of information laws for scholars and citizens to mobilise. So the character of the problem is broadly different between liberal democracies and other forms of state, but in all cases, arms exports are expressions of relationships: between state and industry, and between governments, so the public/private, domestic/foreign methodological challenges persist, albeit in different forms.

\section{Knowing about the arms trade: Sources, methods and tactics}

In what follows, I set out three sets of sources and methods that can usefully be combined in iterative, mutually reinforcing ways to start to understand how a sensitive national security issue like the arms trade operates. Analysis of publicly available sources such as official statistics and policy documents is a good place to start one's empirical analysis. This generates some preliminary findings that can be followed 
Analysis of publicly available sources e.g. policy documents or official statistics
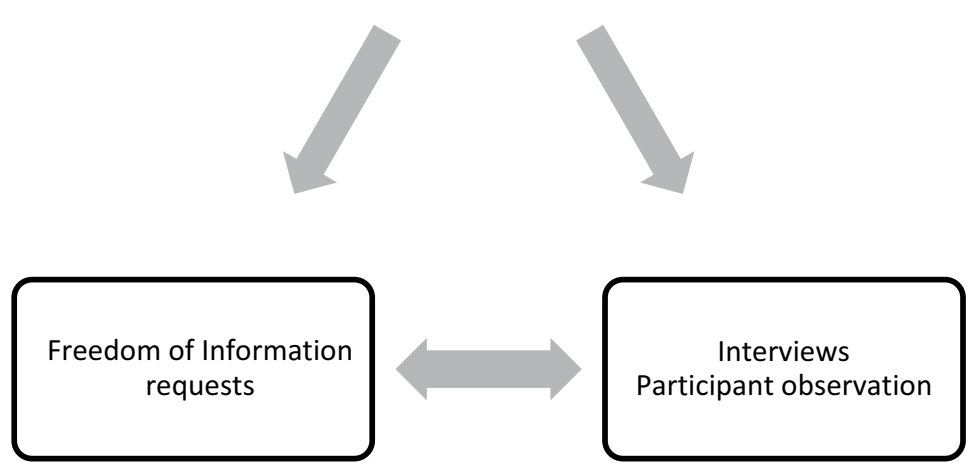

FIGURE 13.1 Iterative, mutually reinforcing methods

up with interviews and participant observation (PO), in order to find out more information but also understand how such policies came into being, or how such statistics were generated. They can also generate some questions to be pursued officially via Freedom of Information (FOI) requests. And interview/PO work and FOI can be mutually reinforcing: responses (or non-responses!) to FOI requests can generate questions for interviews, and vice versa. This iterative combination of methods facilitates multiple points of entry into the topic and allows for triangulation in the sense that a variety of methods are mobilised in order to enhance the credibility of data. However, they are not intended to necessarily generate replicable results, generalisable findings, or universally valid explanations.

\section{Analysing licensing and export data}

Governments' own licensing or export data and associated qualitative reporting provide the contours of policy. The UK government does not report on deliveries, only on licences, which may not be (fully) used. Nonetheless, looking at licensing patterns gives an indication of what the government is prepared to see exported - it sets the parameters of policy. Assessing this data requires familiarity with a host of acronyms (Standard Individual Export Licences (SIELs), Open Individual Export Licenses (OIELs) etc., representing different types of licence) and shorthand terminology (Criterion 2, for the UK's commitments to human rights and IHL, for example). Learning this technical language is important, partly because it allows the researcher to understand different modes of licensing, but crucially because it is also the currency of policy debate. Demonstrating familiarity with this language is part 
of what establishes one's credentials as an expert in the field. Learning how to read this sort of data takes time and is best done in conversation with other technical experts. And there is always a double task of reading: first, to understand what information is being conveyed; and second, to understand what function the conveying of the information in this way is serving. That is, there is a host of technical information that is largely useless even to those with specialist knowledge; key changes are buried in technical detail; and lots of things are not said, which require the use of other methods to follow up on.

Official licensing data can be interpreted in clearer detail using a web browser developed by Campaign Against Arms Trade. The browser uses the government's own published licensing data and is able to show the specific date that licenses were granted, for what value of which category of goods, and what items. This allows for much greater specificity than the quarterly data provided by the UK state. There are still inherent limits based on the fact the state controls and publishes the basic information: licensing data does not allow the researcher to concretely link licences to deliveries, let alone to weapons used in violations - this latter step is the bread and butter of investigative journalists, researchers and NGOs working in the field. Nor does the data allow the researcher to understand why and how decisions were made. This is why analysis of licensing data needs to be supplemented with qualitative methods such as interviews and FOI requests. Nonetheless, the browser has been a key investigative resource. And the different ways that data can be produced and represented remind us that generating data is always a political practice, transparency is not a clear-cut phenomenon, and information needs to mobilised politically in order to contribute to accountability.

A second avenue to better understand state-generated licensing data is to supplement it with Stockholm International Peace Research Institute (SIPRI) data on patterns in international arms transfers. SIPRI works to document patterns of deals between specific importers and exporters, which are set out in the Trade Registers; and Trend Indicator Value (TIV) tables provide statistical data on deliveries of weapons. The innovation of the TIV is that it is not a financial value; it is a way of comparing between states based on publicly available information. The price of weapons is set politically, is spread over time, and there is a lot of barter trade and gifting, so SIPRI uses the TIV in order to generate robust, comparable data. The TIV is based on "the known unit production costs of a core set of weapons" and represents "the transfer of military resources rather than the financial value of the transfer:" it is a measure of volume, not financial value (SIPRI, n.d.). For example, one Eurofighter combat aircraft is valued at 55 million TIV, while a Leopard-2A4 tank is valued at 4 million TIV. A weapon that has been in use in another armed force before being transferred is allocated a value of $40 \%$ of that of a new weapon, while a used weapon that has been refurbished before transfer is allocate $66 \%$ (SIPRI n.d.). TIV figures are therefore not directly comparable to GDP, military spending and other figures. Rather, their use lies in helping researchers calculate trends, percentages and flows. One limitation of SIPRI data is that it 
does not include small arms and light weapons (SALW). Until October 2017, the Norwegian Initiative on Small Arms Transfers (NISAT) ran an online database of small arms transfers between 1962 and 2015, which remains available but is no longer being updated.

\section{BOX 13.2 USEFUL DATA SOURCES}

To identify relevant databases, scour the grey and academic literature on your topic, as well as media coverage. These reports are often based on information from such databases.

- $\quad$ Stockholm International Peace Research Institute (SIPRI) "Arms transfer database": https://www.sipri.org/databases/armstransfers

Information on all international transfers of 11 categories of major conventional weaponry since 1950 (not including small arms and light weapons)

- UK government "Strategic export controls: Licensing data": https://www. gov.uk/government/collections/strategic-export-controls-licensing-data

Country-level data about UK arms exports, including number and value of licences, categories of equipment, and licence processing times

- Campaign Against Arms Trade "UK arms export licences": https://www. caat.org.uk/resources/export-licences

Searchable web application that uses the information provided by the UK government to allow users to see the date, value and items of export licences

- European External Action Service "Annual reports on arms exports": https://eeas.europa.eu/headquarters/headquarters-homepage/8472/ annual-reports-arms-exports_en

Data on EU Member States' arms exports/licences and refusals per destination by calendar year

- Campaign Against Arms Trade "EU arms exports": https://www.caat.org. uk/resources/export-licences-eu/licence.en.html

Uses EU data to break down source and destination country of exports/ licences, year, and type of goods

- Norwegian Initiative on Small Arms Transfers "Small Arms Trade Database": http://nisat.prio.org/Trade-Database/ 
Data on transfers of small arms and light weapons, ammunition, parts and accessories, between 250 states and territories, 1962-2015

- $\quad$ Arms Trade Treaty Baseline Assessment Project: http://www.armstrade.info/

Country profiles and aggregate data of states' implementation of the UN Arms Trade Treaty

From licensing and transfer data, we get a sense of the broad contours of the international arms trade and of government policy. But the gap between stated policy (e.g. we do not export weapons where there is a clear risk of misuse) and outcomes (e.g. increased, speeded up transfers to Saudi Arabia as allegations of war crimes in Yemen rise) remains. Statistical data on the number and value of arms export licences cannot tell us how decisions are made or how policy is designed and implemented. For that, we need qualitative methods. Here I focus on two types: interview and participant observation work; and FOI requests.

\section{Interviews and participant observation}

To try to understand the how of arms export policy, I have undertaken semistructured interviews and participant observation (PO) with civil servants, members of parliament (MPs), and NGO and campaign group staffers. Interviews can be a means of accessing new information, in which your interviewees are primarily sources of facts, figures and other information that is not publicly available. But interviews are also a means of generating data: understanding how agents understand the process to work. This is an inter-subjective process of meaning-making and takes longer as it requires a certain level of trust. One thing to think about as you design your interviews is who you want to build relationships with, why, and how. Identify the horizontal and vertical networks of people to interview and keep track of where they move to and from. Often, issue areas comprise relatively small, closed worlds, with fairly high levels of movement within them. For example, there are dual networks involved in the operation of arms exports and their regulation in the UK. There is the integration of arms capital into the state (via a revolving door, military advisory bodies, etc.) that contributes to a pro-export orientation to state policy; and a (weaker) set of relationships and alliances between NGOs and state and multilateral aid agencies. Who can help you get access to these networks, and who might block your access? What technical language will you need to learn to gain access to their fields?

Participant observation is a good way of immersing yourself in the everyday reality of actors' involvement on and understanding of an issue. And it is a two-way process that can blur the boundaries between yourself as a researcher and the topic you are working on. My own way in to interview and PO work, indeed to research 
on weapons control at all, was through an internship at a conflict prevention NGO working on UK, EU and international arms export control after my Masters; it was this experience that prompted my $\mathrm{PhD}$ research. So for me, research has always had a policy as well as scholarly orientation. In my experience PO works best when I have something practical to offer. For example, when I do PO work with NGOs I might offer to take notes for them and provide summaries of events; make short presentations during their workshops and conferences, and so on. It can be useful for NGOs to have an academic speaking at events, for reasons of the credibility afforded to scholars, their social capital based on expertise and academic status. This is made easier by the (shared but by no means complete) common ground we have around export control policy. For those doing PO with actors with whom they have less in common or disagree, the lines will be drawn differently as to how much practical contribution will be made during the "participant" element of PO. In my case, another, less immersive and more conflictual way that I have engaged in PO is providing written and oral evidence to the parliamentary committees responsible for scrutinising UK arms export policy. Some MPs were keen to mobilise the information and argumentation I provided for the purposes of stricter controls; others were indifferent or hostile. So my participation was more circumscribed in this example and required attention to power dynamics within the committees as well as between the committees and those giving evidence.

With both interviews and PO, you are constantly traversing the space between being a participant and an observer. I find myself having to be multiple versions of myself, often at once: the expert giving evidence or the ally providing food for thought; and the scholar observing the interaction. Depending on your experience, your politics, and what you are comfortable with, you will find yourself at varying points of the spectrum between observation and participation. Things to reflect on for yourself include: What are your politics about your research topic, and how do you understand your role as a researcher? Especially in relation to participant observation, do you see yourself as working with or alongside these people, with some degree of shared goals; or are you observing them from a neutral or oppositional position? Are you putting your own views forward as part of the conversation (which is more at the participant end, whether sympathetic or critical), or observing how they understand an issue?

Interview work and participant observation work are deeply political practices. Think about what you expect from interviews: I catch myself wanting off-the-record admissions of "what really happened". This is the assumption in play that there is a smoking gun, that someone, somewhere really does know what is going on, and is in control of events. However, whilst a named minister is politically responsible for approving arms export licences, a sole focus on that moment of decision obscures what happened along the way. I am in no doubt that political direction is issued during the arms export licensing process - but it is unlikely to be done explicitly. Rather, there are cultures at work, implicit direction, career concerns, and so on. And access to this process is closed, especially in relation to controversies, when the shutters come down. Rather than focus on searching for who gave the orders, it can 
be useful to think about a systemic set of practices such that these bad outcomes happen without anyone necessarily deliberately wanting them to.

Less explicit, but also deeply political, are the inter-subjective and positional dynamics of interview and PO research. That is, any such inter-personal work is shaped by racialised, gendered and classed identities, by sexuality and (dis)ability status, by perceived levels of expertise and status between the researcher and other participants. Researching the arms trade is shot through with gendered and racialised power relations (see also Hoijtink, this volume). State arms export policy, and the academic field of arms control, are both male-dominated and masculinised: that is, not only do the participants mostly identify as male, but many of the core assumptions around the (benefits of) the arms trade are masculinised ones, around power, conflict, status and prestige. The NGO and campaign world is simultaneously more gender equal in terms of female representation, and also feminised: in trying to amplify concerns around the human cost of arms exports, they are often dismissed as naive or unrealistic. And both communities are very white: there is under-representation of racialised minorities within UK-based state and NGO delegations, and ongoing North-South structural asymmetries in multilateral negotiating fora and international NGO and campaign coalitions. As researchers, our challenge is to recognise and reflect on our own positionality; respond to disadvantageous dynamics by developing response strategies and cultivating allies; and recognise our own relative privilege compared to others who are heard less or not at all, and cultivate our own allyship in learning when to try to amplify others' voices and when not to speak. We can do this by being alert to the politics of citation in our writing, seeking out a variety of audiences and presenting our work in different ways for them, and listening harder to under-represented voices and making space for non-dominant actors to speak and be heard.

\section{BOX 13.3 INTERVIEWING AND PARTICIPANT OBSERVATION (PO)}

- What are you doing when you interview: collecting information or generating data (or both)?

- Identify the horizontal and vertical networks of people to interview and do PO with. Who can help you get access to these networks? Who might block your access?

- Who do you want to build relationships with, why, and how?

- What are your politics about your research topic, and how do you understand your role as a researcher?

- What positional dynamics - including race, gender, class, sexuality, (dis)ability - affect your interaction in interviews and PO? Who are your allies, what strategies can you develop? 


\section{Using Freedom of Information laws}

Analysis of official statistics and documents, and interviews, can generate further questions to pursue via FOI requests, which are a useful yet ambivalent means of attempting to extract information from public bodies. And FOI responses (or nonresponses and refusals) can serve as the basis for further interview questions. In my research, one FOI engagement with the UK Foreign and Commonwealth Office (FCO) came about as I sought to follow up on the government's quarterly licensing reports, asking for the grounds on which licence decisions were referred to ministers and subsequently approved. In another example that shows how PO work can be complemented by FOI, my written and oral evidence to the parliamentary committees prompted them to ask the government about the number of UK military personnel and BAE Systems staff assisting the Saudi armed forces, and how they are advising them on IHL. The government's response to the committees was to claim that "We do not have full visibility of the prime contractor's manpower footprint in Saudi Arabia" (HMG 2016: 8). This response piqued my interest: if BAE Systems are present in Saudi Arabia under a government-to-government contract, how does the government not have full visibility of its presence and activities? So I submitted an FOI request asking whether the MOD knows how many BAE staff are based in Saudi, what tasks they perform, and what the oversight mechanisms are; and requested relevant documentation.

These two snapshots are good examples of the way secrecy and partial visibility work: the former was a lesson in secrecy by delay; the latter was instructive in the art of systematic not-knowing by the state. FOI processes are asymmetric exchanges, but as researcher you are not powerless. Whilst you are engaging in a conversation with an unknown interlocutor who has the discretion to release information or not, and the FOI process is weighted in favour of non- disclosure, there are appeal mechanisms, and researchers can learn how to ask questions in a bureaucratically effective way. FOI responses are put into the public domain, which itself is a form of data generating, and may help build an archive for future research.

\section{Secrecy by delay: civil service and ministerial decision- making processes}

In this first example, I supplemented government licensing data (which I had correlated with CAAT's browser data) and interview material with civil servants with an FOI request about the grounds on which export licences were approved. I hoped that a formal FOI request might generate some data about the black box of decisionmaking: what happens during the licensing process such that seemingly perverse decisions are made. Over the course of a year, my request was eventually refused (a decision I am, at the time of writing, appealing), following six deferrals of the decision, attributed to a public interest test to determine whether the FCO would release the information. After six months I requested an internal review, because in my view the FCO was effectively denying my request without doing so formally, 
avoiding the recourse to appeal that a denial would create, at a time when public interest and scrutiny of the issues it concerns are particularly high. The FCO internal review yielded no substantive progress; I complained to the Information Commissioner's Office (ICO 2016), who found in my favour. From this point on, the FCO managed to conclude its public interest determination, and refused to release the information, on the grounds that disclosure could potentially damage the UK's relationship with Saudi Arabia, and would likely inhibit the candour of exchanges of views between officials. At the time of writing I am appealing the decision.

The refusal raises questions of democracy and accountability. The delay is explained in part by the prospect of the judicial review of government policy. But why not just refuse to release the information in the first place? Who was doing the public interest assessment, what is the information held by government, and on what basis did they even consider releasing the information, given the ease with which they could refuse it? May I have unwittingly stumbled on a smoking gun? But alternatively, is this a rabbit hole, a refusal for its own sake, to protect decision making, rather than any significant information being deliberately withheld? I still do not have answers to these questions. But the lessons I have taken from the experience are: be patient and persistent, as FOI is a long, drawn out process in which public authorities appear to hope you will give up or forget to chase them or appeal; and be prepared for dead ends and (deliberate) wrong turns. FOI is no clear-cut tool for transparency and accountability: it is itself a political intervention in relations between the state and the public, in which delay is a key tactic to avoid disclosure.

\section{Systematic not-knowing: MOD oversight over BAE Systems in Saudi Arabia and IHL violations}

In this second example, I became interested in what the government knows about BAE Systems' activity in Saudi Arabia, and how the lines of accountability are managed. As noted above, PO work with parliamentary committees generated a claim from the government that it does not have full visibility of the company's activity. To investigate the work being performed by this claim I asked the MOD, via an FOI request, whether it knows how many BAE staff are based in Saudi Arabia, what tasks they perform, and what the oversight mechanisms are. The MOD's response was to claim that it does not maintain records that would answer this, nor does it directly oversee what contractors do. Release of information or documentation about the government-to-government agreements was refused on the grounds of international relations, UK economic interests, and commercial interests - a move that demonstrates the extent to which the UK state regards the commercial interests of an ostensibly private company as coterminous with those of the state.

What we see here is the MOD actively claiming not to know about the practices of a company it has contracted to fulfil a government-to-government arrangement a good example of the way that the involvement of private companies in state practices both consolidates and complicates secrecy. The picture becomes more complicated when we learn that contractor companies are contracted by the UK 
MOD; MOD teams oversee and audit the contractors' activities; and contractors generate "detailed quantitative reporting" of Saudi use of UK-supplied weaponry despite this being denied by the MOD in FOI responses (Lewis and Templar 2018: 27-28). One way to explain this complex picture of claim and counter-claim about what the UK state does and does not know about potential IHL violations is via the bureaucratic parcelling out of tasks and functions. In this case, operational and liaison staff working with the Saudi Ministry of Defence are kept separate from advisory and training staff working on various projects (Al Yamamah, Al Salam and Saudi Arabia National Guard Communications Project (SANGCOM)). The functional separation within the MOD means that it can simultaneously support BAE Systems in fulfilling Saudi military requirements and claim not to be aware of any potential IHL violations, whilst also claiming to have all the knowledge needed to be able to assess IHL compliance and argue there is no clear risk of the misuse of weapons. ${ }^{1}$ This example illustrates the importance of in-depth knowledge of specific cases to generate specialised empirical knowledge, and the murkiness of any potential findings. In secretive policy domains, there is rarely a clear-cut right answer.

\section{BOX 13.4 USING FREEDOM OF INFORMATION LAWS}

The UK's 2000 Freedom of Information Act allows anyone to ask public sector organisations for access to recorded information. Many organisations have dedicated forms or email addresses for you to make requests. Key tips include:

- $\quad$ Focus your requests: do not ask anything that is already in the public domain, or can be easily refused because the scope is too wide or allows government to say it does not hold that information.

- $\quad$ Find other researchers also making FOI requests - get their sense of what is being withheld; collaborate!

- Keep a spreadsheet of dates, reference numbers and topics so you can track responses.

- Follow up! Appeal internally and go to the Information Commissioner's Office if necessary. Secrecy by delay and administrative inconvenience are useful tactics for the state, so persist and be patient (see also Hughes and Garnett, this volume).

- Read any responses carefully and sceptically: are you being given other leads to follow, or being sent down the garden path?

\section{Moving between scholarship and activism}

The combination of methods I have described rests on and has contributed to longer-term immersion in the field of weapons control, and have made me into something of a participant as well as an observer. In this final section, I discuss the 
relationship between critique, advocacy and activism in more detail. It was the experience of scholarship as well as that of practical engagement that politicised me. The more I studied the arms trade and arms export policy and engaged with policymakers, the less sense it made, and the angrier I got about the justifications that were made about it, especially as a UK citizen and taxpayer. In turn, from the relatively privileged position of academia, I have come to value the time it takes to translate that research into practical contributions to conversations, whilst recognising that scholarship and activism are distinct activities (see Stavrianakis 2006). As such, I am ambivalently invested in the "impact agenda" that has become influential in UK higher education. Being politically situated is inescapable, yet the bar is higher for critical impact work. As Jan Selby says, "trying to contest entrenched social or policy orthodoxies ... inevitably complicates the processes of obtaining access, of building trust and relationships, and of achieving impact" (Selby 2018). Building long-term relationships involves the researcher as part of a movement, rather than an expert outsider doing occasional "impact" work that is recognised in terms of the metrics that have come to dominate the management of higher education.

One of the challenges in moving between scholarship and activism is time, and the relative pace of scholarly research, academic publishing, and policy change. That is, engagement and impact is often quite fruitful around controversies, which demand an immediate response. But the practices and policies that generate controversies usually have deep historical roots and may themselves obscure more mundane but equally unjust power relations. And scholarship benefits from - indeed, often requires - going slow, in order to have space to think. But the impulse to think creatively about the political and historical significance of what is happening rubs up against the desire to publish quickly, which stems from both the feeling of need to "do something" about export policy, and the demands of academic governance that scholars are ever more productive.

One way of managing this tension - one in which I was supported by proactive and generous mentoring from a senior colleague - has been to think more creatively about different styles of writing, for different audiences, in different outlets. Short comment pieces in online media outlets allow the researcher to comment on specific controversies as they resonate publicly. Mid-length (4,000-6,000 word) academic survey or commentary articles in academic journals can be a good means of building the kernel of a scholarly argument without losing sight of the political impetus that drives one's research - and these can be written and published quite quickly (especially if they are not peer-reviewed). And longer articles (8,000-12,000 words) that are more traditionally academic, in that they are focused predominantly around engaging with scholarly debates, allow the researcher to focus on the wider conceptual, theoretical and political questions raised by one's specific empirical issue area. These articles take longer to research and write, and take longer in review; they are also what have traditionally been predominantly valued in the academy, to the detriment of other types of writing. Hence it is no surprise that early career researchers become fixated on them - as I did for the first five to ten years of my career! The irony of this was that it was counter-productive. Building up my writing skills and experience of the publication process through 
these other avenues allowed me to build a wider body of work, of which longer articles in "top" journals are just one component.

Finally, much of the debate about the relationship between scholarship and activism is framed in terms of how to make the former more relevant to the latter. Defences of scholarship for its own sake are important here, as is emphasis on the relationship between scholarship and teaching, which is itself a central route of social change. And one of the things I have found most difficult has been moving back to scholarship from activism. I have experienced the demand and desire for change in ways that sometimes obstruct creative and nuanced thinking - even though I know that critical distance and intellectual creativity are key to the contribution scholarship can make to activism. Bringing conceptual clarity and technical criticism to bear on practical scenarios is one thing; circling back out from the policy world to intellectual analysis and reminding oneself of the value of scholarship in itself, is another. My experience of engaging on arms export policy and multilateral arms transfer control has confirmed for me the simultaneous importance of both engaging with practitioners and valuing scholarship for its own sake. Mobilising one's research towards practical ends comes with no guarantees. Politics and scholarship serve distinct social purposes, even if we cannot draw rigid boundaries between them. Researchers working on security issues have opportunities and duties to engage with the ramifications of their research, whilst recognising the political obstacles that stand in the way, the shifting terrain and different modes of political activism, and the intrinsic value of scholarship.

\section{Suggestions for further reading}

- Claudia Aradau (2017) “Assembling (non)knowledge: security, law and surveillance in a digital world," International Political Sociology 11(4): 327-342.

- Clare Birchall (2014) "Radical transparency?" Cultural Studies $\leftrightarrow$ Critical Methodologies $14(1), 77-88$.

- Peter Galison(2004) “Removing knowledge," Critical Inquiry 31(1): 229-243.

- Linsey McGoey (2012) "Strategic unknowns: Towards a sociology of ignorance," Economy and Society 41(1): 1-16.

- Lisa Stampnitzky (2016) “The lawyers' war: States and human rights in a transnational field," The Sociological Review Monographs 64(2): 170-193.

- William Walters (2015) "Secrecy, publicity and the milieu of security," Dialogues in Human Geography 5(3): 287-290.

\section{Note}

1 I am grateful to Mike Lewis for clarifying this for me.

\section{References}

CAAT (n.d.) "Rigorous repetition," https://rigorousrepetition.tumblr.com/ 
Cable,Vince (2014) “Consolidated EU and national arms export licensing criteria," Hansard. Written Statements,Volume 578, 25 March 2014.

Erickson, Jennifer (2015) Dangerous Trade:Arms Exports, Human Rights, and International Reputation, New York: Columbia University Press.

HMG (2016) The use of UK-manufactured arms in Yemen. Response of the Secretaries of State for International Trade, Defence, Foreign and Commonwealth Affairs, and International Development, November 2016, Cm9353.

Information Commissioner's Office (ICO) (2016) “The public interest test. Freedom of Information," https://ico.org.uk/media/for $\ 20$ organisations/documents/1183/the_ public_interest_test.pdf.

Lewis, Mike and Katherine Templar (2018) "UK personnel supporting the Saudi Armed Forces - risk, knowledge and accountability," http://www.mikelewisresearch.com/ RSAFfinal.pdf

Rappert, Brian (2012) "States of ignorance: The unmaking and remaking of death tolls," Economy and Society 41(1): 42-63.

Selby, Jan (2018) "Critical international relations and the impact agenda," British Politics, https://doi.org/10/1057/s41293-018-0081-0.

SIPRI (n.d.) "SIPRI arms transfer database - methodology," https://www.sipri.org/ databases/armstransfers/background.

Stavrianakis, Anna (2006) "Call to arms: The university as a site of militarised capitalism and a site of struggle", Millennium 35(1): 139-154.

Stavrianakis, Anna (2016) "Legitimizing liberal militarism: Politics, law and war in the arms trade treaty," Third World Quarterly 37(5): 840-865. 


\title{
14
}

\section{CRITICAL ENGAGEMENT WHEN STUDYING THOSE YOU OPPOSE}

\author{
Erella Grassiani
}

- Research objective: This chapter will help social science researchers who are "engaged scholars" and might have a political agenda to think through issues of positionality, reflexivity, methods and ethics.

- $\quad$ Research puzzle: The puzzle the chapter addresses in relation to secrecy and methods concerns ideas about subjectivity, positionalities and methods that are inherent to studying perpetrators of violence or other people who are part of a system or regime you oppose. I will show how one can carry out such research that is inherently subjective with people one opposes, while being an activist at the same time.

\section{Introduction}

You are not objective; you do research on soldiers while you are leftist?!

Aren't you "untrue" to your informants as they don't know your "real" opinion?

Why aren't you looking at the victims, the Palestinians, but only at soldiers?!

Comments and questions like these have come my way frequently in the last decade or so. They are queries into my position as (a) an anthropologist who (b) studies Israeli soldiers and Israeli security personnel while (c) being a political activist opposing the occupation these soldiers and professionals are (in)directly part of. These confrontations have, in fact, helped me to articulate my positioning and to deal with surfacing dilemmas.

This chapter will help social science researchers, some of whom might have a clear political agenda, to think through and understand issues of reflexivity, advocacy, methods and ethics. I will not be able to give clear-cut answers, as these issues 
should always be seen within their specific context, but hopefully I can make it easier to position oneself with more conviction, while keeping research rigorous. In order to do so, I will draw from my experiences as a Dutch-Israeli academic who studies the Israeli military and its security industry critically. And I will explore how I navigate my roles as an academic researcher and as an activist who acts against the military occupation of Palestine by Israel. My academic work is, inherent to my subjective positionality as an anthropologist, deeply political. Furthermore, I engage in the public debate as an academic. I see my academic work in a way as an extension of this political stance and both positions are fluid and blur into one an other. In this chapter I will look at the ways I learnt to deal with dilemmas and questions concerning my role in my research and beyond it.

The "puzzle" I will engage with first of all concerns the idea of "objectivity" in research, which is still widespread in academia and the public debate. Qualitative scientists, especially those coming from anthropology, are scrutinized for being "subjective", opinionated or "too political" within their research. Anthropologists have countered these attacks by explaining that their research is inherently subjective and have highlighted the importance of reflexivity; to be aware of and describe our subjective positions in the research (see also Hoijtink, this volume).

At the same time, within anthropology there has been a long tradition of trying to "give voice" to people who can't speak up themselves because of a lack of power. Empathy becomes an important concept here. The researcher is seen as the one who can take the voice of those studied to the outside world. Some have taken this to the extreme by writing that all anthropology should be "militant" in this way (ScheperHughes 1995). Empathizing with the people we study and trying in some ways to support them has become almost synonymous with anthropological study.

I will deal with the question of what happens to our subjectivity, mentioned earlier, when (anthropologically) studying the "unwanted" powerful other, even if we "don't like" them and/or, as in my own case, we oppose the system they are part of explicitly. What could this mean for studies involving secrecy and sensitive information where trust and rapport are extremely important for access? How can we as researchers who are concerned with the ethics of our research deal with surfacing dilemmas and critiques? I will discuss these ethical and methodological difficulties and possibilities through my own research experiences and by using the figures of the "trickster" and the "professional stranger". As I argue, these concepts help recognize and embrace the ambivalent positions that engaged ethnographers find themselves in. They are important as they open up possibilities for the researcher to be in different positions, which might seem contradictory, at the same time. These figures can, furthermore, help us to think in an alternative way about relationships with the other whom we are studying.

\section{Research design}

The main aspect of the research design that I will tackle in this chapter is reflexivity and positionality, or consciousness of our own positions within the research and its 
effects. For anthropologists this is a central notion and crucial part of the research process. An anthropological, especially ethnographic, research approach can be seen as inductive and circular, meaning that the process goes in "circles", bottom up, instead of along a straight line from A to B. This implies that reflection takes place during all phases of research. It is part of the research proposal (expectations of one's positioning), of the collection of material (how do I introduce myself, what do I share, what do I not, how do I situate myself, etc.) and after the research in the analytical and writing phase (writing about our position and the way it has influenced our research is at the heart of anthropological writing). However, in this chapter I will also show that taking an ethnographic approach, which involves empathy and closeness to our research participants, is not always advisable within specific contexts and in relation to certain (political) positions we take up.

\section{Anthropology, positionality and subjectivity}

In this chapter I discuss the issue of positionality and subjectivity from the perspective of the anthropologist. This does not, however, mean that these concepts are irrelevant for other social scientists dealing with similar questions. I believe, though, that anthropology, as a discipline that has actively engaged in the discussion around the position of the researcher can be helpful outside of its boundaries.

\section{Positioning the researcher: subjectivity and critique}

Positionality is a theme that is an intrinsic part of doing anthropological research such as ethnography. And ethnography is one of the central anthropological approaches to study social phenomena and write about them. Importantly, and as Coffey (1999) writes, the position of the self, the identity of the researcher is something that is constructed and produced during and after fieldwork (p. 1). Anthropologists are expected to be conscious of the different positions and roles they have within the field and the way these influence and shape their study and writings. Such roles can serve as lenses through which social life is observed, analysed and described (Reinhartz 2011).

However, also when not doing ethnographic research, we should be aware as anthropologists of our positions and our research participants' subjectivities and the politics at work (Ortner 2005). The fact that we take our positions as lenses into our fieldwork shows how anthropology embraces the subjectivities of the researcher as something that should be reflected upon.

In fact, anthropologists have written at length about their positions and subjectivities in their research and writings, especially since the "reflexive turn" that the discipline went through, which called upon anthropologists to be outspoken about these positionalities in the texts that they produced. The researcher thus received a bigger role in ethnographic writings, while in the past she had stayed in the margins. Especially for feminist anthropologists reflexivity became "a second nature" (Nencel 2014) in protest of approaches that stayed stagnant within anthropology's colonial legacy. 
Such reflexive work is part and parcel of critical ethnography. This kind of research, developed by anthropologists, "begins with an ethical responsibility to address processes of unfairness or injustice within a particular lived domain" (Madison 2011: 5). Taking an ethnographic approach is deemed crucial here in order to deeply understand this "lived domain". The critical tendencies of anthropology can be traced to Mead's work in the 1940s and later as a reaction to the direct enlistment of many anthropologists by the state, especially during the Cold War (Low and Merry 2010: s205). And already in the 1960s there were calls for direct action in support of groups that were studied. The works of, for example, Gramsci (1971) were furthermore influential for critical ethnographers in the ways that class struggle and collective (class) cultures came on the agenda (Foley 2002).

Today we still find anthropologists calling for more engaged research; Low and Merry (2010) distinguish several types of such engagement ranging from "sharing and support" to activism (p. S203). Hale (2006), for example, draws a difference between activist research and cultural critique in his research among black and indigenous land rights activists in Central America. Activist research is considered to be "a method through which we affirm a political alignment with an organized group of people in struggle and allow dialogue with them to shape each phase of the process" (2006: 97-98). Cultural critique, by comparison, is

an approach to research and writing in which political alignment is manifested through the content of the knowledge produced, not through the relationship established with an organized group of people in struggle . . to champion subaltern peoples and to deconstruct the powerful.

(ibid.: 98)

Hale argues the two approaches should cooperate.

However, others disagree; Hastrup and Elsass (1990) argue that ethnography cannot be combined with advocacy as this would mean for "anthropologists to step outside of their profession, because no 'cause can be legitimated in anthropological terms"” (1990: 301). Their position has been criticized for being too rigid, and for implying that anthropologists should "not have morals" other than their research objectives.

Importantly, outside of this attention to subjectivities and engaged research within anthropology, there is a whole (academic) world for whom this discourse is a strange one. Actors in the public domain (such as journalists) and quantitative social researchers often view subjectivity in research as a flaw. I will come back to this shortly.

\section{Ethnography and empathy}

An important element of taking on an ethnographic approach is developing a relationship with the people we study that includes empathy. Within ethnography we engage in deep relationships where trust is extremely important. In order for us to 
deeply understand the social life we study we need to gain the trust of our research participants and build rapport. However, within anthropology this approach goes hand in hand with a static notion of power relations between researcher and researched; the researcher is in a more powerful position than the people she studies. Empathy, also in light of what I discussed above, becomes a natural part of such research relations. In the following I will problematize this position.

\section{When studying perpetrators}

I have tried to clarify the relationship between critical anthropological research and the positionality of the researcher. However, if we depart from the previous, we can understand that many anthropologists today still focus on the underprivileged of society; the poor, the victims of political and economic upheavals. Critical and engaged research is seen as very much in line with ethnographic research, and this kind of research is almost synonymous with studying people you want to support, act on behalf of or advocate for. Although there has been a change visible in the last decades with an increasing stream of studies on the powerful (elites and victimizers) (e.g. Abbink and Salverda 2012; Rodgers 2009; Grassiani 2013; Diphoorn 2017), this change is still quite limited.

An important question to ask within such a context is what happens with a critical position (or how can we integrate it into our research) when you do research on perpetrators of violence, and/or with people who are part of a regime or system you oppose? (see also Chappuis and Krause, this volume.) Especially when researching victimizers or the perpetrators of violence in on-going conflict and or war/ occupation, questions surface about the way researchers position themselves in the field and about empathy. While this positioning seems to go without saying when researching the underprivileged or victims as described above, it is not necessarily so for those researchers studying the ones on the other side of the power balance. Importantly, a different kind of relationship comes into being between researcher and research subject than one is used to or expects. However, also from outside of the discipline critiques are voiced: about the subjectivity of our kind of research and the influence this could have on the "quality" of our research. ${ }^{1}$

One of the most important rules within the code of ethics of the American Anthropological Association (AAA) is "doing no harm". ${ }^{2}$ It tells us to be very careful in our research and never do anything that could possibly hurt the people we study. In many cases this means that we try to make sure we give voice to our informants and identify and sympathize with them. When we study victimizers this issue gets a twist. How should we position ourselves in such a field? What happens to our engagement if our research itself is not directly "engaged" as defined by anthropologists (see, for example, Sanford and Anjel-Ajani 2006). Can we be both good anthropologists, while opposing the world our informants are part of? And can we do so without ignoring our political ideas and maybe even responsibilities? The challenge here is to stay true to our personal and political beliefs and research objectives and true to the research at the same time. However we often cannot do 
this within an ethnographic approach that supposes empathy. Can we empathize with perpetrators of violence and should we? I believe we need to consider alternatives to this kind of relationship and use the "trickster" as one possible model. In line with this I argue that when studying a (colonial) regime through its actors, an ethnographic approach should in some instances be avoided, especially when the researcher could be seen as part of the colonial power. I will come back to this below when I study my position as Dutch-Israeli, Jewish researcher.

\section{Doing critical research in Israel on perpetrators}

In 2006-2007 I conducted fieldwork in Israel amongst (former) Israeli soldiers. My research interests were directed at their moralities, the way they perceived and gave meaning to their daily surroundings within a-symmetrical conflict (which today, with my increasing political awareness, I would have simply called an occupation, abandoning neutral wordings such as "conflict"). For my research I interviewed Israeli combat soldiers who had served in the Occupied Palestinian Territories as conscripts. Ultimately, my work critically examined the context wherein Israeli soldiers act and thus the Occupation itself, looking beyond the empty state slogan of "the rotten apple". I tried to voice an approach for studying perpetrators of violence by looking at the enabling context they acted within.

A decade or so later, I found myself studying Israeli security professionals and their export practices: the knowledge, technologies and materialities they sell to foreign clients. These professionals all hail from the Israeli military and came into the private security world after retirement. ${ }^{3}$ The knowledge and "stuff" these men (there are hardly any women in the industry) sell at security fairs and during trainings, are directly connected to the Occupation as weapons, drones, anti-riot technologies are used and tested on Palestinians before they are sold to (foreign) customers (Graham 2010). In my work I explicitly engage with the politics of the industry and the way it enables human rights violations in Israel and beyond.

During both periods of research, violence broke out: in 2006 the Second Lebanon War started and during my latter research Gaza was attacked multiple times by the IDF (Israeli Defence Forces). During all this time I was actively engaged in protesting both the War in Lebanon and the attacks and continuing siege on Gaza. The reality was thus that at the same time as I was interviewing soldiers who had been active as combatants in the Occupied Palestinian Territories and Lebanon and security professionals profiting from the violence against Gazans, I engaged in activities against the regime they were part of.

\section{Critiques and what it taught me}

As I mentioned above, anthropologists studying perpetrators are more likely to be asked to explain their moral position within the debates surrounding said conflict/ war/occupation in order to legitimize our findings. In my case, I typically am confronted with two kinds of criticisms concerning my position as a researcher. 
The first is critical about the subject of my research: I look at victimizers without focussing on their victims, and the second is critical about my "dubious" role as an activist on the left side of the Israeli political spectrum, while doing research about the military. In very general terms, I would call these left vs right criticisms, both of which attempt to force the researcher into a certain position they deem fit for the anthropologist or researcher in general.

As mentioned earlier, while positioning ourselves is crucial, some issues that relate to ourselves and our position in the field continue to be rather taboo within anthropological research. I first encountered these issues when I entered the university with the idea of studying Israeli soldiers, and I realized that I was immediately put into the "bad guys" category by some of my new colleagues, as an Israeli researcher who studied the IDF could not possibly fit into the leftist ideal picture of an engaged Amsterdam-based anthropologist. After learning about my politics, I was eventually accepted.

The first kind of criticism usually means an attack on the research for being "one-sided," i.e. writing from the point of view of Israeli soldiers, not from that of Palestinians. Such a reaction can be understood in light of the critical focus within anthropology, which is based on engaged ethnography. I will give an example: during the European Association of Social Anthropologists (EASA) conference of 2008, I presented a chapter of my $\mathrm{PhD}$ dissertation in a panel on the discourse of violence. I spoke about discursive strategies Israeli soldiers use and the themes that come up when they explain or legitimize their behaviour. Being an anthropologist who studied Israeli soldiers seemed to be enough for someone in the room to harshly criticize me. This person assumed I was not interested in the plight of the Palestinian people and was in some way "protecting” Israeli soldiers and legitimizing their acts. When I then positioned myself politically and told the audience about my activism in Israel and the Occupied Palestinian Territories the critique died down quickly.

Different critiques came from outside of the anthropological or academic community. As an activist, so these critics said, I could not possibly do "fair" or decent research about Israeli soldiers or security professionals, because I was biased and not objective. In this case, my critics used my identity as an activist to delegitimize my research. Most of all, such critique tries to delegitimize the academic who chooses to be an activist as well. Studying victimizers as opposed to victims, especially in such a politically charged context as Israel-Palestine, is often seen as problematic. Such a focus only becomes accepted, it seems, when one has the "correct" political profile, which is an apolitical one. However, in this kind of context, I believe, politics never disappear and only the "left" are scrutinized for their subjectivity, while those in support of the powers that be are perceived to be "objective".

As these critiques triggered me to think deeper about my strategies, I will now attempt to show in what ways the anthropologist, especially the one doing research amongst especially powerful victimizers, can position herself without having to give in to these different forces. I want to argue that while we have to be acutely aware of the ways our political ideas and positions influence the way we do research (what 
methods we can or cannot use), who we study and the way we understand and write about who we study, this does not necessarily mean we have to study those who are victimized by the power structures we scrutinize.

An interesting approach that helped me to rethink these issues is the work of Van Meijl (2005) who did research among Māori in Aotearoa-New Zealand. In the public and academic debate Māori are perceived as "victims", he writes, and he discusses his position in supporting their cause and being critical about them at the same time. He explains that as a social anthropologist, his position in supporting the Māori cause was assumed without questioning and he asks whether we should be committed politically to our sponsors (the group we research).

Van Meijl, in line with Pels (2003), then argues for a position of the anthropologist as trickster: we should stay in and embrace our ambivalent position, which makes it possible to support but still criticize what we see at the same time. The trickster, a mythical figure, is ambiguous by nature, equivocal and even unreliable (Van Meijl 2005: 240). Still, it is a good model, Van Meijl writes, as ambiguity and ambivalence are important for the role of the anthropologists. We need to be emphatic but critical as well and, most importantly, involved and detached when needed. He builds upon the concept of the "professional stranger" by Agar (1996) who wrote about detached involvement within fieldwork. This anthropologist can be engaged, but does not become "one of them", one of the people she is studying and she will not necessarily agree with them either. The anthropologist-trickster can thus be an advocate for the people she studies, while at the same time being able to "take a step back and reflect on the construction, development and implementation of indigenous political strategies" (Van Meijl 2005: 241). She is then "not a traitor, but rather a trickster" he writes, "who embodies different roles in different contexts and combines both in the practice of what I would label critical ethnography" (ibid.).

I think this is an interesting position. I would, however, propose to shift the roles of the trickster somewhat, in the following way. While Van Meijl holds on to the ethnographic approach, I believe the anthropologist should be able to study and understand the powerful, or victimizers in other ways as well. By using methods that require less proximity than classical ethnography, we can still gain understanding about the people we study, but we can let go of a deep kind of empathy that is expected of anthropologists in many ways, without betraying the trust of our informants. Taking a role as a "trickster" then, the anthropologist can take a step back and look critically at the situation her informants are part of and openly criticize it, even as an activist without this compromising her research and as such the understanding of the people she studies. She does not need to empathize with those she studies, or establish close relationships with them in order to study them and understand their worlds. As a trickster these positions are never set and can be fluid, shifting according to the reality in "the field" of the anthropologists. The anthropologist, as the trickster, is indeed an ambivalent figure who "combines an eitheror position with a both-and one" (Pouwer 1978 as quoted in Van Meijl 2005). Importantly, however, this is not to say that the role of the trickster is always easy 
or comfortable. It gives the researcher some freedom to manoeuvre, but complex positionalities, as I shall show below, will always go hand in hand with dilemmas.

\section{My positions in the field}

I will now lay out the specifics of my own position and the ways these different layers form the lenses through which my research is coloured. I chose to discuss a few "lenses" in more depth that are relevant for our discussion here, while realizing there are many more positions that influence my research, such as me being a woman (for example, see Hoijtink, this volume).

\section{Being a Dutch-Israeli Jewish researcher}

As was written in the introduction to an important special issue on Israelis studying the Occupation, "the occupier has always studied the occupied population and the occupied territory" (Handel and Ginsburg 2018). What could then be the role of engaged Israeli researchers studying this occupation? They are in a special position in which they can speak out about it critically, but as Hagar Kotef (2018) asks: how can Israeli Jews write and act against the Occupation while being part of it? Should we deliberately not write about Palestinians, as we are part of the colonial power? Shall we write to "remove the masks" and show the world what is going on, and would this work? There are no easy answers to her questions, but importantly and as I understand it, there is a role for academics in our position and that is not to be silent.

A side-note is important here, however; my role is a bit more complex than sketched out above, as I am both Dutch and Israeli. This gives me more freedom to manoeuvre my identity, like a trickster, between emphasizing my Dutch side and my Israeli one - and most of all it has given me the opportunity not to work within Israeli academia, which is complicit with the Occupation in many ways. ${ }^{4}$

\section{Being an activist: the political self}

Some people urge me to begin every presentation with positioning myself within the activist field, to avoid the kind of criticism described above from the start. However, I do not believe the researcher should be forced to position herself politically in order for our research to be legitimate in some way. This would, I suspect, disadvantage critical leftist researchers while "rightist" researchers would be seen as "objective". However, it is an important lens through which we come to our research subject, to the questions we ask and the way we do our research.

I have been active against the on-going Israeli occupation of Palestinian land for a few decades. Being Israeli made my connection to the political situation in the area even more emotionally charged and I have been active within the Israeli "leftist", often called "radical leftist", activist community for many years. In the Netherlands I co-founded an organization for "Critical Israelis in the 
Netherlands" in 2007 that organizes a range of events to raise awareness about the Occupation with a Dutch audience.

During my fieldwork in 2006-2007 and again in 2016, when living in Israel, my activity meant taking part in protests against the Occupation, the siege and attacks on Gaza, and other events taking place during that time. This included participating in solidarity protests with conscientious objectors and participating in a critical conference called "In-Security" organized in "the shadows" of one of the main security fairs in Israel. ${ }^{5}$

As mentioned above, it is not to say that the role of the "trickster" does not come into play here (quite literally in the last example as I did fieldwork at the "real fair" while participating in the shadow conference the next day). At times, especially during my research on security professionals, I felt "guilty" after interviewing informants as they assumed me to be "on their side". This assumption came with me being Israeli and speaking Hebrew with them, and in the Israeli context the mainstream population is very uncritical of security companies and their work. While not lying to the people I research, I also do not feel the need to convey my political stance before interviews. However, some feelings I believe cannot be avoided. It will always entail the juggling between doing right by your informants and your own beliefs.

\section{Being an anthropologist}

As I have shown above, with the "title" of being an anthropologist, certain expectations arise and many were surprised not to say suspicious when hearing about my topic of research, especially when combined with the Israeli context it was placed in. By identifying as anthropologists our research methods are also assumed, with ethnography being the main approach used. However, as I already indicated above, I believe we cannot and should not take on the ethnographic approach, as it is defined within anthropology, in every context. As mentioned earlier, anthropologists take ethnography to be almost synonymous with deep and empathetic relations of trust with the people they study, the communities they research. In my own case, in which I studied soldiers and security professionals in Israel I believe that I could only stay critical and true to my political position if I avoided ethnography and the expectations of empathy and trust. Of course, important ethical issues such as anonymity still apply in such research, but I could not have gotten "ethnographically close" to the people I studied while deeply disagreeing with what they stood for. This is especially true for the research I am currently conducting on security professionals, as they chose much more consciously to be part of a regime than the conscripts I studied a decade ago. Instead, I use methods that allow me my ambivalent position; of an academic with a clear political stance. I use observations that are sometimes more, sometimes less participative and (in depth) interviews to answer my anthropological queries. I continuously shift along the continuum of taking part and taking my distance, according to the situation. Other methods that I use are (indepth) interviews and the analysis of secondary sources, films and PR materials, for 
example. These methods allow me to understand a world, but don't force me into relationships of trust and deep empathy that I am not comfortable with.

\section{BOX 14.1 NON-ETHNOGRAPHIC ANTHROPOLOGICAL RESEARCH}

Ethnography has been synonymous with anthropology for a long time. I pose that doing anthropology and taking an anthropological approach to studying the social world can be done in different ways, including without doing "pure" ethnography. Our questions can be still anthropological, and touch upon the everydayness of acts, on interpretations of meanings, on power differences and all from the bottom up. However, to answer these questions we don't necessarily need to engage in deep participant observation, create deep relationships with our research participants or develop trust and empathy. These issues are difficult and, I argue, not advisable when studying power holders and members of regimes we oppose.

Linda Tuhiwai Smith (1999) makes a similar argument concerning methods, albeit she is concerned with the study of the occupied by the occupier, while in my case one could say I studied the occupier himself. Others have argued that the study of the occupier blurs the occupied (Handel and Ginsburg 2018). However, I believe that such studies, in a non-ethnographic way, are the only way to "unmask" the realities of the regime I am critiquing (Kotef 2018).

\section{In conclusion: being a "trickster"}

In this chapter, I showed how having an outspoken political agenda can go hand in hand with ethically and thoughtfully studying perpetrators of violence or other power holders who are part of systems or regimes we oppose. While in anthropology engaged research is usually almost synonymous with an ethnographic approach where relations of trust and empathy play a role, this is more complex when studying people we oppose or whose agendas we don't sympathize with or even oppose. I argued in this chapter that in some cases, abstaining from the use of ethnographic methods, which include a high level of intimacy, is the most ethical choice. In this way we don't have to come too close to our research informants and can stay true to our political selves and our engagement with the bigger political context, which in my case was my criticism of the Israeli occupation of Palestinian lands and accompanying human rights violations.

However, what approach we choose depends on the context and our positionalities; who are we, who are we studying, and what is the question we want to 
answer. For example, the soldiers I studied are not necessarily only perpetrators; they are victims themselves on a certain level. They are part of the system, a system we should study from every perspective possible. The security professionals I interviewed were much more complicit and hence my research relationship with them was different.

In my research I do everything to ensure the anonymity of my informants and I was honest about my research intentions. However, this does not mean conveying all aspects of my identity and opinions (as we never do in research). At the same time, I do not sympathize with their actions or goals in life or even empathize with them. Often what soldiers told me they had done during their military service or to whom professionals would sell their security technologies appalled me. However, as mentioned earlier, concerning the soldiers I could see them as "victims" of the system in some ways, and thus my views and approach was never black and white.

The concept of the trickster (Van Meijl 2005 and Pels 2003) is useful here and shows that it is possible to study a group you do not support or agree with while indeed doing them no harm, but at the same time without the need to sympathize or empathize with them. One can go in and out of roles and be an engaged researcher without this engagement being directed towards the people we study. As such we should not shy away from embracing the ambivalence this brings. Reflection on our positions and politics is key here.

\section{Suggestions for further reading}

- $\quad$ Heidi Armbruster and Anna Lærke (eds) (2008) Taking sides: Ethics, politics and fieldwork in anthropology, Oxford and New York: Berghahn Books.

- Didier Fassin (ed.) (2014). A companion to moral anthropology. Chichester: John Wiley \& Sons.

- Ciara Kierans and Kirsten Bell (2017) "Cultivating ambivalence: Some methodological considerations for anthropology”, HAU: Journal of Ethnographic Theory, 7(2): 23-44.

- Victoria Sanford and Asale Angel-Ajani (eds) (2006) Engaged observer: Anthropology, advocacy, and activism, New Brunswick: Rutgers University Press.

\section{Notes}

1 In the Netherlands parliamentary questions were even asked concerning the need to be transparent about the political color of researchers, as a result of anthropologists wrongly being accused of supporting a militant group. See here for more information: http://reli gionresearch.org/closer/2018/05/31/de-wetenschap-de-nrc-en-de-veiligheidsdiensten/ (Dutch only, accessed 9 July 2018).

2 http://ethics.americananthro.org/category/statement/ (accessed 2 July 2018).

3 Those who become career officers in the IDF often retire at 45.

4 https://972mag.com/is-academia-the-last-bastion-of-progressive-thought-inisrael/132623/ (accessed 9 July 2018).

5 See https://en.hamushim.com/in-security-conference/ (accessed 9 July 2018). 


\section{References}

Abbink, Jan and Tijo Salverda eds (2012) The anthropology of elites: Power, culture, and the complexities of distinction, New York: Palgrave Macmillan.

Agar, Michael H. (1996) The professional stranger: An informal introduction to ethnography, San Diego: Academic Press.

Coffey, A. (1999) The ethnographic self: Fieldwork and the representation of identity, Cardiff: University of Cardiff.

Foley, Douglas. E. (2002) "Critical ethnography: The reflexive turn", International Journal of Qualitative Studies in Education, 15(4): 469-490.

Gramsci, Antonio (1971) Prison notebooks, New York: International Publishers.

Graham, Stephen (2010) "Laboratories of war: United States-Israeli collaboration in urban war and securitization", The Brown Journal of World Affairs, 17(1): 35-51.

Handel, Ariel and Ruthie Ginsburg (2018) "Israelis studying the Occupation: An introduction", Critical Inquiry, 44(2): 331-342.

Hale, Charles R. (2006) "Activist research v. cultural critique: Indigenous land rights and the contradictions of politically engaged anthropology", Cultural Anthropology, 21(1): 96-120.

Hastrup, Kirsten and Peter Elsass (1990) "Anthropological advocacy: A contradiction in terms?”, Current Anthropology, 31(3): 301-311.

Kotef, Hagar (2018) "Fragments", Critical Inquiry, 44(2): 343-349.

Low, Setha M. and Sally Engle Merry (2010) "Engaged anthropology: Diversity and dilemmas: An introduction to supplement 2", Current Anthropology, 51(S2): S203-S226.

Madison, D. Soyini, (2011) Critical ethnography: Method, ethics, and performance, Thousand Oaks and London: Sage Publications.

Nencel, Lorraine (2014) "Situating reflexivity: Voices, positionalities and representations in feminist ethnographic texts”, Women's Studies International Forum, 43: 75-83.

Ortner, Sherry B. (2005) "Subjectivity and cultural critique", Anthropological Theory, 5(1): 31-52.

Pels, Peter (2000) "The trickster's dilemma: Ethics and the technologies of the anthropological self", pp. 135-72 in Marilyn Strathern (ed.) Audit cultures:Anthropological studies in accountability, ethics and the academy, London and New York: Routledge.

Reinharz, Shulamit (2011) Observing the observer: Understanding our selves in field research. New York, NY: Oxford University Press.

Rodgers, Dennis (2009) "Slum wars of the 21st century: Gangs, mano dura and the new urban geography of conflict in Central America”, Development and Change, 40(5):949-976.

Sanford, Victoria and Asale Anjel-Ajani (2006) Engaged observer: Anthropology, advocacy, and activism, New Brunswick: Rutgers University Press.

Scheper-Hughes, Nancy (1995) "The primacy of the ethical: Propositions for a militant anthropology", Current Anthropology, 36(3): 409-440.

Tuhiwai Smith, Linda (1999) Decolonizing methodologies: Research and indigenous peoples, London: Zed Books Ltd.

Van Meijl, Toon (2005) "The critical ethnographer as trickster", Anthropological Forum, 15 (3): 235-245. 


\title{
15
}

\section{SECRECY VIGNETTES}

\author{
Marieke de Goede
}

- Research objective: This chapter helps researchers who want their academic writing to include explicit accounts of the ways in which they navigated secrecy and its ethical dilemmas in their fieldwork. It proposes that one way of including such accounts is by way of 'secrecy vignettes'.

- Research puzzle: The puzzle the chapter addresses in relation to secrecy and methods is how to analyse the way in which secrecy played out in particular fieldwork sites, and how best to account for such challenging and ethically complex situations of secrecy and confidentiality when writing.

\section{Introduction: writing with secrecy}

This chapter discusses the possibility of incorporating secrecy into academic writing and publication by way of 'secrecy vignettes,' that show how secrecy was navigated in research practice. Inspired by Rappert's invitation to develop and deploy creative strategies of "writing with secrecy," I explore the use of vignette-like, reflexive notes from the field (Rappert 2010; also Rappert, this volume). Rappert asks how we may "attend to the absent" in research accounts, in particular where it concerns research relating to classified sites or practices (2010:574). His work resists the common injunction to deal with secrecy through exposure or disclosure. This is not just because exposure possibly entails ethical challenges or confidentiality breaches by the researcher, but also because the notion of 'revealing secrets' entails a particular approach to secrecy, which casts the researcher in a problematic role as the one with the capacity to reveal (also Walters and Luscombe, this volume).

In contrast, Rappert encourages a lateral approach to confidential knowledge, that seeks to give the secret a place in the research practice or writing. If, as Graham Jones points out, "absolute transparency in social relations is impossible," then how can we attend to the secret in a way that moves beyond the sensationalist economy 
of exposure or disclosure (2014: 61)? Sometimes, it is possible to give the secret literally a place in the text, as in Rappert's experimentations with blacked-out text in his academic writing on nuclear weaponry (see also Chapter 7). More broadly, 'writing with secrecy' attends to the complex and processual nature of secrecy. If secrecy is ad-hoc and controversy driven - as many of the chapters in this book suggest - then rendering some of these processes explicit through vignettes or excerpts could be a promising way to reflect on how they played into the research process.

In this contribution, I explore vignettes as a way to give secrecy a place in academic writing.Vignettes offer a specific register or genre to convey "academic voice," beyond the limited repertoire of academic writing (Dauphinee 2010: 805). They give access to "something intimate," while enabling us "to draw broader lessons" (Michael 2012:28), and this makes them suitable for rendering explicit ethical dilemmas and ongoing fieldwork negotiations.

Furthermore, this writing form can give academic voice to the complex entanglements between researcher and researched that participant-observation produces. As the vignettes in this chapter illustrate, practice-based research into security communities fosters complex relations between researchers and the communities of practice that they study (Adler-Nissen and Pouliot 2015). This has implications for critical voice and the scope for engaged advocacy. The purpose of the chapter is not to fully tease out these implications and dilemmas (see the contributions of Stavrianakis and Grassiani, this volume). However, I suggest that vignettes offer one productive way of drawing out these entanglements, allowing for what Wanda Pillow (2003: 192) calls a "reflexivity of discomfort." As textual forms, vignettes can be placed in advance of or alongside more conventional social scientific prose, for example as a narrative introductory examples or as a textbox (such as the ones used throughout this book). In this manner, they offer an opportunity to include auto-ethnographic fieldwork reflections into a published piece, without having necessarily to embrace auto-ethnography as the primary genre for a written piece.

\section{Vignettes}

Vignettes are understood as short narrative stories or examples that function as a "window through which the reader can view some of the pleasure and pain" of research in practice (Humphreys 2005: 842). ${ }^{2}$ They are commonly but not exclusively deployed in ethnographic writing, and may comprise a number of elements. First, vignettes exemplify the mundane, everyday, lived reality of research practice. They "afford the possibility of conveying something that we would not otherwise have been able to hear" (Dauphinee 2010: 806; Ackerly, Stern and True 2010). In this sense, 'secrecy vignettes' speak to the themes of the book in a double sense. On the one hand, I explore their use as a window onto the practical and ethical dilemmas of studying secretive security practices. On the other hand, vignettes in themselves are a way of rendering visible that which normally remains invisible in research.Vignettes offer a glimpse of the elements of research practice that normally 
remain implicit, because they are held to be mundane, preparatory, irrelevant, offtopic or perhaps too boring to include. They can be one way of generating an "active account of ambivalence" that - for Debbie Lisle (2016: 418) - is key to the project of International Political Sociology.

Second, vignettes make space for accounts that divert from the initial research questions or objectives, but that come to absorb much time, effort and thinking as the research is conducted. They speak of elements of the research that are unexpected, unplanned or improvised. They can attest to moments that escape the research questions or that gave cause to rethink the research objectives. As Mike Michael has written about the anecdote: it "captures moments when things go wrong or are out of sorts in one way or another" (2012: 28). What I propose, then, is that vignettes - or auto-ethnographic interludes - are particularly useful to make space for accounts of how secrecy was negotiated and navigated in fieldwork. In the case of my own research project, the main research question: 'how does the suspicious transaction related to terrorism financing get translated along the chain of reporting and investigation' (de Goede 2018), was quickly and temporarily displaced by the question 'how can we create proximity with relevant fieldsites where counter-terrorism financing is being done, while retaining our critical distance?' Third, vignettes allow for attending to reflexivity. They allow the researcher to write "self into the narrative in order to problematize the authorial voice" (Michael 2012: 28). As discussed below, they can render explicit the "constant negotiations" between researchers and researched, and help the author reflect on how their own role, positionality, appearance, gender etc., played into practical research moments (Bueger and Mireanu 2015: 129; Pillow 2003).

However, auto-ethnographic writing (as exemplified in vignettes) potentially also has a number of drawbacks. As Michael Humphries acknowledges, autoethnography risks becoming "self-indulgent" (2005: 51). I would add that autoethnography poses particular gendered pitfalls. Writing auto-ethnographic vignettes require the author to render herself vulnerable by explicating the confusing, failing, ambivalent or ethically complex moments of fieldwork (Page 2017). This may impact the way in which professional identities are crafted and perceived: less established, non-white and/or female researchers can perhaps less afford to demonstrate such vulnerabilities. Humphries' compelling account of his unusual career path, for example, allows readers to reflect on class identities, but avoids the question of gender (see Hoijtink, this volume).

Still, I explore the use of secrecy vignettes as particularly promising for a number of reasons. Writing vignettes can be one way of incorporating the mundane, hard work of field research into academic writing. It can give a place to unexpected happenings, personal investments and embodied research practice. It is one promising strategy to write with secrecy, because it gives a place to the "excluded presence" of the events that produce data; they allow researchers to "fruitfully remain sensitive to ... those and that which is excluded in the process of research" (Michael 2012: 33). Vignettes do not entail full auto-ethnographic accounts, but can accompany more formal writing in order to incorporate the excluded, invisible 
or unsayable. They can illustrate how to understand secrecy as data, and allow the writer to reflect on the way that access is a process of ongoing negotiation rather than a clear moment of 'getting through the door'. They are one way of rendering visible the ethical stakes and dilemmas of navigating secrecy in security research. Moreover, they can help reflect on the situatedness of knowledge, by showing how information was available to whom, in which moments, places or contexts (Haraway 1988).

The remainder of this short chapter will use vignettes to show how secrecy was experienced, navigated and deliberated in our research into the chain of translation of suspicious financial transactions (Latour 1999; de Goede 2018). This project seeks to 'follow' the suspicious financial transaction from bank to Financial Intelligence Unit to court case, to analyze how suspicion is inscribed, how transactions are rendered mobile and how (in some cases) they gain the capacity to act as evidence before a court of law in criminal prosecutions. The research is funded by the European Research Council (ERC), and the dominant set of questions I was asked during the interview with the funding agency was about possibilities and strategies of access to the secretive world of counter-terrorism financing. Committee members explicitly questioned the very possibility of being able to undertake the participant observation in banks and Financial Intelligence Units that my research proposal foresaw (but see Bosma, this volume). From the very early stages of grant application, to the current state of fieldwork and analysis, then, issues of secrecy have actively shaped our research design, process, practice and team discussions.

\section{Secrecy as practice}

Vignette 1: It was not easy to find out when the terrorism financing court case would take place. The indictment had been widely noted in the news, and it was known that the trial would take place at the Central Criminal Court in London (also known as the Old Bailey). However, Old Bailey court listings are not easy to find online, they are posted late and subject to last minute changes. Nevertheless, I made it to the court's public entrance on the day of what was expected to be the first day of trial. After some delay, and waiting before a closed door in a London underpass, I was let into the public gallery, together with family and supporters of the defendants.

The proceedings, at least when the jury was not there, were a lot less formal than I had expected. A number of contentious issues were debated, for example reports of terrorism expertise that had been brought before the court by the defendants. Some key points on the applicable law were discussed. These issues of law were not openly laid out, they were apparently already known to the trial participants. Before these issues were clarified and agreed, the trial was unable to start. The judge encouraged the Crown Prosecution and Defence to get together informally to come to a compromise proposal on these contested issues of law. At times, it was almost as if the judge was thinking out loud. He lost his train of thought. He invited the barristers to 'think along with him,' to help solve the problems and contentious issues before the jury trial started. He said, you don't have to answer right now, 'I just want everyone to think about 
these things for themselves'; to 'just have a look at it'. Though attending the court case proved to be a fascinating embodied experience - of waiting, of speaking informally to supporters of the defendants, of watching the trial ritual unfold - I feel that I leave with more questions than I arrived with.

Part of our research focuses on observing criminal trials, as the locus where new (counter-terrorism financing) laws are being given practical significance and reach (e.g. de Goede and de Graaf 2013). However, instead of a privileged site where law is publicly enacted, our fieldwork has found criminal trials to be obfuscated, unpredictable, and difficult to access. The scene in the court room in vignette 1 illustrates how secrecy can function as an (expert) practice, rather than being a clear binary of the visible and invisible. Some of the mystifying and secretive nature of the court proceedings in this case - which indicted parents who had sent money to their young adult son while he was in IS-held territory in Syria - was not directly related to the classification of materials, but arose from the normal course of legal practice.

The rules, documents and speaking turns of a trial are regulated through courtroom rituals. Such rituals strictly structure what takes place in the courtroom, and they give material shape to broad goals like 'justice' (Felman 2002). Much of the legal contestations before the court were left implicit in the spoken proceedings, and were included in documents strictly accessible only to the legal professionals. The courtroom rituals amounted to a profound but not necessarily deliberate obfuscation to outsiders (see Belcher and Martin, this volume). This is what Van Veeren (2018: 197) calls "invisibility as inexpertise": decoding the courtroom proceedings requires specialist knowledge or "visual prosthetics." It is worth pointing out though, that this level of obfuscation affects family and friends of defendants as well as researchers. My position in the public gallery of the Old Bailey and my positionality as a white, professional, woman, in this case allowed me to converse informally with (the white, middle-class) friends of the defendants, who had made an early morning journey to attend the trial but who remained mystified concerning the significance of the proceedings and the future of the trial.

However, in this particular case, additional layers of secrecy were in place. Even if some of the dynamics of obfuscation were due to the specificities of the legal procedure, it matters that it was a terrorism-related trial. Specifically, an UK "anonymity order" applied to this case, which means that case reporting is strictly regulated. The anonymity order means that the people involved in the case cannot publicly speak about or share any of the legal materials. They cannot share details of the offences as charged or of the evidence presented - though, surprisingly, the "names, ages, home addresses and occupations of the accused and witnesses" are exempted from the reporting order. ${ }^{3}$ The order is in place so that the jury cannot be influenced in advance of the jury trial that is still to take place. The defendants have publicly critiqued the fact that they are unable to talk about the case to "counter lies that have been printed [about their son]" because of the UK contempt of court rules. ${ }^{4}$ When I was able to speak to the defence barrister in this case, she appeared sympathetic to our research project of analyzing how new laws are enacted and given meaning 
in this hotly contested field, but extremely reluctant to share information or documents beyond what is strictly available online. The case is ongoing.

To conclude, then, this first vignette speaks to secrecy as a layered, expert practice. It shows how, in this particular case, obfuscation arose from expert courtroom rituals, but also from the added layer of a formal, legal, anonymity order. The vignette gives a glimpse of the embodied experience of navigating this layered secrecy, while also attending to the question: where does security happen (see also Nyman, this volume)?

\section{Secrecy as process}

Vignette 2: In trying to achieve access to a bank's compliance department for ethnographic observation of their counter-terrorism financing practices, we had met contacts at The Bank several times. Sometimes, these meetings were very informal and simply involved a coffee to make acquaintance. Sometimes, they were slightly more formal and took place in meeting rooms at The Bank, whereby we were invited to present our past research findings to bank compliance employees. Employees of a few different departments of The Bank came along to the meetings so that they, too, could ask us some questions as to why we wanted to do this research and how we would protect our research data. Eventually, a meeting with The Bank's legal department was called. This was to be the most formal meeting to date, though it was not entirely clear to us whether this was to be a final hurdle before bank access was decided, or whether it was just one more layer of consent. We diligently prepared for this meeting, in particular by refining and rehearsing the ethical protocol of our research and the way in which we would secure privacy and anonymity of respondents and of client data. We expected privacy to be the main concern and topic of discussion with The Bank's legal department.

Once the meeting got underway, the atmosphere was relaxed and friendly. We presented our research and made the case that it might be of benefit to the bank itself and to wider political debates on compliance issues. We agreed that The Bank's name would be anonymized: after all, we are interested in counter-terrorism financing compliance practices, not the behavior of individual employees or the protocols of one bank in particular. To our surprise, the main concern of The Bank was not strictly the privacy of their clients and their client databases. The legal department's main concern, at least as expressed in this meeting, was with liability. To what extent did The Bank risk being held liable in case our research would find, for example, that a compliance department was understaffed or overworked? How might our findings impact public reporting or public opinion of The Bank, or banking in general? And what scope might our research give clients on the one hand, and regulatory authorities on the other, to sue the bank for potential compliance gaps?

This particular vignette speaks to the "constant negotiations" that take place when researching secretive or challenging fieldsites (Bueger and Mireanu 2015: 129). In our cases, a clear moment of access - a clear passage through the Gate, as we have called this in the book's introduction - was often missing. Instead, there was 
an ongoing negotiation, involving multiple coffee meetings, chance encounters at industry conferences, and formal presentations. This process allowed a slow building up of a sense of shared concerns, in which our own positionality as engaged, reputable professionals had to be carefully maintained. However, the outcome of meetings was often unclear; there was a seemingly endless process of deferral and referral even as we were building trust and relevant connections. Indeed, recent literature has pointed out that disclosure itself a process and a practice, rather than a clear moment of transparency. For example, Lisa Gitelman (2014) has shown how the disclosure of the Pentagon Papers (now widely understood to be a key historical example of the revelation of state secrets) was a complex material and juridical process, in which the new Xerox machine played a crucial role (see also Hughes and Garnett, this volume). "Xeroxing was only a first step in what became a lengthy disaggregation and multiplication process," writes Gitelman in her discussion of Watergate and the materiality of disclosure (2014: 86). Our experiences with what is commonly termed 'research access' were that of a slow, embodied, iterative, material and rather confusing process, instead of a clear moment.

In our case, the process of navigating secrecy partly proceeded according to well-known methodological paths, including the crucial role played by professionals who advocated for our research within the organizations that we wanted to study. It is important to emphasize that these key informants, often called 'gatekeepers' in the ethnographic literature (Bryman 2012) take risks when they vouch for our trustworthiness inside the organization. In our experience, these key contacts came to act out of a shared concern in the research themes and their potential importance. In this sense, our field contacts engage in a joint risk with us as researchers: they might have hopes about the research outcomes and about generating more transparency for their organization, but this is not guaranteed or specified in advance. A Pauline Maillet (2017: 936-937) and colleagues write of their experience of doing fieldwork in "politically charged arenas": "We had to remember that authorities can also be vulnerable participants: they are workers whose livelihood and employment status may be jeopardized by disclosures made to researchers."

Our work with field contacts at The Bank and other organizations in the domain of police and security entails a challenge of proximity and distance that requires reflection on our research objectives, our role as academic researchers and what this means for our space and capacity for critique (Bueger and Mireanu 2015; Cohn 2006). Other chapters in this book reflect in a more detailed way on these challenges of critique. As Jonathan Luke Austin has put it for example (this volume): "It is perfectly possible to retain a caring and non-judgmental attitude towards those we speak with, while still normatively rejecting and even attempting to combat the particular social system or events that they have been connected with."

However, our slow, iterative, confusing process of 'access' also entailed many surprising twists and turns, as exemplified in our encounter with The Bank's legal department. The legal department raised a number of concerns - for example, over liability - for which our standard research ethics protocol was quite unprepared. In fact, we found that our prepared ethics documents, with their focus on 
anonymization, informed consent and formal agreements, were not the only and main concern of our (highly educated) respondents. Though safeguarding anonymity was a prime shared concern between us and informants, it seemed that some larger organizations in which our researchers conducted participant observation actually avoided the drawing up of tailored documents of informed consent and protection. Highly educated respondents (not necessarily in The Bank) seemed to find that leaving the conditions of proximity in a juridical grey zone to be to preferable to seeking written approval and juridical documentation at the highest level of their organization.

To conclude, then, this second vignette speaks to secrecy as an iterative, embodied, and uncertain process. It problematizes the notion of access, suggesting that it might be better understood as a dynamic of proximity and distance, rather than a clear moment or position of 'inside' or 'outside'. The vignette gives a glimpse of the multiple formal and informal moments in which we navigated this process, to which our formal ethics protocols were not always well suited (see also Amicelle, Badrudin and Tanner, this volume).

\section{The ethical stakes}

Vignette 3: I was pleased to be able to accept the invitation from the world-leading think-tank to participate in a day-long seminar on current international efforts to fight terrorism financing, and to join the speaker's dinner in the evening. It promised to be an important moment of engaged participant-observation. The think-tank was renowned for being able to bring together participants from policy worlds, industry, and security authorities for a frank debate. Indeed, discussion at the think-tank was generally thought to be particularly interesting, because of the well-known rule governing non-disclosure of the meeting's discussions. Still, I experienced a marked difference in the dynamic of the discussion during the day-long seminar - attended by around 100 participants from the financial industry, international organizations, Fin Tech companies, Non-governmental organizations, and the diplomatic world - and the discussions over dinner, attended by about 25 participants, who mostly worked for the seminar's main sponsor, but also including a well-respected NGO campaigner and some academics (including myself).

The dinner was hosted in the think-tank's first-floor grand library, and to my pleasant surprise, it was very much a working dinner with a tightly chaired common conversation for the duration of three courses. This conversation, as it turned out, entailed some elements that were markedly different from the day's discussions. First, there appeared to be a strong consensus around the dinner table that targeted publicprivate information sharing (whereby police share personal information of suspects with the financial industry), was the future of counter-terrorism financing. Second, unlike the daytime discussions, it was acknowledged explicitly and quite forcefully that privacy regulation (in particular the EU General Data Protection Regulation) poses a huge problem to public-private data sharing. Third, I realized that the company sponsor of the seminar (and the host of the dinner) had a specific interest in the sponsorship: the 
company had recently purchased a software program that had incurred some bad press in relation to its counter-terrorism financing practices, and was seeking to connect to the professional field and rebuild its reputation. This left me with a number of ethical questions: what was my role as an academic in helping boost the legitimacy of the day's discussions, which were at least partly sponsored by a company seeking to rebrand? What trade-off was taking place between our research access and the sponsor's quest for legitimacy? ${ }^{5}$

In this third example, I use vignette-like writing to render explicit the ethical dilemmas and "deliberative moments" of fieldwork practice, and the scope for engaged critique (Montgomerie 2017: 13). As Johnna Montgomerie notes, fieldwork is replete with "choices, trade-offs and judgements," not all of which can be anticipated and codified in advance (2017: 13). The ethical stakes of field research under conditions of secrecy are quite specific, as detailed in the chapters in part 3 of this book. The "openly ambiguous textual form" of the vignette or anecdote can offer a place to reflect on these choices and judgements, without necessarily providing definitive answers (Michael 2012: 27).

Sharing in secrets can create affective responses in researchers, from "guilty excitement" to "intense paranoia about the consequences of . . disclosing" (Jones 2014: 61). However, with research commonly being focused on accessing information, it is easily forgotten that perhaps one does not always want to know secrets (as also pointed out by Chappuis and Krause, this volume). Becoming initiated into secretive or closed off materials produces a shared responsibility. Knowing a secret creates a bond, and renders the researcher - even if in a limited way - co-responsible for keeping or disclosing the material. In extreme cases, this can place researchers in a moral dilemma. In this case, the company sponsorship of the seminar was, of course, not strictly a secret: their logos had been prominently displayed throughout the day, and sponsorship for these types of professional events is not unusual. However, the extent of the company's involvement in the day, and their specific interest after acquiring the controversial software program, only really became clear to me through the dinner discussions. Other elements of the dinner conversation, such as the identification of privacy as a problem to the industry, were similarly revealing. Being let in on these 'secrets' was both revealing for understanding the dynamics of the professional field, but also gave me an uneasy co-responsibility. ${ }^{6}$ The challenge is how to incorporate such research findings into published work in a way that respects the confidentiality of the dinner setting while being transparent about research methods.

This third vignette shows my uneasy positioning at the inside-outside of the international community of practice of counter-terrorism financing. My years of research into this field has created a critical dialogue with practitioners. I welcome the occasional invitations to participate in professional seminars, and regard them to be important fieldwork moments in this generally secretive domain. At the same time, I am weary that my university affiliation and professorial standing can provide legitimacy to a contested field. My own sense is that 'uneasiness' is a durable 
and productive position in such encounters. For Pillow (2003: 92) for example, a "reflexivity of discomfort" entails a self-reflexive methodological account that does not seek to erase tension into a smooth narrative, but that, instead holds on to such tensions, or includes them as "confounding disruptions." The vignette can offer a creative, disruptive, narrative form that departs from traditional academic voice, but that is suitable to rendering such uneasiness and its ethical stakes explicit.

\section{Conclusion}

This chapter has experimented with vignettes as creative writing strategies that can give secrecies a place in academic writing. My proposal is that researchers in critical security studies, International Political Sociology, and beyond, could more actively use such creative writing strategies to create transparency and reflexivity concerning their fieldwork approaches in secretive settings. Rather than erasing the secretive and the complex challenges of access from research output, I have sought to express the secrecy dilemmas and deliberations that have absorbed much time and energy in our own research project. These secrecy vignettes move beyond common injunctions to disclose or reveal, but instead incorporate confidentiality and its ethical stakes explicitly in academic writing. All vignettes in this chapter are based on ongoing, team-based fieldwork, whereby it is our experience that undertaking joint fieldwork can help strengthen the position of the researcher and create a productive sounding board for the ethical dilemmas at play.

The specific form of the vignette is that it is both open-ended and selective. Vignettes necessarily privilege certain moments over others. Their selection and narration should be based on fieldwork notes, but are at least partly in the realm of an intuitive assessment of key fieldwork moments or events. Vignettes offer one form of "vulnerable writing" (Page 2017), but mostly refrain from showing the depth of despair that can sometimes accompany fieldwork.Vignettes need not necessarily present smooth narratives or clear lessons: their ambiguous form lends itself to exploring tensions and contradiction in fieldwork, and producing a 'reflexivity of discomfort'. Vignettes provide only snippets of complex and continuing processes of fieldwork; they are open-ended in the sense that they raise ethical questions without seeking to fully close them down.

In addition to giving a place to secrecy, the vignettes also help to reflect on the nature and shape of secrecy, and how it played into our research project. Specifically, these vignettes show how we encountered secrecy as a practice and a process, rather than purely a barrier to be overcome. Navigating secrecies in our case entailed a material and embodied process. We experienced secrecy as layered, requiring repeated investments, meetings and dialogues, and multiple iterations of our research questions and objectives. Many of these encounters did not easily match formal methodological rules of access and ethics protocols as established in the literature. Auto-ethnographic writing in the forms of vignettes, anecdotes or text boxes are one way of giving a place to these experiences, while countering the invisibilities that are normally accorded to embodied fieldwork. 


\section{Suggestions for further reading}

- Christian Bueger and Manuel Mireanu (2015) 'Proximity', in Claudia Aradau. Jef Huysmans, Andrew Neal and Nadine Voelkner (eds) Critical Security Methods. London: Routledge, pp. 118-141.

- Carol Cohn (2006) 'Motives and methods: Using multi-sited ethnography to study US security discourses,' in Brooke A. Ackerly, Maria Stern and Jacqui True (eds) Feminist Methodologies for International Relations. Cambridge: Cambridge University Press, pp. 91-107.

- Elizabeth Dauphinee (2010) 'The ethics of autoethnography', Review of International Studies 36(3):799-818.

- Michael Humphreys (2005) 'Getting personal: Reflexivity and autoethnographic vignettes,' Qualitative Inquiry 11: 840-860.

\section{Notes}

1 Tasniem Anwar, Esmé Bosma, Rocco Bellanova, Pieter Lagerwaard, Polly Pallister-Wilkins and Natalie Welfens are both common travellers during the fieldwork moments expressed in these vignettes, and generous readers of this chapter. Their many excellent comments and suggestions have helped shape the chapter in important ways.

2 So this chapter is not about the other meaning of vignettes in social science research, where they are sometimes used as examples or scenarios to spark conversation or response of research participants.

3 UK Supreme Court, R v Sally Lane and John Letts (AB and CD) (Appellants) 'Anonymity Order,' July 11 2018, at: https://www.supremecourt.uk/cases/uksc-2017-0080.html

4 Defendant CD, https://globalnews.ca/video/4611014/father-of-jihadi-jack-i-needyour-help-to-save-my-sons-life/, at $00^{\prime} 40$

5 Fieldnotes, London, November 2018.

6 In this particular case, after having realized the extent of the corporate sponsorship of the seminar, I decided to decline the offer of the think-tank to reimburse my flight, claiming the expenses from my own research budget instead. However, I regard this to be a situated, ethical decision, and not a generalizable stance on accepting or rejecting reimbursements from particular institutions or places.

\section{References}

Ackerly, Brooke A., Maria Stern and Jacqui True (eds) (2006) Feminist Methodologies for International Relations. Cambridge, UK: Cambridge University Press.

Adler-Nissen, R. and V. Pouliot (2015) 'Power in practice: Negotiating international intervention in Libya,' European Journal of International Relations 20(4): 889-911.

Bryman, Alan (2012) Social Research Methods. (4th ed.). Oxford and New York: Oxford University Press.

Bueger, Christian and Manuel Mireanu (2015) 'Proximity', in Claudia Aradau, Jef Huysmans, Andrew Neal and Nadine Voelkner (eds) Critical Security Methods. London: Routledge, pp. 118-141.

Cohn, Carol (2006) 'Motives and methods: Using multi-sited ethnography to study US security discourses,' in Brooke A. Ackerly, Maria Stern and Jacqui True (eds) Feminist Methodologies for International Relations. Cambridge, UK: Cambridge University Press, pp. 91-107. 
Dauphinee, Elizabeth (2010) 'The ethics of autoethnography', Review of International Studies 36(3):799-818.

De Goede, Marieke (2018) ‘The chain of security,' Review of International Studies 44(1): 24-42.

De Goede, Marieke and Beatrice de Graaf (2013) 'Sentencing risk: Temporality and precaution in terrorism trials,' International Political Sociology 7(3): 313-331.

Felman, Shoshana (2002) The Juridical Unconscious: Trials and Traumas in the Twentieth Century. Cambridge, MA: Harvard University Press.

Gitelman, L. (2014) Paper Knowledge:Toward a Media History of Documents. Durham NC: Duke University Press.

Haraway, Donna (1988) 'Situated knowledges: The science question in feminism and the privilege of partial perspective,' Feminist Studies 14(3): 575-599.

Humphreys, Michael (2005) 'Getting personal: Reflexivity and autoethnographic vignettes' Qualitative Inquiry 11: 840-860.

Jones, Graham M. (2014) 'Secrecy', Annual Review of Anthropology 43: 53-69.

Latour, Bruno (1999) Pandora's Hope: Essays on the Reality of Science Studies. Cambridge, MA: Harvard University Press.

Lisle, Debbie (2016) 'Waiting for international political sociology. A field guide to living inbetween.' International Political Sociology 10(4): 417-433.

Maillet, Pauline, Alison Mountz and Keegan Williams (2017) 'Researching migration and enforcement in obscured places: Practical, ethical and methodological challenges to fieldwork,' Social \& Cultural Geography 18(7): 927-950.

Michael, Mike (2012) 'Anecdote,' in Celia Lury and Nina Wakeford (eds) Inventive Methods: The Happening of the Social. Routledge, Oxon and New York: Routledge, pp. 25-35.

Montgomerie, Johnna (2017) Critical Methods in Political and Cultural Economy. London: Routledge.

Page, Tiffany (2017) 'Vulnerable writing as a feminist methodological practice,' Feminist Review 115: 13-29.

Pillow, Wanda S. (2003) 'Confession, catharsis of cure? Rethinking the uses of reflexivity as methodological power in qualitative research,' International Journal of Qualitative Studies in Education 16 (2): 175-196.

Rappert, Brian (2010) 'Revealing and concealing secrets and research:The potential for the absent,' Qualitative Research 10(5): 571-587.

Van Veeren, Elspeth (2018) 'Invisibility', in Roland Bleiker (ed.) Visual Global Politics. London: Routledge, pp. 196-200. 
Section VI: Research ethics in practice 


\title{
16
}

\section{RESEARCH ETHICS AT WORK}

\section{Account-abilities in fieldwork on security}

\author{
Anthony Amicelle, Marie Badrudin \\ and Samuel Tanner
}

- Research objective: This chapter will help researchers wanting to further reflect on research ethics in action when doing qualitative studies on security practices in secret environments.

- Research puzzle:The chapter addresses the entanglement of accountabilities in the midst of research fieldwork that defies ethics as coded and planned by universities predetermined protocols and forms.

\section{Introduction}

To what or to whom is science - or, more precisely, are scientists - accountable?

(Smith 1996: 45)

Following Harold Garfinkel's tradition in ethnomethodology (1967), accountability refers to a shared property of any practical activity. Along these lines, people tend to organize their everyday actions and interactions so as to make them observable-andreportable (Eriksén 2002). Notwithstanding this longstanding sociological reference to the centrality of accountability, numerous authors have, nevertheless, observed increasing calls for "extended regimes of accountability" over the course of recent years, especially with the rise of audit cultures (Power 1997; Neyland 2007; Strathern 2000; Hood 2014; Neyland and Coopsman 2014). In this context, Daniel Neyland and Steve Woolgar argue that accountability involves both "the mere "recognizability" of action (for example, that it is an answer to a question)" and "sanctionable consequences (for example, as a result of the deficiency of your action you will be penalised)" (2002: 263). Science and scientists have not escaped from these demands for greater accountability (Smith 1996). As a result, a wide range of new norms and dedicated committees now exist to further inspect, hold to account and eventually sanction scholars' fieldwork activities, especially relating to research ethics. 
"[I]t is widely recognised empirically that the most common action formally taken by organizations to deal with ethical issues is the development and implementation of ethical rules through codes of conduct and values statements" (Clegg et al. 2007: 109). Filing ethical protocols established by universities - in the light of national and supranational requirements - and waiting weeks or months for approval to proceed with the research has become routine for academics in numerous countries. Most of us have internalized key words and expressions such as: free and informed consent procedure; do no harm principle and risk minimization for human participants; maintenance of confidentiality; data codification or anonymization; secure data storage and so on and so forth. In this respect, ethical clearance represents an unavoidable procedural step. It must be obtained before any recruitment and data collection may begin if research involves individuals, whose rights and welfare have to be protected. As security scholars using qualitative methods such as semi-structured interviews and ethnographic observations in environments of secrecy, we are clearly under the obligation to comply with ethics procedures and internal board reviews from academic institutions. Therefore, the extensive codification of research ethics has made the duty to account for one's actions more explicit, with many scholars feeling more strongly that they are accountable for their behaviour and actions before, during and after field research.

To some extent, we plan our fieldwork through ethical lenses, describing in advance what we intend to concretely do and how we intend to do it once in the field as well as later in the writing process. Yet, this planned ethics does not perfectly overlap with ethics in practice (LaFollette, 2014), particularly for security-related fieldwork where secrecy is the professional norm of choice (see also Wissink, this volume). Some of the ethical issues remain uncharted by universities' guidelines as they are often highly context specific and emerge throughout the research process and dynamic interactions with respondents. As a crucial feature of everyday "accountability sensitive work" in academia (Neyland and Coopsman 2014: 4), research ethics is not just about the approval of predetermined ethical plans by dedicated review committees. Both early-career and experienced researchers have to confront ethical dilemmas that are not necessarily foreseen during the preparatory steps of the research, as they may emerge in the messiness of field research. Ethics in practice, although guided by principles, occurs in the course of social actions involving many parameters that play out unpredictably in the here and now, but also in the future. Furthermore, as argued by Bennington (2000: 15), a great deal of "ethics begins where the case does not exactly correspond to any rule, and where the decision has to be taken without subsumption".

With this in mind this chapter is not intended to help security scholars fill out standardized ethics forms more efficiently. Here many universities and related funding bodies already offer a wide range of (online) tutorials. Rather, this chapter aims to shed light on "non-trivial ethics" that defy codification (Clegg et al. 2007). To paraphrase Clegg et al., it aims to open and foster a critical dialogue on situations of ambiguity where ethical dilemmas and practical research problems are dealt with without the comfort of consensus and certainty. We approach research ethics as 
a way to be "account-able" to certain specific audiences in the light of the "dual meaning of being demonstrably open to inspection as an account of some matter and being able to demonstrate competence in making sense of some matter" (Neyland 2016: 55; Lynch 1993; on accountability and audiences, see Neyland and Woolgar 2013). Drawing upon personal experiences doing qualitative research on a range of public and private institutions involved in secretive security practices, we detail and question research situations where we have been or have felt accountable and held to account by various audiences such as: the responding institutions and research participants as well as our academic peers, the general public, and ourselves as both professional researchers and private citizens.

This chapter therefore engages with the following questions in two sections:

- Section 1: Where to draw the ethical line between academic freedom and respondents' interests in light of fieldwork access?

- Section 2: How to negotiate the dynamic tension between ourselves as academic observers and as citizens in the field during ethnographic observation?

Rather than providing clear-cut answers and ready-made solutions, the objective is more modest offering reflexive 'accounts' about what we actually did and how we did it when we engaged with "research ethics in practice" (Scott-Jones 2016). "It is in this way that ethics can be enhanced by vigorous and persistent selfcritique, practised through open dialogue and the creation of ethical spaces [such as this collective book] in which such issues can be discussed" (Clegg et al. 2007: 117). Seen in this light, writing this chapter is also a form of accountability in action, as an organized effort of making sense of our fieldwork practices and being open to inspection by members of the scholarly community.

\section{BOX 16.1 FIELDWORK}

The proposed 'accounts' and reflections are mostly based on the following research experiences:

1 A research program on the surveillance and policing of financial flows in the name of crime-fighting and national security. Qualitative methodology: semi-structured interviews within financial institutions such as banks and state security-oriented agencies such as financial intelligence units in Canada, France, Switzerland and UK.

2 A research project on the emerging use of body-worn cameras by street police officers in their daily routines and interactions with citizens. Qualitative methodology: ethnography in a Canadian municipal police force, including observations and interviews with equipped police officers. 


\section{Questioning fieldwork access}

Where to draw the ethical line between academic freedom and respondents' interests in the light of fieldwork access? This first section accounts for research ethics in the face of presentations, discussions, explanations, negotiations, compromises and commitments - e.g. accountability relations - with respondents to conduct empirical studies on secretive security practices.

As a fundamental step in gaining fieldwork access, to be account-able in relation to responding institutions means firstly being responsible for the intelligibility of our research project. What, why and how do you want to conduct your study, and to what extent is it of interest for targeted respondents? In our experience, representatives of security-related institutions may expect a presentation or a onepage document that includes a short "outline of the research project", the "goals of the project", the "modalities of the project" AND a sub-section about the "direct benefits" for their organization. Whether this last expectation is made explicit or not, consideration for the responding institutions' interests should not be underestimated. Responding officials may or may not be convinced by the potential contribution of social sciences but, in any case, they would like to get an idea of the added-value for their institution in participating and opening their doors. This is especially true when sensitive institutions and their agents' daily work are the main objects of research. Indeed, it is easier to make sense of a study on crime trends or security threat and risk assessment that falls within the mandate of the responding institution than a study on the everyday activities of the institution as such. Intuitively speaking, representatives of security-related institutions are more receptive to research proposals on their targets than on themselves. They fully comprehend that they can attract research interests and become a research object but it is not selfevident to them how this might ultimately be relevant for them and not (only) a waste of time at best or a reputational danger at worst.

For instance, one of us conducted a qualitative research program on financial intelligence units (FIUs) (Amicelle 2018; Amicelle, Iafolla 2018). According to international norms, FIUs serve as "a national centre for the receipt and analysis of: (a) suspicious transaction reports; and (b) other information relevant to money laundering, associated predicate offences and financing of terrorism, and for the dissemination of the results of that analysis" (FATF 2012: 22). In this respect, when I first introduced myself and my research interests on financial intelligence and the policing of illicit money flows, any high level official's immediate and professional reaction was to expect an applied expertise on dirty money typologies and trends. It took me several meetings to account for my research project on financial policing practices. On the one hand, the prerequisite was to make it clear that I was not interested in sensitive, operational and/or classified data. Here is the formulation I used at the time in e-mails:

Indeed, my approach is mainly based on academic interviews (generally recorded) with anti-money laundering/counter-terrorism financing (AML/CTF) 
professionals. Interviews are anonymised, any personal information is deleted. Such interviews with [the Financial Intelligence Unit] members are directed towards a better knowledge of their professional activity as a whole and their challenges on a daily basis. Thus, I would like to make it clear that I am not interested in classified data.

On the other hand, I had to explain and justify that my research project, my methodology (semi-structured - anonymized - interviews) and the anticipated findings will be of interest for the responding institutions, starting from the premise - made explicit by e-mail - that "academic interviews are a key contribution for ongoing reflection on AML/CTF changes and challenges”.

\section{Situating respondents' interest for qualitative research on (their) security practices}

Sometimes, the respondents' interest in participating in academic interviews is not, at least not only, what we expect. As already stated by Gérard Mauger (1991), Laurent Bonelli and Fabien Carrié (2018: 31) remind us that, without any obligation or material and symbolic benefits, the most common reaction is a refusal to take part in research. In this context, why do officials from security-oriented institutions and secrecy environments participate and let themselves or their employees talk to social scientists whilst being recorded? An interest in collaboration may be partly instrumental. For instance, I discovered that one financial intelligence unit had a strong bureaucratic incentive to show some academic collaboration in their annual report. Later, with another similar agency in the context of an ad-hoc research project, the key element was that the European Parliament commissioned the project in the aftermath of the Panama Papers scandal (Amicelle et al. 2017). The director of the financial intelligence unit saw this institutional connection as an opportunity to put forward his ideas and political recommendations whilst promoting the results and working model of his agency as a whole. In a similar vein, many interviews within financial institutions, starting with banks, were facilitated greatly by the respondents' willingness to share their (very critical) views - about their role and difficulties in the fight against dirty money - outside professional and regulatory circles. Respondents' attempts at enlisting scholars to "voice" (Hirschman, 1970) external critique are far from uncommon. Two of us have experienced such attempts with street-level police officers that saw us as intermediaries able to channel their views and concerns to their hierarchy and beyond. We were aware of this instrumental perception that is not without methodological issues and ethical dilemmas. On the one hand, while such a situation contributed to setting tongues wagging and stimulating a very direct discussion, it required further reflexivity during the recorded-interviews and then during the in-depth analysis of transcripts. On the other hand, our ambivalent acceptance of this role of intermediaries also enacted an unexpected relation of accountability in practice that had to be managed for the length of the research project. 


\section{Researchers' ethics, research benefits and respondents' money}

It is one thing to make sense of the research project and to explain and justify that it may be of interest for the responding institutions but it is another to define the form that "direct benefits" will take. It is here that many of the ethical dilemmas arise around maintaining critical distance and academic freedom. To paraphrase interviewees, what are these ethical dilemmas to account for when 'you have to give to get', e.g. when you have to give something, or at least to promise something to the respondents, to get access to fieldwork?

\section{BOX 16.2 DIRECT BENEFITS FOR THE INSTITUTION}

1 As already mentioned, the institution will benefit from the researcher's observations and interviews in the heat of the moment. This might take the form of regular oral presentations about the ongoing research and the related key elements.

2 The partner institution will also benefit from the research project by means of a final report for internal use. Moreover, the institution will have access to the academic publications in relation to the research. Here, it is worth noting that anonymity rules regarding this type of research project will be strictly applied. Interviews and discussions during observations will be anonymized and there will be no direct or indirect nominative reference to the institution in academic publications.

We have used this framework recently in two different technological-oriented fieldworks (e.g. police body-worn cameras and technologically mediated financial surveillance). In contrast with previous studies, the basic proposal of sharing results in the form of academic publications several months, if not years, after the end of these technological projects was not enough to get access to fieldwork in the first instance. They were eager to receive research results that were more suited to their own temporality and needs. For instance, as both projects were in-the-making, responding institutions were eager to get feedback - via short but regular oral presentations - throughout the duration of the fieldwork. Ethical issues may be multiple in this specific context and their management largely depends on how relations of accountability with the responding institutions are organized. To put it bluntly, how to draw the line between working on a security-related institution and working for this institution?

Money was a red line. Although one could argue that work must pay in the literal sense of the word, we indicated since the outset of discussions that our research demand did not in any way include a financial component. To be clear, this does 
not mean that we reject the legitimacy of doing expert study commissioned and funded by non-academic programs as a matter of principle. Indeed, many critical academic publications are based on empirical data that derive from submissions to calls for tenders and institutional orders for expertise (Gardella and Fossier, 2009). Nevertheless, our research in relation to both technological-oriented fieldworks was already funded by public research grants and we did not need any other funding. Furthermore, we did not want to run the risk of having to alter our research design and, more generally, our academic freedom because of financial incentives and related contractual rules; not to mention any apparent or actual conflict of interest to be accounted for.

This position has not raised any particular problems in either case, they probably saw us as either free labour or not useful enough to be paid. However, in other instances, representatives of responding institutions insisted on paying and even on setting a financial contract as an initial condition of possibility for conducting the research. We interpreted this request as a test at best - along the lines of "first please do this funded and preliminary study and we will see if you are serious and trustworthy enough to get further research access" - or, at worst, as a way to have a scrutiny right on the research design, results and (non) publication avenues. In such situations, we reiterated that our research demand was in no way financial, with the underlying idea that we were not their consultants but scholars by profession who were ultimately dedicated to writing and publishing worthy and independent scientific papers. In one specific case, it resulted in this reply by e-mail: "This is not a context of consultancy services but a specific framework for academic research. We will not reinvent the wheel. Basically, if you disclose any confidential information, we will sue you!" (e-mail). In another case, the discussions (and research process) ended at this stage. Although the ethical issue at stake with money was settled in both technological-oriented research projects, we still had to draw the line between academic collaboration and consultancy-oriented configuration. Indeed, we were still accountable for delivering the two above-mentioned "direct benefits" for the responding institutions, e.g. regular oral presentations and a final report

\section{Academic freedom in the face of extra-academic accountability relations}

First, with reference to oral presentations during the fieldwork, we kept ourselves to short and descriptive communications in front of executive committee members about broad trends (never individualized to protect the participants who were also their subordinates) on the basis of our interviews and ethnographic observations. For instance, in connection with the police body-worn camera pilot project, we made presentations about the evolving opinion of the equipped police officers throughout the pilot-project (pro/against/uncertain and why; anticipated and unexpected effects of the camera on police work and interaction and so on). Regarding accountability, we clarified that we were responsible for giving account of our research actions as knowledge producers aiming to analyse and make sense 
of the situation in and on the field, and not recommendation makers trying to show what the situation should be. In this regard, the executive committee members got used to expecting general feedback on the evolving representations and practices of the equipped street-level agents. Consequently, we became one source of information among others in the management of the pilot-project, with two significant consequences for us. On the one hand, although our role should not be overestimated, it became clear very early on that we were constitutively part of our research object and we had to be reflexive on this. On the other hand, our regular oral presentations during executive committees also formed "audit rituals" (Neyland, 2018) in our accountability relation with the responding institution. Indeed, these presentations became "part of an ordered temporality of repeated assessment" (Neyland 2011: 846) of our commitments and the related "direct benefits" for the respondents. In this respect, it happened that (interviewed) street-level police officers were invited to executive committees. As a result, we had to manage two accountability relations at the same time, e.g. one with the executives of the pilot-project who gave us access to the field-research (in exchange for being included in analytical feedback) and one with the street-level agents who perceived us as intermediaries accountable for voicing their critique to their executives without fear of reprisal. Paradoxically, it is precisely the tension-balance between this dual accountability that helped us to manage our ethical dilemmas and find our academic position as neither secret informants to the executive committee nor official spokespeople of the street-level officers.

Second, we had to clarify the format of the "final report for internal use" we were accountable for. The police service (with quantitative analysts) also prepared a report for a public consultation on whether or not to move forward with body-worn cameras in light of the pilot-project results. The first suggestion of the pilot-project supervisors was to merge our writings with their homemade report. We successfully negotiated that our own writings should stand alone as a separate report, at least for two reasons. First, we argued that it was central to maintain a critical distance from the pilot-project, as it was partly why they accepted having us on board in the first instance. Second, we argued that it was also a relevant way for them to publicly show their openness through collaboration with independent researchers. As a result, we wrote a separate 45-page report on the main outcomes of our one year-fieldwork, with a general overview of the wide array of issues that emerged from interviews and ethnographic observations. Each issue was briefly described and illustrated by representative quotations from interviewees and it was not associated with any sort of recommendation. As agreed, our report was made available to the pilot-project supervisors who were free to use it for internal reflection. Writing a separate report does not mean strict separation from the responding institution. In fact, their own report referred to many quotations from interviews and insights that were included in our document and, in contrast to a single merged report, they had to mention their source and quote us as a separate publication every time. Consequently, we appear as a distinct source, we wrote alone, we did not contribute directly to their report and we cannot be 
held accountable for their conclusions. The context specific ethical issues at stake between fieldwork access, academic freedom and accountability relations with responding institutions has been an on-going source of critical reflexivity, if not a research object on its own.

Last but not least, project-related academic publications were also a significant and increasing discussion point, especially after the submission of the report for internal use. While we had made it clear since the beginning that our aim was to publish scientific articles, a critical question popped up at the end the project, in addition to confidentiality and anonymity issues. Officials from the responding institution wanted to know if they could get access to the papers before publication. Such a critical question at a highly delicate moment was resolved with a "yes but" answer. Based on previous modus operandi negotiated by one of us with other units of the same police service, we agreed to send the article before publication but right after its acceptance in a peer-reviewed journal without any possibility to modify the content. While it was critical for us to avoid any form of direct censorship, we argued successfully that such advanced access to the articles was still valuable for them, especially in order to have time to prepare a considered response in case of journalist questions about research results.

One might note that such informal agreement on publications does not necessarily solve all of the ethical dilemmas related to academic freedom. For instance, early access can still lead to some elements of pressure or self-censorship. In practice, however, we have found that such an existing risk of self-censorship can become an opportunity to avoid a classic trap for social scientists, including critical security scholars, e.g. over-interpretation of research findings. Indeed, writing an academic article and having in mind that it will be read within the responding institution can be helpful to resist "interpretative dropout" (Lahire 1996). Here we refer to a common form of over-interpretation when academic writers put forward general thesis and arguments without sufficient data to support them. To avoid this trap, as researchers, we should ask ourselves whether we can confidently defend our results and interpretation in front of research participants on the basis of our empirics. To be clear, this trick of the trade is a sort of mental gymnastics to practise during the writing process. It does not imply that you need to seek comments or assessment from research participants. In other words, it differs from the proponents of "member checks" who consider that respondents' feedback and agreement on research findings enhance their credibility or validity (Guba and Lincoln 1985; Thomas 2016). If respondents would have the legitimacy and the right scientifically to decide what is "good" or "bad" interpretation, they would participate in thesis juries, peer-review processes and so on (Lahire 1996). Nevertheless, having them in mind throughout the writing process forces us to raise questions that are at the core of scientific work and ethics: do we have enough data and can we provide empirical evidence in support of our arguments? In light of our fieldwork, do we go too far in terms of generalization? From this perspective, having your respondents in mind is also a relevant way of both thinking and acting accountably to your primary audience, e.g. your peers from the "scientific community" 


\section{Ethical dilemmas in the research field}

How to negotiate the dynamic tension between us as academic observers and us as citizens in the field during ethnographic observation? This second section aims to account for ethical dilemmas emerging from unexpected events that may occur in the midst of ethnographic observations with security actors.

If human relationships bring the issue of ethics to the forefront in conducting fieldwork, the researcher's ethical accountability goes beyond the individuals from the responding institutions. It addresses more globally what we could do in the course of social actions in the research field with people holding different and changeable roles, expectations and positions within context specific situations (e.g. suspects, witnesses, observers and so on). As social actors, researchers might be confronted with conflicting ethical dilemmas in situations that, on the one hand, challenge their beliefs and principles as a citizen, a parent, a member of the public, but also, on the other hand, might interfere in their professional tasks and research ethics as an observer, rather than a judge, of those they are observing. When confronted with an extraordinary and unscripted situation, what are the elements researchers should have in mind that might help guide their practice of ethics in the immediacy of the process? At the risk of stating the obvious, as widely shown by the anthropological literature (Aull Davies 2008; Driessen 1998; Monsutti 2007; Rabinow 1988; Tillmann-Healy 2003), the critical question of ethical principles regarding proximity with research participants in the field and, more broadly, the sensitivity of ethnographic fieldwork is not unique to secrecy and security environments. However, observing secretive security practices may add new elements, especially in connection with any person in a position of public authority with coercive means such as police officers who also need to be accountable to us, not as researchers but as members of the general public. Again, our objective is not so much normative, rather it is in sharing thoughts about the complexity of accountability relations based on research experiences. We will first describe two research actions that raised ethical issues, before discussing them in more detail and then generalizing our point in terms of ethics. The following examples are drawn from observations collected by one of the authors in two neighbourhood precincts during fieldwork on police body-worn cameras.

\section{Example 1 - looking after suspects' relatives}

On one observation that occurred in April 2016, at a neighbourhood precinct, and just after the 'fall in', ${ }^{1}$ I am introduced to the team I will be riding along with for the next eight hours. It is composed of two female police officers (Cindy and Cathy). ${ }^{2}$ As they pack their gear, I put on a jacket with a label mentioning my status as an observer. I also sign the disclaimer form stating that the police organization will not be accountable should anything happen to me (accountability is not always a two-way relationship...). Then, they shortly brief me on the first assignment. A suspect in a jewellery store robbery case got arrested the day before and, while he was 
being put in custody, he told police officers that he was living with his 80 -year-old father and is worried that he is alone at home without enough resources. Thus, the officers are going to check that everything is $\mathrm{OK}$ with the old man and inform him about his son's situation and arrest. As we are driving, the two partners exchange words about a private matter. I am surprised they talk so openly about their private life, thinking that my presence would dissuade them to do so. A climate of confidence seems to prevail and the distance between us is smaller than I expected. We then pull off at the given address and once Cindy communicates our position and the nature of our intervention to dispatch over the radio, we get out of the car. Cindy is on the lookout and I understand that the mission has started already. Then Cathy knocks on the door of the building and, as they are waiting, they wonder whether they should start their body-worn cameras or not. After a short discussion, they both agree to leave them off as the situation is not an emergency nor seems to present any danger for their security. The door remains closed and Cathy knocks again, harder. Finally, the old man comes to the door and greets us.

The two officers introduce themselves and state the reason for their presence. They ask permission to be allowed in the house and the three of us go in. The man, who does not seem to be preoccupied by my presence, invites us to come to the kitchen to talk. Once in the kitchen, Cindy and Cathy alternatively ask questions about the man's situation and whether he knows what happened to his son. They all have difficulty understanding each other. They also ask him if he has relatives besides his son, so they can contact them and make sure he won't be alone. The officers take notes on their pads. All of a sudden, while the discussion was developing, one of the doors we passed in the corridor opens and a loud noise - that I realize after one second is a dog - is followed by a strange spectacle. While our focus is on the small dog coming at us barking (yet clearly not threatening) a form comes out of the door and falls on the floor screaming and making us all jump. A woman in a nightgown lies on the floor after stumbling on the carpet. She immediately gets back on her feet, pulling in the tails of her dressing gown. After making sure she is $\mathrm{OK}$, the two police officers ask her who she is and what she is doing there. The 50ish-year-old woman says she is the son's girlfriend and is there to take care of the father. Considering how she is dressed, a certain ambiguity sets in about the true nature of the relationship between her and the old man, yet nobody asks. The conversation is strange, and the woman is not able to provide clear answers to genuine and simple questions as if she does not understand the conversation. I can see that the officers are not satisfied with the answers they get from either the old man or the woman, yet, since they are not suspected of any violation, there is no justification in pushing the questions further. As the conversation goes on, I start to look around and I realize that the main door has been forced and is broken. The prop on the lock side of the door is broken, clearly revealing that the door has been forced open. The two police officers have not noticed it.

I am wondering: should I mention it to the officers? Should I thus become a participant observer (Spradley 2016)? Since mentioning it will unquestionably transform the situation, aren't I overstepping my role as an observer, while becoming a 
participant? On the other hand, as a citizen who should account for one's actions, what could be the consequence of my silence in terms of the old man's security, in the context of the current uncertainty? I decide to tell the officers, but will not interrupt them while they are still questioning the two people and trying to get enough information as possible on the situation. Finally, the officers decide it is time to leave and as Cindy moves closer to me, I discreetly tell her that the door is broken and invite her to have a closer look at it. She acknowledges it secretly - another original demonstration of secrecy in security practices - and waits a few seconds before raising it in the discussion with the two people. The old man explains police officers broke the door the day before suspecting the presence of the son's stolen goods. This raises the ambiguity to a new level and the perplexity of the two police officers even more. They look at each other and both of them realize there is nothing more they can do since their mission is a routine visit and no one is suspected of anything. But still, I can feel their scepticism and the visit ends with no closure, leaving a kind of fog over them, us.

\section{Example 2 - a visit with a plaintiff after an intervention went wrong}

The second example is also drawn from a ride-along with a neighbourhood precinct, this time at night, in a different neighbourhood. It concerns just one episode in a rather busy shift. As I get in the sergeant's car I understand that we have to visit a person who filed a complaint against a team of male and female police officers the night before. At this point, it is important to explain that every time a citizen files a complaint against a police officer, his immediate superior, the sergeant most of the time, has to contact and meet with the plaintiff to file a proper report. Consequently, the sergeant has to find a moment to meet the plaintiff. In the present case things looked complicated, as the plaintiff does not seem to be reachable directly, by phone or text message. So, in a moment of respite, the superior decides it is time to meet the plaintiff, on Monday night, past midnight. We arrive in front of the plaintiff's address and two police officers I have met during the fall-in are already there. I understand that the two officers are actually those against whom the person has filed a complaint. The sergeant and the two officers enter the apartment building. They ring at the door and the officers stay further back. I stay at a distance from them, not to interfere in the procedure. From my position, I can see the sergeant and the officers, and I can hear the plaintiff without seeing his face. He will stay in his apartment and at no point will he see me.

At this time, I have no clue as to the complaint filed against the police officers and I will only learn about it once the scene is over. Yet, for the sake of the presentation, it seems appropriate to explain it now. The night before, the officers responded to an emergency call of a woman screaming in a suspected domestic violence episode. As they arrived at the apartment building, they could hear the screams but had difficulty to identify with precision where they were coming from. They explained that the screams were loud and particularly preoccupying, making their own stress and adrenalin level 
rise and demanding an urgent intervention. After a few seconds, they identified an apartment on the first floor as being the source of the problem and rushed into the building. After knocking on the door, a man - the plaintiff - finally opened it, wondering what was going on. As he questioned the officers, one of them put him on the ground to neutralize him, while the other started to search the apartment. The officers realized they were in the wrong apartment since no one else was there, but also because they could still hear the screaming in the building. However, while being forced to the floor the plaintiff hurt his head and received no apology from the officers who then rushed out in the emergency. This was the reason for the complaint.

The sergeant introduces himself and the reason for his presence. The tone is polite yet firm. The visit has clearly woken the plaintiff up and it takes a few seconds for him to gather his thoughts. During the first seconds of the encounter, the two police officers remain a few steps back but when the sergeant asks the plaintiff to tell him what happened the night before, they come closer and greet the man. He is now alone in the presence of three police officers (as he does not see me) and has to tell his version of the story. The two officers do not contradict his version, but add some element of context, such as the emergency of the situation, the on-going screaming and the fact that, according to them, he did not cooperate immediately while he was asking questions about what was going on rather than answering the officer's ones - justifying his neutralization on the ground. The officer apologizes for the head on the floor. The sergeant shows the plaintiff the forms he has to fill in and bring back to the precinct, where he will meet with him again. The plaintiff acknowledges and says he will think about it again, and the discussion ends there. Even though I can feel that it is a genuine incident, I do not feel comfortable in the whole situation and I am wondering: is it regular procedure to come to the plaintiff's door with the 'incriminated' police officers? How would I react should the person or persons (police officers) against whom I filed a complaint outnumber me at my door, at midnight on a Monday? What message does it send about the (im)partiality of the process to the citizen? And what about a visit in the middle of the night, as the plaintiff was clearly sleeping? As I raise the question about the presence of the two officers to the sergeant, he says that they have a right to defend themselves. I have no doubt about that, but is it the right context, or the right moment? Moreover, what might the dynamics of the situation have been should I have come forward and into the sight of the plaintiff as a non-police representative? Would it have changed the balance of the situation, this time in favour of the plaintiff ... and against those I am supposed to observe and not interfere with?

\section{Reflections}

In concluding this section, we would like to raise a few practical observations and comments in relation to field research in the making.

First, as both examples reveal, social situations are characterized by a kind of 'fog', where actions, events and stories' dynamics are not all played on the same stage as the researcher. The stage is only a window on people's lives where actions happen without being self-evident and understandable upfront for those outside. 
Therefore, the participants, whether police officers or researchers, have to make sense of events based on the (lack of) information available in the here and now. For instance, in the first example, the police officers framed the old man as some kind of 'victim' and at no time was this status questioned. The same dynamics apply to the researcher in the interpretation of the situation. As an observer, his interpretations of the situation are not only based on his representations, but also on the relations and position he has with the other protagonists. In both examples, he aligned with the police's position. In the first case, he decided to step beyond his role of observer and mention the broken door, and in the second, he chose to stay back so as not to interfere with the sergeant's discussion with the plaintiff, although, as a citizen, he felt uncomfortable with the situation that could have been framed as a form of intimidation.

How to decide to step in or not, we realize, is linked to at least two elements that we need to account for. The first is the negotiation between the status, or identity, of the researcher as an ethical researcher, but also a moral citizen. Here,

[t]wo different norms, both claiming sovereignty over ethics in their own context of application, may clash when enacted together. Predetermined ethical systems cannot account for these ethical dilemmas, since it is the way that they related to each other in practice that creates the dilemma.

(Clegg et al. 2007: 112)

The second element is related to the degree of knowledge the researchers may have about the situation they are embedded in, especially in a security context. In the first example, both statuses of researcher and moral citizen aligned themselves and this alignment makes it easier to answer Hannah Arendt's question: Would I be capable, after all is said and done, of living with my actions? (2003). Indeed, having a dialogue with himself about how he acted, he feels comfortable about overstepping his role of observer by having mentioned the broken door to the police officers whom he however is not supposed to influence. Also, the type of assignment was key, being a 'social' mission rather than as a 'repressive' mission of the police, framing the police as a positive actor. Yet in the second example the answer to this question is different to the extent that the alignment between his role as both an observer and a citizen is not so clear. As an observer, he chose not to interfere with the situation, thus complying with a known principle of fieldwork. Yet the situation differs when we adopt the citizen's perspective on the situation. How to negotiate the status between observer and citizen in such cases? This is where the second element of the debate concerning the degree of knowledge the researcher has of the situation steps in, in our opinion. As indicated in the second example, he did not have a full picture of the situation before the encounter with the plaintiff. He did not know beforehand what happened and why the person filed a complaint. Overstepping his status of observer would probably be too much of a citizen-centred statement, raising ethical issues in terms of our integrity as a researcher in influencing a situation, while the situation had too many elements missing to clearly understand and thus had potential consequences for those who granted us access to the field. The fact remains that the management of this case 
in point is one of the most critical 'accounts' in our chapter as "statements made to explain untoward [e.g. uncomfortable] behavior and bridge the gap between actions and expectations" (Scott and Lyman 1968: 46).

\section{Conclusion}

"[A] crucial feature of everyday 'accountability sensitive' work is the identification of relevant audiences for the discharge of accountability" (Neyland and Coopsman 2014: 4). As many other practical activities, conducting empirical studies on security practices in secretive environments is ultimately characterized by the "messiness of accountability in action", with numerous ethical issues (Neyland, Woolgar 2002: 272). At first glance, to be account-able regarding ethics in critical security research would appear to be relatively simple and straightforward. As academic researchers, most of us must, first and foremost, be account-able to one very specific audience: the research ethics committees of our respective universities. In this respect, the first condition for the possibility of researchers to conduct studies on secretive security practices is to account for their research project in front of the appropriate research ethics board, e.g. to explain and justify the ethical nature of the precise strategy envisaged for data collection, processing and storage whilst being open to inspection and possible sanctions in case of deficiency at a later date. However, as shown throughout this chapter, the ethicality of our research expectations and actions is also put to the test in the face of other audiences, including the responding institutions, the research participants as well as academic peers and readers more generally to name just a few. In other words, account-abilities about research ethics also derive "from the ability of other members to assess and make sense of [our] actions in a [research] context" (Neyland 2016: 55).

Moreover, while standardized ethics codes provide a framework for and discipline on empirical research, the day-to-day conduct of qualitative studies in the field of security is fraught with ethical dilemmas that may defy such a codification. Most of these dilemmas arise from the tension-balance between accountability relations (with academic and non-academic audiences) and between norms of responsible behaviour (as a researcher, a private citizen and so on) that may conflict with each other at times during the research process, from fieldwork access to publication. From this perspective, instead of approaching the ethics of research through the sole and only lens of university-like certification and tutorial "best practices", this chapter is rather an invitation to further share experiences about critical security research ethics at work.

When ethics is something one does rather than something one has, then this "doing" [...] is enhanced by the opportunity for debate, discussion and plurivocal exchange and dialogue. The result is not unanimity with regards to ethics, but rather an ongoing questioning of the adequacy of the [scholars]' ethics in relation to the novel situations and contexts in which [they] find [themselves]. 


\section{Suggestions for further reading}

- $\quad$ Stephane J. Baele, David Lewis, Anke Hoeffler, Olivier C. Sterck and Thibaut Slingeneyer (2018) "The ethics of security research: An ethics framework for contemporary security studies", International Studies Perspectives, 19(2):105-127.

- Kevin Haggerty (2004) "Ethics creep: Governing social science research in the name of ethics”, Qualitative Sociology, 27(4): 391-414.

- $\quad$ Shane Mac Giollabhuí, Benjamin Goold and Bethan Loftus (2016) "Watching the watchers: Conducting ethnographic research on covert police investigation in the United Kingdom", Qualitative Research, 16(6): 630-645.

- Ian Shaw (2008) "Ethics and the practice of qualitative research", Qualitative Social Work, 7(4): 400-414.

- James Sheptycki (2016) “'In there like a dirty shirt': Reflections on fieldwork in the police organization", pp. 343-358 in Georgios A. Antonopoulos (ed.) Illegal Entrepreneurship, Organized Crime and Social Control, Cham: Springer.

- Will C.van den Hoonaard (ed.). (2002) Walking the Tightrope: Ethical Issues for Qualitative Researchers, Toronto: University of Toronto Press.

\section{Notes}

1 The fall-in is the team meeting that occurs just before the police officers are dispatched to their respective positions and assignations for their shift. All updates are provided on what happened during the previous shift, such as the priorities of the day. Important information about the organization of the precinct are also provided.

2 These are pseudonyms in order to preserve their anonymity.

\section{References}

Amicelle, Anthony (2018) "Policing through misunderstanding: Insights from the configuration of financial policing", Crime, Law and Social Change, 69(2): 207-226.

Amicelle, Anthony and Vanessa Iafolla (2018) "Suspicion-in-the-making. Surveillance and denunciation in financial policing", The British Journal of Criminology, 58(4): 845-863.

Amicelle, Anthony, Julien Berg and Killian Chaudieu (2017) Comparative analysis of Financial Intelligence Units (FIUs) in Canada, France, Switzerland and United Kingdom, Brussels: European Parliament. http://www.europarl.europa.eu/RegData/etudes/ STUD/2017/598603/EPRS_STU(2017)598603_EN.pdf

Aull Davies, Charlotte (2008) Reflexive Ethnography: A Guide to Researching Selves and Others (2nd ed.), New York: Routledge.

Arendt, Hannah (2003) Responsibility and Judgment, New York: Schocken books.

Bennington, Geoffrey (2000) Interrupting Derrida, London: Routledge.

Bonelli, Laurent et Fabien Carrié (2018) La fabrique de la radicalité: Une sociologie des jeunes djihadistes français, Paris: Éditions du Seuil.

Clegg, Stewart, Martin Kornberger and Carl Rhodes (2007) "Business ethics as practice", British Journal of Management, 18: 107-122.

Driessen, Henk (1998) “The notion of friendship in ethnographic fieldwork", Anthropological Journal on European Cultures, 7(1): 43-62.

Eriksén, Sarah (2002) “Designing for accountability”, NordiCHI, October 19-23.

FATF - Financial Action Task Force. (2012). International Standards on Combating Money Laundering and the Financing of Terrorism and Proliferation. Paris: FATF. 
Gardella, Édouard and Arnaud Fossier (2009) “Avant propos: les sciences humaines au miroir de leur public", Tracés, 9: 5-18.

Garfinkel, Harold (1967) Studies in Ethnomethodology, Englewood Cliffs, NJ: Prentice Hall.

Hirschman, Albert O. (1970) Exit, Voice and Loyalty, Harvard: Harvard University Press.

Hood, Christopher (2014) "Accountability and blame-avoidance", pp. 603-616 in Mark Bovens, Roert E. Goodin and Thomas Schillemans (eds) The Oxford Handbook of Public Accountability, Oxford: Oxford University Press.

LaFollette, Hugh (ed.) (2014) Ethics in Practice: An Anthology, Oxford: Blackwells (fourth edition).

Lahire, Bernard. (1996) "Risquer l'interprétation”, Enquête [online], 3.

Guba, Egon G. and Lincoln, Yvonna S. (1989) Fourth Generation Evaluation, Newbury Park: Sage.

Lynch, Mike (1993) Scientific Practice and Ordinary Action: Ethnomethodology and Social Studies of Science, Cambridge, UK: Cambridge University Press.

Mauger, Gérard (1991) "Enquêter en milieu populaire", Genèses, 6: 125-143.

Monsutti,Alessandro. (2007) "Le baiser de l'ethnographe : entre don de soi et usage de l'autre sur le terrain", pp. 23-35 in Suzanne Chappaz-Wirthner, Alessandro Monsutti et Olivier Schinz (eds) Entre Ordre et Subversion: Logiques plurielles, alternatives, écarts, paradoxes, Paris: Karthala.

Neyland, Daniel (2007) “Achieving transparency: The visible, invisible and divisible in academic accountability networks", Organization, 14(4): 499-516.

Neyland, Daniel (2011) "Parasitic accountability", Organization, 19(6): 845-863.

Neyland, Daniel (2016) "Bearing account-able witness to the ethical algorithmic system", Science, Technology, \& Human Values, 41(1): 50-76.

Neyland, Daniel (2018) The Everyday Life of an Algorithm, Cham: Palgrave Pivot.

Neyland, Daniel and Coopsman, Catelijne (2014) "Visual Accountanility", The Sociological Review, 62(1): 1-23.

Neyland, Daniel and Steve Woolgar (2002) "Accountability in action? The case of a database purchasing decision", The British Journal of Sociology, 53(2): 259-274.

Neyland, Daniel and Steve Woolgar (2013) Mundane Governance: Ontology and Accountability, Oxford: Oxford University Press.

Power, Michael (1997) The Audit Society: Rituals of Verification, Oxford: Oxford University Press.

Rabinow, Paul (1988) Un ethnologue au Maroc: réflexions sur une enquête de terrain, Paris: Hachette.

Scott, M. and S. Lyman (1968) "Accounts", American Sociological Review, 33(1): 46-62.

Scott-Jones, Julie (2016) Research Ethics in Practice, London: SAGE Publications Ltd.

Smith, Bruce (1996) "The Accountability of Science", Minerva, 34(1): 45-56.

Spradley, James P. (2016) Participant Observation, Long Grove: Waveland Press.

Strathern, Marylin (ed.) (2000) Audit Cultures: Anthropological Studies in Accountability, Ethics and the Academy, New York: Routledge.

Thomas, David (2016) "Feedback from research participants: Are member checks useful in qualitative research?”, Qualitative Research in Psychology, 14(1): 23-41.

Tillmann-Healy, Lisa M. (2003) "Friendship as method”, Qualitative inquiry, 9(5) : 729-749. 


\title{
17
}

\section{MATERIAL GUIDES IN ETHICALLY CHALLENGING FIELDS}

\section{Following deportation files}

\author{
Lieke Wissink ${ }^{1}$
}

- Research objective: This chapter will help social science researchers who use ethnographic methods in their practice-oriented research. Practice-oriented research is understood here as research where a research population does not form the central focus, instead the focus is on a practice that is mobilized by various actors who become part of the research given their relatedness in this practice.

- Research puzzle: This chapter focusses on ethical challenges that arise in such practice-oriented fieldwork due to the tendency in ethical guidelines to focus on research populations as a singular actor. This makes "textbook ethics" incapable of addressing differences between ethical needs of the various actors involved in a practice. This difference is especially the case if a researcher manages to get behind closed doors during fieldwork and such challenges were unforeseen during research design. This chapter therefore addresses the gap between pre-fieldwork ethics, or "ethics in the books", and ethical dilemmas that practiceoriented ethnographers encounter in the field.

\section{Introduction}

How do daily bureaucratic practices manage to make a deportable person? This was my empirical question during my ethnographic fieldwork in the Deportation Unit of an Immigration Office. ${ }^{2}$ Here, contemporary deportations are carried out in a highly bureaucratized process where the work is extensively divided. For a deportation file to present a legalized deportation many different little steps are mobilized where various actors with different skills and authorities are involved. This makes it impossible to become familiar with the development of deportation cases by staying put in one setting. Bureaucrats, my initial research participants, stuck mostly to their desks while adding their small bit to the file's trajectory. So instead of focusing on bureaucrats as my research population, to get a sense of the deportation process 
as a whole I followed the deportation file and observed the practices that unfolded around it. I did so for six months in the year 2016 during which time my fieldwork proved to be a fruitful soil for ethical dilemmas. Dilemmas that were not covered by the ethical guidelines in my research design but weighed heavily on me given the high political, financial, and in particular human costs involved with deportations.

In this chapter I highlight how research ethics as perceived in the phase of research design fell short whilst I was on my fieldwork. The reason for this shortcoming is twofold. First, the ethical dilemmas I faced were unanticipated due to the securitized environment where deportations take place. Access difficulties and the obfuscation created by the file's dispersed trajectory made it hard to anticipate beforehand what I would encounter. The second reason is related to my methodological choice to focus on file-work as a practice rather than (the motivation of) people. In attending to a practice, a network of multiple actors involved became visible rather than a singular research population. But the ethical guidelines in social science methodology handbooks that I adopted in my research design were formulated in an actor-centered manner. This caused a misfit between ethical guidelines and fieldwork practice since the uniform and bounded actor to whom these guidelines were directed did not exist in my field. Hence the at times conflicting ethical needs among several research actors, enforced by the unequal distribution of power between bureaucrats and deportees, were similarly missing in ethical guidelines.

To learn from this experience, I aim to stir a discussion about the gap between ethics in the phase of research design that is mostly inspired by "textbook ethics", and ethical dilemmas that an ethnographer encounters in the field. I firstly share the dilemmas faced during my fieldwork in the Deportation Unit. The thoughtexperiment that follows serves to further illustrate the gap between textbook ethics and ethics in the field. Then I discuss the challenge to prepare for ethical dilemmas in a field where practices remain hidden until you get to them. Thereafter I show how the actor-centered character of ethical guidelines makes them not necessarily useful when using practice-oriented methods. The question thus becomes how to rethink ethics so that they support a practice-oriented ethnographer to make ethical decisions when embedded in ethically challenging fields.

\section{Clean hands? Losing innocence on fieldwork in the Deportation Unit}

- $\quad$ Ethical dilemma \#1: Participant observation and involvement in the field.

I followed deportation files from the moment that the police presented a potential deportee to the Immigration Office's Deportation Unit, to the identification of a deportee's nationality in order to obtain travel documents from the embassies, to the preparations of an eventual flight. Although my main ethnographic method was "participant observation" by being present on the work floor fulltime, I was adamant not to actively participate in the deportation process. This meant that I avoided any contribution from my side to the development of deportation files. Keeping the ethics of my research in mind I felt obliged to uphold such moral 
integrity even though this sometimes came at the expense of social acceptance in the field. For example, if someone took the time to guide me through every tiny step in their work and they would ask me to copy something for the file, I would refuse by explaining I had to stay out of the actual practices in order to maintain a strict dividing line as a researcher. Although this seemed to be accepted, I could not deny that, despite my efforts, my embeddedness in the field actually did change the practice I attended to.

I remember sitting next to a bureaucrat, Abigail, ${ }^{3}$ whose work I had followed that morning. Meticulously following every step, I hoped to better understand the file's trajectory. At a certain point though I got confused and asked her why she did not tick a specific box in the file she was working on. She hesitated and took some seconds to think. Then Abigail replied: "Indeed, you are right, it has to be marked! That would've been an administrative mistake otherwise!" I thus had unexpected influence on the completeness hence future development of this file. Whereas such influence from my side on the file happened accidentally, I had restless nights about the extent to which I carried an ethical responsibility for actively intervening in a deportation file's trajectory. The knowledge that became accessible to me by being present inside the Deportation Unit could influence individual deportations if I took this knowledge outside of the Immigration Office to make it accessible to a lawyer or NGO, for example.

- Ethical dilemma \#2:What to do when being witness to the bureaucratic art of cheating in legal practice.

During a training for new functionaries in the Deportation Unit that I attended in my first days, a senior functionary called Evelyn had repeatedly emphasized the importance of checking the completeness of a deportation decision in the files. If it is decided that a person arrested by the police will be detained in order to eventually be deported, the potential deportee has to be informed about this, which is then confirmed with a signature on a legal document stating that the person is detained with the prospect of deportation. This legal decision has to be "signed" within 24 hours of the arrest. Evelyn emphasized: "This is very important. Make sure you do it right. Otherwise we will have to release them on the basis of an administrative mistake." From the examples that she showed us in running files it occurred that the potential deportee is not always the one who signed. Evelyn explained that the decision may also be signed by the functionaries themselves by stating "refusing to sign", so that "for us, it is signed nonetheless".

However, it still happens that a functionary further down the process discovers that there is no signature nor a "refusal to sign" indicated on the decision in the file. Kevin, a colleague of Evelyn, shared his view on juridical rules like this signature:

We cheat on little things that do not really matter to us. For example, if a decision for detention is not signed, well, for me that's a futility. But for a jurist it is not. For me however, that person is not unfairly detained. 
Kevin further shared his opinion that the current legal framework stands in the way of a fair system:

We will do a bit of cheating but well, I justify that for myself by . . . they cheat even more; with their endless asylum requests ... We get the feeling that there are too many rights, so many that we cannot do our job! According to the law, someone can file an asylum request up to ten minutes before departure so that means nobody can ever leave. So, we need to cross the line a bit because if we don't we will never succeed ...

\section{Thought-experiment: "is it ethical to continue fieldwork if . .."}

A few months after I came back from fieldwork in the Deportation Unit, I lectured in the same bachelor course on research methods that I myself had attended as a student. The students were asked to stand up and then I told them to sit down and remain seated if they would answer "no" to one of the questions I was about to ask them. The questions started with the following: "Is it ethically justified to continue research if ...", hence sitting down meant that the student considered the fieldwork transgressed ethical boundaries. The questions were:

\section{BOX 17.1 IS IT ETHICALLY JUSTIFIED TO CONTINUE RESEARCH IF}

1 Your participants act unlawfully?

2 These participants act from a position of power towards those who might be disadvantaged by these unlawful acts?

3 The unlawful acts by your participants potentially harm this disadvantaged group?

\section{Question 1: Is it ethically justified to continue research if your participants act unlawfully?}

Some murmuring and a little thinking time resulted in a handful of students sitting down. It is not uncommon for ethnographers to observe illicit or illegal acts by their research participants (see also Small et al. 2014). The protection of participants as an ethical rule mostly justifies not reporting these cases. To report illegal acts in these cases could seriously cause harm to participants. Think about a jail sentence, loss of income, or social exclusion. 


\section{Question 2: Is it ethically justified to continue research if these participants act from a position of power towards those who are disadvantaged by these unlawful acts?}

Now the murmuring intensified in the lecture hall. After all, early ethnographies that are as such part of a student's literature list mostly deal with respondents who might not quite stick to legal frameworks but who formed part of a marginalized group. Now that this question turns this relationship of ethnography with the marginalized versus the powerful upside down some turmoil went through the lecture hall but after consulting one's neighbors eventually about $80 \%$ of students sat down.

\section{Question 3: Is it ethically justified to continue research if the unlawful acts by your participants potentially harm the disadvantaged group over whom they have power?}

Adding "harm" to the situation does seem to make things easier. This comes as no surprise given the curriculum on research ethics wherein there seems to exist a consensus on the ethical "rule" that, at all times, harm to participants must be prevented. Without much deliberation, all students sat down indicating their opinion that it would be unethical to continue the research if unlawful acts of one's "powerful" participants might harm marginalized others.

Considering the thought experiment, none of my students answered yes to all three questions "whether it is ethical to continue research if ...".Yet, in my research, all given situations occurred: (1) bureaucrats knowingly cheated in legal practices, (2) they were doing so from a position of power in relation to those who might be disadvantaged by these acts, and (3) this influenced the possibility of an actual deportation which could be considered as serious harm. Was my research unethical? Not according to my ethical justification in my research design. Yet this was not reassuring since my research design failed to address the ethical challenges I faced. Hence, I explained my dilemma to my supervisors in an email with the subject "serious ethical challenges". The reply was that neither knew how to advise me but "to follow your own moral compass". Having run out of my sources for ethical guidance I was still highly confused and worried about what to do. Why was I not prepared for these ethical challenges I faced? My answer to this question is twofold: first of all, the ethical challenges themselves and their seriousness were unforeseen especially due to the secretive character of the field. Secondly, ethical guidelines are shaped around a singular actor whereby the broader network involved gets overlooked and therewith the relations between actors in this network, although conflicting ethical needs might be produced between them as well as differences in positions of power.

\section{Navigating access to a Deportation Unit}

One reason for being unprepared for the ethical concerns that arose in the field is that the Deportation Unit appeared to be such a closed off environment that 
it was impossible to get a taste of what to expect behind those closed doors. The Deportation Unit as part of the Immigration Office cannot be entered unless one is an employee or registered guest who is accompanied throughout the visit. Even bathroom visits require a personalized key card. That access had to be worked for was certain but there was no clear-cut trajectory on how to gain access for research purposes (see also Belcher and Martin 2013 and this volume). For about a year I worked on gaining access in a trial and error fashion. During this year the extent of access I would eventually obtain remained unknown.

I approached local organizations, academics, policymakers, and collectives formed by undocumented migrants through emails, phone calls, events, and visits. I also studied annual reports and deportation statistics from the Immigration Office, followed news related to the subject through different media outlets and worked on my local language skills. Through the wide network I had built, after some months I joined a lawyer during his consultation hours at an NGO supporting those with immigration issues. Here I learned crucial terminology like the relevant legal articles and orders and their abbreviations on the work floor. To make oneself knowledgeable of the appropriate terms is also key. For example, the term "deportation" is not considered neutral but understood as a term used by opponents of deportation. Instead, "removal" is used within the Immigration Office.

On some rare occasions I managed through my contacts to schedule a coffee appointment with an immigration officer but some days later these meetings would be cancelled due to a supervisor who did not give the required permission. Hierarchy, I learned, was crucial in this state institution. Then, over drinks after a lecture organized by an association for international relations that I had attended for networking purposes, I was lucky to meet a rather high-ranking official. He was kind enough to use his old boys' network to forward my contact information directly to the director of the Immigration Office with the request for a meeting. Soon after, the personal secretary of the director contacted me to schedule a meeting at the director's private office. The gigantic room with a stunning skyline view was cheered-up by scale model airplanes and a desk loaded with stacks of paper. We endlessly talked about the national deportation rates, why annual figures differ drastically at times, which legal articles or measures smoothen or obstruct the process, and the differences between neighboring countries - subjects and figures I became familiar with whilst preparing my fieldwork.

Last but not least, the conversation went rather smoothly as I was not primarily interested in bureaucrats due to my methodological choice of following file trajectories. The former approach is more common in bureaucracy studies. Think for example about Arendt's analysis of the "banality of evil" (2006) or Herzfeld's "production of indifference" (1993). Both these studies aim to solve the puzzle of how ordinary individuals can become involved in extreme practices. The answer is sought in the machinery that a bureaucracy becomes through the acts of multiple individual bureaucrats. Although my findings do not necessarily contradict this answer, the puzzle that I aimed to solve was not focused on bureaucrats but the technicalities of the work. This enabled our conversation to move away from initial 
normative judgements around questions like "how can one possibly execute this policy?" Such questions easily create dichotomies in politically loaded topics like deportation. Not long after our conversation the director granted my request for an employee badge, which also served as a key. I was also provided with my own desk within the Deportation Unit. For the six months that followed I stuck to a nine to five office rhythm being present fulltime on the work floor.

\section{Lost in a beehive: obfuscation behind closed doors}

Soon after I received my key card I realized that I did not have full access yet. As a newcomer it was impossible to make sense of what was going on around me. Behind the closed doors of the Deportation Unit I had to get beyond the obfuscation inside created by the complicated, scattered and constantly changing trajectory of deportation files. Gaining access to the Deportation Unit did not get me beyond this obfuscation; access still had to be worked on in matters of transparency and visibility. Hence what a fieldworker might observe or - even more ethically challenging participate in given the non-transparent character of the field remained open questions during the fieldwork let alone in the phase of research design.

The deportation file was my methodological guide offering unique insights into the webs of this bureaucratic process of file making. Following the file I obtained a different visibility from others "inside" whose whereabouts were mostly determined by the careful division of work in the procedure. The productivity of such partial visibility inside is also related to the secretive character of the field. Security thus exists not only through closed doors, but also in matters of legibility or transparency. The whole of the bureaucratic process towards deportation remained rather invisible to bureaucrats who were only involved with fragments of it. Therefore, it seemed not so much the case that "transparency was often feared because it could be the source of public embarrassment that would reveal internal incoherence" (Belcher \& Martin 2013). Rather, this internal incoherence was invisible to bureaucrats themselves as well, hence it being revealed could not be feared. Staying put in their own sub-units, for bureaucrats their work made sense within that limited space. It is exactly the division of work, and the obfuscation of cohesion between the work as a result of it, that eases a continuation of the work. The single units themselves functioned in a coherent fashion. For a procedure to be considered as incoherent, the relation between these single units has to be envisioned. Exactly this whole is obfuscated in a carefully divided bureaucratic practice.

Bureaucrats were self-aware about their partial vision caused by the division of labor. In a conversation I had with Aaron, a senior bureaucrat, he said:

My disadvantage is that I am in the middle of this forest which makes that I cannot see the trees anymore. You come from outside and can say, "oh what is happening here" but once you are in the middle of it . . . all the different units . . . like a beehive. Bzzz. Last week someone called and asked about 
whom to contact about this residence permit . . . and I honestly admitted

"I don't know!" It is all changing so fast in here, so rapidly, and there are always these exceptions.

Aaron highlights an invisibility that means it is not possible to recognize incoherence. For to recognize incoherence, a certain degree of visibility is needed to get a sense of the existence of a whole, a forest to borrow Aaron's comparison, rather than there to be merely singular trees. The partial visibility Aaron points to is inherent to bureaucracies because the division of labor produces obfuscation and thus also disguises possible incoherence for insiders.

\section{Actor-centered ethics and practice-oriented methods: "textbook" stances on ethics}

What I learned about ethics during my studies is that despite there being several stances on ethics they share certain basic ethical principles. In his classic social science research methods book Bryman shows how these principles are formulated around four main topics: a lack of informed consent, invasion of privacy, deception, and causing harm (2004: 509). The shared aspect of these ethical concerns is that they are all organized around the interest of the main research participant as a uniform, bounded actor who is the focus of these ethical boundaries of protection. So, the second factor of the gap between ethics in the books and ethics in the field that I aim to highlight, is that "textbook" ethical stances are actor-centered, presuming the research participants to be the center of ethical concerns. Staging the research participant here as the central actor these principles pose challenges for practice-oriented research where a relational network hence multiple actors form the research focus rather than a bound off population as a clear singular actor.

\section{The myth of "the" research participant}

Rather than the motivation of bureaucrats to execute deportations I was interested in how the file mobilizes practices for it to develop into a deportation case. I joined individual bureaucrats behind their desks but the file also brought me to court, to detention centers, to canteens, police trainings, fingerprint machines, embassies, databases, cocktail parties, (inter)national meetings, and bureaucratic trainings. Just like research populations not necessarily being marginalized communities any longer, it is also not obvious anymore (if it ever was) that participants are considered to belong to one specific group in the way it appeared in more classical ethnographies (Malinowski 2013; Mead et al. 1973). Especially when focusing more on practices and the networks formed around them, the focus of the research is not so much actor centered as it is relational. As Annemarie Mol stated in her ethnography The Body Multiple: "To be is to be related" (2002: 53-54). Existence does not exist 
outside of relations. In this light a practice exists through the interaction between different actors, including material ones. These actors form a social network through their interactions and it is through these relations that a practice is made.

Take, for example, the daily practice of preparing deportations. The development of a deportation case comes about through the transformations of the deportation file. As such, the files are mutable mobiles (De Laet and Mol 2000). The file can transform exactly because of the acts and actors that become related through the file and produce a certain reality. "[R]ealities are created and enacted in many different locations, practices and relations, and the connections between them, and the coherence of what has been created, is not a given" (Asdal et al. 2007: 36). It is the file that assembles the many different acts and actors, that (partially) connects them with one another so that they form a network wherein deportations take place. Bureaucrats, police, signatures, transferring files from one place to the next, consuls, the fingerprint database, the plane, stamps, and so forth. My empirical question of how daily bureaucratic practices manage to make a person deportable is actually the question of how relations are built in the process of deportation.

\section{BOX 17.2 ETHICAL BOUNDARIES THAT PRESUME A SINGULAR ACTOR}

- Lack of informed consent

- Invasion of privacy

- Deception

- Causing harm

\section{Informed consent, deception, and privacy}

The bureaucrats were explicitly informed that my research was the reason for my presence. But since I was not only interested in their work but in the social life of the file, they took me with them on visits to other actors involved as well. In the beginning especially, I had no idea where I was following them to. After all, getting a sense of the deportation network was a matter of learning by doing due to the obfuscation of the process. These visits of me accompanying bureaucrats were exemplary of the many unknowns about, in this case, the trajectory of a file.

So, it happened that I attended meetings between bureaucrats and detainees awaiting their deportation in a detention center. Without informing me beforehand, the bureaucrat who invited me to come along introduced me to the security guards and the detainee as a colleague. The same goes for the police training I attended, or the visits to ambassadors that I joined with bureaucrats who hoped to arrange travel documents for detainees. This was to the benefit of my research in the sense that I would probably not have gained access to these external settings if I had 
had to ask the authorities at those settings for permission. But whereas bureaucrats were informed, there is no informed consent in the wider network. Giving the impression that I am a colleague might even qualify as deception. Moreover, the privacy of potential deportees was not always respected in the sense that I received confidential information on individual's cases.

\section{When harm is caused: considering relations of power when studying up}

Working as a bureaucrat in the Deportation Unit and as such being responsible for the implementation of administrative law, Kevin's earlier mentioned take on cheating can be seen as a form of discretionary power, or, as Aretxaga says, "the state in this sense is and is not the law" (2003: 405). This form of power is exclusively forwarded to authorities. Hence, I was troubled by my own pre-designed ethical guideline of protecting my research participants, whom I understood to be the bureaucrats when I designed my proposal. Between them and potential deportees an unequal distribution of power is at stake given their crucially different relation to authority. In fact, this power dynamic is made exactly in the relation between bureaucrats and deportees. The ethical consensus that research should not cause any harm to participants does not teach a researcher about degrees in the seriousness of potential harm done to different participants in one and the same network. Especially so if dichotomized parties participate in the research given their relatedness in the practice one researches. Interests of different participants can be opposite but nevertheless intertwined since they are mobilized in the very same network. Which actors involved in the network should then be prioritized when it comes to ethics?

Historically, ethnography was mostly a methodological tool for anthropologists commissioned by colonizing authorities. It has been argued that anthropologists in the 1980s turned their attention from these "others" to the "suffering" subjects closer to home (Robbins 2013; also Grassiani, this volume). Ethnographies tended to focus on marginalized populations or the underprivileged who typically needed protection from authorities. Take, for example, Bourgois' ethnography "In search of respect" (2003) wherein crack dealers form the research population. Here, Bourgois' concern of protecting research participants who cross legal boundaries lies in protecting them from authorities, mostly the police. But a phenomenon that was first referred to as "studying up" by Laura Nader in her article titled "Up the anthropologist" (1974) increasingly inspired social researchers. Nowadays, both anthropologists and ethnographers from increasingly varied backgrounds do fieldwork among the "powerful" rather than the "marginalized". Think about the police, the army, elites, state-functionaries, banks, and more (e.g. Garriott 2013; Aguiar \& Schneider 2016). When ethnographers extend their focus from societal underdogs to authorities, the question of how to reckon with the ethical treatment of research participants is cast in a new light. For example, does the ethical breakpoint of "harm to participants" always get priority over harm to others, even if those others are in a more vulnerable position than your main research participants? 
Within secrecy research in general it is often the case that a researcher is "studying up", which comes with fields that are generally hard to access due to their exclusiveness to the elite group in power. What can ethics teach us if the population over whom research participants exercise power, a population that forms part of the research too (through this relation with the research participants), is in an arguably "needier" position for protection than the main research participants? One could raise the valid ethical question to what extent ethical codes apply equally to a drug dealer or a police agent? But this narrows the question down again to two singular research populations whereas the answer should not be sought in two separate guidelines of how to treat a drug dealer and how to treat the police. The point is that these are not two separate questions. On the contrary, they are intrinsically related. The ethical question therefore becomes even more complex: how to apply ethical codes in research where both the police and the drug dealer, exactly through their relation with one another, are involved in the practice one researches?

Acknowledging the myth of the singular actor in practice-oriented research and recognizing the layered and varied networks of actors involved does bring up further questions about how to direct ethics. My earlier shared observations of bureaucrats' balancing between il/legality were shared by bureaucrats themselves. However, according to Kevin this is justified:

It is that feeling of, "they play it that way too", it's exactly like that: they cheat too. It's similar to a football match. If you are on the losing side, you can say "well, at least I do not make mistakes and I respect all the rules", but you will end up losing!

The "they" Kevin is referring to are individuals who Kevin and his colleagues in the Deportation Unit attempt to deport whereas the potential deportee tries to escape from deportation. I let his explanation sink in for a while before starting a follow up question: "But ... isn't your position somewhat different?" Kevin releases a mocking laugh "Ha! Well, nobody thinks that way of course. I won't be thinking like, I am in a power position. I am just thinking, I am simply doing my job”, "But why then do you immediately conclude that I referred to you being in a power position?" I ask Kevin. "Because of ... this prevailing idea that one should be professional when working for the government."

\section{Distribution of ethical concerns within relational networks}

In a football match both parties equally suffer or benefit from the same rules. That cannot be said about a bureaucrat and a deportee. A "loss" for one party comes with a completely different (human) cost for the other. Also, the privilege to play with the rules is not equally divided either. After all, endlessly requesting asylum abides by the legal rules of the "game" whereas cheating on a signature on a legal document does not. Opposite interests or ethical needs among research participants are often accompanied by unequal (power)relations (Lavanchy 2013). Thinking back to 
the protection of underprivileged participants like crack dealers, this ethical choice is based on a difference in power positions too. Namely, the human costs for a drug dealer who crosses legal boundaries to get arrested are not equal to a police agent who is unable to arrest a drug dealer. For that reason, it seems ethically justifiable not to report such activity. But what is more in practice-oriented research, is that if ethical codes do not apply equally to the various actors involved in the network, it is often exactly because of the unequal relations that exist between actors within the practice that is focus of the research. This further complicates a question of balancing ethical needs. It is not a simple weighing of what human costs weigh heavier than others because the action following this answer will unavoidably affect the ethical stance of the researcher towards other participants.

The needs of several actors within a network and the ways of protecting them are hardly ever homogenous. The network where the deportation process is shaped consists of bureaucrats, files, stamps, consuls, identification papers, representations of deportees, legal terms, political preferences, databases, judges, detention centers, transport services, diplomacy, and events that at first sight do not seem to have much to do with deportations like for example flight delays due to stormy weather. The network of research reaches further than only the actors in the direct environment of the field. A crucial question for ethical concerns then becomes where to "cut the network" (Strathern 1996). Which actors or practices count as part of the network enough to fall under the scope of ethical guidelines? Indeed, the people I surrounded myself with in a physical way were mostly bureaucrats working on deportation files. Deportees themselves were often only present in the process in a translated form, namely through the files. However, these files are very much part of the network that is formed in the deportation process. To what extent can deportees as the files' referent be considered participants too? And what to do if the ethical treatment of one implies the crossing of ethical boundaries for another? An obstructed trajectory of the file carries a totally different ethical concern for a bureaucrat than for a potential deportee. The same goes for protection needed in cases of legal cheating. In practice-oriented research, one could even take potential harm to a legal procedure or an infrastructure into ethical consideration.

New questions have to be addressed for research where the focus does not lie so much with a specific population (actor-centered) but more with a practice within a (relational) network. After all, it is the relationality between actors and the specific network that exists through these relations where file-work hence contemporary deportation can be done. "Textbook ethics" contains the assumption that it is clear who the subject of ethical concerns is. This suggests too that one peculiar (group of) actor(s) can be isolated from another. But networks are fluid, dynamic, and never static but constantly changing. Ethical guidelines therefore are by default "situated knowledge" (Haraway 1988). What we understand as an objective ethical boundary, shared by various ethical stances, is rather relative and mutable. It is context bound and depends on our own position within the network, on the relations of power involved, and on the transformations of these relations. For this 
reason, a practice-oriented researcher encounters an ontological miscommunication between one's methods - where the field is formed by practices that exist through relations, and one's ethics - where the field is formed by separable actors.

\section{Conclusion: relational ethics?}

Highlighting the friction between "textbook" ethics versus ethics in the field here is not an attempt to make fieldwork more ethical. It is an attempt to prevent ethics from becoming an empty promise that works to make a neat research proposal pass ethical boards but subsequently fails to provide guidance in the field. Therefore, stirring this discussion is an attempt to take ethics seriously. Ethics are dynamic rather than bounded or objective. Just like the networks in the field are constantly in-themaking, ethics has to be made in the field too in order to connect to the situations that occur in the field. This demands effort whereby the situated and relational character of ethics has to be acknowledged. Imaginaries of clear ethical boundaries stand in the way of such discussion and further increase the gap between textbook ethics and fieldwork ethical challenges.

These gaps between ethics in the books and ethics in the field are potentially intensified in fields with a secretive character where knowledge is so scarcely circulated, especially so when the fieldwork is practice-oriented. Besides the inability to prepare for ethical challenges due to the limited knowledge I could gather beforehand, I also encountered an ontological misfit between the ethical guidelines in my research design and challenges that arose once in the field. If the practices a researcher attends to are obfuscated, the relations formed in these practices cannot be foreseen let alone the ethical challenges they might produce. Moreover, the field is formed by a network of multiple actors whose relations and positions are constantly subject to change. Formulating ethics as if research participants are singular actors with equal needs is not sustainable. Burdened with the task to do the "ethically right", this imaginary weighs heavy on a researcher's shoulders. Dealing with different needs and positions of research participants, how does one direct ethical guidelines like informed consent, harm to participants, or invasion of privacy, if these mean various or even conflicting things for different actors?

Ethics in the field differs from ethics in the books. Rather than relying on clear ethical answers that fail to provide guidance in practice, ongoing reflection about unsolvable ethical dilemmas during fieldwork is crucial. How do we as researchers deal with the burden of (distributing) ethical concerns? What if one's research does transgresses "textbook" ethical boundaries? Is it possible to simply leave such a situation and if yes, is it clear-cut that it is more ethical to leave or stop the research rather than to continue such "unethical" fieldwork? Rather than producing prefieldwork ethical answers we need to raise ethical questions during fieldwork itself. This is to prevent ethical guidelines that sound solid on paper but become meaningless in practice. After all, the unpredictability of ethical challenges and the changing character of their boundaries in the field are a known unknown. 


\section{Suggestions for further reading}

- Diana E. Forsythe (1999). "Ethics and politics of studying up in technoscience", Anthropology of Work Review, 20(1), 6-11.

- Donna Haraway (1988) "Situated knowledges: The science question in feminism and the privilege of partial perspective", Feminist studies, 14(3): 575-599.

- John Law (2004). After Method: Mess in Social Science Research. London: Routledge.

- Marilyn Strathern (1996) "Cutting the network", Journal of the Royal Anthropological Institute, 2(3): 517-535.

\section{Notes}

1 This chapter is published in the context of the $\mathrm{PhD}$ dissertation of the author.

2 Given the sensitive information in the data, the location of the fieldwork is anonymized for protection reasons.

3 All the names in this chapter are pseudonyms in order to protect the sources.

\section{References}

Aguiar, Luis L. \& Christopher J. Schneider (eds) (2016). Researching Amongst Elites: Challenges and Opportunities in Studying Up, New York: Routledge.

Arendt, Hannah (2006) Eichmann in Jerusalem, Penguin Books.

Aretxaga, Begoña (2003) "Maddening states”, Annual Review of Anthropology, 32(1): 393-410.

Asdal, Kristin \& Brita Brenna \& Ingunn Moser (eds) (2007) Technoscience:The Politics of Interventions, Oslo: Oslo Academic Press.

Belcher, Oliver \& Lauren L. Martin (2013) "Ethnographies of closed doors: Conceptualising openness and closure in US immigration and military institutions", Area, 45(4): 403-410.

Bourgois, Philippe (2003) In Search of Respect: Selling Crack in El Barrio, Cambridge, UK: Cambridge University Press.

Bryman, Alan (2004) Social Research Methods, Oxford: Oxford University Press.

De Laet, Marianne \& Annemarie Mol (2000) "The Zimbabwe bush pump: Mechanics of a fluid technology”, Social Studies of Science, 30: 225-263.

Garriott, William (Ed.) (2013). Policing and Contemporary Governance:The Anthropology of Police in Practice. New York: Springer.

Haraway, Donna (1988) "Situated knowledges: The science question in feminism and the privilege of partial perspective", Feminist Studies 14(3): 575-599.

Herzfeld, Michael (1993) The Social Production of Indifference, Chicago: University of Chicago Press.

Lavanchy, Anne (2013) "Dissonant alignments: The ethics and politics of researching state institutions", Current Sociology, 62(5-6): 677-692.

Malinowski, Bronislaw (2013) Argonauts of the Western Pacific: An Account of Native Enterprise and Adventure in the Archipelagoes of Melanesian New Guinea [1922/1994]. Abingdon: Routledge.

Mead, Margaret, Anna Sieben \& Jürgen Straub (1973) Coming of Age in Samoa, London: Penguin.

Mol, Annemarie (2002) The Body Multiple: Ontology in Medical Practice, Durham, NC, and London: Duke University Press. 
Nader, Laura (1974) "Up the anthropologist - Perspectives gained from studying up", pp. 284-311 in Dell Hymes (ed.) Reinventing Anthropology, New York:Vintage Books.

Robbins, Joel (2013) "Beyond the suffering subject: Toward an anthropology of the good", Journal of the Royal Anthropological Institute, 19(3): 447-462.

Small, Will, Lisa Maher \& Thomas Kerr (2014) "Institutional ethical review and ethnographic research involving injection drug users: A case study", Social Science \& Medicine, 104: 157-162.

Strathern, Marilyn (1996) "Cutting the network", Journal of the Royal Anthropological Institute, 2(3): 517-535. 


\section{INDEX}

Aegean 56-7

\section{"A. N. Other" 136}

academic freedom 8, 276-7, 279-80, 282

academic integrity $17,20-3$

access: (in)accessibility 18, 83, 85-6, 114,

$188-9,225$; as a process $1,36,45,81-2$, $84-5,87,94,245,264,267-8,296-7$; as deferred or delayed $33-5,84-5,222-3$; to secretive organisations $29,40,44-5$, $81,83-4,87,94,264$; to (de)classified material 34, 213-17, 225; to lifeworlds $12,97-109$; documents for $84-5,92$, 166 ; gaining access as relational 2,124 , $143-5,150-1$, safe access $112-14$, 116-22; strategies for $6,45,90-1,93-4$, 109, 118, 121-2, 150-1, 154, 159, 239-41, 264, 277; see also encircling, Freedom of Information (FOI) requests/ FOIA requests, gatekeepers accountability 21, 36, 44, 48, 198, 218, 234, $237,243,274-83,288$

activism 20, 44, 104 232, 235, 244-6, 248-9, 251, 254-6

Actor-Network-Theory (ANT) 53-4, 180-2, 187, 193-4, 202-3, 205-6 advocacy 17-20, 37, 41-2, 245, 248, 251, 262

agency $19,81,83,104,148-9,163,165$, 193, 195, 198

Akrich, Madeleine 16, 53, 195, 203 algorithms 14, 16, 23, 175-84, 186, 188, 195, 197-202, 213; proprietary 1, 15,
179; racial bias in algorithms $175,177-8$, $180,183-4$

ambiguity $35,65,119,169,217,255$, 269-70, 275, 284-5

Amoore, Louise 14, 16, 23, 198-200 anonymity $20,22,81,85-6,109,115,170$, 196, 257, 259, 265-6, 268, 279, 282 anthropology 6, 92, 99, 149, 177, 198, 249-52, 254, 257-8, 283

apartheid 137

appropriation 200, 202, 170, 204

Aradau, Claudia 6, 8, 14, 15, 19, 34-5, 99, 198, 200

archival research $34,39-40,44,65-6,70-2$, 74, 131-2, 159, 188; see also Freedom-ofInformation requests arms export 231-35, 238-41, 245-6; see also arms trade

arms trade 20, 145-6, 231-2, 234-5, 239, 241, 245; see also arms export "arrival story" 8, 12, 82

Atomic Weapons Research Establishment (AWRE) 67-8, 71

authoritarian contexts 112-13, 115, 159, $162,170,231$

autoethnography see ethnography

BAE Systems 233, 242-44; see also arms export, arms trade

Balmer, Brian 6, 10-11

banks 16, 193-201, 203, 205-6, 208

barriers of secrecy 2, 7, 13, 15, 114, 119 
Biological Weapons Convention (BWC) 139-40

biometrics 175-8, 199

Birchall, Clare 6-7, 11, 13

black box 16, 175, 177-86, 188-9, 202; opening the black box 16, 177-80, 182-5, 187-8, 201; see also algorithms

blacked out text 136, 262

borders; border security 14, 49, 54-5, 58-60, 176; see also Eurosur; border studies 12, 50, 52; German-Polish border 81, 88-91

Bourgois, Philippe 6, 91, 300

bricolage 8,58

bureaucracy $12-13,34-5,44-5,64,71$, 80-1, 83-90, 92-4, 114, 220-1, 232-4, 244, 278, 291-3, 295-302

Campbell, David 1

Chatham House Rule 129-30, 134

citizenship 89

civil war 17, 101

classification 1-2, 5-7, 11-12, 14-15, 87, 113, 215, 233, 261; classified material 19, $33-4,45,65,68,85,122,213-17,222-6$, $233,265,277-8$

co-construction 59

Cobra Mist $67-8,71,73,75$

codification 23, 53, 269, 275, 288

Cohn, Carol 144, 150-2, 154, 200, 267

Cold War 63-4, 66-7, 70, 75, 144, 251

Coleman, Mat 36-8

"collateral murder" 215, 223

commercial security 145, 150; see also arms export, arms trade, privatised security

compliance 42, 194-8, 201, 203-4, 206, 244,266

concealment $6,10-11,15,45,129-30$, 132-3, 138, 140, 178, 181, 189, 218

Confidence Building Measures (CBM) 139-40

confidentiality $1,5-8,12,14,17,20-3$, 33-4, 39, 44, 55, 106, 109, 112, 124, 196, 199, 208, 223, 233, 261, 269-70, 275, 280, 282, 300,

conflict: (post)conflict settings 89, 108, 112, 116, 118-19, 124, 253, 257

consent 10, 20-3, 48, 139, 162, 170, 266, $268,275,298-300,303$

conspiracy theorists $73,220-1$; see also ufologists

controversy 5, 11, 13, 76, 104, 234, 240, 245,262 counter-terrorism 11, 16, 152, 233; counter-terrorism financing 193, 195 , 208, 263-6, 268-9, 277

courts 43, 52, 194, 215-16, 264-66, 298; court-martial 16, 213-18, 225

covert research 10-11,166

Critical Security Studies (CSS) 2, 4-6, 19-20, 28-9, 50, 97, 160, 168, 194-5, 225-6, 270, 282, 288

Critical Military Studies 6, 146, 152-3

critique 18-20, 144-145, 152-154, 232, 245-246, 251, 254-256, 267; feminist critique 149,221 ; cultural critique 251 credibility 118, 138, 207, 236, 240, 282

cultural anthropology 80; see also anthropology

Curtin, Deidre 12

dark web 216; see also WikiLeaks

data analytics 11

datafication 51

deception 71, 152, 155, 198, 298-300

"deep hanging out" 13, 99-101, 103, 109, 160

declassification 11, 63, 65-6, 70-1, 216; see also classification

deportation 291-302

Derrida, Jaques 6

design see follow

detention centres 2, 12, 39-40, 42, 298-9, 302; family detention centres 35,42 ; immigration detention centres 11-12, 34-40, 42, 101; see also security institutions; refugees; torture

“difficult terrain" 2, 9, 66, 80-6, 93-4, 113; see also bureaucracy

digital devices $16,175,182,184-5,187-8$, 194, 200, 202

digital security technologies $15-16$, 193-208

diplomats 134

disarmament 15, 129-30, 133, 136-7, $139-40$

discourse analysis $8,14,80,89,145,187$

disclosure 15, 19, 34, 36, 43, 45, 73, 129-30, 132, 134, 144, 149, 233, 243, 261-2, 267, 269-70;

(non)disclosure agreements 129-30, 133-6, 242, 268

discretion 20, 89, 121, 196, 206, 215, 242,300

disinformation 71-2

dissidents 21, 153 
document analysis $59,85,145,183,187$, $232,235-7,242,277-8$

"do no harm" 20-22, 151, 252, 275, 299-300

elite interviews see interviews

emergent technologies of state control 16, 213-15, 218, 222, 226

embodiment 14, 21-2, 34, 90, 109, 137, $165,167,255,263,265-8,270$

empathy 20, 139, 249-53, 255, 257-9

enactment $8,10,14,35,51,68,103,105$, 129, 165, 193, 200, 203, 265, 278, 287, 299;

re-enactment $13,106-9$

encircling 4, 7, 9, 14, 23

Enloe, Cynthia 147-9, 154

epistemology 8, 10, 28, 54, 153, 194, 217, 225

espionage 112, 119, 122, 171, 214; see also research

ethical security studies 19

ethics 109, 217, 224-5, 248; ethical dilemmas 7, 6, 99, 171, 194-5, 202, 205, 214, 226, 232, 261-2, 269-70, 278-9, 281-3, 287-8, 291-3, 303; ethical review 1, 20, 22, 303; research ethics 13, 17, 20-2, 143-6, 152, 199, 224, 249, 274-5. 278-9

ethnography $5-6,20,53,80-4,87-91$, 93-4, 144, 149, 152-3, 250-5, 257-8, 276, 280-1, 283; autoethnography 20, 132, 217-18, 220, 226, 262-3, 266-7, 270 ; insider 86,115 ; ethnographic interviewing 99, 103, 106-9; see also interviews; ethnographies of technologies 15, 177, 180, 183, 187-8, 195, 198, 200, 202-3, 205, 208, 213-14, 217, 226; multi-sited 193-6, 200, 208; practiceoriented 291-2; visual 15, 158-60, 165, 171

European Asylum Support Office (EASO) 55

European Union 20-1, 49, 55-6, 123; Commission 21, 49, 55-6, 58; Council 48; Parliament 48, 278

Europeanization 81, 83

Europol 55, 194

Eurosur 49, 51, 55-60

exemplification 133,138

experiment 167, 202, 292, 294-5; experimentation 202-6; experimental writing 15, 129-30,136, 139-40; sites of experimentation 34, 193-6, 202-5, 208 experts $168,183,186-7,196,201,204,237$, 240, 245; see also expertise

expertise 121, 187-8, 194-5, 240-1, 264, 266, 277, 280; inexpertise 15, 265; technical 16, 19, 175, 195, 198; see also experts

Facebook 176, 223

face detection 175-7, 183-4, 188; see also algorithms

feasibility of research 1,99-100,154, 183, 201, 203

feminism 15, 149, 154, 241; feminist critique see critique; feminist research $143-51,153-4,250$

fieldnotes 22, 37, 94, 123, 158, 160-1, 165, $171,206-8,215,225,261,270$

financial institutions 1, 195-7, 200-1, 204, 276, 278; see also banks

Financial Intelligence Units (FIUs) 197, 264, 276-8

fog 13, 285-6

following: actors 5, 50-1, 53-4, 56-60, 76; see also Actor-Network-Theory; files 23, 292-3, 296-7, 299; technology from design to use 16, 193, 195, 202-4, 208

(UK) Foreign and Commonwealth Office (FCO) 242-3

Foucault, Michel 51-2, 202

Freedom of Information (FOI) requests/ FOIA requests $6,12,33-4,39-42,44-6$, 72-3, 132, 136, 213, 215, 217-21, 225-6, 231-2, 236-7, 239, 242-4

friendship 20,119, 151

Frontex 55, 57

Galison, Peter 12, 64

gate $2,16,23,266$; gatekeepers $2,17-18$, $88-9,93,121,154-5,267$

Geertz, Clifford 81-2, 89, 99, 160

gender $75,90-1,100,113,118,124,143-4$, 146-8, 150-1, 153-5, 166, 176, 183, 241,263

glossing 134

governance $16,41,51,55,145,149,167$, $168,179,196,200,233$

Gusterson, Hugh 69, 76, 83, 85-6, 131, 145, $147,149-50$

Haraway, Donna 52, 57, 153, 264, 302

hotspots 18, 21, 49, 55-6; "hotspot approach" 49, 51, 55, 59-60

Horn, Eva 6, 10, 91

human-computer interaction (HCI) 8,16 , 193, 195, 198, 203, 205, 207-8 
humanitarian organisations $18,51,55,123$ human rights 114-15, 21, 231-6, 253, 258; see also international humanitarian law (IHL)

Human Terrain System (HTS) 84

Huysmans, Jef 5, 8, 34, 99

identity 19, 50, 124, 151, 155, 204, 241; collective 87; of the informant 123,129 , 154; of the researcher $113,143,162,166$, $250,254,256,259,263,287$

immanence $12,48-53,58-60$

immersion 5-6, 8, 12, 99, 115, 133, 140, 239-40; long-term 5, 160, 244

inductive research 217,250

informants $65,84-5,88,90-3,107-8,113$, $115,121,123,130-1,144,147,149,248$, $252,255,258-9,267-8,281$; see also gatekeepers, positionality

infrastructure $12,17-18,23,50-2,54-5$, 57-60, 63-4, 66, 100, 199, 302

inscription 6, 16, 34, 89, 180, 182, 196, 204, 264

integrity see academic integrity interferences 8

international humanitarian law (IHL) 231-6, 242-4

International Political Theory 50

International Relations (IR) 5-6, 10, 137, 144, 148, 153, 194, 222-3, 243, 296

interoperability 57

interpretivism 165

interviews 8, 34, 37, 39, 65, 75-6, 98; elite 159; ethnographic interviewing 99, 103 , 106-9, 279; see also ethnography; semistructured 34, 59, 107, 118, 145, 196, 217, 239, 275-6, 278-9; interview guide 84, $103,107-8,150,154,240-2,277-8$

invisibility see visibility

Israeli military (IDF) 89, 249, 253-4

iterative research $5,8,14,208,217,231$, $235-6,267-8$

Jones, Graham 6, 14, 261

journalists $13,17,45,56,116,119,124$, 131, 187, 215-16, 218, 231, 234, 237. 251, 282

judgment see suspension of judgement

laboratory $5-6,67-8,70,149,202$

language 51, 53, 100, 144, 168-9; language and culture 21, 108, 122, 168-9; programming languages 179-80, 182, 188, 201, 236; technical languages 5,
28, 144, 150, 235-6, 239, 296; see also performativity

Latour, Bruno 16, 50, 52-4, 104, 181-2, 188, 193-5, 198, 202-3, 205-7, 209, 264

law $8,40-1,44,82,113,117,122,198$, 215, 232, 264-5, 300; see also Freedom of Information (FOI) requests/FOIA requests, International Humanitarian Law (IHL)

leaked material 16, 85, 213-7, 222, 224-6; see also whistleblowing, WikiLeaks

legitimacy/legitimising 10-11, 28, 92, 147, 150, 152, 234, 253-4, 251, 256, 269, 280, 282; delegitimising 147, 254

liability $266-7$

lifeworlds 12, 14, 97-101, 103-6, 109

localisation 194, 200, 202-4, 208

mapping secrecy $2-3,5,7,13,131,188$, 196, 226

Manning, Chelsea 16, 147, 213-17, 222, 224-5

methods 8-10, 14-16, 19, 23, 29, 34, 49-51, 53, 59, 70, 75, 98, 109, 161; mixed 159; photographic method 166; see also archival research, ethnography, following actors, photography, qualitative research; access

methodology 8-9, 50-51, 99, 113, 145, 151, 216, 232, 278, 292; ethnomethodology 274; qualitative 276 ; reflexive 145 ; situated 50, 52, 58-9, 194; see also immanence, performativitiy, qualitative methods, research design, situatedness migration 12, 48-52, 54, 59-60; see also deportation, detention centres

(UK) Ministry of Defence (MoD/MOD) 233, 242-4

mirror see reflective surface mixed methods see methods mobility $18,48-54,57,59$

Mol, Annemarie 8-9, 202, 298-9 multi-sited ethnography see ethnography mystification of the secret $6,10,105,265$

Nader, Laura 80, 150, 300

nationality 54, 91, 123, 292

National Trust (NT) 67-75; see also Orford Ness

navigating secrecy $1,5-9,14,21,23,75$, $144,149,231,261,263,266-7,270$

networks 49, 104, 115, 161, 168, 295; bureaucratic 89 ; communication 17-18; financial 11; horizontal and vertical 
networks of people 239, 241; neural 179-80, 183-5, 199; relational 298-9, 301-3; research networks $88,93-4$, 116, 121, 296, 300-1; transport 18; technopolitical 56-7, 60; see also ActorNetwork-Theory (ANT) non-disclosure agreement see disclosure non-human 23, 54, 98, 193, 195, 203, 208 non-governmental organisations (NGOs) $50,57,121,133,136,231,234-5,237$, 239-41, 268, 296

non-participant observation see participant observation

objectivity 15, 105, 148, 160, 187, 248-9, $254,256,302-3$

obfuscation 1-3, 5, 7, 13, 71, 113-14, 131, 217-18, 221, 234, 265-6, 292;

obfuscation and technologies 9, 15, 208, $213,215,217,226$; in bureaucracy 12 , 297-9; of practices 9, 14, 303; through the state $213-15,217$

observation 19, 57, 59, 87, 131, 196, 208, 279; ethnographic 217, 266, 275-6, 280-1, 283; participant 5, 20-1, $82-3,86,99,107,115,145,158-60,232$, 236, 239-41, 258, 262, 264, 268, 292; non-participant 34,36 ; unstructured 201

obstacles 5, 40, 80-1, 87, 113-114, 180, 246 off-the-record conversations $34,36-39$,

121,240

oligoptica 52,54

ontology 8,64 , opaque $14,87,177,202,233$ opening the black box see black box openness 11, 15, 152-153, 281; managed openness 232,

Orford Ness 12, 64-5, 67-76

over-research 17-18

Paglen, Trevor 63, 165, 170

panoptica 52

participant observation see observation participatory photography see photography performativity $12,51-52,59$; of security 145; see also language

perpetrators $101-3,108,248,252-3,258-9$ photography $15,67,158-159,162,171$; ethnographic 160,165 ; participatory 166-170

place $12,18,64-65,67,72,74,101,113$, 161 ; everyday places 167 ; giving secrecy a place $136,138,261-263,269-270$ policing $37-38,56,90,114,124,150$, 162-163, 176, 278, 280-282, 285-287, 300-301; police violence 37; border police $81,84-85$

politics $50,114,235,253-4$; of access 42 ; of information 40, 217, 223; technopolitics 49,60 ; security politics $158-60,164,170$; of research 240

positionality: of the researcher $4,53-4,148$, 153, 241, 249-50, 267

postcolonial $66,253,256$

postsecrecy $12,65-69,73-5$

power 83-6, 94, 177, 252, 258, 294-5, $300-1$; gendered power $144,148,151$, 241 ; secrecy as power 9-10, 100, 147; state power $34,39,60,81,233,255$; power of documents 92 ; power of technologies 198

powerless $166,168,249$

practices $5,44,51,98,170,181,288$, 291-2; bureaucratic practices 45, 298-9; knowledge practices 11 , secrecy practices $13,83,147,218,222$; security practices 14, 133, 158-9, 161-2, 195, 278; research practices 35

privacy $11,176,181,208,266,268$, 298-300

privatised security $34-36,42$, 44; private security guards $35,163,165$; see also commercial security

Project Coast 137

proximity $13,118,263,267-8,283$

public secret 14,149

qualitative methods $99,177,231,237,239$, 275-6; research 80, 87, 94; fieldwork 7, 150,276

race 100, 166, 241; see also algorithms recordings $8,123,161,171$ re-enactment see enactment reflective surface 2,15 reflexivity: reflexive attitude $14-15$; reflexive methods $248-51,261,263,270$; reflexive vigilance $163,170-1$

refugees see detention centres relational 303; gaining access as relational see access; networks 298-9, 301-2; ontology 8, 48, 50, 55, 59; see also ontology

research: design 1, 5, 7-8, 15, 22, 29, 45, 124, 198, 207, 224, 291-2, 297; integrity see academic integrity; espionage 104 , 106; see also espionage; secrets 16-17 
responsibility: co-responsibility 269 ; distribution of 104; ethical 23, 155, 251, 253, 293; for respondents and collaborators $112,115,120,123-4,145,155$

restricted data see classification revelation $72,76,133,139,267$

rigour 9, 22, 28-9

risks: personal see responsibility, safety rumours $64,66,73,134$

safety: of respondents $21,112-16,119-24$, 162; see also responsibility; of the researcher 24, 112-18, 121-2, 124

Salter, Mark 5-6, 8, 19, 28, 235,

Scheper-Hughes, Nancy 6, 10, 83, 249

Science-and-Technology Studies (STS) 5, 50, 98, 180-1, 194-5, 198, 202, 205 secrecy: allure of 5-6; as relational 10; effect 6 ; value of 6, 10, 71, 149; Secrecy Studies 6,132

securitisation $5,35,153$; see also obfuscation security: digital security technologies 16 , 193-6, 198, 200-5, 207-8; checkpoints 158, 160-2, 168; discourse 33; devices 194, 196, 199; institutions 113-15, 119, 122, 145, 148-9, 152; field 5; landscapes $158,160-1,164,170-1$; practices 14 , 129, 145, 158, 161-3, 165, 194-5, 198, 206, 208, 276-8, 283, 285, 288; spins, stalls or shutdowns 5,87

self-care 116

self-declaration 103, 105-6, 109

self-forgetfulness 100-1, 103, 106

silences 17, 45, 147-9; diplomatic 139; government 73 ; significance of 124 sites of experimentation see experiment situatedness 84-5, 92, 94, 153, 162; situated knowledge 52, 54, 199, 264, 302 snippets 13, 134-5, 270; see also vignettes Snowden, Edward 66 sociology: International Political Sociology 263, 270; of translation 53; see also ActorNetwork-Theory (ANT)

Spradley, James 107-8, 284

stakeholder meetings $145,152,196$

state: actors 16, 33-4, 213-14, 221; agencies 80-1, 83, 86-7, 89-91, 94, 166, 178; control 213-15, 217-18, 221-2, 225-6; policy $234-5,239,241$; secrecy $63-4,66$, 68; secrets $214,217-18,223,225-6,267$; statecraft 129, 132, 136, 140

Stockholm International Peace Research Institute (SIPRI) studying up $19,150,300-1$ subjectivity $248-52,254$

surface see reflective surface surveillance 48-50, 52, 55 60, 63, 66, 112, 115-17, 120; Surveillance Studies 50, 176, 198; surveillance technologies 48 , 50-1, 57, 146, 164, 199, 231

suspicious transactions see transaction monitoring systems

suspension of judgement 103-5

SWIFT 11

Taussig, Michael 14, 65, 72, 132, 149

technical expertise see expertise

technologies; border technologies; design and use; see also security

technological mediators 55, 194, 198, 202, 279

technopolitics 48-9, 51, 53, 55, 57, 59-60, 200

technoscientific systems 63,68

Terrorism Finance Tracking Programme (TFTP) 11

threat: the researcher as possible $88,94,119$, 151,166

torture see perpetrators

transaction monitoring systems 16 , 194-208, 263-4, 277

translation see sociology

transparency 44, 63, 86, 113, 139-40, 231, 233, 237, 243, 267, 270, 297; academic 21-2, 28-9; see also postsecrecy

“trickster" 20, 249, 253, 255-9, trust $81,90,93-4,99,104,107,118,122$, $239,245,249,251-2,258,267$

ufologists $69-70,72-3,76$

United Nations (UN) 113, 118, 234, 239 uncovering 3-4, 9-11, 14, 22, 72-3, 98, $131-2,144,149,154,234$

undercover research see covert research unstructured observation see observation U.S. military 34, 36, 39-40; see also private security

validity $8,22,28-9,73,282$

veterans $70,73-5,153$

victims $21,252,255$

vignettes 261-6, 268-70; see also ethnography

violence see perpetrators, torture visibility 9-10, 159, 178; partial (in)visibility 231-2, 234, 242-3, 297-8; invisibility $14-15,265,270,297-8$

visual ethnography see ethnography 
Walters, William 5-6, 10, 12, 71, 103, 130,261

Wandering 161

Ward, Rob 1-4

Weber, Max 84, 86

website security certificates 213, 218, 220, 226 whistleblowing 19, 65, 123, 147, 153

WikiLeaks 214-17, 222-3

writing 39, 148, 245-6, 250, 282; writing with secrecy $15,17,129-30,132,134$, $136,138-9,261-3,270$

Za'atari 17-18; see also refugees 